\title{
THE INTEGRATION OF HUMAN FACTORS INTO A COMPANY'S PRODUCTION DESIGN PROCESS
}

\author{
by \\ Judy Lynn Village \\ Master of Science (Kinesiology), Simon Fraser University, 1988 \\ Bachelor of Science (Kinesiology, Coop), University of Waterloo, 1983
}

\author{
A dissertation \\ presented to Ryerson University \\ in partial fulfillment of the \\ requirements for the degree of \\ Doctor of Philosophy \\ In the program of \\ Mechanical and Industrial Engineering \\ Toronto, Ontario, Canada, 2014
}

CJudy Lynn Village 2014 


\section{AUTHOR'S DECLARATION FOR ELECTRONIC SUBMISSION OF A DISSERTATION}

I hereby declare that I am the sole author of this dissertation. This is a true copy of the dissertation, including any required final revisions, as accepted by my examiners.

I authorize Ryerson University to lend this dissertation to other institutions or individuals for the purpose of scholarly research.

I further authorize Ryerson University to reproduce this dissertation by photocopying or by other means, in total or in part, at the request of other institutions or individuals for the purpose of scholarly research.

I understand that my dissertation may be made electronically available to the public. 


\title{
THE INTEGRATION OF HUMAN FACTORS INTO A COMPANYS PRODUCTION DESIGN PROCESS
}

Doctor of Philosophy, 2014

Judy Lynn Village

Mechanical and Industrial Engineering

Ryerson University

\begin{abstract}
Human factors (HF) considerations, integrated early in design of production assembly systems, can improve both worker health and business performance. A longitudinal case study using an action research style collaboration between researchers and a large electronics manufacturer was the platform for this investigation. The findings show "how" HF, previously outside engineering with HF specialists (HFS) performing reactive injury assessments, increasingly became integrated into each stage of the design process with HF adapted tools, enforceable targets, sign-off, and most HF work focused on proactive design alongside engineers. An operations research tool (cognitive mapping) was used to identify the HF perceptions of Senior Directors and link these to their strategic goals. As a result, HF specialists changed their focus from injury risk to reducing fatigue and improving worker performance and assembly quality. Several industrial engineering tools were also adapted for HF (eg. HF failure mode effects analysis, HF design-for-assembly) and used to quantitatively communicate HF concerns, drive continuous improvement, visibly demonstrate change, and lead to benchmarking. Qualitative data analyzed with a grounded theory methodology resulted in six constructs in the final "Design for Human Factors" theory. The theory propositions state that when: 1. HFS acclimate to the engineering process, language and tools; and 2. strategically align $\mathrm{HF}$ to the design and business goals, then HF becomes perceived as a means to improve business performance. This results in 3. HFS being pulled onto the engineering team, which increases HF application
\end{abstract}


and engineers' awareness of HF, and 4. Management hold engineers accountable for HF targets. Being on the engineering team leads to 5. Engineering tools adapted to include HF targets, and in combination results in 6 . HF becoming embedded in the design process. Senior directors reported that increased HF application has improved the design of more recent assembly lines and made it easier for operators. The theory contributes an explanation about how HF can be integrated into design processes to inform researchers and practitioners and improve proactive HF application. Recommendations include increased education for HFS in engineering, and more collaborative research to develop tools that quantify and link worker performance to business metrics. 


\section{ACKNOWLEDGEMENTS}

The author wishes to acknowledge funding support from the Alexander Graham Bell Scholarship of the Natural Science and Engineering Research Council of Canada, the Ontario Graduate Assistance Program, and the Workplace Safety and Health Insurance Board of Ontario.

The author also wishes to acknowledge BlackBerry Ltd., who at initiation of the collaboration was one of the fastest growing companies, with 20,000 employees world-wide (Sweeny, 2009). It has been a tremendous opportunity and a privledge to work with the engineers, ergonomists, managers and directors in the new product realization site of this unique Canadian company and to witness its journey. I appreciate their willingness to participate, engage, support, and provide ideas.

Finally, the author appreciates the opportunity, guidance, and support provided by Dr. Patrick Neumann. I am honored to be his first PhD student and look forward to future collaborations (without as much commuting). Thanks too for the support from the students in the Human Factors and Engineering Lab - especially Michael Greig, who shared in all the experiences with BlackBerry Ltd.

\section{DEDICATION}

To make this adventure work, my husband Ron, and children Ryan (now 19) and Jason (now 15) stepped up to the plate on the home-front. I appreciate their love and support, and know they are proud of my accomplishment. 


\section{TABLE OF CONTENTS}

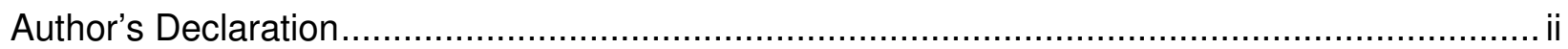

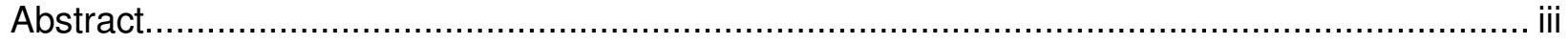

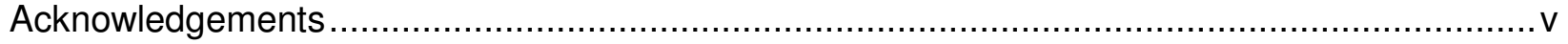

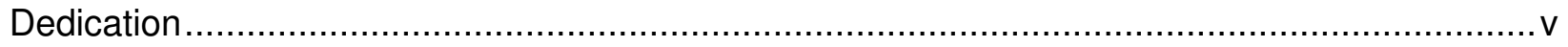

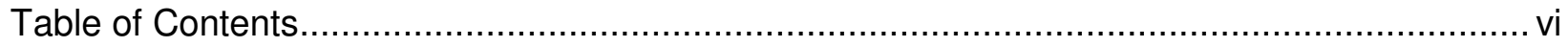

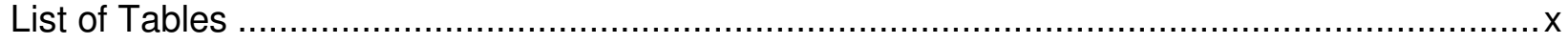

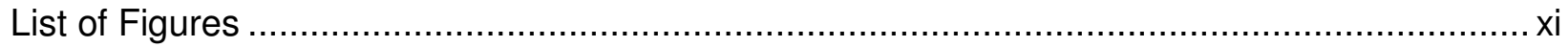

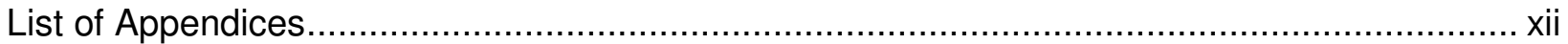

Chapter 1: Introduction: Statement of the Problem, Research Questions, Literature Review and Organization of Thesis............................................................1

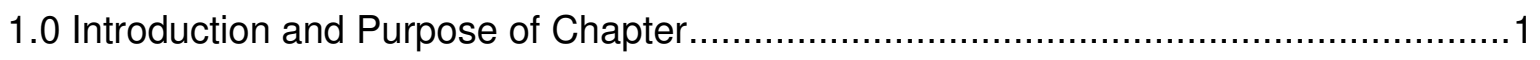

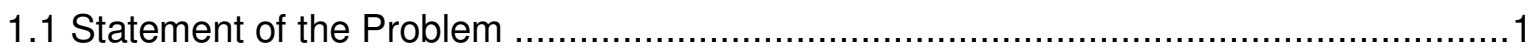

1.2 The Need for Human Factors Application in Production Systems Design......................3

1.3 The Need for Human Factors Considerations in Business Improvement Programs .....5

1.4 The Need for Guidance on the Development Process for Integrating HF into Design

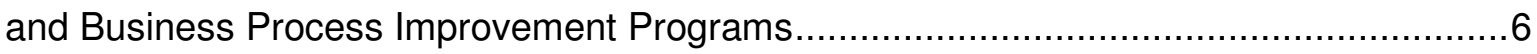

1.5 The Need for Theories about the Process of Integrating HF into Organizations ...........8

1.6 Organization of Thesis and Research Sub-Questions ...........................................10

\section{Chapter 2: Methods: Justification for Methodological Choices and Overall Research}

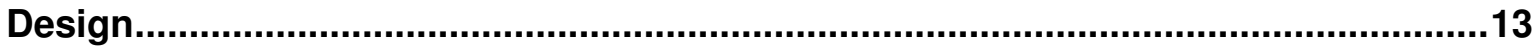

2.0 Introduction and Purpose of Chapter...............................................................13

2.1 Justification for Methodological Choices.............................................................13

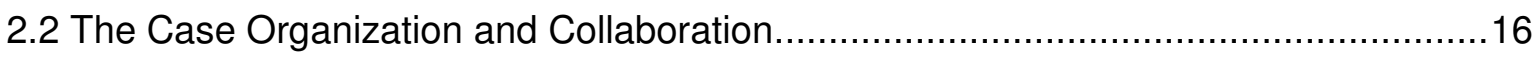




\section{Chapter 3: How Can an Ergonomics Action Research Approach, Demonstrating the Integration of Human Factors into Production Design Processes, be Conducted and Communicated?}

3.0 Introduction and Purpose of Chapter.

3.1 Action Research Approaches and Application in this Collaboration

3.2 The Three Phases of the Action Research Collaboration

3.3 Indicators of Human Factors Integration in Production Design Processes in

Collaborating Organization

3.4 Discussion: How can an ergonomics action research approach, demonstrating the integration of human factors into production design processes, be conducted and communicated

3.5 Conclusions

\section{Chapter 4: How Can and Why Should HF be Linked to Strategic Goals in an}

4.0 Introduction and Purpose of Chapter.

4.1 What is a Cognitive Map?

4.2 Review of Cognitive Mapping Methodologies.

4.3 Linking Human Factors to Strategic Goals with Cognitive Mapping: Results of Mapping Exercise and Focus Group in Collaboration

4.4 Discussion

4.5 Conclusion 
Chapter 5: How Can and Why Should Industrial Engineering Tools be Adapted to Include HF? Demonstration of Tools Adapted for HF

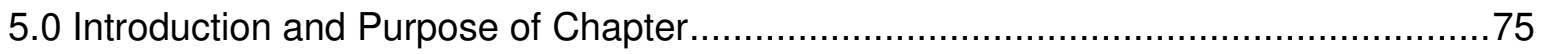

5.1 The Organization`s Design for Manufacturing and Assembly Process .......................75

5.2 Overview of Tools Adapted to Include Human Factors in the Design Process............76

5.3 Description of Industrial Engineering Tools Adapted for HF ..................................76

5.4 Features of the HF Tools Found to be Effective for Proactive Design ........................84

5.5 Discussion: How can and why should industrial engineering tools be adapted to

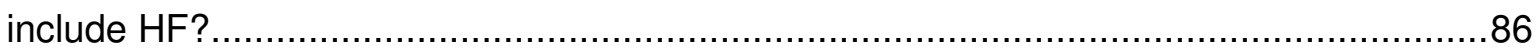

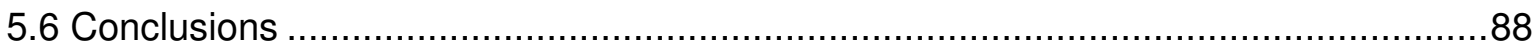

Chapter 6: How Can Qualitative Data in an Ergonomics Action Research Approach be Analysed Using a Grounded Theory Methodology? .................................................91

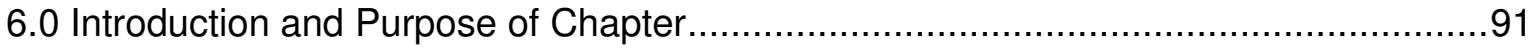

6.1 Qualitative Analysis and Development of Tentative Grounded Theory ......................91

6.3 Discussion: How can qualitative data in an ergonomics action research approach be analysed using a grounded theory methodology ..................................................115

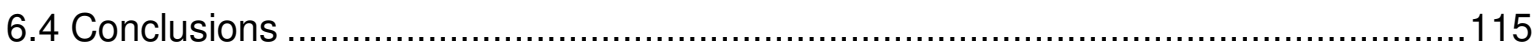

Chapter 7: Design-for-Human Factors (DFHF): A Grounded Theory for Integrating HF into

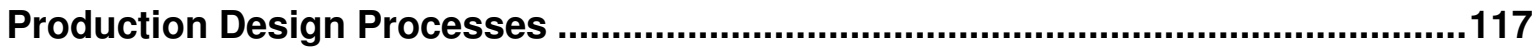

7.0 Introduction and Purpose of Chapter...............................................................117

7.1 Description of Process Structure of Theory …………............................................117

7.2 Summary of the Design for Human Factors Grounded Theory ................................118

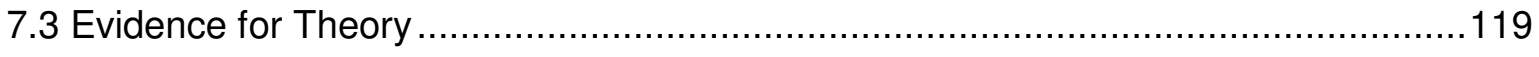


Chapter 8: Discussion: What is Needed to Increase the Integration of HF into Production Systems Design Processes? ....................................................................................137

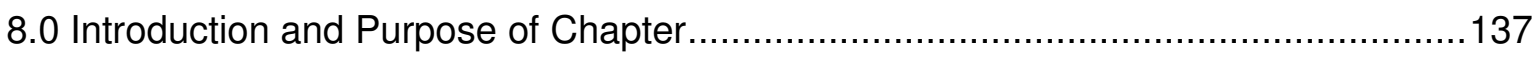

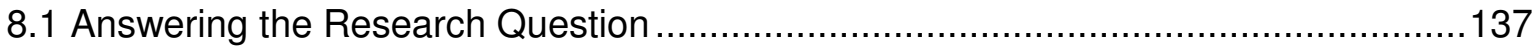

8.2 How does the Design for Human Factors Theory Compare to Other Theories, Frameworks and Models 145

8.3 What are the Implications from this thesis .................................................. 146

8.4 Comments on Methodological Approach and Study Limitations ...........................151

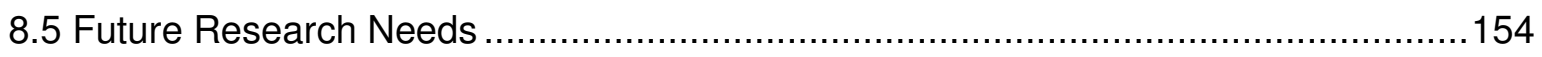

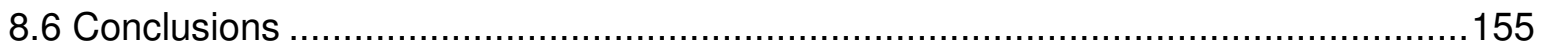

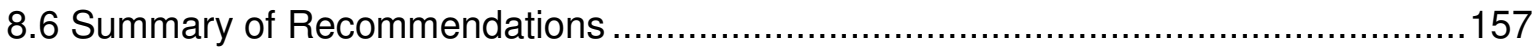

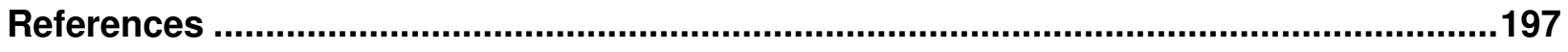

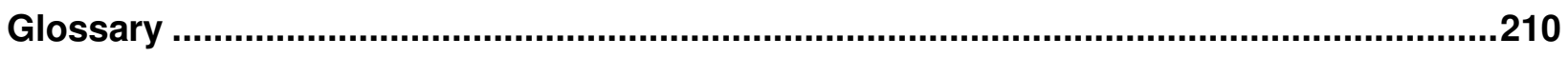




\section{LIST OF TABLES}

Table 1. Sample questions for the researcher/practitioner at each action research stage 21

Table 2. Description of the three case study phases over three year period using the AR

framework

Table 3. Activities, Organizational Participants and Value towards Goal for Phase 1 of the

Collaboration

Table 4. Activities, Organizational Participants and Value towards Goal for Phase 2 of the Collaboration.

Table 5. Activities, Organizational Participants and Value towards Goal for Phase 3 of the Collaboration.

Table 6. Summary of descriptive statistics for each individual map and the merged map 62

Table 7. Top 15 most central concepts from the map merged on quality (centrality score and number of concepts linked)

Table 8. Description of HF Purpose, Inputs, Outputs and Tool Application in Case Study.........77

Table 9. Empirical materials $(n=222)$ used for open coding and example events and participants 94

Table 10. Summary of Comparison between Original and Final Coding Scheme .95

Table 11. Coding Density (number of times a code was used) for Facilitators and Barriers sorted by Descending Total Density

Table 12. Properties and Dimensions of Category 1: Vision, Leadership and Support 100

Table 13. Empirical materials $(n=44)$ used for theoretical coding and example events and participants 


\section{LIST OF FIGURES}

Figure 1. Action Research Cycle and Spirals (adapted from Meyer, 2000)..........................21

Figure 2. Activity timeline for initiatives in collaboration .............................................

Figure 3. Human Factors targets are one of 5 monitored for overall DFA score in new product builds

Figure 4. Yellow boxes in the design-for-fixture process indicate newly created steps

where the HFS was required to sign-off on fixture designs.

Figure 5 The number of engineers participating in HF, and the percent of time the HFS spent in proactive HF work in each of the 3 phases of the collaboration

Figure 6. Distribution of percent of concepts associated with each theme for each of the seven directors (1-7) and the average (8) of all directors

Figure 7. Merged map from goal "improve quality" based on seven individual maps (for illustration purposes, not for reading)

Figure 8. Concepts linked to central concept of "reduce repetitive activities" from map merged on "improve quality" from seven directors.

Figure 9. Concepts linked to "Reduce fatigue" from a map merged on "improve quality"

from the seven managers . .66

Figure 10. Generic Assembly Design Process in Collaborating Organization .........................76

Figure 11. Tools adapted for HF and the stage in the design process where they are used......76

Figure 12. Overview of the Grounded Theory Data Analysis .........................................92

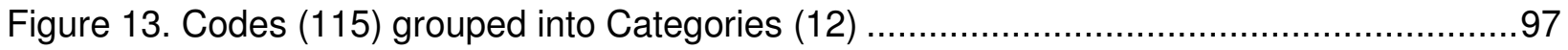

Figure 14. Summed scores from 65 properties in the comparative matrix (in appendix) for 10 initiatives, and overall for HF integration pre-2010 and 2013 (max score 130) .... 105

Figure 15. Early exploration of "core" category and its relationship to other categories to describe the action 108

Figure 16. Second iteration of tentative theory .

Figure 17. The design for human factors grounded theory and keys to the meaning of each structural shape in the process diagram. 


\section{LIST OF APPENDICES}

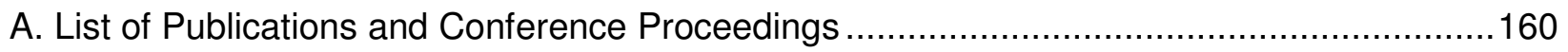

B. Empirical Evidence Indicating HF was Integrated into design processes .........................166

C. Human Factors Failure Mode Effect Analysis Tool ......................................................167

D. Human Factors Design for Assembly Scorecard …….................................................169

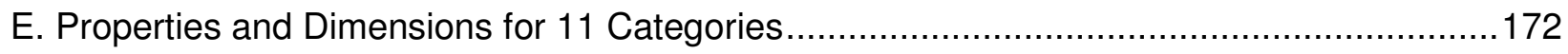

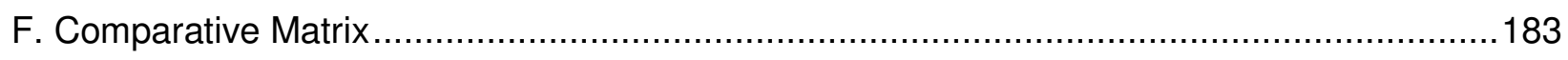

G. Tentative Propositions for Theoretical Sampling .....................................................187

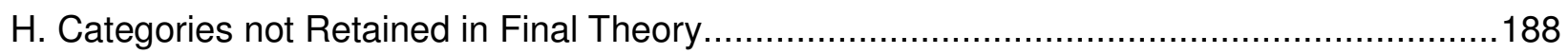




\section{Chapter 1}

\section{Introduction:}

\section{Statement of the Problem, Research Questions, Literature Review and Organization of Thesis}

\subsection{Introduction and Purpose of Chapter}

This chapter provides the statement of the problem, or underlying reason for conducting this research. The broad research question is introduced, followed by a review of scientific literature pertaining to the thesis topic. First, the review describes the need for human factors (HF) principles to be applied early in production systems design processes for both improved human and technical performance. Second, the argument is made that integrating HF principles into business process improvement (BPI) programs would improve their effectiveness as well. The third section describes the need for guidance on the development or improvement process to achieve successful integration of HF in design processes. The fourth section discusses the need for theory in HF, especially with respect to the process of how HF can be integrated into organizations. The theories guiding this research and informing the methodological design are described. The final section in this chapter provides an overview of the organization of the thesis, and sub-research questions pertaining to the results chapters.

\subsection{Statement of the Problem}

Human factors (or ergonomics) is:

"the scientific discipline concerned with the understanding of interactions among humans and other elements of a system, and the profession that applies theory, principles, data and methods to design in order to optimize human well-being and overall system performance" (International Ergonomics Association, 2013).

Lack of attention to human factors (HF) in design of systems can result in work-related injuries and disorders, which are not only debilitating for workers, but are costly - comparable to all 
cancers combined (Leigh et al, 1997). Poor HF can also result in financial consequences for the social systems of society, such as early retirement, ongoing health costs, and lost productivity (Zink, 2006). The application of human factors has been shown in numerous studies to not only improve worker health (such as reducing work-related injuries, reducing absenteeism, increasing job satisfaction, reducing fatigue, etc), but it can improve business performance as well, for example by increasing productivity, improving customer service, and reducing human error (Drury, 2000; Eklund, 1997; Eklund, 1995; Neumann and Dul, 2010; Goggins et al., 2008, Abrahamsson, 2000). The European Foundation for the Improvement of Living and Working Conditions (1999) showed that applying ergonomics and including worker participation in design led to quality improvements ( $90 \%$ of cases), reduction in throughput times (60\% of cases) and reduction in costs (60\% of cases) (Vink et al., 2008). HF is therefore profitable for organizations, but only $2 \%$ of the benefits are related to sick leave cost savings, whereas $98 \%$ are related to improvements in productivity and quality (Rose, et al., 2013). The payback times for positive effects of HF improvements among 250 studies was reported to be less than one year (Goggins et al., 2008), and for macro-ergonomic interventions (that include aspects of organizational design and management) resulting in large scale work system improvements, the payback was six to 24 months (Hendrick, 2008). Studies have even shown that implementation of HF was associated with improved customer satisfaction (Yeow and Sen, 2003), better achievement of economic and social objectives within companies (Thun et al., 2011), and increased regional competitiveness and social development (Kleiner and Drury, 1999).

Despite the known benefits of the application of HF principles in design of systems, HF is typically applied too late in the design cycle, i.e. after injuries or problems have occurred, rendering it costly and less than optimally effective (Neumann and Dul, 2009). Many companies use business improvement or reengineering programs to help improve system performance (such as zero-defects or lean manufacturing), but here too there is a lack of HF application. Lack of "human" consideration is suggested as the reason only $15 \%$ of reengineering efforts, as quoted by the Harvard Business Review, were successful (Wilson-Donnelly et al., 2005). Apart from unrealized potential from not including human factors considerations in many such programs, there is evidence that some of these programs (i.e. lean and other rationalizations) may increase health and mental problems for workers (Westgaard and Winkel, 2011). There is therefore a need to consider HF in both design processes and business improvement programs. Neumann and Dul (2010) suggested a need for widespread multi-factorial improvements that 
are owned by and aimed at the whole organisation and include intervention in early design stages where potential impact is highest. This is essentially a macro-ergonomic or organizational change process. However in both the business improvement and design domains, there is a lack of, and call for, increased research on the development process of "how" to implement and sustain HF improvements (Eklund, 2000; Ghobadian and Gallear, 2001; Holden, et al, 2008; Zellner, 2011). This research therefore aims broadly to address the following main research question:

\section{Main Research Question:}

“How can human factors be integrated into a company's production design process?"

\subsection{The Need for Human Factors Application in Production Systems Design}

When it comes to integrating HF into production systems design, earlier is better (Kirwan, 2000). Human factors application is increasingly more difficult and costly the closer one is to production (Falck et al., 2010). In the Swedish automotive sector, 60-70\% of musculoskeletal disorders were estimated to be caused by product design issues, such as tight fittings, and $30-40 \%$ by assembly process decisions, such as reaches (Eklund, 1999). Implementing HF on large scale system development projects takes only $1 \%$ of engineering design budget compared with $5-12 \%$ or more when applied during routine operation (Hendrick, 2008). Early decisions regarding design of the system have important implications for not only health outcomes, but for productivity as well (Dul and Neumann, 2006; Battini, 2011). For example, decisions such as automation level, assembly system layout, and cycle time determination are strongly linked to production volume, number of tasks in a cycle, and number of parts in product assembly. These decisions are also strongly linked to workload for an operator, thereby affecting repetitions, duty cycle, and work-rest recovery (Battini et al., 2011). Improving human factors aspects of work design therefore has a direct impact on improving worker health, and a direct effect on work performance, making it a win-win for both employers and workers.

Despite these findings, HF is not routinely integrated into systems design. The engineering design process in manufacturing has traditionally focused on the technology and machine capabilities, rather than focusing on the role of the operator in the production process (Paquet 
and Lin 2003). In a Swedish study, $80 \%$ of designers reported spending less than $5 \%$ of time on human aspects (Willen, 1997). A number of reasons have been offered, including the training and engineering process used by engineers, the organizational positioning and rewards of engineers, the nature of blame for system failures, the "side-car" positioning of human factors engineers, the tendency for human factors to be seen as threatening, and the lack of customer demand for human factors (Broberg, 2007; Dixon et al., 2009; Kirwan, 2000; Paquet and Lin, 2003; Perrow, 1983; Waterson, 2010). Perrow (1983) suggests that engineers use "design logic" rather than designing from an operational (or human) point of view.

To fill this gap, researchers have suggested providing engineers with HF information, principles and data, especially in support tools they are already familiar with (such as CAD systems) (Broberg, 2007). Another strategy is to develop HF standards and regulations which provide requirements. In Scandinavia, engineers were required to use HF design criteria and work environment training was provided to engineers in technology schools, supported by development of handbooks, checklists and other tools (Jensen, 2002). Despite the efforts, the diffusion of HF did not become widespread, perhaps because the customer requires compliance with quality, cost and time and these are emphasized over HF (Jensen, 2002). Alternatively, it may be that HF was not understood as a "means" to achieve improved performance (Dul and Neumann, 2009). Kirwan (2000) suggests that the use of facts and regulations without the "soft systems" that come from relationship building will have limited success. He further suggests that success depends on the choice of methods and communication, how information is presented with respect to company goals, and the HF credibility of the people (Kirwan, 2000).

In many cases, organizations seek to improve their HF capabilities by building bigger teams, or designing policies requiring HF (Jensen, 2002). However, frequently HF becomes an added requirement - sometimes negotiated or legislated and therefore contentious (Adler et al, 1997). HF specialists struggle politically to be as important as other priorities. Further the tools and techniques they use come from the HF domain and do not become embedded in the culture of the design process. Neumann et al. (2009) demonstrated that when HF is a separate program or group convened to do HF, their existence is fragile because groups can fold and people can leave positions. 
For $\mathrm{HF}$ to be integrated into design processes, it needs to be positioned within the organization in such a way that it affects business strategies and their implementation (Drury, 2000; Dul and Neumann, 2009). In this way it will have the attention of senior management and will be seen as contributing to the success of the organization. HF needs to be integrated at multiple levels in an organization. This requires a systems approach, with special emphasis on the "soft systems" of communication and relationship building (Kirwan, 2000). It also should address multiple functions across many departments (Kirwan, 2000), and multiple levels of the organisation to develop a sustainable capability (Eklund, 1999; Neumann and Village, 2012). Therefore, the aim is at organisational design capability by many, not just an individual based design solution (Neumann and Village, 2012). This thesis addresses the need for how HF can be integrated into design processes.

\subsection{The Need for Human Factors Considerations in Business Process Improvement Programs}

Business process improvement (BPI) was the number one priority among ten top business priorities in a 2009 survey of over 1500 organizations (Zellner, 2011). Companies use BPI to keep pace and adapt to persistent technological, organizational, political and other changes in a complex environment. A recent survey of 453 organizations in 43 countries found $72 \%$ use quality management systems, 36\% lean management, $22 \%$ six sigma, 30\% 5S, $65 \%$ improvement teams, $41 \%$ total quality management and $43 \%$ the balanced scorecard (Adebanjo, 2010). Many of these techniques share common features. They all have a goal of improving performance and processes and usually the focus is customer based (quality of product, timeliness of delivery), or production based (eliminating waste, reducing cost). They commonly have widespread employee involvement, function at several operational levels (throughout all parts of the design cycle), and apply to a wide range of functions within the organization (Adebanjo, 2010).

While business process improvements aim to increase the effectiveness and efficiency of business processes (Zellner, 2011), the worker in the system is not usually considered. Programs may include workers, but the focus is generally to provide leadership, to encourage a customer focus, to assist with generating improvement ideas, and to effect cultural change (Antony, 2011). Few programs include the human factors concerns of the assembly or 
production worker (such as their ease of assembly, fatigue, or work-related injuries) in order to achieve the business goals for the organization (be it quality, cost, delivery etc). In operations research, models are typically used for simulation and optimization of manufacturing processes to identify process problems, such as bottlenecks. These models, however, usually "black box" the operator, much as a machine, assuming that workers perform at the same pace with the same variance (Boudreau, 2003). Solutions focus on adding resources such as additional people or machines, rather than improving performance of the operator through motivation, training and other means (Boudreau 2003). Boudreau et al. (2003) called for operations management models that are richer and more realistic with regard to how they represent humans and their interactions with operating systems.

The reason cited for lack of success in implementation of $85 \%$ of BPI programs is lack of consideration for the social or human system (Wilson-Donnelly et al, 2005). There is also evidence that some of these programs (i.e. lean and other rationalizations) may increase health and mental problems for workers (Westgaard and Winkel, 2011). In a review of 162 studies of various types of rationalization, the authors reported a dominant negative effect on health and risk factors (Westgaard and Winkel, 2011). There is, however, some evidence that HF considerations may provide value added to BPI programs. Womack et al. (2009), incorporated HF into design of 56 jobs in a lean plant and reported both greater productivity compared with a traditional plant, and a reduction in risk factors for injury. Similarly, Ryan et al. (2011) successfully combined operations research and human factors for improvements in a study of road maintenance workers. They report that the combination of HF and operational research adds value to the investigation of improvements in road maintenance work (Ryan et al., 2011 ). Boudreau et al. (2003) too, provided examples where operations research and practice is enhanced by incorporating HF. In this thesis, it will be shown that when integrating HF into the production design process, the business improvement programs in the organization should also be considered for optimal effectiveness.

\subsection{The Need for Guidance on the Development Process for Integrating HF into Design and Business Process Improvement Programs}

In both the business improvement field, and the HF field, there has been ample literature detailing the components of successful programs, the specifics of tools and techniques, and the 
outcomes of the improvement programs. However in both domains, there is a lack of, and call for, increased research on the development process of implementing and sustaining the new improvements (Eklund, 2000; Ghobadian and Gallear, 2001; Holden et al., 2008; Zellner, 2011). Eklund (2000) stated that the "outcome" of work design during the socio-technical movement has been given more emphasis than the "process" of how to implement changes. Holden et al. (2008) suggests that the literature on macro-ergonomics provides guidance on how to design research, but not how to implement it. Ghobadiam and Gallear (2001) discussing total quality management (TQM) suggest that there is evidence it is effective, but central to success is the implementation process. When TQM or human factors interventions fail, the reason cited is often the improvement (implementation) or development process, which is less well studied and documented (Ghobadiam and Gallear, 2001; Holden et al., 2008).

After studying 31 total quality management implementation plans, Ghobadiam and Gallear (2001) concluded that those organizations with successful programs were heavily weighted on the "soft side" (attitudes, values, mobilizing commitment, participation, responsibility), compared with the "hard side" (systems, tools, techniques). Zellner (2011) suggests that most BPI approaches concentrate on what needs to be done, but the act of improving itself seems to be a black box, lacking methodological structure.

In contrast with production work where something is produced, development work is about improving organizational capabilities, processes and routines. Improving organizational capabilities can also be thought of as "organizational learning". Learning can be "single loop", meaning an organization learns from a change or intervention. Learning can also be "double loop" which means the organization learns from a change, modifies their goals by asking if they are doing the "right" thing, and applies what is learned to the next change or intervention, thereby improving its capabilities. Development work is becoming increasingly relevant for organizations due to increasingly complex production, use of communication and information technology, and competition, in rapidly changing and turbulent markets (Eklund, 2000). In "developmental evaluation", which is compatible with action research, the evaluator is part of the design team and collaborates to conceptualize, design and test new approaches in an on-going process of development, adaptation and intentional change (Patton, 2011). Developmental evaluation attempts to make sense of what emerges under conditions of complexity by documenting and interpreting the dynamics, looking for evidence of emergent tipping points and 
investigating what might need to be changed and adapted. This thesis uses the approaches of both developmental evaluation and action research to document essential elements of the development (or implementation) process of incorporating HF into design processes.

\subsection{The Need for Theories about the Process of Integrating HF into Organizations}

A framework is a set of non-linked constructs, whereas in a model the constructs are linked, and in theory, they are causally linked to explain how and why a phenomenon occurred. Numerous theoretical frameworks and models exist that describe the role of HF specialists in design of work systems, for example the soft system framework (Kirwan, 2000), the work compatibility improvement framework (Genaidy et al., 2009), the framework for social and organizational aspects of HF integration (Waterson and Kolose, 2010), the processural framework of change (Dawson, 2005) and other change management frameworks (Commissaris et al, 2006; Holden et al, 2008). Seim et al (2012) suggest that these frameworks, largely developed by academics, have been useful, but what is lacking is knowledge of "how" HF specialists can acquire the necessary capabilities and new work practices based on the models. In other words, the question remains as to "how" to turn a framework into proactive integration of HF into design processes in an organization. The action research framework proposed by Neumann and Village (2012), and used in this thesis, is a broad approach for doing this, by integrating HF into as many levels of the organization as possible, and using whatever tools and techniques are most appropriate to the organizational context.

Recently, Broberg (2010) suggested a shift in the HFS' role to one of a "political reflective navigator" who helps stage the workspace design process and brings appropriate design tools and techniques to bridge HF with design. Similarly Burns and Vicente (2000) suggest the true leverage points in design occur in negotiation of contextual constraints, and therefore human factors specialists (HFS) need access to context and rich design examples to show how different constraints can be satisfied. Indeed, the design literature recognizes that design cannot be split apart into a collection of separate tasks that are independently pursued. It requires continual engagement of and exchange among different actors trained in different disciplines. The concept of differing "object worlds" has been used to describe the final design as a harmony of different object worlds that depend on a social process among individuals, the 
competence of participants working within object worlds, and the infrastructure and its vital sustaining ecology or culture (Bucciarelli, 1994).

It has been stated that "meaningful change requires good theory, and the development of good theory requires attempts to change the world" (Freidman and Rogers, 2009). A theory can be defined as a statement of constructs and their interrelationships that shows how and why a phenomenon occurs (referenced in Miles, 2012). A good theory can explain a social phenomenon, and it can guide action (Freidman and Rogers, 2009). It can provide a "reflective transfer" of knowledge to practitioners such that they can learn from past experience and the vicarious experience of others (Freidman and Rogers, 2009). Theory in HF intervention, however, is lacking. While there are numerous theories and models explaining the causes of work-related musculoskeletal disorders (Karsh, 2009), a literature review for theories as a basis for design of HF interventions (Wijk and Mathiassen, 2011) found only 30 studies: 13 had explicit theories and in 17 studies it was implicit. Most common is the participatory ergonomics intervention approach, suggesting that increasing worker participation in design will improve the design. With this focus, most often the role for the human factors specialist (HFS) has been relegated to setting up structures and methods for end users to participate in the design process (Seim et al, 2012). There is therefore a need for theory, developed from empirical field data, to guide HF practitioners who want to engage directly to increase capability within an organization for proactive HF integration in design.

Given the lack of HF-specific theories, two non-HF theoretical stances informed this research: the Complex Systems Theory and Soft Systems Methodologies (SSM) of Systems Theory. The Complex Systems Theory suggests that organizations are complex, and the future is unpredictable and characterized by sudden dramatic changes. Complex systems have a large number of interacting and interdependent elements and there can be self-organizing and emergent behaviours that generates learning, evolution and development (Patton, 2011). Complex systems, as recognized in operational and management science, can have complex problems where there is a high degree of uncertainty about how to solve a problem (Patton, 2011). Both systems and complexity theory provide a useful context when dealing with complex organizations and complex issues (Senge, 2006; Siemieniuch and Sinclair, 2006; Sinclair, 2007). The goal of integrating HF into design processes is a complex issue, and the 
collaborating organization is a complex system. Complex systems theory suggests that affecting change may not be planned and linear in such an environment.

Soft Systems Methodology (SSM) emerged from the inability of systems engineering methodology to cope with the full complexity of management problems (Checkland, 1985). It uses a systems approach, which means viewing a situation holistically through interactions of the various elements and focuses on the qualitative social interactions, management of change, and learning (Mingers and White, 2010). It is also considered a process of enquiry for management of change (Mingers and White, 2010). SSM provides a framework and justification for the methodological approach used in this research called "Action Research" which uses systems models to understand and intervene in real-world complexity (Checkland, 1985). Action research in a longitudinal case study approach provides opportunities for deep enquiry into processes at multiple levels in the organization. This will be explained more fully in the methods section (chapter 2). The goal of the action research and SSM approach is to determine appropriate change, implement the change, learn from the change, and continue the learning cycle again (Checkland, 1985). Informed by the complex systems and SSM theories, this thesis will use an action research approach to develop a theory explaining how HF was integrated into design processes in the collaborating organization.

\subsection{Organization of Thesis and Research Sub-Questions}

Chapter 2 of this thesis will present the justification for methodological choices in this research and the overall research design, which was a longitudinal case study collaboration with a large electronics manufacturer. Using an action research approach, the goal of the collaboration was to assist the organization to integrate human factors into their design processes in ways that would be sustainable for them. Subsequent chapters ( 3 through 7 ) will each address a subquestion of the main research question. Within these chapters, contents will include the specific objectives, methods, results, and discussion pertaining to the sub-question. Chapter 8 will discuss results from the perspective of the overall research question, and will provide implications and recommendations based on the findings. Appendix A provides a full list of publications arising from this thesis. 


\section{The main research question is:}

"How can human factors be integrated into a company's production design process?"

\section{Chapter 3 will address:}

"How can an ergonomics action research approach, demonstrating the integration of human factors into production design processes, be conducted and communicated?"

This chapter uses an action research model (plan, act, observe and reflect) to describe the actions and reflections of the three year collaboration chronologically in three phases. The chapter briefly describes the various initiatives in the collaboration and indications that human factors considerations were becoming integrated into design processes. The chapter (and publication on which it is based) demonstrates how an ergonomics action research project can be conducted, and one way it can be communicated.

\section{Chapter 4 will address:}

"How can, and why should, human factors be linked to strategic goals in an organization?" Adapting the cognitive mapping technique to $\mathrm{HF}$

In this chapter, based on three accepted publications, a review is conducted of cognitive mapping techniques, from the operations research field. A recommended approach is then applied in interviews and a focus group with senior management in the collaborating organization. The goal was to determine the perceptions of senior management regarding human factors and to see how they linked HF to their strategic goals in the organization. The findings and merits of the cognitive mapping approach are discussed.

\section{Chapter 5 will address:}

"How can, and why should, industrial engineering tools be adapted to include human factors?" Demonstration of IE tools adapted for HF.

In this chapter, based on a submitted publication, five industrial engineering tools are adapted to include human factors and integrated into the design process in the organization. These tools are described briefly. The chapter also describes the unique development 
process for each of the tools. It will also answer the question of why adapt industrial engineering and business process improvement tools for human factors.

Chapter 6 will address:

"How can qualitative data in an ergonomics action research approach be analyzed using a grounded theory methodology?"

This chapter demonstrates how the qualitative data from multiple sources in the three year collaboration was coded in three ways and analysed using a grounded theory methodology. It provides an example of how to conduct a grounded theory analysis in ergonomics action research, and also illustrates how the constructs in the final theory described in chapter 7 were developed.

Chapter 7 will outline:

"Design-for-Human Factors (DFHF): A Grounded Theory for Integrating HF into Production Design Processes"

This chapter, based on a publication in progress, presents the "Design for Human Factors" grounded theory describing the process of how the collaborating organization integrated human factors into their production design process. Each of the constructs and propositions in the process theory is described with supporting data and quotes from organization participants.

Chapter 8 is a discussion that will address:

"What is needed to increase the integration of HF into a company's production design process?"

In this discussion, the implications of the thesis findings for human factors specialists, researchers, organizations and universities will be described. The chapter will discuss strengths and limitations of the work, and future work that is needed based on the findings. A summary of recommendations will also be included. 


\section{Chapter 2}

\section{Methods: Justification for Methodological Choices and Overall Research Design}

\subsection{Introduction and Purpose of Chapter}

This chapter provides the justification for the overall longitudinal case study research design for this thesis (in section 3.1). It also provides justification for methodological choices including the action research approach, qualitative data collection, and grounded theory analysis. It then provides a description of the case study organization, the methods of collaboration, and the goals of the collaboration (section 3.2). The final section (3.3) describes the data collection methods common to all results of this thesis. Data analysis will be included separately in each of the following chapters as it pertains to the research sub-question. Chapter 6 is dedicated entirely to the grounded theory data analysis.

\subsection{Justification for Methodological Choices}

\subsubsection{Longitudinal Case Study}

A longitudinal case study is the preferred research method when the research question is one of why, what and how (Cuthbertson, 2011). It allowed for a deep understanding of the nature and complexity of the phenomenon being studied within a real-life context. It was also appropriate for seeing changes or development over time, and for observing and participating in the change in the organization (see 2.1.2 Action Research). The unit of analysis in this case study is the organization itself, and how it adapts to integrate HF into their production design process. Patton (2011) suggests that such purposeful and intentional sampling of a single organization (or "case") provides important information about field-based processes in an information-rich context that would otherwise be unavailable. Such "success case methods" provide credible and concrete field data that others can learn from (Patton, 2011). Learning about how something was done in one organization, while not necessarily generalizable to all organizations, can be valuable for transferring ideas and methods to others attempting to integrate $\mathrm{HF}$ in their design processes. The case study organization provided a unique opportunity to study how HF can be integrated in design processes due to the rapid turnover of assembly lines and the large number of engineers and human factors specialists who could participate. 


\subsubsection{Action Research Approach}

The Action Research (AR) approach used in this research is characterised by the pursuit of action (or change) and research (or understanding) at the same time by using a cyclic and spiral process which alternates between action and critical reflection (Patton, 2011). It assumes that a system can be more deeply understood if the researcher becomes part of the socio-technical system under study (Farris et al., 2011). The AR approach, based on Neumann et al (2012), allowed us as researchers to more fully understand the realities of working with people in complex situations, in this case a macro-level organizational change (Davis, 2007). Action research is increasingly being used in operations management, for example to explore effects of continuous improvement and performance effects on operations management (Coughlan and Coughlan, 2002; Farris et al., 2011). Action research is an appropriate approach for this research since the research question relates to describing an unfolding series of actions over time, and understanding as a member of the group how and why the action changes or improves the working of some aspect of the system, and understanding the process of change or improvement to learn from it (Coughlan and Coughlan 2002).

Action research is grounded in the phenomenological approach, and is consistent with soft systems theory. It is a way of describing data (i.e. "what" happens), and making meaning ("how" it happened), with openness to what emerges, and inside perspective. The goal is not solving a problem "for" others, but "with" others in joint learning. Holden et al. (2008) describes the joint process as a blend of real-world interventions to address identified problems together with research aimed at studying the intervention and gathering generalizable scientific knowledge. Therefore, we as researchers together with organization participants jointly diagnose and analyze the problem, plan the actions, carry out the actions and evaluate, such that there is learning. As researchers, we monitor and evaluate the change process to support the development work, rather than testing a hypothesis (Checkland, 1985). The description by Meyer (2000) of "collaborative spirals of planning, acting, observing, reflecting and re-planning" is particularly descriptive of the process and has been used as a model for the work in this thesis (see Chapter 3). Patton (2011) suggests that the researchers be active, reactive, interactive and adaptive. The notion of "situational responsiveness" from complexity theory fits well with the role of the researcher/facilitator in that we must be continually aware of new 
opportunities, concerns, social networks and other influences on the development work, and able to reflect and respond accordingly.

Academic integrity of AR studies depends on both the capability of solving practical HF problems, while at the same time rigorously scrutinizing the experiences from the field collaboration in order to communicate the findings (Levin, 2012). The balance of acting and reflecting as a researcher promotes "testing" of various approaches in vivo in the organization and promotes learning - both for researcher and practitioner - about what works and doesn't work for the organization (Neumann et al., 2012; Levin, 2012).

\subsubsection{Qualitative Data Collection}

Since this research endeavours to understand a process of change, it is considered a social research relying on qualitative data. In qualitative research, the researcher relies on text rather than numerical data, analyses these data in their textual form rather than converting them to numbers for analysis, and aims to understand the meaning of human action by asking open questions about phenomena as they occur in context (Carter, 2007). There are many types of qualitative data and the data collection should serve the aims of the research as it confronts its topic (Wertz et al, 2011). In qualitative research, we choose the samples purposively to serve an investigative purpose rather than to be statistically representative of a population. In this thesis we used a combination of theoretical sampling, sampling for maximum variation, and time or place-based sampling. Data collection methods included field observations, field notes and reflections, interviews, focus groups, participation in meetings, and review of internal documentation. These will be described in more detail in section 3.3. Data management methods included recording, transcription, and use of computer-assisted analysis software for data management (NVivo software, QSR International, 2010). Data analysis methods included coding, categorizing, constant comparison, memo writing and a grounded theory analysis (described in detail in chapter 6). Writing and reporting of findings in this qualitative research is also considered part of the analytic process as the researcher's thinking and interpretation develops during the writing process. 


\subsubsection{Grounded Theory Analysis}

A grounded theory analysis was chosen for data analysis (see Chapter 6 for details). It uses qualitative data to develop propositions, which then become grounded by the evidence thus producing a theory (Carter, 2007). Grounded theory was chosen as the analysis method since theory about how to integrate HF into design processes is in early, formative stages and not enough is known about the phenomenon to state hypotheses prior to investigation (Binder and Edwards, 2010). The grounded action methodology is rooted in the systems perspective and has theoretical power and potential for systemic change (Stillman, 2006). It was chosen since it is most appropriate when asking why and how questions of the data, and because of the ability to provide depth and richness for constructing knowledge. Grounded theory lends itself to investigating processes because the techniques involve looking at patterns of relationships between actors and their environment. The interest is in identification and categorization of elements and exploration of connections within a social setting. Grounded theory uses principles of questioning rather than measuring, and generating hypotheses using coding techniques. It enables the researcher to "ground" the hypotheses in empirical data. Hypotheses and concepts not only come from the data, but are systematically worked out in relation to the data during the course of the research. Theories are important in AR because of their explanatory power. They help us understand and interpret the case in reflection, and can help others understand how to improve practice (Whitehead, 2009)

\subsection{The Case Organization and Collaboration}

\subsubsection{Description of Organization}

The case study organization designs, manufactures and assembles hand-held electronic devices. At initiation of the collaboration, it employed approximately 20,000 people world-wide and was named by Fortune magazine as the fastest growing organization. The collaboration focused on the new product realization site in Southern Ontario since this is where new product designs are first manufactured and taken to full assembly, prior to being outsourced to high volume production sites. The site realizes multiple new products yearly, offering opportunity during the multi-year collaboration of participation in repeated design cycles. 


\subsubsection{Method of Collaboration}

The collaboration began with a memo of understanding between the organization's Occupational Health and Safety Manager, the Director of Engineering, and the University's Principle Investigator in 2008. Two research students started in the fall of 2009 followed by two more in the fall of 2010. Research students in the Human Factors Engineering Lab of the Department of Mechanical and Industrial Engineering had either engineering or a human factors background. Four Ergonomists and an Ergonomics Manager from the organization participated in the collaboration at various times. The term "Human Factors Specialist" (HFS) will be used generically to describe actions of Ergonomists, whether a single person or multiple, and whether from within the organization or from Ryerson University, without specifics of which Ergonomist.

\subsubsection{Goals of Collaboration}

The goal of the collaboration was to help the organization increase its capabilities to integrate human factors (HF) early in production design processes with the underlying assumption that doing so would improve both worker and production outcomes. We started with the broad framework by Neumann and Village (2012) to guide integration at multiple levels in the design process. As the collaboration proceeded, we looked for opportunities or initiatives that would lead to improved HF integration. The approach is participatory, but in this collaboration, we were seeking participation with manufacturing production engineers and HFS, rather than workers. Instead of physical changes to equipment or workstations, we were seeking changes to their design processes.

\subsection{Data Collection}

In this collaboration, qualitative data was collected from mid-2010 to mid-2013. To substantiate findings, data was triangulated from three sources: tracking of actions/interactions, review of organizational documentation, and collection of participant and researcher reflections.

\subsubsection{Actions/Interactions}

In-person interactions were planned approximately weekly and electronic interactions (web-ex and teleconference) between site visits. Actions/interactions were collected with a tracking log and through note-taking. The log was used to document, for example, meetings, interviews, 
focus groups, etc. The log included people involved, type of interaction, topic, and time. Notes taken during and after every interaction documented items discussed, observations, and actions taken.

\subsubsection{Documentation}

Documentation from within the organization was used to plan and track action and to support observations. It included, for example, meeting minutes, product designs, tooling procurement, assembly layouts, work instructions, manufacturing process documents, company newsletters, and organizational charts.

\subsubsection{Reflections}

Reflections were a mechanism to evaluate what was working and not working in the collaboration and for planning the next steps. They were also a way, separate from notes about what was said and done, to capture impressions of meaning. Reflections were captured in several ways:

- By documenting researcher "impressions" with each action/interaction entry;

- By asking participants to reflect after meeting or focus group interactions and recording or noting their reflections;

- With semi-structured interviews with participants annually in the fall of 2010,2011 , and 2012; and

- By researchers regularly discussing data at university research team meetings.

During the semi-structured interviews, participants were asked in an open-ended way what is "helping" with HF integration, and what is "hindering". Reflections at these three points in time informed and facilitated the next phase of planning and action in the collaboration. All formal meetings, interviews and focus groups were digitally recorded, transcribed and entered into NVivo software for qualitative analysis. 


\section{Chapter 3}

\section{How Can an Ergonomics Action Research Approach, Demonstrating the Integration of Human Factors into Production Design Processes, be Conducted and Communicated?}

\subsection{Introduction and Purpose of Chapter}

This chapter presents a description of what occurred during the ergonomics action research (EAR) collaboration, organized into three approximately year-long phases that emerged from the data analysis. Because of its uncommon application in HF research, this chapter has been organized to demonstrate how the EAR was conducted, one way to communicate an EAR study, and to highlight the benefits of using an EAR approach to provide deep understanding about a problem. The various initiatives within the collaboration will be presented, including the goals for each, the participants involved, and the approximate timeline. While not all initiatives were sustainable or resulted in development of a tool or change in process, all initiatives had an overall goal of helping to find ways to integrate HF into the production systems design process. Whether successful or not, both researchers and participants in the collaboration learned from each initiative. In this chapter, a non-traditional reporting format was chosen to demonstrate the EAR approach, and to show how EAR was helpful in this collaboration for integrating HF into design processes. Instead of "methods" and "results", Section 1 first describe the EAR approach and its application in this collaboration under sub-headings that give the context. This is followed by a description of the role of the researchers and the industry partners, and the roles of both scientific literature and theory in this study. Section 3.2 describes the three phases that emerged from the data, called:

1. Gathering information;

2. Seeking the human factors fit; and

3. Human factors specialists acclimate and strategically align to engineering. 
This shows the intertwining of research and action, theory use and theory development, and learning and adaptation as the collaboration proceeded. Section 3.3 will highlight five indications that the integration of HF into production systems design processes had improved in the collaboration. The final section (Section 3.4) includes a discussion pertaining to the research sub-question of how an ergonomics action research approach, demonstrating integration of HF into production design processes, can be conducted and communicated.

\subsection{Action Research Approaches and Application in this Collaboration}

\section{Using Action Research}

In the AR approach, it is the responsibility of researchers and practitioners together to define the plan, carry out the initiatives, and monitor what is helping achieve the goal in the organization. It is generally considered the responsibility of the researcher to then analyze and communicate what is learned in the context of scientific literature and theories in ways that other organizations and researchers can benefit and learn.

The approach used in this study was based on the approach discussed in Neumann et al (2012), and the iterative AR model from Meyer (2000), shown in Figure 1, as "plan", "act", "observe", and "reflect. This model assisted researchers with ensuring that each action or initiative was part of an overall plan. It also reminded researchers, who are part of the action that they had to frequently disengage from the actions sufficiently to observe the effects and reflect on what was working and not working as the action research proceeded. While depicted as a cycle with distinct stages, in reality the stages overlap, are on-going, and are non-linear, which can be depicted more like a spiral over time. Questions, such as those in Table 1, were helpful for both researchers and practitioners in each of the AR stages as the collaboration proceeded. 


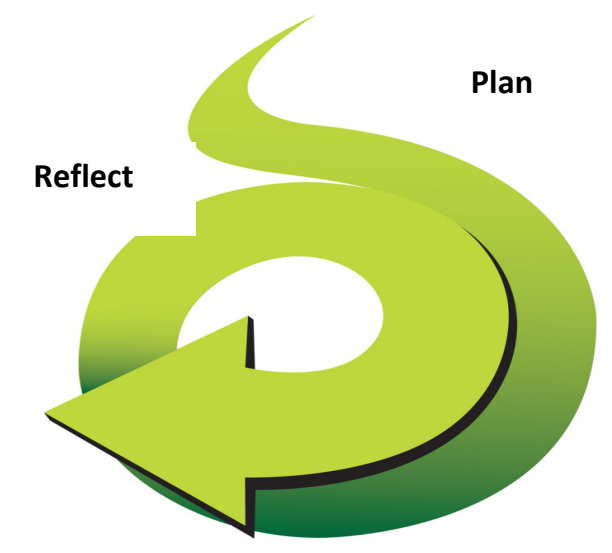

Observe

Act

Figure 1. Action Research Cycle and Spirals (adapted from Meyer, 2000)

Table 1. Sample questions for the researcher/practitioner at each action research stage

\begin{tabular}{|l|l|}
\hline Stage & Sample Questions \\
\hline Plan & $\begin{array}{l}\text { - What is the issue or challenge at this stage? } \\
\text { - What does ergonomics practice and the researchers' experience } \\
\text { suggest would work best at this stage? } \\
\text { - What does the scientific literature contribute? } \\
\text { - Who should be involved? } \\
\text { - How can this be done? } \\
\text { - What role should the researcher take? }\end{array}$ \\
\hline Act & $\begin{array}{l}\text { - What type of action would work best? } \\
\text { - When, where and how should the action occur? } \\
\text { - How will the action be recorded, documented or assessed? }\end{array}$ \\
\hline Observe & $\begin{array}{l}\text { - What was the response to the action? } \\
\text { - What else is going on in the organization that affects the action? }\end{array}$ \\
\hline Reflect & $\begin{array}{l}\text { - What would have improved the action? } \\
\text { - What hindered the action? } \\
\text { - How can the scientific literature or theories provide insight? } \\
\text { - What are the next steps or strategies? }\end{array}$
\end{tabular}




\section{The Evolving Role of Researchers in the EAR collaboration}

In action research, the researcher may take on a variety of roles, depending on circumstances. Since the researcher is an active participant "in" the intervention (rather than collecting data "about" the intervention), and since the bias and experience of the researcher is relevant to qualitative interpretation of the data, researcher disclosure is important in communicating findings (Fisher and Phelps, 2006). In this study, the researcher is a certified professional ergonomist with more than 25 years of experience practicing ergonomics and conducting applied research to reduce work-related injuries. She has extensive experience working with engineering teams and designers and strongly supports the goal of implementing HF early in design processes.

The researchers' role was informed in this study by reviews of organizational change (Palmer and Dunford, 2008), and action research literature (especially Patton 2011). Palmer and Dunford (2008) suggest six potential roles, based on differing organizational theories and ontological assumptions: directing; navigating; care-taking; coaching; interpreting; and nurturing. As applied in this collaboration, during the first phase of gathering information, researchers were navigating to understand processes and the people involved. When needing to demonstrate the $\mathrm{HF}$ benefits during the second and third phase there was some directing of initiatives, as well as coaching and interpreting. In the latter phase as company HFS were becoming more integrated with engineers, the researchers' role shifted more to one of care-taking and nurturing of the HF integration and HFS. Patton (2011) suggests the researchers' role in AR is adaptive - thus changing as needed. This mode of operation recognizes that roles and actions are not planned and linear in AR.

\section{The Role of Industry Partners in EAR Collaboration}

The role of industry partners in AR can involve complete collaboration and responsibility for all aspects of planning, acting, data collection and analysis, and reporting of results (Huxam and Vangen, 2003; Meyer, 2000). In this AR study there was collaboration, especially with the HFS within the organization and increasingly with engineers and managers, but not necessarily a complete "joint" involvement and responsibility. Some initiatives in the first two phases were conducted by university researchers with little involvement from participants in the organization. However, all resulting data were presented, discussed and verified with industry partners. As 
the AR proceeded into the third phase, industry partners took not only more of a planning role, but collected and interpreted data, and initiated communication of findings to other peers, suggesting a higher level of involvement and ownership. In the final phase, HF activities were initiated, carried out and documented entirely by the organization, with researchers acting as observers. Organizational participants also took on the reflective role by recording meetings and reviewing these recordings afterwards.

\section{The Role of Scientific Literature in EAR}

In traditional intervention studies the scientific literature is reviewed initially to inform methods, then later when comparing results with other studies. In AR, scientific literature is accessed and reviewed throughout the intervention. Reflecting on the actions in the case study within the larger context of scientific literature ensures ongoing learning and application of new knowledge to the intended changes (Neilsen and Svenssen, 2006). In essence, research validity in AR has been described as systematically alternating between performing "on-stage" and reflecting critically with the literature "back-stage" (Neilsen and Svenssen, 2006).

In this EAR study, the first phase of gathering information was informed by studies of organizational change, facilitators and barriers of HF integration, socio-technical systems theory, macro ergonomics and complexity theory. In the second phase of seeking the HF fit, researchers planned to increase understanding of strategic goals in the organization and thus reviewed literature and methods pertaining to strategic goal setting (such as cognitive mapping). Researchers also reviewed literature for links between quality, fatigue, performance, and assembly design, with the goal of providing the industry partners with evidence as to how HF benefits worker performance. In the third phase where the focus was on adapting engineering tools for HF, researchers reviewed literature pertaining to business process improvement and engineering tools to look for relevant examples.

\section{The Role of Theory in EAR}

As with the scientific literature, theory is used in AR throughout the study to frame actions, help interpret actions, or to help reflect on actions for the research community. As discussed in Section 1.5, the theoretical underpinning in this study lies in soft systems methodology and 
complexity theory (Mingers and White 2010). In contrast to earlier theories suggesting organizations are static and that change involves un-freezing and re-freezing, complexity recognizes features of instability, dis-equilibrium, sudden change, and complex behaviour. It is thought that the complexity sciences within systems thinking may lead to a better understanding of the behaviours of social and organizational systems when faced with increasing uncertainty both internally and externally.

\subsection{The Three Phases of the Action Research Collaboration}

\section{Overview}

The collaboration will be described chronologically in three phases coinciding with the yearly reflective interviews with participants. Phases were named according to the dominant action in the phase as:

1. Gathering information.

2. Seeking the HF Fit.

3. Acclimating to engineering and aligning HF to strategic goals.

Table 2 provides an overview of the three year-long phases, organized for discussion purposes using the AR model of plan, act, observe and reflect (shown in Figure 1). Describing the case study in this way helps communicate how the methodology of observing and reflecting in turn influences the next phase of planning and action and how the scientific literature and theory is woven throughout the study and informs the process. While each initiative forms its own cycle and they are ongoing in reality, we apply the model loosely to the three phases for illustrative purposes. 
Table 2. Description of the three case study phases over three year period using the AR framework

\begin{tabular}{|c|c|c|c|c|}
\hline & Plan & Act & Observe & Reflect \\
\hline $\begin{array}{l}\text { Phase 1. } \\
\text { Gathering } \\
\text { Information } \\
\text { Mid 2010- } \\
\text { mid } 2011\end{array}$ & $\begin{array}{l}\text {-plan to get "into" organization } \\
\text { at multiple levels, work with } \\
\text { those interested, gather } \\
\text { information, and look for } \\
\text { multiple initiatives that would } \\
\text { help with goal of HF integration }\end{array}$ & $\begin{array}{l}\text {-gathering information eg. current } \\
\text { HF work, reporting of injuries, } \\
\text { workstation layout concerns, HF } \\
\text { perceptions, possible HF metrics } \\
\text {-mapped design process to find } \\
\text { opportunities to integrate HF } \\
\text {-interviewed participants about } \\
\text { how best to integrate HF }\end{array}$ & $\begin{array}{l}\text {-HF work is reactive (after injury) } \\
\text {-few resources or connections in } \\
\text { organization } \\
\text {-HFS reports to OH\&S } \\
\text {-little documentation } \\
\text {-little access to engineering } \\
\text {-OH\&S manager leaves }\end{array}$ & $\begin{array}{l}\text {-lack of senior management } \\
\text { involvement or knowledge of HF } \\
\text { and HFS } \\
\text {-HF needs repositioning } \\
\text {-HFS need to learn design and } \\
\text { business processes } \\
\text {-need for senior management } \\
\text { steering committee }\end{array}$ \\
\hline $\begin{array}{l}\text { Phase } 2 . \\
\text { Seeking the } \\
\text { HF Fit } \\
\text { Mid } 2011 \text { - } \\
\text { mid } 2012\end{array}$ & $\begin{array}{l}\text {-plan to engage more senior } \\
\text { management in HF integration, } \\
\text { get access to relevant initiatives } \\
\text { to integrate HF, and learn about } \\
\text { company's strategic goals and } \\
\text { how HF could help }\end{array}$ & $\begin{array}{l}\text {-cognitive mapping to understand } \\
\text { strategic goals and HF } \\
\text { perceptions of management } \\
\text {-access to some limited proactive } \\
\text { engineering initiatives (eg. HF } \\
\text { pFMEA, discrete event } \\
\text { simulation) } \\
\text {-reflective interviews with } \\
\text { committee regarding facilitators } \\
\text { and barriers to HF integration }\end{array}$ & $\begin{array}{l}\text {-Senior management perceive HF } \\
\text { related to fatigue, quality and } \\
\text { systems design } \\
\text {-attempts to "push" HF into } \\
\text { engineering get little traction } \\
\text {-strategic goals reposition } \\
\text { company as new product } \\
\text { realization center with continuous } \\
\text { improvement and product quality } \\
\text { key } \\
\text {-re-organization - Senior Director } \\
\text { leaves }\end{array}$ & $\begin{array}{l}\text {-HF needs to be aligned with } \\
\text { strategic goals (quality) and } \mathrm{Cl} \\
\text {-HFS need to learn engineering } \\
\text { processes, language, tools and } \\
\text { goals (eg. quality metrics) } \\
\text {-HF not visible, tangible and } \\
\text { engineering-like - disconnected } \\
\text { and little traction on ideas } \\
\text {-HF must deliver on business } \\
\text { goals } \\
\text {-layoffs forcing alignment and re- } \\
\text { focus in organization }\end{array}$ \\
\hline $\begin{array}{l}\text { Phase } 3 . \\
\text { HFS } \\
\text { Acclimate } \\
\text { to Engineer- } \\
\text { ing and } \\
\text { Align HF to } \\
\text { Strategic } \\
\text { Goals } \\
\text { Mid } 2012- \\
\text { mid } 2013\end{array}$ & $\begin{array}{l}\text {-plan to be more visible, on the } \\
\text { shop floor, demonstrate HF } \\
\text { initiatives, show HF as a means } \\
\text { to improve quality and reduce } \\
\text { operator fatigue, engage more } \\
\text { engineers, develop useful tools } \\
\text { and metrics }\end{array}$ & $\begin{array}{l}\text {-HFS work on manufacturing floor } \\
\text { with engineers to optimize next } \\
\text { assembly cycle } \\
\text {-HFS moves to engineering floor } \\
\text {-adaptation of IE tools for HF } \\
\text {-demonstration of usefulness of } \\
\text { HF tools to improve assembly } \\
\text {-Senior Director adopts HF } \\
\text { targets in assembly design stages }\end{array}$ & $\begin{array}{l}\text {-HFS has improved access to } \\
\text { meetings, documents, software, } \\
\text { schedule and engineers } \\
\text {-HFS assisting with engineering } \\
\text { goals with HF as a means to } \\
\text { improve assembly quality } \\
\text {-increased requests for HF } \\
\text {-most HF work now proactive } \\
\text {-HFS participates in next } \\
\text { assembly design and process } \\
\text { requires HF sign-off }\end{array}$ & $\begin{array}{l}\text {-HFS needed to shift focus from } \\
\text { injuries to business goals } \\
\text {-lack of HF tools for assembly } \\
\text {-adapting IE tools leads to } \\
\text { adoption of HF in process } \\
\text {-Senior Director adopting HF } \\
\text { target ensures engineers } \\
\text { consider HF } \\
\text {-HFS pulled into next product } \\
\text { build ensuring process } \\
\text { sustainability }\end{array}$ \\
\hline
\end{tabular}




\section{Phase 1: Gathering Information}

Table 3 summarizes the initiatives in phase 1 of the collaboration. The initial plan was to get "into" the organization at as many organizational levels as possible, gather information, and look for initiatives that would help integrate HF into multiple levels of the design processes. The main participants early in the collaboration were the manufacturing HFS, an industrial engineer, and a manufacturing manager. The occupational health and safety $(\mathrm{OH} \& \mathrm{~S})$ manager who helped initiate the collaboration left the organization during the first year.

Activities to gather information focused on understanding the role and tasks performed by the HFS, identifying typical workstation and assembly concerns, reviewing worker injury data, gathering information about metrics driving business performance and potential HF metrics, and determining links to engineering groups or design processes. A "metric" is a quantifiable measurement used to track and assess performance. One student, through a series of interviews and focus groups, developed a process map of the assembly design process to help the group understand the stages and decision gates. The map was then used in collaborative focus groups with engineers and HFS to identify potential initiatives for integration of HF (see Lim et al, 2013 for details). In this way, the action (of producing the map and discussing HF initiatives), could lead to planning the next HF actions for integration. The map helped the HFS and others realize the role of various departments in the design process, and potential overlap with HF considerations. All initiatives in this first phase were initiated by Ryerson researchers.

The observations from this phase illustrated that most of the HF work in manufacturing was reactive (after an injury or incident). With the HFS situated within the OH\&S department and reporting through facilities, there were very few links to engineering groups. The HFS were not only physically separated from engineering, but had few other connections to engineering personnel and none of the engineering design processes involved HF. The HFS expressed frustration at not knowing when a new product was coming, what the steps were, and what meetings they could attend to bring the HF agenda forward. The following quote and researcher notes from fall 2010 exemplify these points:

HFS: "how do I find out when things (design activities) are happening? - there must be a schedule - l'd like to put this on my calendar - a whole lot of work would come" 
Researcher notes: "HFS is not sure how to get in"

The main reflection documented from this stage was that HF needed repositioning in the organization. Senior management and engineering lacked knowledge of the HFS and what value they could provide to the assembly design process. The HFS were rarely on the shop floor, and did not otherwise have much contact with engineering. HFS performed a narrow range of reactive assessments, and there were no lessons learned documented from these for future assembly builds. It was evident that HFS needed to become better informed about the design process and the business processes used in the organization. To help improve the positioning and networking of $\mathrm{HF}$ in the organization, we recommended the need for a steering committee with senior directors from various departments. A steering committee would also help ensure stability of the collaboration during organizational changes and management departures. 
Table 3. Activities, Organizational Participants and Value towards Goal for Phase 1 of the Collaboration

\section{Phase 1. Gathering Information}

\begin{tabular}{|c|c|c|c|}
\hline Activity & Inputs & Organizational Participants & Value towards Goal \\
\hline 1. Design process mapping * & interviews and 2 focus groups & $\begin{array}{l}\text { Manufacturing engineers, } \\
\text { industrial engineers and } \\
\text { manufacturing managers }\end{array}$ & $\begin{array}{l}\text {-determine design steps and } \\
\text { potential opportunities for HF } \\
\text { integration } \\
\text {-initiate a process oriented dialogue } \\
\text { amongst a cross-functional group } \\
\text { inside the organisation }\end{array}$ \\
\hline $\begin{array}{l}\text { 2. Review of accident and injury } \\
\text { data * }\end{array}$ & $\begin{array}{l}\text { documentation and database } \\
\text { review }\end{array}$ & HFS & -seeking HF injury metric \\
\hline $\begin{array}{l}\text { 3. Investigation of potential HF } \\
\text { metrics }{ }^{*}\end{array}$ & Interviews & $\begin{array}{l}\text { Quality engineers, Ergonomics } \\
\text { manager and team, } \\
\text { manufacturing managers }\end{array}$ & $\begin{array}{l}\text {-determine business and quality } \\
\text { metrics and key features for HF } \\
\text { metric system }\end{array}$ \\
\hline $\begin{array}{l}\text { 4. Review of HF issues on } \\
\text { current assembly lines * }\end{array}$ & $\begin{array}{l}\text { shop floor observations, } \\
\text { document review }\end{array}$ & $\begin{array}{l}\text { Industrial engineers, HFS, line } \\
\text { supervisors, workers }\end{array}$ & $\begin{array}{l}\text {-determine HF concerns from } \\
\text { workers and understand process }\end{array}$ \\
\hline $\begin{array}{l}\text { 5. Review HF documentation } \\
\text { and reporting }\end{array}$ & document review and interview & HFS & $\begin{array}{l}\text {-determine tracking of HF problems } \\
\text { and links back to engineering design }\end{array}$ \\
\hline $\begin{array}{l}\text { 6. Initial development of hand- } \\
\text { travel tool for workstation layout } \\
\text { planning* }\end{array}$ & Shop floor measurements & HFS & $\begin{array}{l}\text {-investigating possibility of new tool } \\
\text { for use in workstation layout } \\
\text { planning and assessment }\end{array}$ \\
\hline $\begin{array}{l}\text { 7. Year-end review and } \\
\text { planning }\end{array}$ & $\begin{array}{l}\text { interviews with industry } \\
\text { participants on collaboration }\end{array}$ & $\begin{array}{l}\text { HFS, industrial engineers, } \\
\text { manufacturing manager, } \\
\text { Ergonomics manager }(n=5)\end{array}$ & $\begin{array}{l}\text {-determine what initiatives are } \\
\text { helping integrate HF, and plan next } \\
\text { steps }\end{array}$ \\
\hline
\end{tabular}

*initiatives in which other students in collaboration were primarily responsible 


\section{Phase 2: Seeking the HF Fit}

Initiatives in the second phase are described in Table 4. In the second phase, called "Seeking the HF Fit", the plan was to engage more senior management in HF integration, get access to relevant design initiatives to integrate HF, and learn about the company's strategic goals and how HF could help. Through increased involvement of the Senior Director of Engineering, a steering committee was formed with seven senior managers and directors. Organizational changes within the company were occurring at the same time as the steering committee was formed, which resulted in challenges scheduling meetings, planning, and committing to initiatives in the collaboration.

We noted that a new Vice President had been appointed who was bringing a background in Toyota management system and continuous improvement and we observed visible postings on the shop floor of hoshins, kaizens and gemba walks related to this new direction. The senior management group were entering a phase of new strategic planning for the organization with a focus on "new product realization".

While organizational change hindered meetings and commitment to initiatives, it also offered an opportunity to the HFS to improve their understanding of the strategic goals of the organization and how HF may align with them. We conducted a cognitive mapping exercise and focus group with the steering committee to understand their perceptions of the link between HF and the organizations' strategic goals (described in Chapter 4). The focus group revealed that musculoskeletal injuries (an $\mathrm{OH} \& \mathrm{~S}$ perspective) were rarely discussed. Instead, directors were concerned about reducing worker fatigue, which they saw as an outcome of poor assembly systems design. They believed if workers were less fatigued, then their ability to notice defects would improve and this would enhance product quality. This information would be critical for helping HFS realize how best to "position" or frame HF within the engineering process.

In the "seeking the HF fit" phase, a number of initiatives began, including having HFS participate in failure mode effects assessment (FMEA) meetings to understand the connections with HF (an initiative discussed during the process mapping in the first phase). Another initiative involved HF assessment of a newly proposed lean pallet line from CAD drawings, and later in early mock- 
ups of workstations. One student developed a discrete event simulation of the assembly steps to assist with predictions of bottlenecks and worker fatigue. Another student was developing a digital tool to evaluate workstation layout. These initiatives proceeded, although few engineers from the organization were involved at this point. Despite assistance from the Senior Engineering Director, HFS felt they were trying to "push" initiatives into engineering, but getting little traction in the way of participation or interest.

As part of "seeking the HF fit", we conducted an evaluation and needs assessment of previous HF training provided to engineers from outside consultants. Through a survey and focus group, HFS learned that engineers rarely used the generic HF education, and information provided in the training about risk factors and injuries were not considered useful to their design tasks. Engineers suggested that due to tight time constraints, $80-90 \%$ of their designs are copies from past work. HFS learned that a better "fit" for HF information would be the creation of "benchmark" or "best in class" HF designs (eg of tools or fixtures) in the form of easily applied drawings or rules. This information on "fit" would also prove valuable for planning actions in the next phase.

Unfortunately, another organizational change resulted in the Senior Engineering Director leaving the organization and no immediate replacement in the collaboration. In the fall of 2011, reflective interviews were conducted with each member of the steering committee as well as HFS and their manager to ascertain what was working and what else could help with the goals of the collaboration. A main finding was that HF lacked visibility. One member stated HFS need to:

"show that you want to get in there and roll up your sleeves".

Another stated:

"when you have something to change or want to drive ergo improvement - do a demonstration and show what physically changes".

It was emphasized that HF needs to be tangible and engineering-like to be accepted. One initiative was considered successful because:

"it is very concrete and practical - a traditional engineering view". 
Managers said HF has to look like engineering initiatives with a project charter that includes timelines, deliverables, return-on-investment and a sponsor. This would require a dramatic change in how HFS plan and carry out their activities to "fit" the engineers' work style.

Reflections on the HF challenges and successes during this phase reinforced that HF needs to be aligned with the organizations' strategic goals, especially the goal of improving assembly quality. One manager stated that

"we need HF incorporated with our deliverables".

The language and metrics of quality were foreign to HFS, therefore efforts increased to interview those responsible for measuring and improving quality, to review and understand the quality data within the organization and the scientific literature, and to attempt to make direct links between quality data and HF concerns.

Our reflections at this stage also reinforced that HFS need to learn more about engineering processes, their language, tools, and their goals. We further reflected on the positioning of HF as continuous improvement, rather than problem identification and control and realized we needed improved tools to quantify and demonstrate HF as continuous improvement. We realized that the integration of $\mathrm{HF}$ into the design process within the organization, at that point in time, might collapse without visible demonstration of its value to engineering or senior management. 
Table 4. Activities, Organizational Participants and Value towards Goal for Phase 2 of the Collaboration Phase 2. Seeking the HF Fit

\begin{tabular}{|c|c|c|c|}
\hline Activity & Inputs & Organizational Participants & Value towards Goal \\
\hline $\begin{array}{l}\text { 8. Discrete event simulation project } \\
\text { of assembly line * }\end{array}$ & $\begin{array}{l}\text { interviews, data review, } \\
\text { presentation }\end{array}$ & Select engineers and managers & $\begin{array}{l}\text {-to investigate value of simulation tool } \\
\text { for predicting assembly problems }\end{array}$ \\
\hline $\begin{array}{l}\text { 9. Cognitive mapping to link HF to } \\
\text { strategic goals in organization }\end{array}$ & $\begin{array}{l}7 \text { one-hour interviews and 2-hour } \\
\text { focus group }\end{array}$ & $\begin{array}{l}\text { Seven Senior Directors appointed } \\
\text { to steering committee }\end{array}$ & $\begin{array}{l}\text {-determine strategic goals and } \\
\text { perceptions of Directors as to how HF } \\
\text { can help achieve goals }\end{array}$ \\
\hline $\begin{array}{l}\text { 10. Development of HF-FMEA } \\
\text { scoring, charter and participation in } \\
\text { meetings }\end{array}$ & $\begin{array}{l}\text { multiple meetings of ergonomics } \\
\text { team, FMEA engineers, FMEA } \\
\text { meetings, floor assessments of } \\
\text { HF scoring, video assessment of } \\
\text { scoring }\end{array}$ & $\begin{array}{l}\text { Several engineers specific to } \\
\text { FMEAs, managers, Senior } \\
\text { Director }\end{array}$ & $\begin{array}{l}\text {-adapting FMEA to include HF scoring } \\
\text { and integrate HF into FMEA meetings }\end{array}$ \\
\hline $\begin{array}{l}\text { 11. Incorporate shoulder load in \#6 } \\
\text { hand travel tool * }\end{array}$ & demonstrations of tool & $\begin{array}{l}\text { HFS, industrial engineer, } \\
\text { Ergonomics team }\end{array}$ & $\begin{array}{l}\text {-adapting hand-travel tool to provide } \\
\text { more HF information }\end{array}$ \\
\hline $\begin{array}{l}\text { 12. Investigation of quality systems } \\
\text { and potential HF link }\end{array}$ & $\begin{array}{l}\text { Interviews, review of quality data, } \\
\text { review of video with problem task }\end{array}$ & $\begin{array}{l}\text { Several quality engineers and } \\
\text { managers }\end{array}$ & $\begin{array}{l}\text {-seeking link between quality metrics } \\
\text { and potential HF concerns }\end{array}$ \\
\hline $\begin{array}{l}\text { 13. Evaluation of HF concerns on } \\
\text { proposed lean line }\end{array}$ & $\begin{array}{l}\text { review of CAD drawing, mock-up } \\
\text { and first trial, assistance with } \\
\text { reporting }\end{array}$ & $\begin{array}{l}\text { Project manager, engineers, HFS, } \\
\text { Director Advanced Engineering }\end{array}$ & $\begin{array}{l}\text {-demonstrating HF value in proactive } \\
\text { design (evaluation at drawings, and } \\
\text { mock-up, and first trial) }\end{array}$ \\
\hline $\begin{array}{l}\text { 14. Design for fixture (DFF) } \\
\text { guidelines, and process for } \\
\text { integrating HF }\end{array}$ & $\begin{array}{l}\text { Operator input, DFF } \\
\text { documentation, focus group, } \\
\text { meetings with engineers }\end{array}$ & $\begin{array}{l}\text { Several fixture engineers, } \\
\text { procurement manager, } \\
\text { manufacturing manager, HFS, } \\
\text { workers in assembly }\end{array}$ & $\begin{array}{l}\text {-development of HF-DFF guidelines for } \\
\text { proactive design, and establishment of } \\
\text { HF in process }\end{array}$ \\
\hline $\begin{array}{l}\text { 15. Review of Continuous } \\
\text { Improvement Initiatives }\end{array}$ & $\begin{array}{l}\text { literature review, shop floor } \\
\text { evaluation and participation in } \\
\text { kaizens and hoishins }\end{array}$ & $\begin{array}{l}\text { Several engineers, floor } \\
\text { supervisors, workers }\end{array}$ & $\begin{array}{l}\text {-determine integration of HF into } \\
\text { continuous improvement initiatives such } \\
\text { as kaizens and hoishins }\end{array}$ \\
\hline $\begin{array}{l}\text { 16. Ergonomic training evaluation } \\
\text { and needs assessment }\end{array}$ & $\begin{array}{l}\text { preparation of survey, survey } \\
\text { assessment, focus group, } \\
\text { documentation of findings }\end{array}$ & $\begin{array}{l}\text { Seven engineers with previous } \\
\text { ergonomics training, HFS }\end{array}$ & $\begin{array}{l}\text {-determine what ergonomics } \\
\text { information is used in engineering } \\
\text { practice, and perceived training needs }\end{array}$ \\
\hline 17. Year-end review and planning & interviews & $\begin{array}{l}\text { Five members of steering } \\
\text { committee, HFS, and Ergonomics } \\
\text { manager }(n=7)\end{array}$ & $\begin{array}{l}\text {-determine initiatives that are working } \\
\text { towards goal, and next steps }\end{array}$ \\
\hline
\end{tabular}

*initiatives in which other students in collaboration were primarily responsible 


\section{Phase 3: HFS Acclimate to Engineering and Align HF with Strategic Goals}

Initiatives in the third phase are shown in Table 5 and a timeline of all 25 initiatives is shown in Figure 2. In this phase, the plan was to make HF more engineering-like and visible on the shop floor by drafting engineering charters for HF activities, demonstrating HF initiatives, and showing $\mathrm{HF}$ as a means to improve quality and reduce operator fatigue. We looked for ways to engage more engineers, and to develop useful tools and metrics that would include HF. With the departure of the Senior Director, a new Senior Director and project leader were appointed to the collaboration. Another large organizational change and extensive downsizing forced a more streamlined alignment of personnel and a tighter focus on strategic goals in the organization. It was emphasized that HF initiatives would only survive if they could help deliver on the business goals.

The HFS increased their activity and visibility on the manufacturing floor, participating in the new continuous improvement initiatives such as kaizens, and gemba walks and discussing the connection between worker postures and assembly forces to worker fatigue and therefore assembly quality. Under a new engineering charter, HFS participated in FMEA meetings, using a newly devised HF-FMEA score to indicate risks of injury to a worker (described in Chapter 5). During meetings, the HFS helped engineers see that defects occurring in assembly, were at times due to challenges in seeing, detecting, or sensing from tactile feedback, a good quality assembly task. Solutions to improve HF were discussed during these meetings, prior to any parts or equipment yet being manufactured. HF input and changes were being demonstrated to an increasingly larger number of engineers.

HFS also worked together with product focused engineers to prioritize tasks for improvement that had both engineering concerns (eg. slow assembly times), and HF concerns for operators (eg. difficult assembly motions). Realizing that traditional HF tools are ill-suited to communicating assembly difficulties, rather than injury risk, HFS adapted industrial engineering tools (eg. design-for-assembly) and used these to score and compare assembly tasks and monitor their improvement (see Chapter 5 for more information). Reflections from the previous phase about making HF visible led to demonstrations in this phase to show how adapted HF tools can improve assembly steps. The demonstrations resulted in the Senior Director of Engineering becoming directly involved in the HF initiatives for the first time. Focus groups with engineers were conducted to test and refine the tools, and within four months, HF were 
incorporated into a controlled engineering document with required HF targets, enforced by senior management. The Director said:

"if you have something that can help us improve assembly quality, we can implement it fast".

This phase represented a "tipping point" for integration of HF into design processes. The HFS physically moved to the engineering floor which provided improved access to people, meetings, documents, software, schedules and to the shop floor where new products and processes were being tested. Physical proximity, combined with a focus on helping engineers meet their goals, resulted in HF being positioned as a means to help improve assembly quality. This strategic alignment led to increasing requests for HF assistance from engineers. Instead of attempting to "push" their way into engineering, acclimation and strategic alignment led to a "pull" for HF from engineers and management. The HFS was invited to key assembly design meetings and HF assistance was being widely requested from different engineers. With subsequent products, the HFS was given key sign-off status at various stages of the assembly design process.

Appropriate HF tools led to adoption of HF in the design process and ensured sustainability of HF for subsequent builds. By acting as a resource to help improve the engineers' goals, HF became a sustainable part of the design process, and not dependent on skills of any given person, individual relationships, or departmental positioning. 
Table 5. Activities, Organizational Participants and Value towards Goal for Phase 3 of the Collaboration

Phase 3. Acclimating to Engineering and Aligning HF to Strategic Goals

\begin{tabular}{|c|c|c|c|}
\hline Activity & Inputs & Organizational Participants & Value towards Goal \\
\hline $\begin{array}{l}\text { 18. Analysis of HF and engineering } \\
\text { concerns on first build of assembly } \\
\text { line for continuous improvement }\end{array}$ & $\begin{array}{l}\text { Shop floor assessments, video } \\
\text { assessments, meetings with } \\
\text { engineers, floor supervisors and } \\
\text { senior director }\end{array}$ & $\begin{array}{l}\text { Senior Director, product focused } \\
\text { engineers, several other } \\
\text { engineers, HFS, floor supervisors, } \\
\text { workers }\end{array}$ & $\begin{array}{l}\text {-collaboration between HFS and } \\
\text { engineers to determine methods to } \\
\text { identify and improve tasks with both HF } \\
\text { and engineering concerns }\end{array}$ \\
\hline $\begin{array}{l}\text { 19. Development of HF-DFA } \\
\text { scorecard and integration of } \\
\text { targets into DFA process }\end{array}$ & $\begin{array}{l}\text { on-floor and video assessments, } \\
\text { iterations of tool, demonstration of } \\
\text { tool output, focus group with } \\
\text { engineers }\end{array}$ & $\begin{array}{l}\text { Many product focused engineers, } \\
\text { Senior Director engineering, HFS }\end{array}$ & $\begin{array}{l}\text {-development of a tool to monitor } \\
\text { continuous improvement of HF and } \\
\text { assembly issues during early builds of } \\
\text { assembly line } \\
\text {-integration of tools' targets into DFA as } \\
\text { key performance indicator }\end{array}$ \\
\hline 20. Complexity hoishin & $\begin{array}{l}\text { review of literature, participation } \\
\text { in meetings }\end{array}$ & $\begin{array}{l}\text { Industrial engineer, HFS, other } \\
\text { engineers }\end{array}$ & $\begin{array}{l}\text {-integration of HF concepts into hoishin } \\
\text { designed to evaluate assembly } \\
\text { complexity }\end{array}$ \\
\hline $\begin{array}{l}\text { 21. Modification of shoulder load } \\
\text { tool in \#6 to include time aspects* }\end{array}$ & $\begin{array}{l}\text { collection and demonstration of } \\
\text { data, presentations }\end{array}$ & $\begin{array}{l}\text { HFS, Senior Director, manager, } \\
\text { several engineers }\end{array}$ & $\begin{array}{l}\text {-customization and demonstration of } \\
\text { tool to integrate time and HF aspects } \\
\text { into early design of workstation layout }\end{array}$ \\
\hline $\begin{array}{l}\text { 22. Conversion of HF-DFF } \\
\text { guidelines into targets and } \\
\text { incorporating into HF-DFA targets }\end{array}$ & $\begin{array}{l}\text { Multiple meetings with engineers } \\
\text { and DFA manager }\end{array}$ & $\begin{array}{l}\text { DFA Manager, HFS, Senior } \\
\text { Director }\end{array}$ & $\begin{array}{l}\text {-locking HF-DFF into process to ensure } \\
\text { accountability of internal and external } \\
\text { vendors }\end{array}$ \\
\hline $\begin{array}{l}\text { 23. Training in HF-DFF targets for } \\
\text { internal and external vendors }\end{array}$ & focus group & $\begin{array}{l}\text { HFS, several internal and external } \\
\text { engineers }\end{array}$ & $\begin{array}{l}\text {-ensure compliance with HF-DFF } \\
\text { targets }\end{array}$ \\
\hline 24. Year-end review and planning & interviews & $\begin{array}{l}\text { Senior Directors, several } \\
\text { managers and engineers, HFS, } \\
\text { Ergonomics manager }(n=9)\end{array}$ & $\begin{array}{l}\text {-to document efforts and lessons } \\
\text { learned about integrating HF in } \\
\text { assembly design processes }\end{array}$ \\
\hline $\begin{array}{l}\text { 25. Presentations to summarize } \\
\text { efforts and confirm findings }\end{array}$ & meetings & $\begin{array}{l}\text { Senior Director, several } \\
\text { managers and engineers, HFS, } \\
\text { Ergonomics Manager }\end{array}$ & $\begin{array}{l}\text {-communication and confirmation of } \\
\text { findings from collaboration }\end{array}$ \\
\hline
\end{tabular}

*initiatives in which other students in collaboration were primarily responsible 


\section{Activity Timeline}

Year 1: Gathering Information

1. Design process mapping *

2. Review of accident and injury data*

3. Investigation of potential HF metrics*

4. Review of HF issues on assembly lines*

5. Review HF documentation and reporting

6. Hand-travel tool for workstation layout*

7. Year-end review and planning

Year 2: Seeking the Fit

8. Discrete Event Simulation*

9. Cognitive mapping to link HF to goals

10. FMEA HF scoring, charter and meetings

11. Incorporate shoulder load in \#6 tool*

12. Investigation of quality systems and HF link

13. Lean Line, CAD, mock-up, video analysis

14. Design for fixtures guidelines and process

15. Review of continuous improvement

16. HF training needs assessment

17. Year-end review and planning

Year 3: Acclimating to Engineering and

Aligning HF to Strategic Goals

18. Analysis of concerns on 1st build assembly

19. HF-DFA scorecard and targets into process

20. Complexity hoishin

21. Shoulder load tool \#6 to include time*

22. Convert HF-DFF guidelines into targets

23. Train vendors in HF-DFF

24. Year-end review and planning

25. Presentations to confirm findings

*initiatives in which other students in collaboration were primarily responsible
May-10 Sep-10 Jan-11 May-11 Sep-11 Jan-12 May-12 Sep-12 Jan-13 May-13 Sep-13

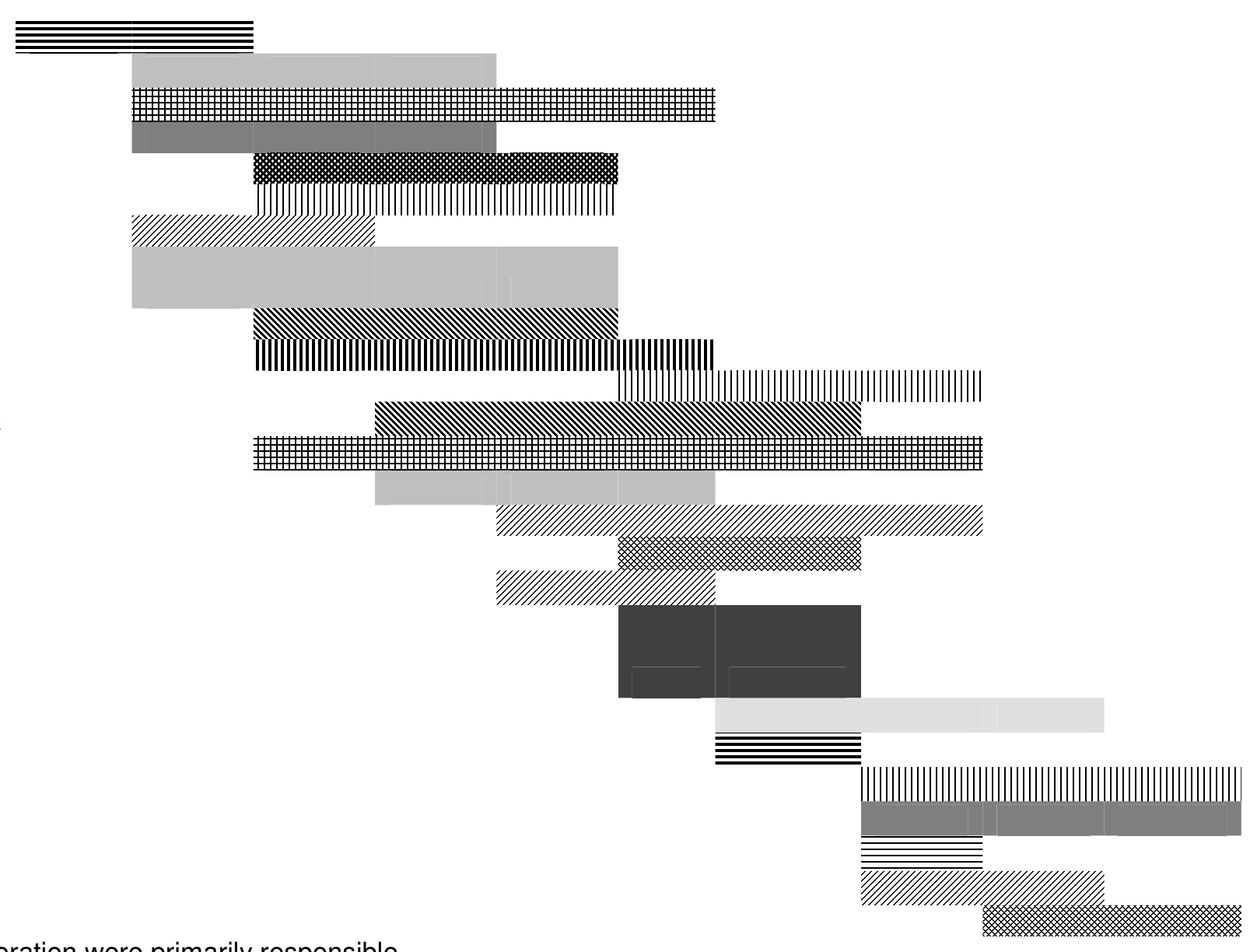

Figure 2. Activity timeline for initiatives in collaboration 


\subsection{Indicators of HF Integration in Production Design Processes in Collaborating Organization}

Although our study did not set out to "measure" changes or outcomes in a pre-post fashion, there were signs that indicated improved integration of $\mathrm{HF}$ into production design processes at the end of phase three - our collaboration goal. To understand "how" HF was integrated into design processes, it is first important to describe "what" HF changes were made. As discussed, at the beginning of the collaboration, there were no HF considerations in any proactive design stages. The majority of tasks performed by the HFS were reactive (after an injury or incident). By the third phase of the collaboration, there were HF targets incorporated into tools at several stages of the design process. Senior directors were holding their engineers responsible for meeting the HF targets in the design process, and the HFS had key sign-off. Five signs were found indicating increased HF application in the design processes. Further examples of empirical evidence indicating integration of $\mathrm{HF}$ in the design process is found in Appendix $\mathrm{B}$. While no single sign on its own is indicative of substantive organizational change, the five combined suggest a strong tendency. These were:

a. Documentation of HF changes, eg. meeting minutes with HF suggestions by the Ergonomist or Engineers, HF targets and sign-offs in design process documentation.

b. Quotes from organization participants indicating changes in HF application and in HF knowledge.

c. Indicators of change in tasks performed by the HFS and in number of engineers participating in HF.

d. Documentation of organizational participants sharing the success of the HF integration with their peers in scientific and technical meetings.

e. Examples of initiatives occurring towards the end of the third phase of the collaboration that indicate learning and new HF applications for participants (double loop learning) and sustainability for HF.

Each of these indications of change will be described more fully below. 


\section{a. Documentation of HF Changes in Process}

There were several processes that adopted a HF target, or sign-off by an HFS as a result of the collaboration. One example of a HF target, shown in Figure 3 below, was incorporated into the design-for-assembly process (described in Chapter 5). Senior management hold engineers responsible for designing parts, fixtures and tooling in new assembly processes in such a way that newly implemented HF targets are met. The dashboard shown in figure 3 indicates that the $\mathrm{HF}$ target is monitored for continuous improvement alongside fixture cost, units produced, scrap, and process defects, contributing to an overall DFA score. The HFS and Engineers score the HF-DFA and work together during product realization to improve the assembly design and reduce the score. Another example is in the design for fixture process shown in Figure 4 (described in Chapter 5). The yellow boxes indicate where the HFS was required to sign-off on fixture designs prior to final design.

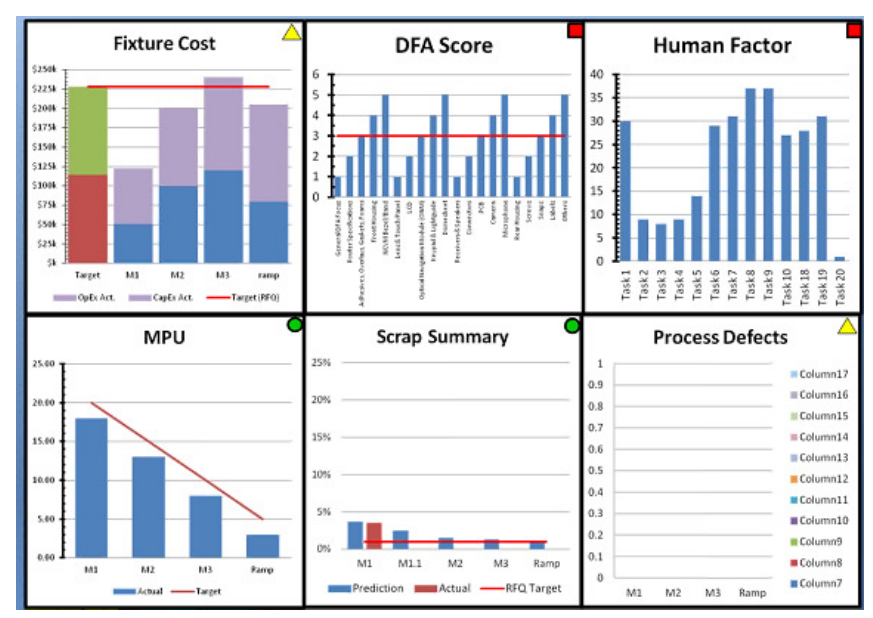

Figure 3. Human Factors targets are one of 5 monitored for overall DFA score in new product builds (note: data is for illustrative purposes only) 


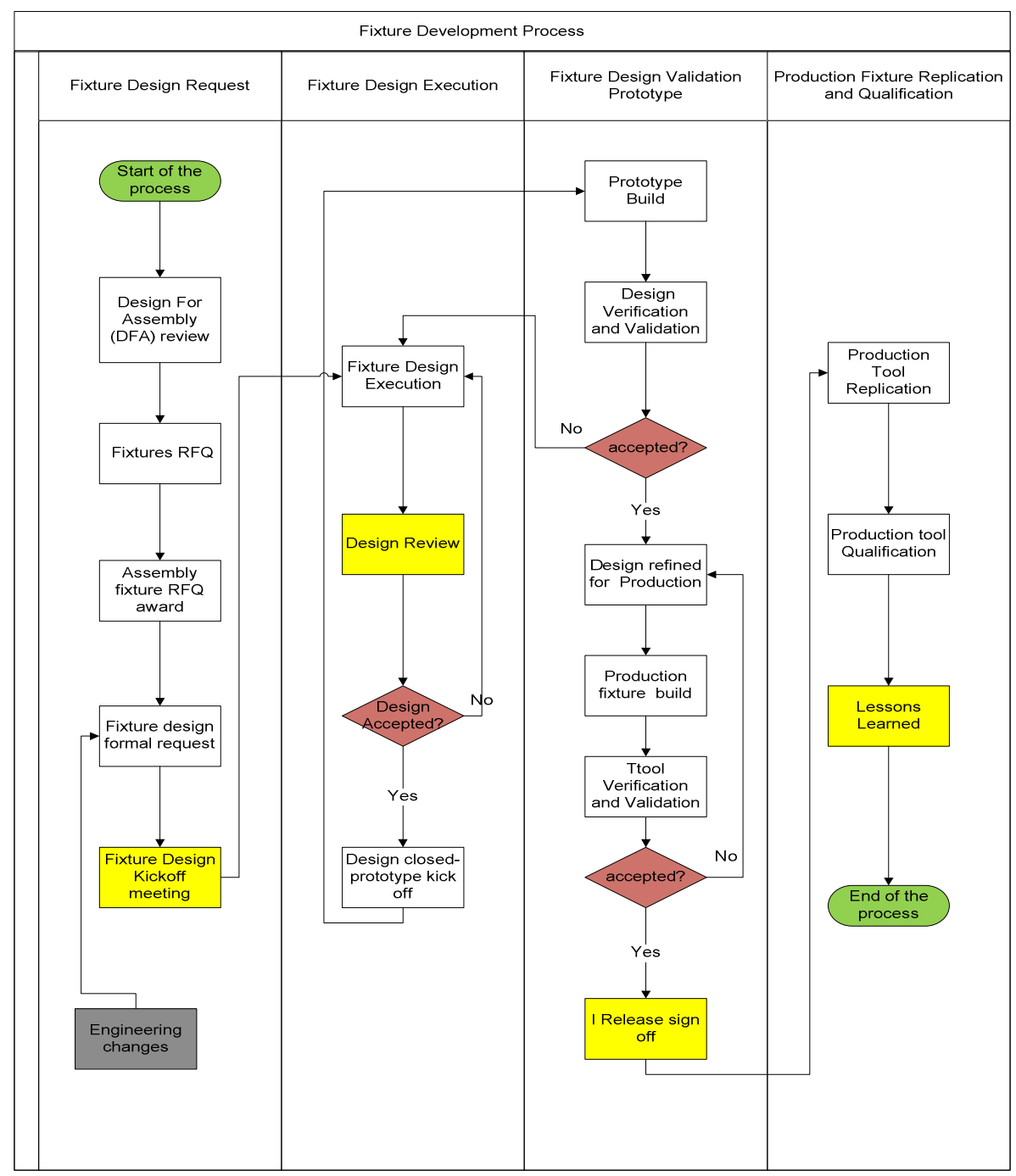

Figure 4. Yellow boxes in the design-for-fixture process indicate newly created steps where the HFS was required to sign-off on fixture designs (note: process is for illustrative purposes only).

\section{b. Quotes from organization participants}

Towards the end of phase 3, results of the effort were presented to engineers and senior directors for verification and confirmation. We asked after the presentation: "to what extent has this collaboration changed the way you, as engineers, think about HF?"

One engineering manager said, referring to working with an internal HFS: 
"I use to come to you (for occasional HF advice), but now we both get called when something happens - it's like welcome to the party"

This change in attitude and openness from engineers to HF inclusion is very different from the 2010 quote from the HFS who did not know how to get "in" to the design process. The framework-inspired macro ergonomic approach led us to undertake numerous initiatives over the three years of the collaboration. Not all were successful, but as one senior director who had participated in the collaboration from the beginning stated:

"the way product and fixture designs are going are definitely in the right direction - from when I joined (the collaboration) to where we're at is night and day and you can say the same thing with the assembly line - we've certainly made it easier on the operator in what they're doing - not every single initiative we worked on was successful but that's the nature of the beast - you can't expect that - some things are going to stick and some things won't but you've got to keep trying - even the ones that didn't stick, or failed, gave you the opportunity to learn things and get to know people and show them what you have"

Two examples further demonstrate the change in attitude within the organization toward proactive HF. In the first, a group of engineers initiated a Hoishin related to assembly complexity. Their goal was to come up with a metric that could be used to predict which assembly tasks would have high complexity for the operator. The HFS was asked to participate and contribute to this Hoishin to bring knowledge about complexity from the human perspective. In the second example, engineers were discussing what could be causing low yield at one particular outsourcing location. The HFS was asked whether one of the HF scorecards might be used in a predictive way at the site to indicate problems in assembly related to production yield. These examples demonstrate that engineers are seeing HF and the HFS as a resource to help them meet their design goals. 


\section{c. Changes in HFS tasks and engineers participating in HF}

As shown in Figure 5 the self-reported percentage of time the HFS performed proactive HF work increased from $3.5 \%$ in 2010 to $72 \%$ in 2013 . The number of engineers the HFS worked directly with increased from 15 in the first phase, to 70 in the third phase. From documentation and observation of subsequent assembly design cycles, the HFS participated with engineers in all assessments and solution development for the new product lines. Changes were documented to parts, processes, materials and fixtures arising from the inclusion of HF in these early design stages.

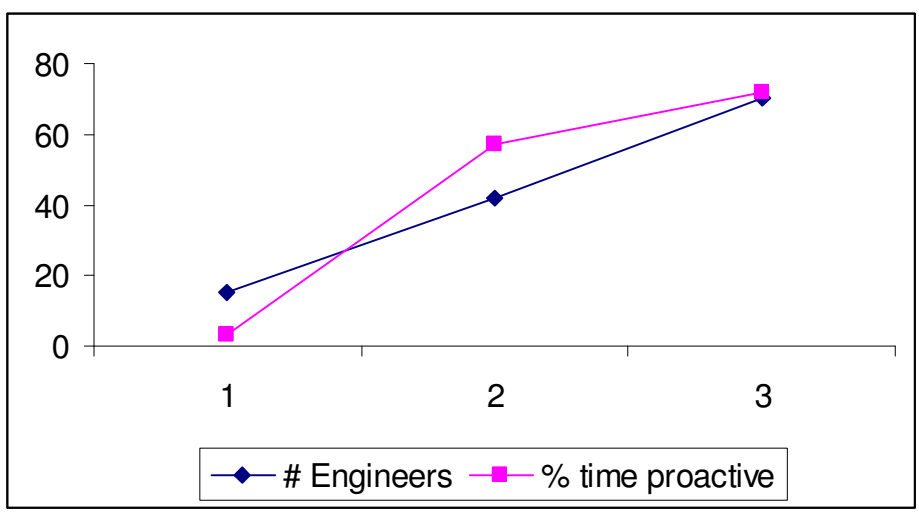

Figure 5. The number of engineers participating in HF, and the percent of time the HFS spent in proactive HF work in each of the 3 phases of the collaboration

\section{d. Organizational Participants Share HF Success with their Peers}

Both the Ergonomics Manager and the Director of Engineering reviewed each conference and journal publication submitted as a result of the collaboration. In most cases, direct acknowledgement was included from the company, and in some cases, participants were named as co-authors, suggesting that they wanted to be formally associated with, and were proud of the outcomes of the collaboration. The Senior Director of Engineering stated about disclosure of information:

"I don't think anyone is outstripping us in this area - we're industry leading in this case, which is exciting - others would have to be really good and invest a lot of time to be where we're at -it took 3 years" 
Another indication the organization took ownership of the changes are presentations by participants to their peers at scientific and technical meetings. For example, one HFS presented the HF-FMEA initiative at an Applied Ergonomics Conference in Orlando, Florida. In another example the Senior Director of Engineering was asked to present a Keynote Address at a Manufacturing Engineering Conference at Dalhousie University. He chose to talk about the HF integration in production assembly design, and specifically the success of the HF-DFA targets.

\section{e. Learning and Signs of HF Sustainability}

During the last six months of the collaboration, researchers took more of an observation role, participating in the background in a few, selected initiatives. The intent was to slowly disengage as researchers in such a way as to ensure the HF integration within engineering design would continue in our absence. During this period, the Senior Director of Engineering requested a meeting with HFS to discuss a new initiative to develop a "Utopian Workstation Layout" that would provide "ideal requirements". These requirements, once determined, would then become a tool for ensuring new workstations in all locations, including outsourcing, would meet ideal specifications. Several things about this initiative demonstrate dramatic change in HF application in the organization compared to before the collaboration, as well as learning for HFS (i.e. learning from what worked in the collaboration, modifying goals to ensure they are doing the right things, and applying this to future projects implies double loop learning):

- The Senior Director of Engineering approached the HFS with a project idea, demonstrating a "pull" for HF from engineering (i.e. the Engineering Director is thinking HF and knows who to go to);

- HFS developed an engineering charter to monitor timelines, deliverables and ROI (i.e. HFS know the process for developing and monitoring projects in the engineering department);

- HFS developed a working group of engineers for the initiative, including those from outsourcing countries (i.e. HFS know who to include and how to access the right people);

- HFS chaired the meetings, prepared minutes, and collected data as appropriate for the initiative (i.e. HFS taking leadership role in joint HF/Engineering project); 
- HFS worked to create a unique "tool" incorporating HF into design requirements, and suggested the tool have a quantitative way of scoring compliance (i.e. HFS is adapting a tool to incorporate HF and creating scores for targets);

- HFS took ownership of the project and had a proactive vision as to its application in promoting improved workstation design (i.e. rather than responding to a problem with a workstation).

In contrast to before the collaboration when the HFS did not know many engineers, or the design process, or "how" to integrate HF within design processes, this initiative points to the learning and organizational change both in HFS and within the Engineering Department.

\subsection{Discussion: How can an ergonomics action research approach, demonstrating the integration of human factors into production design processes, be conducted and communicated?}

The first purpose of this chapter was to demonstrate how to conduct and communicate action research in a macro ergonomics intervention. The first part of the chapter has highlighted unique features of an AR approach and how it worked in the collaboration, including the evolving role of the researcher as participant "in" the development, the ongoing use of literature and theory to inform action, and the importance of continual reflection on actions for planning the next actions. This chapter has also demonstrated that reporting of AR findings tends to be unconventional compared with other scientific studies because the methods and results are difficult to disentangle.

The second section then provided details of the AR collaboration, using the model of the AR spiral with three non-linear cycles of plan, act, observe and reflect. This helped illustrate how actions taken were informed by research and experience, and that observations and reflections, in turn, influenced subsequent actions. Actions to integrate HF were not planned in advance, but were ongoing and embedded in the research process. This is in contrast to most participatory ergonomics interventions, or change management approaches, where a discrete intervention is "planned" and then "tested" (Commissaris et al., 2006). 
The second goal of this chapter was to demonstrate how action research can lead to a deep understanding of "how" to integrate HF into production systems design. It is about meaning of action rather than testing a predetermined hypothesis (Carter 2007). In this way, AR is more closely aligned with soft systems methodologies (Checkland, 1985), and organizational learning (Commissaris et al., 2006; Docherty et al, 2002) where there is more emphasis on learning from the process and less on the outcome evaluation. We started with only a broad framework suggesting we needed to create opportunities to integrate HF proactively into as many levels of the design process as possible (c.f. Neumann and Village, 2012). The "situational awareness" and constant reflecting and questioning within the AR approach helped the team learn from their many initiatives what was working and not working, and to adapt accordingly. At the end of the first phase, we recommended a steering committee to improve the positioning, networking and stability of the HF work in the collaboration. Organizational strategies were shifting and it was apparent that HFS were removed from main line strategic and business goals, much like a "side-car" status (Neumann et al, 2009; Dixon et al, 2009). Other researchers have noted that if $\mathrm{HF}$ is positioned in line with company goals, it is more likely to be effective (Dul and Neumann 2009; Drury, 2000; Eklund, 1997). We capitalized on the strategic changes in the organization to link perceptions of HF to the new strategic goals.

By constantly questioning our assumptions, carefully listening to recordings from meetings, reflecting with the research team, and consulting literature and theory as needed, we began to discover "how" HF needed to be framed to "fit" within the engineering team in this organization. We learned from the cognitive mapping exercise (described in Chapter 4) with senior management that their goal of good production systems design is to minimize operator fatigue (not injuries) to improve performance and therefore their main business goal of good quality assembly. This understanding stretched the HFS to think and act outside of their comfort zone. As others have found, the HFS needed to learn the engineering language, processes, tools and metrics in order to become more "engineering-like" and visible (Broberg, 2007; Wulff et al, 1999). The acclimation and strategic alignment of HF with engineering coincided with a tipping point in the collaboration. The perception and interest of engineers in HF changed when it became a means to help improve their goals and business performance.

It has been reported that the deep understanding that occurs with an AR approach where researchers infuse team discussions with questions, data, and research, facilitates systematic 
reflection and decision-making that results in more effective process sustainability (Patton, 2011). The changes that occurred in the organization during the collaboration included development and adaptation of engineering tools and metrics to include HF, adoption of these into processes, incorporation of the HFS into all proactive design stages, and enforcement of the HF targets by senior directors. There was a dramatic increase in HF application by the HFS in early design stages, and on the number of engineers influenced by the HFS. By the end of the third year, the HFS and engineers were operating as a team with a common goal of improved assembly design. Senior directors reported that increased HF application has improved the design of more recent assembly lines and made it easier for the operators.

This chapter, consistent with the literature, has also demonstrated the benefits to researchers and practitioners of adopting a reflective stance in their HF work (Ellegard et al, 1992; Badham and Sense, 2006). At an individual level, active reflection can improve understanding of issues and performance. At a group or organizational level, the reflexive loops, iterative action for change, and shared observations with users, can lead to a new collective practice, which Docherty et al (2002) suggests is organizational learning. Docherty et al (2002) refer to organizational learning as the "third paradigm" of interventions where reflexivity or thoughtfulness is systematically performed to integrate system perspectives and subjects' perspectives with continuous questioning of group tasks, operative rules, etc. We encourage researchers and practitioners to use reflexivity when working with organizations to improve their HF efforts.

\section{Methodological Challenges in Conducting Ergonomics Action Research}

While effective in making sustainable changes, there are challenges in conducting AR. It is time consuming, resource intensive and demanding on the part of the researcher. There is continual balancing regarding roles and actions, especially whether the researcher should navigate and direct the action, or facilitate and coach those in the organization to take the action. Ultimately, the organization must "own" the actions in ways that work for them, but we found it was sometimes helpful for researchers to take the lead (eg. demonstrating a new method or providing evidence). At other times, an interpretive or coaching role with practitioners helped them reflect on their own actions. The continual reflection and ongoing analysis of the actions 
requires the researcher to be a "participant-observer" always questioning what the researchers or practitioners could do better.

During the three years, the collaborating organization underwent a major shift in organizational strategy, multiple personnel changes, downsizing and layoffs, and re-alignment of various departments. Such organizational changes may make our findings open to criticism. Other intervention studies have been known to suffer, or even collapse with such disturbances (Neumann et al, 2009; Dixon et al, 2009). However, the reflexive nature of the AR approach allowed adaptation and continuation of HF efforts despite the upheaval. In fact, making progress under these difficult circumstances further highlights our success at helping engineers understand how HF can help them achieve their goals. Viewing the organization with reference to complexity theory reminded us that industries with short product cycles view rapid and relentless continual change as necessary for survival. Likewise, for HF to be implemented in such a volatile environment, we needed to shift from viewing change as a barrier, to viewing change as a potential facilitator of HF.

\subsection{Conclusion}

This longitudinal EAR collaboration with an electronics manufacturing firm demonstrated how over a three-year period, HFS went from being completely outside the engineering design process doing reactive HF work to being embedded at numerous stages in the engineering design process doing mostly proactive HF work. We conclude that the EAR approach, especially the active reflection, combined with targeting multiple initiatives at different stages of the design process helped the organization find ways to integrate HF into their processes in a sustainable way. This macro ergonomics change would not be amenable to a step-wise intervention-type research as the steps were not apparent beforehand. The close proximity and involvement of the researcher in the change, the ongoing interaction with stakeholders, the ability to observe and reflect in real time in vivo, and the concurrent data collection and analysis led to a deep understanding in this organization about "how" to integrate HF into design processes. With the researchers both involved in the process, as well as removed to reflect and theorize, they acted as a catalyst to the change. The strength and flexibility of the EAR approach demonstrated that change occurred despite downsizing and management turnover in 
the organization. This chapter provides insight to researchers about how to conduct EAR studies where the research question is about "how" something can occur. It also demonstrates the benefits for practitioners of using a reflective stance to question and improve success of $\mathrm{HF}$ goals. Finally, this chapter has also demonstrated one method for reporting an AR study when methods and results are not linear as in traditional intervention studies. 


\section{Chapter 4}

\section{How Can and Why Should HF be Linked to Strategic Goals in an Organization? Adapting the Cognitive Mapping Technique to HF.}

\subsection{Introduction and Purpose of Chapter}

The goal of this chapter is to show why it is important to link human factors to the strategic goals in an organization so it will be seen as a means to help improve business performance. We also demonstrate how this linking can be done by adapting a tool from operations research and management science called "cognitive mapping". We conduct cognitive mapping interviews and a focus group with the senior Directors in our collaborating organization to determine how they perceive that HF is linked to their strategic goals. The first part of Chapter 4 (Section 4.1) describes what a cognitive map is. Section 4.2 contains a methodological review of various methods of conducting a cognitive mapping exercise to inform selection of a mapping procedure for use with the Senior Directors in the collaboration (based on a paper published). In Section 4.3, results are presented of the individual and group mapping exercise conducted with Senior Directors as well as the focus group (based on a second accepted paper). Section 4.4 discusses how the information gained from the mapping improved the HFS understanding of the perceptions of Senior Directors regarding HF, and how they link HF to their strategic goals.

\subsection{What is a cognitive map?}

A cognitive map is a graphical representation, or visual picture, of the content and structure of an individual's belief system (Eden, et al. 1992). The process of cognitive mapping was introduced into the management science field by Axelrod in 1976 (Markoczy \& Goldberg, 1995). The basis of the theory originates in the psychological "personal construct theory" (Kelly, 1955). The personal construct theory posits that humans are scientists who are constantly trying to make sense of the world in order to act within and upon it. In trying to make sense of the world, 
people use a construct system, then compare any new information for similarities and differences and map these relationships to form their perceptions. The process is one of reflective comparison between currently held concepts and new information.

The process of eliciting the map is most commonly performed using interview techniques and open-ended questions about a specific problem or issue. Participants provide their perceptions, known as "concepts." The concepts are written down, and refined through more open-ended questions. Relationships between concepts are identified (for example causality - where one concept leads to or influences another). Concepts are considered "nodes" and the relationship between concepts are considered "links." Links have arrowheads that show the causative direction. Typically, individual maps contain up to 100 nodes and group maps that are made by merging individual maps may contain as many as 800 nodes (Eden, 1988).

The notion of team or group maps began in the 1990's with the idea of helping teams negotiate consensus and commitment to a portfolio of actions (Eden, 1988). Because it makes explicit the concepts of different individuals, cognitive mapping helps facilitate decision-making by promoting a shared understanding of potential problems and design choices (Swan, 1997). With a wider understanding of the issues, negotiation can occur more easily and decision makers can jointly understand the complexity and consequences of a decision (Shaw, et al. 2009). The use of a group strategy map also removes individual ownership of the issues, creating some distance to see and discuss the problem in new ways, thereby facilitating organizational change.

\subsection{Review of Cognitive Mapping Methodologies}

In this section we will present some of the key methodological choices in creating and analyzing cognitive maps, with an emphasis on techniques that are most likely to be of practical use in the context of human factors in manufacturing environments. This section will include: methods to elicit information; the role of the facilitator; mapping methods (software or paper and pencil); and methods for analysis and interpretation of maps. 
The choice of technique for any given context depends on a number of variables, including the likelihood of producing valid and reliable data, logistical considerations such as the time and extent of participation, and seniority of the participants. Other variables include the complexity of the problem, the interest of the practitioner/researcher, and the scope of analysis. Note that none of the methods presume one must have a strong knowledge of the HF.

\subsubsection{Choose the method of eliciting information}

Information can be elicited either through open-ended questions, or through pre-selected "closed" questions. Using an open-ended question, such as "How may one improve customer service?" tends to result in wide-ranging and distinctive maps for any given individual. Alternatively, the researcher may use a more closed structure to provide a set of pre-selected concepts based on the literature and their domain knowledge of the situation, that the participants link or rank by importance (see Markoczy and Goldberg, 1995). One example of a closed structure is pairwise comparison, where participants make judgments of the positive or negative influence of one variable on another in a pairwise fashion (Hodgkinson, et al. 2004). Another example of a closed structure is the repertory grid, an early cognitive mapping technique that involves a very structured approach for clustering and rating concepts (Eden 1988; Swan 1995). The advantage of closed questions is that they make merging of individual maps easier because the concepts are all similar. The disadvantages are that they do not facilitate a rich subjective reflection on the topic, and they presuppose prior knowledge of all relevant domain elements. While either open or closed questions can work, open questions allow individuals to view their responses, re-evaluate, make new links, and at times discover emergent themes that would not be otherwise captured.

\subsubsection{Consider the role of the facilitator}

The role of the facilitator is an important consideration as it influences the mapping outcome, and it varies widely across different techniques. Some of the methods are executed exclusively by the facilitator/researcher; others are facilitator-led but incorporate a large degree of participant involvement; and a very few are performed with minimal involvement of the facilitator. The latter techniques involve less researcher bias - as for example, in the Self- $Q$ Technique (Nicolini, 1999) in which participants perform self-interviews formulating their own questions with structured activities to develop their concepts and the network. These later 
techniques most closely resemble ethnographic methods of data collection (Nicolini, 1999). Group maps can then be built through consensus activities or the use of software that combines individual maps into group maps without any interpretation by a researcher (Nicolini, 1999).

In techniques where the facilitator plays a very active role, they may create the map, add concepts and emergent themes, draw links, and cluster concepts together (see Oval Maps or Group Map Techniques by Tegarden and Sheetz, 2003 and Robertson and Williams, 2006). The advantage of an active facilitator is that they can detect emerging concepts that the individual or group may not see. However, these methods are heavily influenced by the facilitator. In the middle ground are methods where the facilitator plays an active role, but also heavily involves the participants in negotiation of a consensus (see the Strategic Options Development and Analysis (SODA) method by Eden, 1988 and Swan, 1995).

\subsubsection{Choose the method of mapping}

Mapping is usually done actively with the participant, but can be done after an interview by coding transcripts of interviews or other text (Swan, 1995). Coding after an interview does not allow a participant to see the map and to question the links or expand on a concept as they are viewing it (Eden \& Ackermann, 2004). Coding post-interview may also result in the facilitator making assumptions when drawing the links since they cannot check with the participant directly.

The mapping method can use mapping software or paper and pencil. The extensive work by Eden (Eden, et al. 1992; Eden, 1992; and Eden \& Ackerman, 2004) and Ackermann, et al. (1992) describe in detail the paper and pencil process for eliciting concepts and drawing maps. They suggest mapping in layers or hierarchies with the goals at the top, the strategic decisions in the middle and the potential options at the bottom. They suggest evaluation of opposite extremes of concepts (i.e. positive and negative), and distinguishing between actors (persons) and actions (verbs) in the codes. The advantage of paper and pencil techniques is that they require minimal technology and can easily be executed during interviews, with the participant seeing the "whole" map develop visually as they actively assist in its creation. This process helps the participants see new links and concepts they might not otherwise have noticed. It is also considered ethical in that participants can see what is recorded (Brown, 1992). 
Several types of software have been developed to aid both the map drawing and, especially, the analytical processes (see Lee, et al., 1992 for Collective Cognitive Mapping System (COCOMAP), Ackermann, et al., 1992 for Decision Explorer, Sheetz, et al.,1994 for VisionQuest and Eden, 1988 for COPE software). In simpler programs, the facilitator uses the software to draw the map during individual or group sessions. They can later overlay individual maps to create a group map, or they can analyze maps in numerous other ways. Collectively, computerbased systems that combine hardware, software and procedures to structure group activities are known as Group Support Systems (GSS). Some GSS require group members to simultaneously work on separate computers and the systems prompt members to agree to common themes and links. Other GSS tools include electronic brainstorming, point allocation, and voting and ranking systems (Sheetz, et al., 1994). The software then merges the complex maps and facilitates numerous analysis techniques. For example, rules can establish cut-offs for merging concepts. There is tremendous advantage in using software to analyze the information statistically. However, while such analyses may be interesting to the researcher, the data may not be as useful for the participants, or necessary for problem solving in the organization.

\subsubsection{Methods for creating group maps}

There are a range of methods for creating group maps that include: maps made by the facilitator; by the facilitator and participants together; or by participants with little input from the facilitator. Group maps may also be created without first making individual maps.

The first type, where the facilitator alone merges individual maps into a group map, includes examples such as the Etiograph, Congregate Map and Group Map techniques (Swan 1995; Tegarden and Sheetz, 2003; Robertson and Williams, 2006). In the Congregate Map technique, for example, only the nodes that are common to each individual's map are included. This method has been criticized for researcher bias, but has the advantage of likely being quicker and involving less participants' time. However, the final group map may not promote change or action by the group if participants are not involved in its creation. 
In the second type of method, where the facilitator develops the merged map together with participants during a focus group, the level of consensus must be considered. Langfield-Smith (1992) reported that reaching consensus on all concepts is time consuming, and Nicolini (1999) found it may provoke disagreement over the meaning of the nodes. However, if the maps are accepted too readily by participants, they may contain generic statements that may not be as useful.

The third type of method, which relies heavily on participants deriving the map, includes, for example, Strategic Options Development and Analysis (SODA) (Swan, 1997). Software is used to retain all individual differences in individual maps. Negotiation among participants to determine the final shape of the map leads to a richer understanding of complex issues. This type of merging process, while time consuming, allows common features of each individual map to be highlighted while retaining the idiosyncratic beliefs of individuals (Swan, 1997).

Finally, a group can create a shared map without first deriving individual maps (see Sheetz et al.1994). Sheetz et al (1994) reported that the group procedure, which took almost four hours, was much more time efficient and produced the same overall result as conducting individual maps that were then merged. Robertson and Williams (2006) also suggests using a direct group approach if time is limited or if it is essential that all parties identify with, and buy in to, the output. The use of individual maps, however, is suggested when individual concepts are of interest to the facilitator and when participants come from different levels or departments within the organization, or where there may be disagreement between participants.

\subsubsection{Methods to analyze and interpret a cognitive map}

A number of analysis techniques will be discussed in this section to provide an overview of options available for both individual and group maps. Some of these methods will be demonstrated in the section to follow with results from the collaborating organization. Maps are analyzed in three ways: the number of concepts and links; the shape and structure; and the content. 
A map's complexity, reflected by the number of concepts, provides an indication of the person's knowledge or expertise on a topic (Novak and Canas, 2008). While a greater number of nodes generally represents greater mastery, expert knowledge, or complexity of the situation, the method of elicitation and length of interview time can influence the number of nodes (Eden, 1992). In addition to the number of concepts, the ratio of links to concepts also reflects knowledge and expertise. Eden (1992) reports that typical ratios of the number of links to the number of concepts range from 1.15-1.2, with higher ratios depicting greater complexity and expert knowledge.

Regarding shape and structure, cognitive psychologists suggest that the "essence of knowledge is structure" (Ruiz-Primo, 2004). Therefore, as a person's knowledge increases through learning, training, or experience, the elements of their knowledge become increasingly connected; this can be revealed in their cognitive map. Work by Hay and Kinchin (2006) in the educational field suggest that more expert maps resemble networks with high numbers of interconnections, compared with those of novices that are linear or spoke-shaped (with numerous concepts coming from a singe concept). One can also explore the ratio of heads to tails. Concepts that are "heads" are at the top of the map with concepts leading into them. "Tails" are at the bottom of the map and represent the action items leading upward. A high ratio of heads-to-nodes can indicate multiple potentially conflicting objectives or goals, which in turn can indicate higher complexity of the problem. A high ratio of tails-to-nodes, or relative flatness of the shape, can indicate a large range of possible options to achieve a particular goal.

The content of the map can be explored by looking for the most frequently linked concepts (known as domains) or most central concepts (calculated with a distance decay function for links successively further from the central concept). Central concepts reflect those with highest overall networks, or perceived "influence". Concepts identified by domain or centrality analysis can then be re-mapped as smaller maps to improve comprehension of concepts and their associations.

Map content can also be explored with cluster analysis to identify groupings of concepts that appear to stand-alone with respect to other groupings. Analysis software looks at each node and the immediate context of that node to determine the similarity rating (mathematically known 
as Jaccard co-efficient). A map with few clusters indicates less complexity as it cannot be simplified and broken apart.

Finally, content can be analyzed qualitatively by following paths either from a strategic goal to a final action item, or vice verse. Software can list the various "explanations" (concepts that explain or lead into the given concept), or "consequences" (concepts that arise as a result of a given concept). In a highly networked map, there may be hundreds of these for central concepts. Particularly informative paths are the causal loops where concepts connect circularly. Both virtuous and vicious loops - indicating growth, decline, or feedback control - may be studied as opportunities for action.

\subsection{Linking HF to Strategic Goals with Cognitive Mapping: Results of Cognitive Mapping Exercise and Focus Group in Collaboration}

Based on the methodological review in section 4.2, a practical approach for conducting the cognitive mapping exercise in an organization was pilot tested (not presented here, see Village et al, 2013). This chapter demonstrates the methods and results of using cognitive mapping with Senior Directors in our collaborating organization to link HF with strategic goals. The goals of the mapping were (a) to harness individual tacit knowledge from senior directors about human factors as it relates to strategic goals and (b) to make explicit their shared managerial thinking with an aim to identifying improvement opportunities using HF. This section will discuss how seven individual maps were merged into a group map aligned to the most important identified strategic goal of "improved quality," and how this led to identification of HF opportunities.

\subsubsection{Data Collection for Individual Maps}

A one-hour interview was conducted and digitally recorded with each of seven senior directors representing manufacturing engineering, advanced engineering, continuous improvement and Ergonomics. The open-ended question posed to each director was: "How can integrating human factors into your production system design processes help you achieve your strategic goals?" As directors responded to the question, a map with action-oriented concepts in the directors' own words was hand drawn and linked with directional (causal) arrows on an 
oversized sheet of paper. Strategic goals were placed at the top of the paper, sub-goals in the middle, and actions to achieve goals at the bottom (see Eden and Ackerman, 2004).

The digital recording was later reviewed to verify accuracy of wording of each concept and direction of each link. Concepts and links were entered into Decision Explore software (Banxia Software Ltd. 2002, U. of Strathclyde) and linkages were disentangled as much as possible to facilitate comprehension of the map.

\subsubsection{Data Analysis and Development of the Merged Group Map}

\section{Individual Map: Qualitative Analysis}

Concepts on the individual maps were coded by dominant themes (Strauss and Corbin, 1990) as they emerged in analysis (by assigning unique box structures to each concept). The number of concepts within each of the themes was counted, clustered, and compared between directors. The most common strategic goal mentioned by the directors was chosen as the key to merge the individual maps into a single group map.

\section{Development of the Merged Group Map}

Starting with the most complex individual map, a second individual map was merged on the common goal using the Decision Explore software. The software combines concepts and links from both maps on the common goal, but then each concept must be manually reviewed on the new map. If the merged map contains duplicate concepts, then these and all related links were manually combined. Concepts on an individual map that did not link to the common goal were considered "orphaned" and were eliminated from the final merged map. The removal of duplicated and orphaned concepts and links means the merged map contains fewer concepts than the sum of each person's individual map. This merging process and manual review was repeated until all of the seven individual maps were combined into a single merged map. The final merged map was then re-drawn to untangle concepts as much as possible. 
Quantitative Analysis: Individual and Merged Group Map

Data from both the individual and merged group maps were analyzed for descriptive statistics using the Banxia Software, including: the total number of concepts; number of heads (concepts at the top of the map with multiple concepts leading into them); number of tails (action items at bottom of map); and number of loops. Data from individual and merged maps were also analysed for "centrality" of each concept. Centrality analysis is performed by assigning a value of 1.0 to each direct link, and a diminishing weight (distance decay function) for each link removed from the central concept (such as $0.7,0.5,0.3$, etc). Concepts with the highest centrality scores reflect those with the highest overall density of network linkages. Smaller maps were then drawn based on concepts with highest centrality scores from the merged group map (c.f. Village et al. 2013).

\subsubsection{Focus Group Method to Review Merged Group Map and Determine Action} Approach

A focus group was held with the team of directors to review the combined map and identify HF action opportunities. Prior to the focus group, each director was provided with an electronic version of their own individual maps, and drawings of three of their smaller maps based on their most central concepts. At the two-hour focus group, directors were provided with a package of their individual maps, which were treated as confidential, as well as results of the merged group map (descriptive statistics and smaller maps). Findings from the merged group map were presented and discussed at the focus group. Directors were encouraged to discuss observations from the maps and themes presented. The focus group ended with a brainstorming of potential action items arising from the merged group map.

\section{Data Collection in the Focus Group}

The focus group was digitally recorded, transcribed, and entered into NVivo software (QSR International, 2010). Notes were also recorded during the meeting by the facilitator and three other Ryerson researchers. The notes and the transcription were reviewed using a general inductive approach for discussion points, decisions, and themes. Quotes from the focus group were collected to highlight the findings. 
Focus Group and Mapping Evaluation Survey

At the completion of the focus group, the directors completed a written evaluation and rated (on a 7 point Likert type scale) the usefulness of the maps (individual, group and smaller maps), as well as the focus group. Directors were also asked whether they would recommend others use the mapping tool, and how interested they were in performing the mapping exercise in the future to compare findings. Finally, participants completed open-ended questions about what they gained from the focus group and any further suggestions.

Data from the evaluations were entered into excel software and mean ratings and standard deviations were calculated. Themes emerging from the open-ended questions were summarized.

\subsubsection{Results}

In this section, the qualitative themes from each of seven individual maps are compared and contrasted. The quantitative descriptive statistics of the seven individuals, as well as the merged group map are then presented, with some basic interpretation of the findings related to map size and structure. Concepts with the highest centrality scores are listed, and smaller maps are presented for two of these central concepts. Finally, the results of the focus group and evaluations are presented.

\section{Qualitative Themes from Individual Maps}

In linking HF to strategic goals, seven common themes emerged from qualitative coding of the directors' concepts in the individual maps. Figure 6 shows the distribution of themes (by number of concepts per theme) for each director, and the average for the group. Definitions for each theme are provided below:

- Quality: Pertaining to detection or elimination of errors or defects.

- Process rigor: Pertaining to standards, processes and technologies to ensure adherence to performance goals. 
- Design of process: Pertaining to design of manufacturing, assembly, tooling and materials used in assembly.

- Product design: Pertaining to design of the product, feedback to product designers or satisfaction of designer needs.

- Cleanliness: Pertaining to procedures, processes and the experience of ensuring minimal contamination of the product during manufacturing and assembly.

- Psychosocial factors: Pertaining to the perceptions of workers concerning how the work is structured and carried out (such as stress, motivation, engagement and involvement).

- Client/partner service: Pertaining to the ability to satisfy customers or partners requirements (manufacturing or supply).

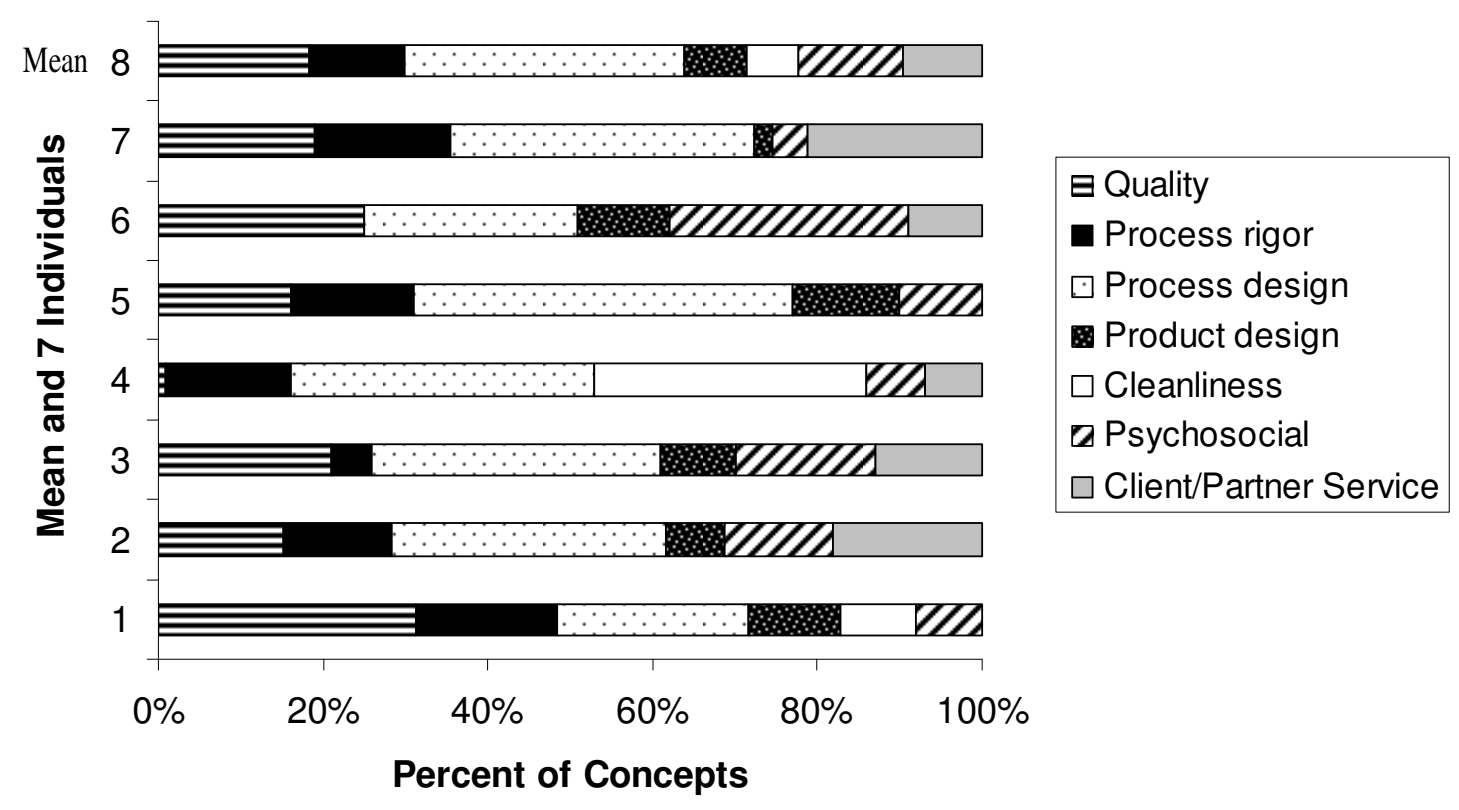

Figure 6. Distribution of percent of concepts associated with each theme for each of the seven directors (1-7) and the average (8) of all directors

The theme most discussed when asked to consider $\mathrm{HF}$ with respect to strategic goals was process design (33.3\% of concepts, range $23-46 \%$ ). This theme included improvements to design and layout of equipment, tools, and fixtures as an important way to achieve the strategic goals. Concepts relating to quality represented on average $18 \%$ of concepts (range 1-31\%), and a further $11.4 \%$ related to process rigor (range $0-17 \%$ ). HF concepts related to quality include, 
for example, "improve ability to detect failure/bad components", "ensure all equipment is right", and "group like actions together".

Considerable variability was found between directors. Psychosocial factors, for example, represented $29 \%$ of concepts for one Director (of the Ergonomics Group), but as little as 4\% for some other directors. Psychosocially-related factors included improving worker buy-in, recognition from leaders, increasing pride, and improving relations between workers and supervisors. The extent of discussion regarding cleanliness ( $6 \%$ of concepts on average), product design (7.6\%) and client/partner service (9.4\%) varied depending on the role of the particular director. Some directors stated they have little influence on product design, so they did not discuss it. Other directors suggested improved product design was highly central to improving production design, and therefore quality.

\section{Quantitative Analysis of Maps}

\section{Descriptive Statistics of Individual Maps}

Table 6 shows the descriptive statistics for each individual map, as well as for the merged group map. The total number of concepts derived in one hour ranged from 69 to 91 . The number of tails was consistently higher than the number of heads, suggesting a relatively flat (as opposed to steeply hierarchical) shape of each person's map. This in combination with a high ratio of tails to concepts illustrates a large range of possible intervention options, as understood by these directors, for achieving their company's goals. The number of loops varied dramatically, from 0 for one director, to 900 for another. Higher numbers of loops, depending on the individual and context, can illustrate greater understanding of a topic. Loops can also illustrate the possible existence of dynamic considerations within an issue (i.e. exponential growth or decline), and may be an indication of the complexity of the issue (Eden, 2004). They should be interpreted with care and consideration of the context. The number of main strategic goals identified by each senior director ranged from 1 to 4 , and sub-goals ranged from 2 to 7 .

The strategic goal "improve quality" was the most common and therefore the concept chosen for merging the seven maps. Other goals listed by at least three managers included: "increase 
productivity and throughput"; "improve product design"; and "improve position as a manufacturing center that focuses on new product realization".

Table 6. Summary of descriptive statistics for each individual map and the merged map

\begin{tabular}{|l|c|c|c|c|c|c|c|c|c|}
\hline $\begin{array}{l}\text { Descriptive } \\
\text { Statistic }\end{array}$ & \multicolumn{7}{|c|}{ Individual Maps } & $\begin{array}{l}\text { Merged } \\
\text { Map }\end{array}$ \\
\hline & $\mathbf{1}$ & $\mathbf{2}$ & $\mathbf{3}$ & $\mathbf{4}$ & $\mathbf{5}$ & $\mathbf{6}$ & $\mathbf{7}$ & Mean (SD) & \\
\hline $\begin{array}{l}\text { Number of } \\
\text { concepts }\end{array}$ & 69 & 65 & 86 & 84 & 75 & 74 & 91 & $77.7(9.5)$ & $\mathbf{2 2 1}$ \\
\hline $\begin{array}{l}\text { Number of } \\
\text { heads }\end{array}$ & 12 & 15 & 18 & 4 & 18 & 8 & 14 & $12.7(5.2)$ & $\mathbf{4 3}$ \\
\hline $\begin{array}{l}\text { Number of } \\
\text { tails }\end{array}$ & 14 & 23 & 29 & 45 & 28 & 26 & 36 & $28.7(9.8)$ & $\mathbf{7 7}$ \\
\hline $\begin{array}{l}\text { Heads: } \\
\text { Concepts }\end{array}$ & 0.17 & 0.23 & 0.21 & 0.05 & 0.24 & 0.11 & 0.15 & $0.2(0.1)$ & $\mathbf{0 . 1 9}$ \\
\hline $\begin{array}{l}\text { Tails: } \\
\text { Concepts }\end{array}$ & 0.20 & 0.35 & 0.34 & 0.54 & 0.37 & 0.35 & 0.4 & $0.4(0.1)$ & $\mathbf{0 . 3 5}$ \\
\hline $\begin{array}{l}\text { Number of } \\
\text { loops }\end{array}$ & 0 & 1 & 137 & 37 & 900 & 2 & 384 & $208.7(334.8)$ & 900 \\
\hline $\begin{array}{l}\text { Number of } \\
\text { goals }\end{array}$ & 1 & 3 & 2 & 2 & 2 & 1 & 4 & $2.1(1.1)$ & $\mathbf{3}$ \\
\hline $\begin{array}{l}\text { Number of } \\
\text { sub-goals }\end{array}$ & 3 & 2 & 3 & 4 & 6 & 7 & 3 & $4.0(1.8)$ & $\mathbf{8}$ \\
\hline
\end{tabular}

\section{Merged Group Map}

The merged group map based on the common concept "improve quality" resulted in a total of 221 concepts. It is shown in Figure 7, not for the purpose of reading the text boxes, but instead to illustrate the complexity and high interconnectedness of concepts. Strategic goals can be identified by large circles and sub-goals by square boxes. Since the merging establishes all links to a concept from each individual, a large number of loops and tails were maintained in the final map. The 77 tails represent different human factors-related actions that can lead, by various routes, to the strategic goal of improved quality (for example, improve design of equipment). The ratio of links to concepts in the merged map is 1.55 , well above typical ratios (1.15 to 1.2) even for persons with "expert" knowledge about a topic (Eden, 1992). 


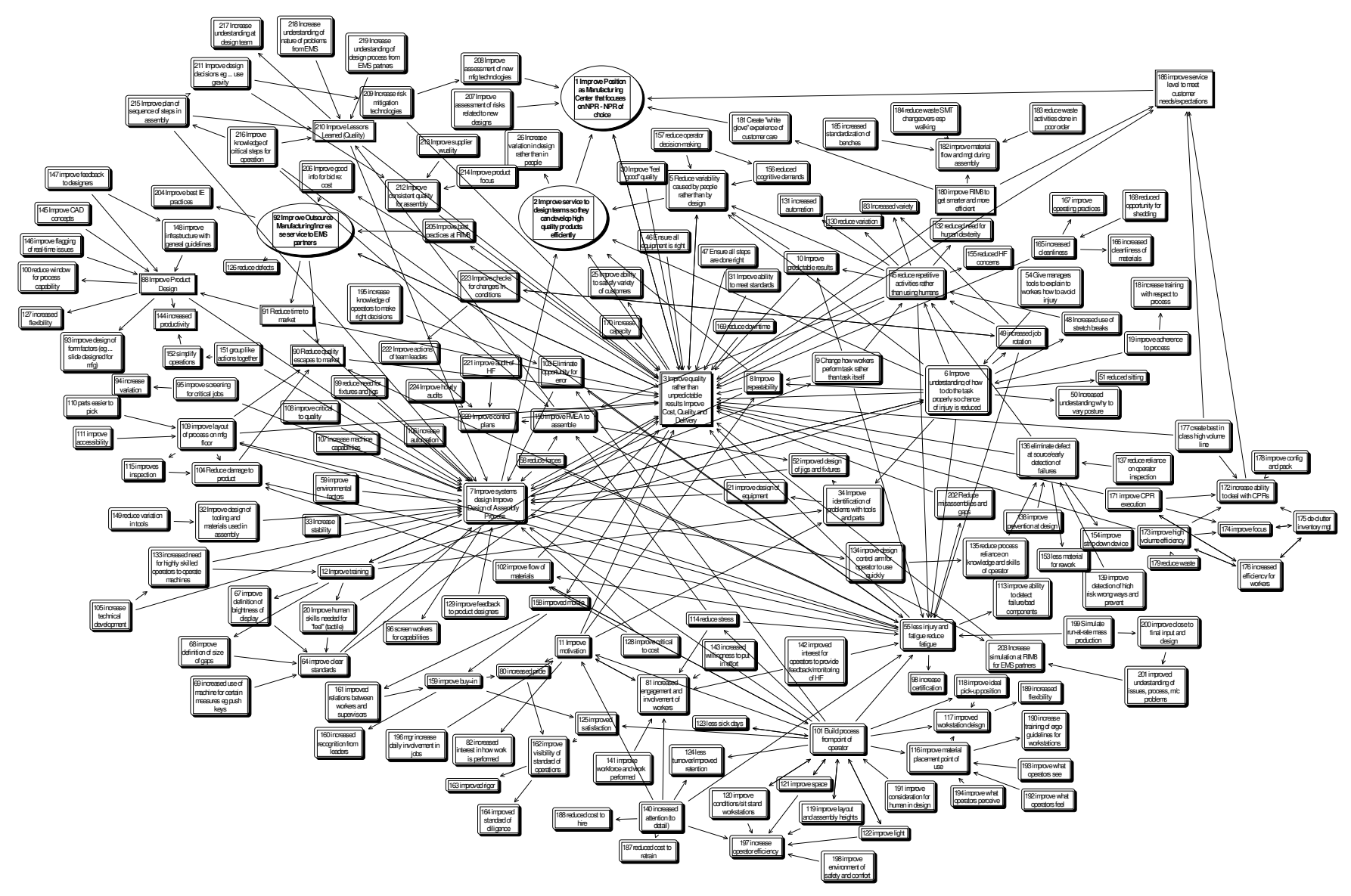

Figure 7. Merged map from goal "improve quality" based on seven individual maps (for illustration purposes, not for reading)

\section{Most Central Concepts}

The centrality scores and number of concepts linked to the most central fifteen concepts of the merged group map are shown in Table 2. Not surprisingly, the strategic goal of improved quality is the most central concept by nature of the merging of individual maps.

Of the 15 central concepts listed in Table 7, almost all of the concepts have HF aspects. For example: "reduce repetitive activities", "increase understanding of how to do the task", "build the process from the point of view of the operator", "improve design of equipment" and "improve flow of materials". The third most central concept was "reduce fatigue". When reviewing the top five central concepts of each individual, two directors had "reduce fatigue" as a central concept. However, when the concepts were merged, "reduce fatigue" emerged as a highly central 
concept strongly linked to improving quality. Similarly, "improve understanding of how to do the task" was a central concept for only one director in the individual maps. However, when links and concepts from the group were merged with this concept, it became a central concept for the group map due to related links. Two other concepts similarly emerged as high scoring central concepts: "reduce repetitive motions" and "improve motivation".

Table 7. Top 15 most central concepts from the map merged on quality (centrality score and number of concepts linked)

\begin{tabular}{|l|c|c|}
\hline Merged Map on Quality: Central Concepts & $\begin{array}{c}\text { Centrality } \\
\text { Score }\end{array}$ & $\begin{array}{c}\text { \# Concepts } \\
\text { Linked }\end{array}$ \\
\hline Increase quality & 110 & 198 \\
\hline Improve systems design & 100 & 191 \\
\hline Reduce fatigue & 91 & 186 \\
\hline Increase understanding of how to do the task & 87 & 186 \\
\hline Improve service to design teams & 83 & 188 \\
\hline Reduce repetitive activities & 78 & 166 \\
\hline Increase motivation & 77 & 178 \\
\hline Improve repeatability & 77 & 184 \\
\hline Improve layout of process on manufacturing floor & 75 & 175 \\
\hline Build process from point of view of operator & 74 & 160 \\
\hline Improve lessons learned (quality) & 71 & 169 \\
\hline Improve flow of materials & 70 & 168 \\
\hline Reduce time to market & 70 & 169 \\
\hline Improve clear standards & 70 & 169 \\
\hline Improve design of equipment & 68 & 170 \\
\hline
\end{tabular}

Re-drawing Smaller Maps of Most Central Concepts

Two of the smaller maps, re-drawn based on the most central concepts mentioned by the directors, are shown in Figure 8 for "reduce repetitive activities", and Figure 9 for "reduce fatigue". 


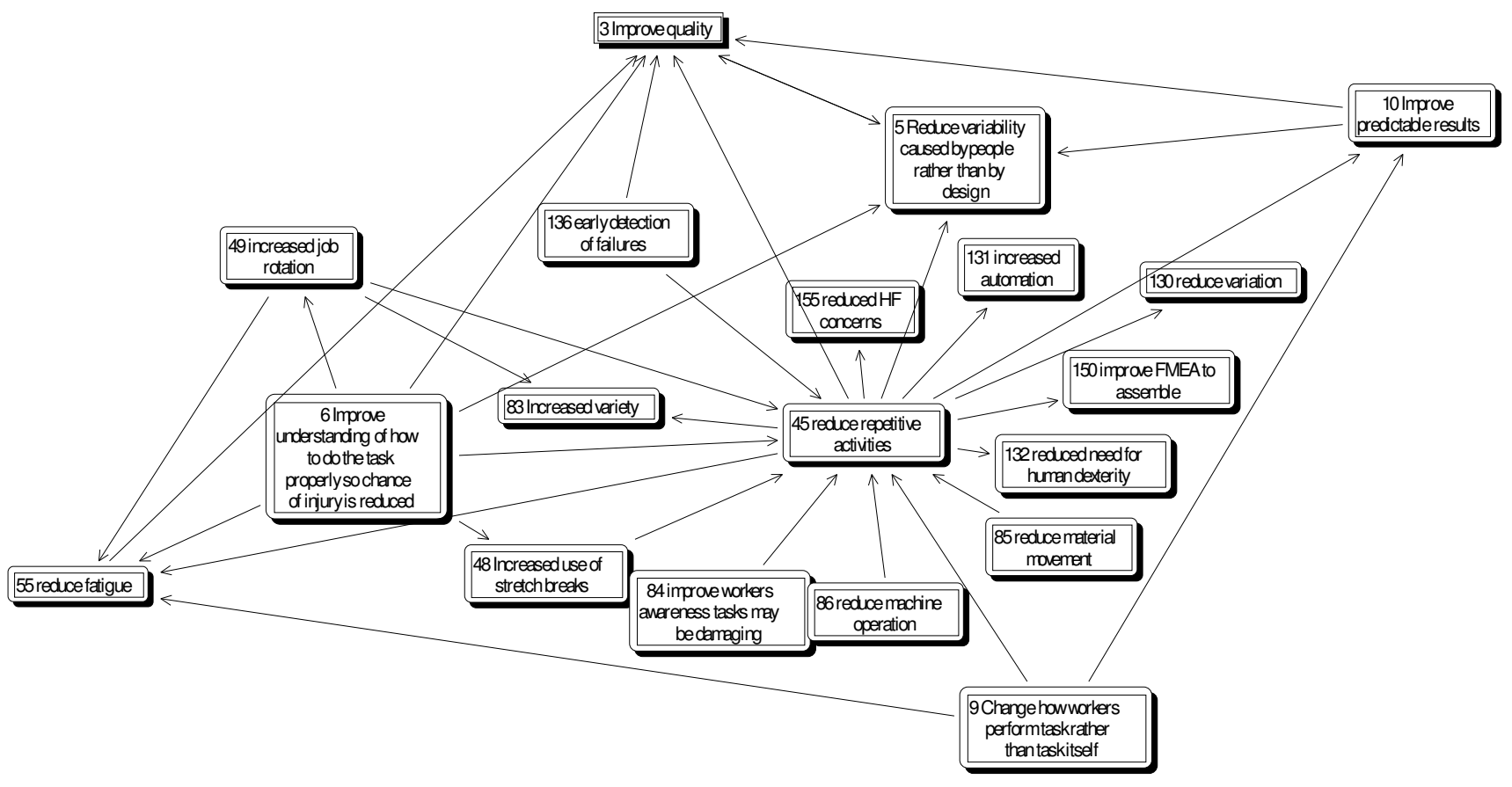

Figure 8. Concepts linked to central concept of "reduce repetitive activities" from map merged on "improve quality" from seven directors

"Reduce repetitive activities" (concept box number 45), found in the middle of the map in Figure 8 , has a direct link to the main goal of improved quality (\#3 at top) and a link to "reduce fatigue" (\#55), which also links directly to improved quality. There are another ten "consequences" (arrows leading out of box 45) of "reducing repetitive activities," such as "increased variety" (\#83), and "reduced HF concerns" (\#155). The small map illustrates the intricate links between quality and human factors that were identified by the directors during the interviews. The eight explanations for ways to reduce repetitive activities (arrows leading into box number 45) include, for example "reducing material movement" (\#85), and "change how the operators perform the task rather than the task itself" (\#9). These latter concepts, or tails, are potential action items that, in the perception of the group, lead to reduced repetition, and thereby to improved quality.

Figure 9 also contains the central concept of "reduce repetitive activities" (box \#45) on the right side showing how the small maps overlap. "Reducing fatigue" was also directly linked to improving quality, and had numerous other indirect connections to the main goal as well. The 
explanations for ways to reduce fatigue are numerous as seen in Figure 9. Noteworthy for human factors considerations include for example "improving layout of process on the manufacturing floor" (\#109), "improving knowledge of critical steps for operation" (\#216), and "improving interest for operators to provide feedback/monitoring of HF" (\#142). Therefore, while both central concepts discussed in Figure 8 and Figure 9 lead directly to improved quality, there are numerous other effects and routes they may take to arrive at the strategic goal.

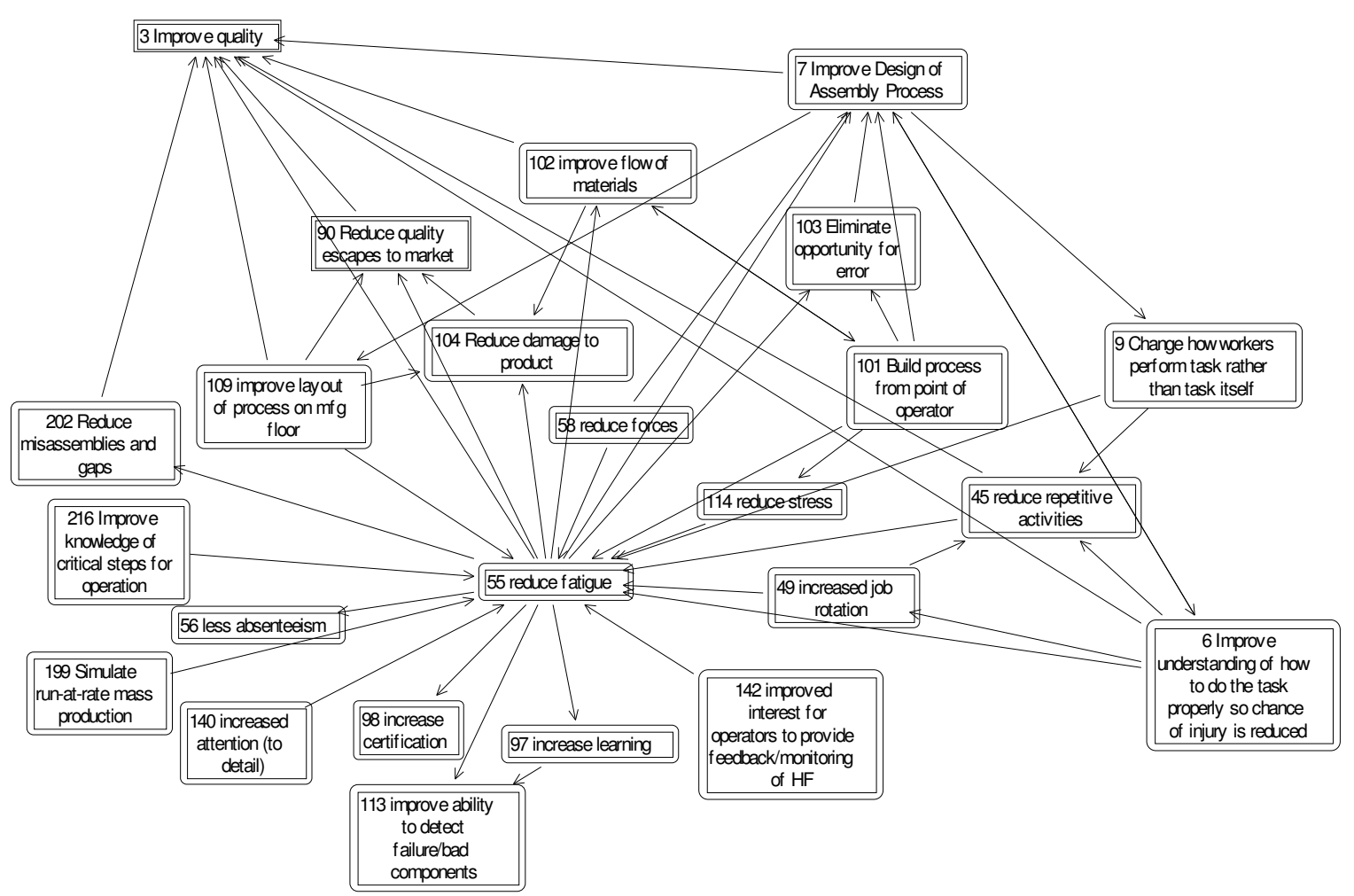

Figure 9. Concepts linked to "Reduce fatigue" from a map merged on "improve quality" from the seven managers

\section{Focus Group Results}

The maps presented at the focus group led to a discussion among the directors about two main findings and two main opportunities, described below. In addition, we will describe how the managers treated the maps as valuable indicators of HF performance. Finally, we will present results of the evaluations of both the maps and the focus group. 


\section{Two Main Findings by the Participants}

There was considerable discussion when Figure 6 was presented at the focus group showing the distribution of concepts from each theme. The directors noticed that process design was the theme with the majority of concepts for each individual. There was a consensus that their process design is the single largest influence of good quality. It was stated that this "finding" confirms the organizations' internal emphasis at the time of the focus group on improving process design. Quality, in fact, was discussed as being the by-product of good process design. One director commented that if we improve process design, then quality would follow automatically. Within this theme, there were expressions about how visual and apparent this finding was when looking at the maps. One director stated:

"it's interesting how the loops go around and it all makes sense"

And another:

"it's like an oh my gosh, if we had better design, it would impact all these things..."

The second main finding from the maps was the direct and indirect relationships between fatigue and quality that became apparent to the directors. One participant noted that fatigue and quality seem to go hand-in-hand, and that fatigue is not only the root cause of our quality problems, but one of the biggest factors. One director stated that "fatigue seems to sum it up" when referring to the number of links between quality and fatigue. The directors looked closely at the quality issues linked to fatigue. Each person could see their concepts, but the group map revealed new concepts from other directors. For example, one person expressed interest in how the map revealed that fatigue affects the ability to detect a quality issue. Some directors had not previously made these connections.

\section{Two Main Action Opportunities}

In viewing the maps, the directors realized there was a need in their organization to look holistically at broader systems design issues (for example floor flow, patterns of work, job rotation and enlargement, etc.). This realization led to suggestions for various initiatives looking at systems design aspects. The second outcome opportunity revealed by the maps pertains to psychosocial factors. The directors were interested in the opportunities arising by improving the workers' understanding of how to do the task properly. Linked to this were concepts such as 
involvement, ownership, empowerment, and taking leadership with respect to quality. One director mentioned that:

"it is interesting to see that if we improve workers' understanding of their tasks, this will lead to improved repeatability - which is important for quality."

As with the systems design gap, there were also suggestions made for initiatives that could improve psychosocial aspects of the work environment.

In total, the brainstorming session based on the two outcome opportunities led to a list of 12 potential initiatives (actions) derived directly from the merged group map and discussion during the focus group.

Observations about use of the maps in the focus group

Throughout the focus group, directors were observed to be checking their own individual maps and comparing information with the merged group map. There was a tendency among directors to assume the map was the "correct" view of the workplace - or an indication of organizational performance with respect to HF. One director indicated

"if we address some of the issues - maybe the map will change".

In other words, the map indicated problems and potential solutions and would change when problems are resolved. They therefore saw the map as being dynamic and changing over time and its value as an indicator of performance.

\section{Results of the Evaluation of the Maps and Focus Group}

Overall, the mapping tool, mapping exercises and focus group were felt to be very worthwhile, enjoyable, and were highly recommended for other organizations. The mean scores on a 0-7 scale (with 0 being "not at all" and 7 being "extremely") ranged from 5.2 to 6.2 (standard deviations ranged from 0.4 to 1.1). The highest rating was whether participants were interested in repeating the mapping exercise in the future (6.2). Mean scores of 6.0 were reported for the usefulness of the smaller maps for understanding the link between HF and strategic goals and the discussion arising from the maps. In the open-ended questions, directors commented that 
they were surprised and intrigued at how much information (shown on the maps) came out of a one-hour interview.

\subsection{Discussion: How can and why should HF be linked to strategic goals in an organization? Adapting the cognitive mapping technique to HF.}

\section{What Cognitive Mapping Revealed about HF and Strategic Goals}

The cognitive mapping technique revealed the main strategic goals of the organization and their links to HF. It also helped identify HF initiatives that would strengthen the business goals directly. Most HFS focus on reducing occupational health and safety concerns (Whysall, et al, 2004), but aligning HF with the strategic goals of the organization would likely result in more successful application of HF (Dul and Neumann, 2009). The directors in this case study exhibited a strong tacit knowledge of human factors. This is in contrast to the more common belief among HF specialists that engineers and management know little about HF because they rarely realize the direct implications of poor design of equipment on operators (Perrow, 1983). However, the framing of HF by directors in this organization focused on the importance of reducing fatigue as the human factors connection to their goal of improved quality. The mapping exercise illustrated the numerous links perceived between reduced fatigue and improved quality outcomes, such as reduced errors and earlier detection of quality problems. Fatigue was seen as both a physical risk that arises from force and repetition, which directly affects the assembly performance, and also a cognitive risk related to poor decision making and inability to detect defects and failures. It should be noted that the relationship between fatigue and quality was not formally evaluated in this collaboration. However, learning the managers' perceptions about the relationship helped the HFS understand how to "frame" HF to align with strategic goals in the organization. While there is evidence in the HF literature for the link between HF and quality (Drury, 2000; Herrera, 2011; Eklund, 1995; 2000; Falck et al., 2010), the link between fatigue and quality is reported less often and potentially an important area of further study for improving business performance.

The discussion among the senior directors in the focus group while viewing the merged group maps emphasized their need to focus on process design and the importance of good design of equipment, layout, flow of materials, and material placement to improving quality. This "hard 
systems" approach to HF in design is well documented in regards to reducing musculoskeletal disorders (Hendrick, 2008; de Looze et al, 2003), but less well documented with respect to reducing fatigue. The discussion also led to two opportunities within the organization for furthering their strategic goals. One opportunity involved broader systems design issues, such as job enlargement and patterns of work. The second opportunity involved improving psychosocial factors such as worker motivation, involvement, and knowledge of how to do the job properly. Optimizing such "soft systems" design such as work organization and psychosocial factors are also well-documented human factors strategies for increasing worker effectiveness (Bongers et al, 1993). The mapping therefore helped reveal their current knowledge and perceptions of socio-technical systems, but also untapped potential to further their strategic goals. It also provided the avenue to discuss their internal strengths and weaknesses, and make action plans with the potential to improve their business management practices using human factors.

\section{Implications for Managers}

The mapping exercise revealed not only the main strategic goals of the organization, but also how HF knowledge, expertise and action should be positioned to help achieve the strategic goals. This is of vital importance both to HF specialists and to managers, such that efforts are aligned with strategic goals, and HF will be seen to be contributing to the success of the organization (Dul and Neumann, 2009; Drury, 2000). In this particular organizational context, promotion of HF for the purposes of reducing musculoskeletal injuries would have been misdirected since there are very few work-related compensation claims. However, promoting HF with a goal to reducing fatigue and improving quality became immediately apparent through this exercise. If indeed fatigue is related to quality, then reducing fatigue to improve performance has the added benefit of simultaneously reducing musculoskeletal injuries - regardless of whether this is an immediate goal (Ahsberg, 1998).

Organizations may benefit from having HF personnel within the Operations Management or Engineering Departments rather than separated functionally into Occupational Health and Safety Departments $(\mathrm{OH} \& S)$, removed from the main production and operations. An understanding of strategic goals and the operations links to HF can help HF specialists navigate in the engineering domain (Dul and Neumann, 2009; Theberge and Neumann, 2010). We 
believed that making this connection explicit in this collaboration was the first step to increasing the application of $\mathrm{HF}$ in the design process and developing sustainable capability in $\mathrm{HF}$ to improve business performance (Neumann and Village, 2012).

\section{Benefits of using cognitive mapping}

Cognitive mapping has been used to reveal gaps in managerial knowledge or perceptions (Fiol and Huff, 1992). Similarly, when used to map knowledge of HF, the technique may reveal people who would benefit from additional training and education about HF. The process of combining individual maps into a merged group map can be a way to encourage "learning" about HF among senior directors in a way that "saves face" (Eden, 1988). The visual nature of the map simplifies complex ideas and facilitates transmission between people, while divorcing any individual from specific ideas, making it less likely a participant would feel bereft or defensive regarding their concepts (Fiol and Huff, 1992). Learning takes place in the interaction of the maps and one's mental models (Moreroft, 1992). As directors compare their individual maps with the merged map, they see their ideas and concepts alongside those of their peers. Mapping causes one to self-reflect on the knowledge they possess, which produces learning and change (Nicolini, 1999). HF specialists may find that learning about HF through mapping can be more effective than other instructional techniques.

The cognitive mapping exercise successfully converted the tacit knowledge of individual directors about human factors into shared explicit knowledge in the team. There is management recognition in the literature of the importance of pulling together collective, or "tribal" knowledge in organizations (Mohanty and Deshmukh, 1999; Savolainen 1999), and of making the understanding explicit (Tegarden and Sheetz, 2003). Such a shared understanding about HF could enable companies to learn and develop a continuous capacity to adapt and improve (Senge, 2006).) In operations research interventions, understanding the managements' perspective of the problem is vital to action and success of the interventions (Ackermann, et al., 1992; Siemieniuch and Sinclair, 2004). With mapping, options, dilemmas and feedback loops about HF could be examined, and conflicts explored to increase understanding (Ackermann et al., 1992). 
Another benefit of cognitive mapping compared to other techniques is the potential to identify emergent concepts. For example, in our case study, the concept "reduce fatigue" mentioned by a couple individuals was linked to other concepts that were common among the group, such as "reduce repetitive activities" and "increase job rotation". When the maps were merged, the concept of "reduce fatigue" became a central concept for the group map due to the nature of merging the links in a combined map. This led to discussions and opportunities about reducing fatigue that may not have been uncovered with interviews or brainstorming, or with other traditional HF techniques (Eden, 2004). The technique can open the enquiry and raise further questions, as occurred during the focus group reported here. Cognitive mapping has also been highly rated for being truthful and ethical compared with a variety of methods (such as surveys, comparison matrices, soft systems methods and systems mapping). This is because participants can see what has been recorded (Brown et al, 1992). Especially relevant to our case study of integrating $\mathrm{HF}$ into design processes, cognitive mapping, compared with other techniques, is especially useful for indicating paths for action, and leading to targeted steps (Eden, 1988; Eden, 2004; Robertson and Williams, 2006).

Finally, the map in our example was viewed as a potential yardstick for measuring change as actions are taken and new problems are revealed - akin to a performance indicator. In this way, changes in the content and structure of the map may usefully indicate increased understanding (learning) or increased action taken to incorporate HF. Such a performance indicator may help move HF beyond health and safety to serve a deeper role in contributing to the organizational strategies.

\section{Suggestions when using cognitive mapping}

The open-ended question used when mapping must be carefully crafted such that sufficient and useful information can be obtained. The structure of the map depends heavily on what is asked and how the question is asked. The question should be broad such that individuals can provide details that they believe are important (Tegarden and Sheetz, 2003). Concepts must be written in a way that is action oriented or the participant should be asked to rephrase concepts. The facilitator needs the skill to keep the concepts accurate, encourage the participant to make appropriate links between concepts, and to fill in gaps or connect concepts that appear loose during the mapping process. The facilitator must therefore listen, document, link, and facilitate 
concurrently. While the actual mapping process is time effective (one hour), the merging of individual maps into a group map is very time consuming (approximately 20 hours in this case). The technique, therefore, would not be appropriate with large samples of individuals (Brown, 1992). Software facilitates some of the merging and analyzing functions, but replaces neither careful treatment of the data, nor careful interpretation of the findings. The merging process can lead to interpretation errors or concepts that do not make sense when removed from an individual map and placed in another context. Referring back to audio recordings of the interviews, and checking information with the source can minimize these sources of error.

\section{Limitations and Areas for Further Research}

The results reported from this methodological demonstration of cognitive mapping are specific to the directors and organization involved in this case, and cannot necessarily be generalized to other organizations or groups who may have different strategic objectives. While the sample included only seven senior directors, and cannot be assumed to represent the perceptions of the entire management team, these directors were those most responsible for design of the manufacturing production system in this case. More case study applications of cognitive mapping in different organizations are needed to refine the approach and ascertain whether the tool can consistently reveal HF knowledge or gaps in knowledge among different management groups. Communication (scholarly and otherwise) of findings about the perceived managerial links between HF and strategic goals may broaden current thinking about the benefits of HF and expand learning and discussion beyond health and safety applications. Further research is needed to test whether the action items identified in the mapping exercise can translate into the anticipated benefits for strengthening business performance. Creating dynamic modeling approaches based on the relationships identified via cognitive maps are another means to further "test" and evaluate different action options for effectiveness.

\subsection{Conclusions}

Cognitive mapping has been shown to be a useful tool for revealing the strategic goals of the organization and their links to HF, and to indicate action opportunities to further strengthen this relationship. The tool allowed the tacit HF knowledge and experience of senior directors to be shared and made explicit. In this case study, directors revealed a rich understanding of HF, but 
not as a health and safety benefit. The directors clearly linked HF with the ability to reduce worker fatigue, which led directly and indirectly to improved assembly quality - their main strategic goal. They also identified two HF opportunities for reducing worker fatigue and improving quality- that of improved systems design, and improved psychosocial factors (such as worker motivation and involvement). Cognitive mapping has shown that HF has strong links to strategic goals in organizations, beyond health and safety benefits. Acting on these links can help companies improve human performance, and therefore business success. 


\section{Chapter 5}

\section{How Can and Why Should Industrial Engineering (IE) Tools be Adapted to Include Human Factors? Demonstration of IE Tools Adapted for HF}

\subsection{Introduction and Purpose of Chapter}

The goal of this chapter is to show how five industrial engineering based tools were adapted to include HF and integrated into various stages of the design process within the collaborating organization. The tools were mentioned in Chapter 3 as some of the various initiatives in the collaboration. As discussed in Chapter 3, during the second and third phase of the collaboration, we looked for ways to integrate HF into existing tools and processes. Some of the tools were direct adaptations of tools in current use in the organization. Others were developed in conjunction with the engineers, or to fill a need for a proactive design tool. This chapter provides the unique development process for each tool, the details of the contents of each tool, and a summary of key features of HF tools based on findings in the collaboration.

\subsection{The Organization's Design for Manufacturing and Assembly Process}

The design for manufacturing and assembly process of the collaborating organization is shown generically in Figure 10. Product design is in dotted lines as it is provided from other company locations and seen as an input to the design process. Manufacturing and product focused engineers receive product drawings, they then plan for how best to manufacture the product parts and determine quality metrics (new product realization stage). They then design and manufacture parts, materials and components and determine the order of assembly. At the next stage is the design of tooling and fixtures, then prototype build. During the process optimization stage, more adjustments are made to improve the assembly for mass production. In product launch, the assembly system is sent to another facility for mass production. Several new products are realized annually and the cycle takes approximately one year. 


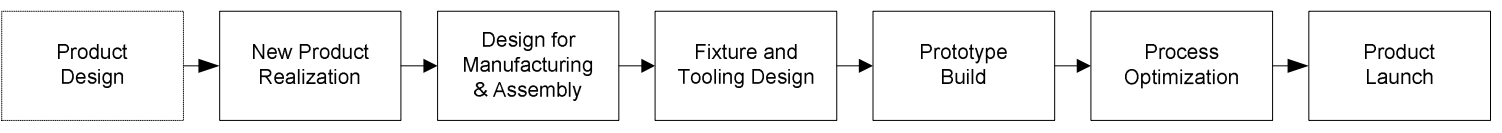

Figure 10. Generic Assembly Design Process in Collaborating Organization

The next section provides an overview of the five prototype tools adapted to include HF and briefly describes for each its purpose, what input information is used, output information, how the tool was adapted within the case study organization, and the tool application. Worksheets for two prototype tools (HF-FMEA, and HF-DFA) are provided in Appendix C and D.

\subsection{Overview of Tools Adapted to Include HF in the Design Process}

Figure 11 shows the various tools adapted for HF integration in the assembly design process: HF process failure mode effects analysis (HF-pFMEA), HF design for assembly (HF-DFA), HF design for fixtures (HF-DFF), workstation efficiency evaluator (WEE) and HF kaizens. At product launch, HF lessons learned regarding each of the adapted tools are documented with other manufacturing lessons learned in a standardized engineering reporting structure for feedback during the next product launch. While not shown in Figure 11, the HF lessons learned implies that the tools themselves are also continually improved and refined in practice.

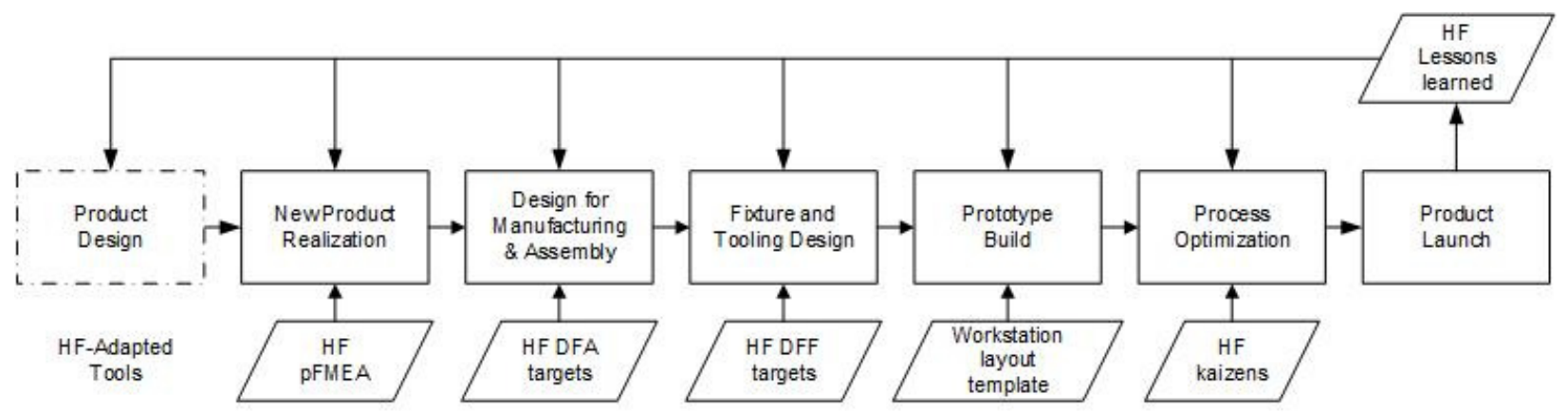

Figure 11. Tools adapted for HF and the stage in the design process where they are used.

\subsection{Descriptions of IE Tools Adapted for HF}

Table 8 summarizes for each tool the purpose, inputs, outputs, and tool application in the case study. A description of each will follow. 
Table 8. Description of HF Purpose, Inputs, Outputs and Tool Application in Case Study

\begin{tabular}{|c|c|c|c|c|}
\hline Tool & HF Purpose & Inputs & Outputs & Tool application \\
\hline HF-pFMEA & $\begin{array}{l}\text {-to detect risks that } \\
\text { predispose worker failure } \\
\text { (i.e. injury, fatigue, or } \\
\text { assembly difficulty) prior } \\
\text { to manufacture of parts }\end{array}$ & $\begin{array}{l}\text {-3-D product } \\
\text { drawings initially } \\
\text {-possibly prototype } \\
\text { parts } \\
\text {-video at first build }\end{array}$ & $\begin{array}{l}\text {-risk priority number (RPN) } \\
\text { per task as product of } \\
\text { severity, occurrence and } \\
\text { detection of risk }\end{array}$ & $\begin{array}{l}\text {-HF specialist scores HF-pFMEA } \\
\text { at meetings with engineers } \\
\text {-tasks with high RPNs are } \\
\text { improved by engineers and HF } \\
\text { specialists prior to manufacture }\end{array}$ \\
\hline HF-DFA & $\begin{array}{l}\text {-to ensure tasks meet HF } \\
\text { and assemblability } \\
\text { targets at first build } \\
\text {-to prioritize and monitor } \\
\text { tasks for improvement }\end{array}$ & $\begin{array}{l}\text {-observation or } \\
\text { videotape of first } \\
\text { build using prototype } \\
\text { parts }\end{array}$ & $\begin{array}{l}\text {-HF-DFA score }(0-2) \text { for } 22 \\
\text { items and overall score } \\
\text { (maximum 44) }\end{array}$ & $\begin{array}{l}\text {-HF specialist scores each task } \\
\text {-any "2" requires improvement } \\
\text {-tasks with highest overall scores } \\
\text { require engineering improvement } \\
\text {-final sign-off by HF specialist }\end{array}$ \\
\hline HF-DFF & $\begin{array}{l}\text {-to provide HF fixture } \\
\text { design targets prior to } \\
\text { design and manufacture } \\
\text { to improve human } \\
\text { performance }\end{array}$ & $\begin{array}{l}\text {-fixture and tooling } \\
\text { requirements } \\
\text {-fixture design review } \\
\text {-prototype build } \\
\text {-qualification }\end{array}$ & $\begin{array}{l}\text {-DFF score (0-2) for } 12 \\
\text { items and overall score } \\
\text { (maximum 24) }\end{array}$ & $\begin{array}{l}\text {-HF specialist scores fixtures at } \\
\text { each input stage } \\
\text {-any "2" requires redesign } \\
\text {-final sign-off by HF specialist }\end{array}$ \\
\hline WEE & $\begin{array}{l}\text {-to provide timing and } \\
\text { line balance of tasks, as } \\
\text { well as optimal layout of } \\
\text { workstation parts and } \\
\text { equipment prior to build }\end{array}$ & $\begin{array}{l}\text {-task descriptions } \\
-C A D \text { drawing of } \\
\text { layout } \\
-x, y, z \text { coordinates of } \\
\text { hand locations from } \\
\text { drawing }\end{array}$ & $\begin{array}{l}\text {-time per task and cycle } \\
\text {-reach zones exceeded } \\
\text {-shoulder load (acute and } \\
\text { cumulative) and recovery }\end{array}$ & $\begin{array}{l}\text {-MTM timing input to engineers } \\
\text { for task and process optimization } \\
\text {-HF specialist evaluates layout at } \\
\text { drawing stage to optimize }\end{array}$ \\
\hline HF Kaizens & $\begin{array}{l}\text {-to engage operators at } \\
\text { first build to optimize HF }\end{array}$ & $\begin{array}{l}\text {-operators concerns } \\
\text { (verbal and written), } \\
\text { and quality data } \\
\text { during first build }\end{array}$ & $\begin{array}{l}\text {-recorded suggestions for } \\
\text { improvement discussed } \\
\text { with supervisors, engineers } \\
\text { and } \mathrm{OH} \& \mathrm{~S}\end{array}$ & $\begin{array}{l}\text {-HF considered alongside other } \\
\text { quality and engineering concerns }\end{array}$ \\
\hline Lessons Learned & $\begin{array}{l}\text {-to document HF lessons } \\
\text { learned for subsequent } \\
\text { products }\end{array}$ & $\begin{array}{l}\text {-scores, observations } \\
\text { concerns and } \\
\text { variances noted }\end{array}$ & $\begin{array}{l}\text {-documentation in standard } \\
\text { engineering reporting } \\
\text { structure }\end{array}$ & $\begin{array}{l}\text {-HF lessons learned are fed back } \\
\text { to each appropriate design stage } \\
\text { for subsequent builds }\end{array}$ \\
\hline
\end{tabular}

${ }^{1} \mathrm{~A}$ fixture is a device used to secure a work piece, generally while a machine or tool performs an assembly task. 


\section{HF Failure mode effects analysis (HF-pFMEA)}

\section{Tool Purpose and Tool Adaptation for HF:}

Process failure mode effects analyses (pFMEAs) are routinely carried out by engineering and quality teams to minimize quality problems prior to design of assembly processes by anticipating a potential failure, rating it, and designing improved detection or controls. The purpose of the HF-pFMEA is to detect risks that predispose worker failure (i.e. injury, fatigue, or assembly difficulty) prior to manufacture of parts. Generally, a pFMEA is initiated with only product drawings as inputs, but it can also be used as a continuous improvement tool and scores are revised as parts and tooling are prototyped.

The FMEA risk priority number (RPN) is a product of three ratings; the severity, occurrence and detection of the failure on a 1-10 scale. We have included a working prototype of our scoresheet for the HF-pFMEA in Appendix $C$ for illustration purposes. It may need adaptation for use with assembly tasks with different or additional risk factors. For the HF-pFMEA, severity was defined as the risk of injury or assembly difficulty for the operator. The severity score was based on the cube model (Kadefors, 1994), that includes ratings of force, postural strain and repetition (low, medium and high), which are multiplied together. This was chosen since it is specific to hand-intensive tasks (Laring et al, 2002). Given that electronics assembly tasks are generally low force, but can contain considerable static work and other risk factors (eg. contact stress, hand-arm vibration and high visual demands), we adjusted the score (by adding 1) if significant other risks factors (RF) were deemed to be present. Since the scoring is applied prior to design of an assembly line, actual repetition rates may not be known. Therefore, practical use of the score involves some approximation or anticipation based on previous experience with other assembly lines. Scores for occurrence are based on the likelihood of injury (based on previous data, or estimations), and scores for detection refer to the ability of control measures, if needed or present, to minimize the risk. More information and examples of application of the HF-FMEA can be found in Village et al, 2011, and the following website: http://digitalcommons. ryerson.ca/ie/24/. 


\section{Development of the HF-pFMEA tool:}

HF specialists attended pFMEA meetings to become familiar with the failure modes and means of scoring. They also noted the types of human factors issues arising in the discussions. Various scoring options were discussed and trialed among HFS both on current assembly lines, and with videotape of assembly tasks. HFS also compared scores for consistency to further improve and refine the descriptors. Although HFS noted other HF issues in the FMEA meetings, such as potential for operator error, or challenges with detection of a quality problem, it was difficult to develop a scoring mechanism to include all HF issues. The prototype tool in Appendix $\mathrm{C}$ is designed for physical risk only - but could be further developed to include other considerations.

The HF-pFMEA was incorporated into a template with similar scoring and cut-offs to quality FMEAs, and this was embedded in newly developed software which helped facilitate ongoing buy-in and use by engineers. HFS subsequently attended pFMEA meetings for new products, performed HF-pFMEA scoring for manual assembly tasks, and, collaboratively with the engineering team, identified solutions where RPN scores were high. High RPNs are traced in the FMEA software system and must be resolved with alterations to parts, materials or fixtures before moving to the prototype stage.

\section{HF-Design for Assembly (HF-DFA) Targets}

\section{Tool Purpose and Tool Adaptation for HF:}

The design for assembly (DFA) process developed by Boothroyd et al. (2001) evaluates, for each task, the ease of manual assembly (using standardized times) with the aim to improve assembly quality and time to market, and reduce assembly costs. The purpose of the HF-DFA (shown in Appendix D) is to identify possible HF issues affecting ease of assembly at the earliest stage of design, and to prioritize tasks for improvement using targets.

We adapted the DFA concept to include 22 items known from the scientific literature and experience of engineers and HFS to contribute to concerns related to HF, ease of assembly, quality, and speed of assembly in hand-intensive assembly tasks. Each item is scored subjectively using a 0-2 scoring system where "0" represents an easy assembly, "1" moderate 
ease, and "2" a difficult assembly, for a maximum score of 44. Descriptors provided for each item help with assignment of the score. The prototype HF-DFA tool is shown in Appendix D.

\section{Development of the HF-DFA tool:}

Ergonomists and product focused engineers worked together through the full design cycle of a new product to identify and improve tasks with respect to ease of assembly. Using traditional IE tools (for example, MTM, value-added categorization, waste analysis, root cause analysis) and HF tools (eg. RULA and strain index), tasks were identified as candidates for improvement if they affected the worker (eg. forceful), performance time (eg. cycle time), as well as quality metrics (eg. defect cost). Lack of a precise tool to quantify assembleability led to the adaptation of the DFA. Scores for the 22-items were collected from a current assembly process, and presented to engineers and Senior Directors. Tasks with higher HF-DFA scores corresponded to tasks recognized both by workers and engineers as tasks that needed improvement in that product. Two participatory focus groups were then conducted with twelve engineers to further refine and improve the HF-DFA items, their wording and interpretation. Engineers scored videotaped tasks and scores were compared for consistency and interpretation problems.

The HF-DFA tool is a unique, customized tool that combines HF considerations with quality and production concerns for light assembly in this company. The tool has been used within the company by numerous engineers and HFS to communicate tasks needing improvement and to re-score tasks after improvements. The tool promotes discussion about the combined effects of $\mathrm{HF}$, quality and productivity between engineers and HF specialists. The HF-DFA has since become a "controlled document" owned by engineering and the score is one of four targets (along with quality defects, fixture cost, and scrap) that engineers are responsible for achieving prior to launch of a new product. Any item scoring a "2" must be redesigned to reduce the score. Tasks with high total scores must be continuously improved to the extent possible during the various prototype stages. The tool is endorsed by and "owned" within a controlled engineering process document. This ensures that HF issues are one of the key priorities during design of the assembly. 


\section{Human Factors Design for Fixture (HF-DFF) targets}

\section{Tool Purpose and Tool Adaptation for HF:}

Fixtures, which are used to secure a work piece while a machine or tool performs an assembly task, can be the size of a deck of cards, or as large as a computer monitor. Since fixtures operate at the interface of workers and assembly tasks, their design can influence the forces, postures, and ease of assembly, which in turn influence production speed and quality. Fixtures may be designed and built in-house, or by an outside vendor. The purpose of the HF-DFF tool is to provide targets that ensure the design minimizes HF concerns, prior to design. The HF-DFF has 12 items and, similar to the HF-DFA, a scoring system from "0" (low HF risk), to "2" (high HF risk). More information about the HF-DFF can be found in Village et al, 2012, and the following website http://digitalcommons.ryerson.ca/ie/27/.

\section{Development of the HF-DFF Targets:}

HFS performed assessments of fixture design on an operational assembly line, and consulted with workers to identify 28 design concerns. They also discussed with engineers the quality and production implications of the design concerns. A two hour participatory focus group was held with nine design engineers to "translate" the HF concerns into design guidelines with appropriate wording for designers. In other words, instead of an item worded in HF terminology (i.e. "minimize awkward wrist bending"), the item was worded in engineering terminology (i.e. "remove obstructions for clear access for device insertion").

The HF-DFF, like the HF-DFA, was also incorporated into a controlled engineering document with HF targets established within the written DFF process. Training in the HF-DFF guidelines was provided by the HFS to internal and external engineers who design and bid on fixture development. The HFS attends early meetings with vendors to discuss design requirements and reinforce the HF-DFF items. The HFS scores early and subsequent fixture designs and prototypes. The engineering group set targets for the HF-DFF such that none of the 12 items can score a "2" on any item, unless a written variance is obtained. The HFS also has sign-off at several stages of the fixture design, prototype and final construction phases. Since fixtures 
move with the product to production facilities worldwide, careful design of fixtures ensures not only product quality but improved HF for thousands of workers.

\section{Workstation Efficiency Evaluator (WEE)}

\section{Purpose and Tool Description:}

The WEE tool provides a proactive assessment at CAD design stage that integrates timing and line balancing of tasks (based on MTM) as well as optimal layout of workstation parts and equipment to minimize HF concerns (specifically, reach and shoulder load). Its development, testing and refinement are described elsewhere (Greig et al, 2011). Inputs to the WEE tool are element descriptions, the CAD workstation drawing, and hand locations in the $\mathrm{x}, \mathrm{y}$ and z-axis for each element (eg. reach for part). Its outputs include a time metric (time per element and cycle), and HF metrics in the form of reach zones and shoulder load and recovery time needed. It can also calculate and compare accumulated time and shoulder load between workstations, or before and after workstation optimization.

\section{Development of the WEE:}

More detail of the WEE development is provided in Greig et al (2013). Its initial version was developed to track hand motion. Later versions included models for shoulder load and recovery time. The engineering group became especially interested in the tool with the addition of MTM timing information to predict task and cycle times, to assist with line balancing and production cost estimation before distributing tasks to assembly workstations. HFS and engineers working together realized that minimizing excessive reaches, due to parts layout, fixtures, and assembly steps, poses not only a risk of injury to workers, but increases task time (seen as motion waste). The tool has been used in several product cycles to predict cycle time for engineers, and also (by the HFS) to indicate shoulder loads, and reach zones. Targets for reach zones and for continuous improvement of workstation layout have recently been added to increase usability of the tool. 


\section{HF Kaizens}

\section{Tool Purpose and Tool Adaptation for HF:}

Kaizen is generally translated from the Japanese to imply incremental continuous improvement (Stone, 2010; Manos, 2007). It is a team activity (not a "tool" per se) whose purpose is to turn "lean thinking" into actions to eliminate waste (or non-value added activities) within the work process, job design or equipment. In the early build stage, operators assemble small batches of devices for further testing and refinement. The purpose of the HF Kaizen at this stage is to engage operators to improve and optimize HF issues prior to product launch.

In the case study organization, the Kaizen is conducted in two stages. When operators first assemble small batches of devices, they note concerns with workstation layout, fixtures, or parts by writing these down on sticky-notes and attaching them above their workstations. The floor supervisor assembles these concerns onto flip-charts in the immediate assembly area.

Concerns often have both a human factors component (such as difficulty seeing a small part insertion) and a quality component (such as defects if the part is missed or inserted improperly). Concerns are documented and a kaizen meeting is then conducted where workers discuss their concerns with engineers, HFS, and managers and possible solutions are identified - much like participatory ergonomics. In the example provided, the kaizen, led by the HFS resulted in implementation of a magnifying glass over the assembly process that was difficult to see. Solutions are documented and implemented by floor supervisors and engineers, and once again evaluated by workers in ongoing continuous improvement efforts. In this way, HF issues raised by workers can be tracked and addressed alongside quality and production issues.

\section{Development of HF Kaizens:}

During the case study, the organization had been increasing its emphasis on Toyota production systems methodologies and continuous improvement. Increasing numbers of managers and workers were attending training courses and initiating events such as Kaizens to optimize quality and performance on the assembly line. When an injury occurred on the assembly line and the HFS was called to investigate and assess, the floor supervisor recommended initiating 
a Kaizen event to involve workers in recommended improvements. Results of the initial HF Kaizen were distributed to other engineers and floor managers, increasing their awareness of the overlap between optimizing HF, quality, and production. Seeing the benefit of incorporating HF into their kaizen events, the HFS is now a regular participant with engineers and floor supervisors.

\subsection{Features of HF Tools Found to be Effective for Proactive Design}

Based on data collected from interactions with engineers over the course of tool development during the three years, we have compiled a list of twelve recommended features of an effective HF tool for use in proactive productions systems design (see panel). Each feature was substantiated with qualitative data from the case study. Further, a verification meeting was held with the senior director of engineering and several manufacturing engineers following analysis of the data to review these features. Our case study has demonstrated that if tools contain these features, they are more likely to be locked into the design process by senior management.

\section{Features of Effective HF Tools}

1. Can indicate HF issues at early design stages (vs after problems arise)

2. Fits with engineering processes, language and tools.

3. Directly addresses operational/business goals and influences key metrics.

4. Can be quantified (eg. score, rating, key performance indicator, threshold, target) and can demonstrate change (facilitate action).

5. Leads to best practices and benchmarking.

6. Provides lessons learned.

7. Fits expectations with respect to level of detail, engineering workload, and timing to meet key milestones.

8. Has good tool utility (visual, quick, easy, nimble).

9. Sensitizes engineers to problems - allows them to see differently.

10. Has been developed and validated with in-house expert input and participation.

11. Has ongoing permanence (vs one-off type of assessment) and is not person-dependent.

12. Is well scoped and documented (not observation or verbal). 
The first tool feature indicates that the tool should help indicate HF concerns early in design stages, rather than after problems arise. It therefore needs to have some predictive capabilities. The second feature describes the "fit" between the HF tool and engineering design processes, language and tools. To achieve this "fit", HFS needed to understand the overall design process, as well as processes within each stage of the design process (such as how fixtures and tooling requirements, prototypes, and final designs are determined). They needed to understand intimately the issues faced by the engineers who are building the assembly system and how such issues are resolved. They also needed the terminology and language of in-house design steps and technical aspects of materials, parts and processes in order to participate with engineers.

Introducing $\mathrm{HF}$ into IE tools was easier for engineers in this case study than expecting them to learn HF tools. This required the HFS to learn industrial engineering tools, such as root cause analysis, failure mode effects analysis, five why's, etc. When HFS learned and used typical engineering tools alongside engineers in this case study, HF concerns naturally arose but could be discussed using language and approaches already familiar to engineers. The experienced assembly engineers in the organization had knowledge of operator capabilities and limitations, but their terminology (i.e. precision versus risk factor) and end goal (i.e. ease of assembly versus minimizing injury) were different. Although it was challenging for the HFS to focus on assembly quality, rather than risk of injury, HF concerns apply to both and could nonetheless be identified, discussed and resolved by this route.

The third feature, also critical, was that the tool directly addresses operational/business goals and influences key metrics. The HFS needed to understand the metrics that drive engineers' performance and determine how HF could become a means to support or realize these engineering metrics. HFS learned to frame HF recommendations as ways to reduce defects, or to improve detection of problems, or to ensure operator consistency of performance. The quote below from a senior director of engineering demonstrates this drive for metrics:

"we need to target manufacturing managers to see how our (HF) measures can make their job better - how can it be red/green for them - find a correlation based on their reporting and have them want to measure it - tie it to quality especially". 
The fourth and fifth feature are consistent with tools that are engineering-like in that they provide quantifiable targets that can be measured, and as such can be used for benchmarking and best practices. Quantifiable targets allow for quick indications of problem areas, and a measure of continuous improvement as the assembly design is optimized. Capturing lessons from each assembly design process is an important way to improve subsequent design processes and as such, HF lessons should also be captured by the tool. The seventh feature of fitting expectations of engineers suggests that the tool should be appropriate to the specific needs of the particular design group with respect to level of detail of the assessment, timeliness of the information, and time required of engineers given their workload and other requirements. The engineers in this case reported that tools with a good utility would be quick and easy to use, nimble, and visible. They did not want the tool to overload the engineers in terms of time and unnecessary detail. An interesting feature is that the tool should sensitize engineers to see the assembly design from a different perspective - that of worker difficulties.

The tenth feature addresses development of the tool and suggests that it is important to be participatory, involving engineers and designers in-house in development, pilot-testing, refining and implementation. The last two features suggest the tool should stand alone, and not be dependent on a single individual. It therefore should be comprehensive, well documented and therefore can be built permanently into the process

In this case study, we found that an appropriate tool to communicate HF concerns was necessary, but not sufficient to be locked into the design processes. The tools needed to have targets that were measurable as metrics. It was also essential that engineers be held accountable from senior managers for meeting these metrics.

\subsection{Discussion: How can and why should industrial engineering tools be adapted to include human factors? Demonstration of IE tools adapted for HF}

This chapter has demonstrated the adaptation of five industrial engineering tools to include HF considerations, and described the process of integrating the tools into each stage of a company's production systems design processes. The action research methodology, as others have reported, facilitated implementation and experimentation with HF tools in vivo (Wilson, 2012; Carayon, 2010; Zink et al., 2008). The resulting tools were integrated into the assembly design process in this organization, largely because HF was incorporated into familiar IE tools 
and because they used metrics related to the business goals of the company. Tools that address HF in a proactive way (i.e. before injuries occur) have the potential to improve human aspects of the assembly design for thousands of workers in the case study organization, working in multiple countries. The benefits of adapting IE tools are that engineers are already using them, they are business and performance oriented, and they get the attention of senior management. Adapting internal engineering tools achieves better integration with the design methodology of the organization and the specific production system (Neumann et al, 2009).

A few other researchers have also reported success integrating HF into engineering design tools in health care (Carayon et al, 2007; 2010) and manufacturing (Falck and Rosenqvist, 2012; Zink, 2008; Gawron et al, 2006). In Sen and Yeow's (2003) work in electronics manufacturing, they also developed unique company-specific tools in a participatory way with expert teams. They reported that their approach, compared to other HF methods, reduced effort and resources, was easier and more flexible to apply and was more accurate with lower cost and less need for expert involvement (Sen and Yeow, 2003). Participatory adaptation of IE tools, aligned with business metrics and goals may be one way HF can demonstrate its value to the main stakeholders of systems design.

The results in each section of 5.3 highlighting the process of developing the tools reveals that successful implementation is more than simply adapting or adopting a tool. Each of the tools in our case study followed a different development course and some more readily became enforceable targets than others. We included this information to encourage others to use a participatory approach to development and adaptation of tools. To our knowledge, sharing results of such a process is uncommon in the HF literature and much can be gained by this qualitative analysis of "how" tools were adapted and integrated. Perhaps lack of attention to process is one reason so many efforts to introduce HF knowledge in early production stages has not brought about change (Jensen, 2002). We also encourage others in research to report more about the "how" processes

The tools reported here were all developed within a single case study in the electronics sector, which may limit their applicability to other organizations and sectors. We therefore suggest they be considered working prototypes. Organizations interested may need to adapt and customize the tools to their specific context and evaluate the tools with their internal engineers. The concept and process of adapting IE tools, and the twelve recommended features of an effective 
$\mathrm{HF}$ tool for productions systems design (shown in the panel in 5.4) may be useful to other practitioners developing or adapting tools. We found that it was critical for engineers we worked with that the tool be quantifiable, provide a target or threshold, and could drive improvement. The managers and engineers in this case study were unafraid to pick a number, use the tool, drive the change, and re-evaluate the target. Others have also recommended analysis tools with an intensive focus on hard factors and figures (Falck and Rosenqvist 2010) that are specific and quantifiable (Wulff et al, 1999). In the discussion of HF tools by Wulff et al (1999), the authors suggested that engineers like tools to show and communicate to others what constitutes "good design". Numbers make it easier to establish whether a requirement is being fulfilled.

It was also essential that the tool "fit" with their design process, time frame, level of detail needed and engineering workload. We included in the features that tool utility should include being visual, quick, easy and nimble to use. One final important feature is that the tool should sensitize engineers to problems and help them see an assembly task from a different perspective. In our case study an HF specialist was available to the engineers to use and interpret the adapted tools. The tool acted as a trigger to initiate a conversation about HF implications in the design process, providing an opportunity for HFS and engineer to participate in solution development together. We cannot assume, however, that these adapted tools would initiate HF discussions in organizations that do not have an HFS. Use of the tools without an HFS requires further study and evaluation.

In this case study, there were no HF tools developed to influence product design (the first stage of design in Figure 10), even though $60-70 \%$ of ergonomics-related injuries are affected by decisions made at the product design stage (Eklund, 1999; Falck, 2012). While Senior Directors acknowledge that many assembly difficulties arise from decisions made at the product design stage, the manufacturing and assembly team report little success communicating these concerns, or influencing product design in a proactive way. As others have found, product design engineers are often removed physically from manufacturing, and do not realize the outcomes of their decisions on assembly workers (Wulff et al, 1999; Neumann 2006).

Development of effective tools that include HF considerations and could communicate design concerns to product design groups remains an area in need of more research.

The main limitations of the tools adapted in this case study are the lack of "testing", or scientific "validation". Some HF issues may be overlooked, a different scoring or weighting system may 
work better, and there has been very limited formal repeatability or reliability testing performed. Contrary to the research-focused development process for most HF tools, this may be considered a weakness. However, the need for "practice-focused" HF tools has been identified which can then stimulate and initiate further research (Buckle, 2011). Rather than having strict cause-effect limits, most engineering tools used in systems design are more about continuous improvement and problem solving (Dul et al., 2012). Consistent with the design emphasis and the engineering approach, perhaps HF should aim more at creating novel possibilities for action (Nathaneal and Marmaras, 2012) and taking a problem-solving stance (Broberg, 2007), with methodologies and structures for continuous improvement processes (Eklund, 1997; Zink et al., 2008).

\subsection{Conclusions}

Five industrial engineering tools were adapted to include human factors considerations and were integrated at each stage of assembly design in an electronics manufacturing company. Engineers and management responded positively to the tools because they were designed to help improve assembly design and achieve their business goals. Several of the HF tools became required targets within the design process, ensuring that $\mathrm{HF}$ considerations are built into all future design processes. Adapting engineering tools, rather than using HF tools, required a shift for HFS, who needed to expand their knowledge of engineering processes, tools, techniques, language, metrics, and goals. Having the HF tools "owned" by engineering, however, makes the HFS a critical resource. To be effective in an engineering design environment, we suggest HFS increase their understanding of the design process in the organization, learn which tools are commonly used in their engineering process, focus on important metrics for the business goals, and incorporate $\mathrm{HF}$ into engineering-based tools and practices in their organizations. 


\section{Chapter 6}

\section{How Can Qualitative Data in an Ergonomics Action Research Approach be Analysed using a Grounded Theory Methodology?}

\subsection{Introduction and Purpose of Chapter}

The purpose of this chapter is to demonstrate how qualitative data from multiple sources in the three year action research collaboration was analyzed using a grounded theory methodology. This chapter demonstrates how to conduct a grounded theory analysis using the nine detailed methodological steps prescribed in the classic grounded theory methodology of Strauss and Corbin (1990). The chapter presents the data within each step and demonstrates how it was analysed to progress to the next step. This chapter shows the development of the initial tentative theory propositions, and shows further data collection (theoretical sampling), ending at the point of theoretical saturation and validation. Manuj (2011) suggests grounded theory reporting should carefully describe the series of steps leading to development of the theory, such that the constructs in the final theory (described in chapter 7) can be traced. Note that there will be overlap between Chapters 6 and 7 as the former shows the reader the data and development process for the grounded theory, and the later chapter the final theory.

\subsection{Qualitative Analysis and Development of Tentative Grounded Theory}

Results of the grounded theory data analysis are depicted in Figure 12 as nine steps, and are further described according to the numbered steps in the sections to follow. 
1. data entry

\section{2. coding text}

3. grouping into categories

4. Properties \& dimensions
5. Axial coding \& constant comparison
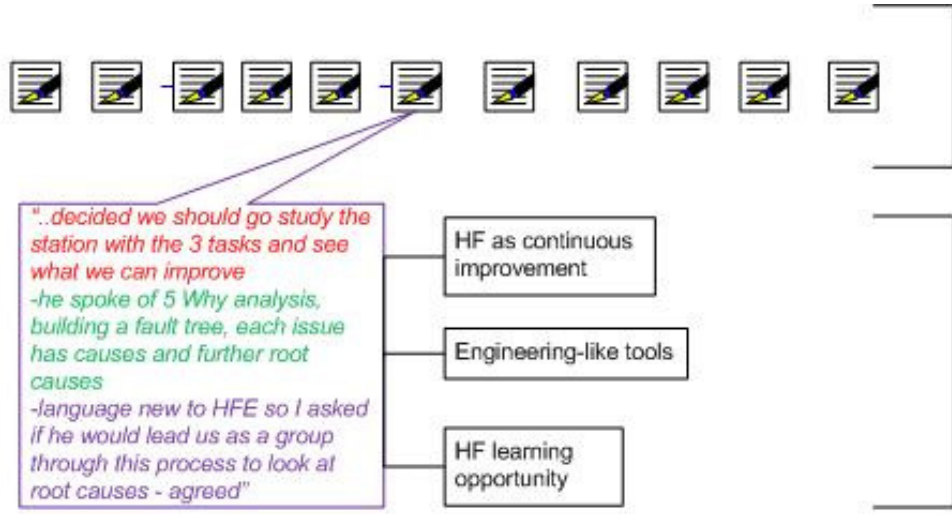

222

entries

115

codes
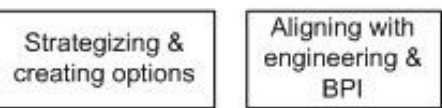

BPI

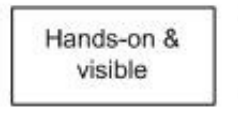

Quality \&

influence

intuence

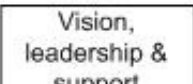

support

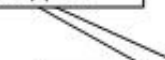

Who's in the sandbox
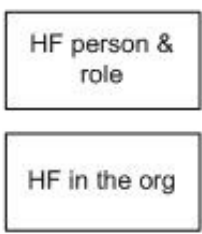

HF comm'n

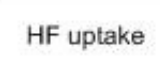

On the outside looking in

Uncontrollable factors

12 categories

Eg.

-timing...

-frequency.

-intensity.

-resources.

-network.

-access...

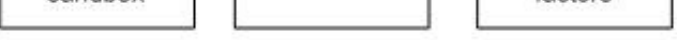

65

proper-

ties

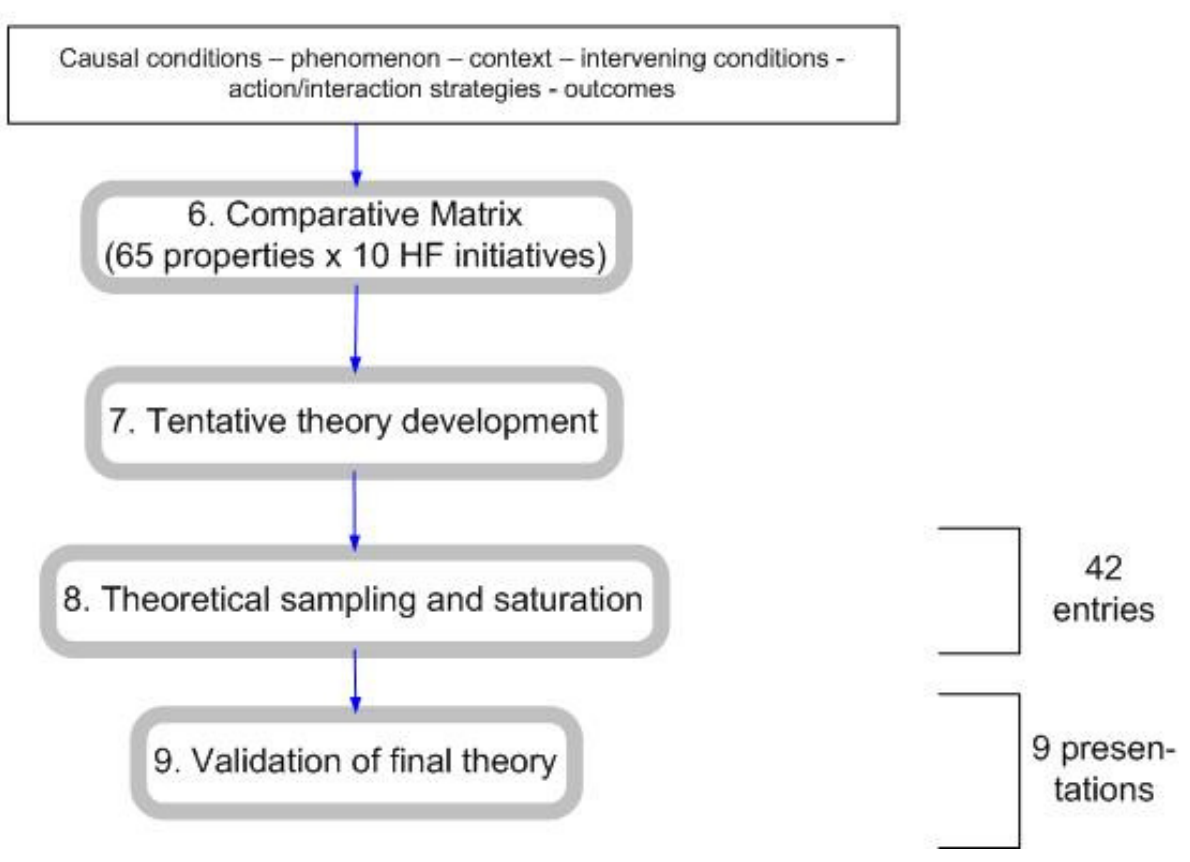

Figure 12. Overview of the Grounded Theory Data Analysis 


\section{Data Entry}

A total of 222 entries in NVivo qualitative analysis software were used for initial data analysis, collected between September 2010 and October 2012. Table 9 summarizes the empirical materials as meetings $(n=126)$, interviews $(n=48)$, steering committee meetings $(n=13)$, focus groups $(n=16)$, and observations $(n=19)$. With each entry there were also accompaning researcher notes $(n=222)$. Table 9 also shows the media by which all data are handled, specific examples of each, and examples of participants. The total number of company participants was 70, and included a Vice President, Senior Directors, Directors, Managers, Specialists (such as quality and HF), engineers (such as product focused, manufacturing and industrial) and assembly workers. Due to several organizational changes during the three year collaboration and subsequent movement of personnel and changes in job titles, a precise breakdown of participants by specialty is not included. Scheduled meetings, whether by telephone, web-ex or in person were generally one hour in length. Some focus groups were up to three hours in length. Most meetings, and all focus groups and steering committee meetings were recorded, transcribed verbatim, and stored digitally. Researcher notes or memos are included with each entry as a separate section and contain reflections on the action/interaction and planning for next steps.

\section{Coding Text}

In this step, open coding was conducted where the data was reviewed (i.e. transcripts, researcher notes) and conceptual labels were placed on discrete happenings, events, statements or other instances of the phenomenon. A broad set of codes was developed to initiate the coding process using scientific literature from macro-ergonomics, organizational change, participatory ergonomics and developmental evaluation. Table 10 summarizes the number and type of codes initially developed, the number used during analysis, the number added during coding and the final number used. Of the total 169 codes originally developed, 99 were unused and 45 new codes were inserted for a total of 115 final codes. Most of the unused codes $(n=59)$ pertained to structural logistics of the project (such as contact hours, dates, type of initiative, etc.). These were deemed unnecessary since the database could be searched pertaining to any of these keywords in the text. Of the 115 final codes, 100 pertained directly to facilitators and barriers of the HF integration, the initiatives and related issues related such as interpersonal, political, knowledge, roles and abilities and communication. 
Table 9. Empirical materials $(n=222)$ used for open coding and example events and participants

\begin{tabular}{|c|c|c|c|c|}
\hline \multicolumn{5}{|c|}{ Open Coding: 222 Entries (Sept 2010-Oct 2012) } \\
\hline $\begin{array}{l}\text { Empirical } \\
\text { materials }\end{array}$ & Number & Media & Explanation (examples) & Example of participants \\
\hline Meetings & 126 & $\begin{array}{l}\text { Almost all } \\
\text { recorded, } \\
\text { transcribed } \\
\text { when recorded, } \\
\text { and electronic } \\
\text { documents }\end{array}$ & $\begin{array}{ll}\text { 1. } & \text { Meetings specific to initiatives (eg. FMEA meetings) } \\
\text { 2. Meetings with HFS manager and team to discuss strategies } \\
\text { 3. Meetings to report on progress of initiative (eg. Root cause analysis } \\
\text { 4. Meetings for feedback on tool (eg. HF DFA) } \\
\text { 5. Meetings to gather information (eg. How quality data is reported) }\end{array}$ & $\begin{array}{ll}\text { - } & \text { Quality engineers } \\
\text { - } & \text { IT Specialist } \\
\text { - } & \text { Product focused engineers } \\
\text { - } & \text { HF specialists } \\
\text { - } & \text { Managers (eg. Advanced } \\
& \text { Manufacturing) }\end{array}$ \\
\hline Interviews & 48 & $\begin{array}{l}\text { All recorded, } \\
\text { transcribed and } \\
\text { electronic } \\
\text { documents }\end{array}$ & $\begin{array}{l}\text { 1. Interviews with collaborating participants and steering committee } \\
\text { members in October } 2010 \text { and October } 2011 \text { for facilitators and } \\
\text { barriers to collaboration } \\
\text { 2. Interviews gathering information on specific topic (eg. perception of } \\
\text { metrics) } \\
\text { 3. Interviews with Directors/Managers using cognitive mapping tool to } \\
\text { determine link between HF and strategic goals }\end{array}$ & $\begin{array}{l}\text { - Senior Directors (eg. } \\
\text { Manufacturing, Continuous } \\
\text { Improvement, Quality Systems } \\
\text { and Improvement, Advanced } \\
\text { Process Engineering } \\
\text { - } \quad \text { Managers (eg. Project manager } \\
\text { quality and metrics) }\end{array}$ \\
\hline $\begin{array}{l}\text { Steering } \\
\text { Committee } \\
\text { Meetings }\end{array}$ & 13 & $\begin{array}{l}\text { All recorded, } \\
\text { transcribed and } \\
\text { electronic } \\
\text { documents }\end{array}$ & $\begin{array}{l}\text { 1. Update on progress of initiatives in collaboration, next steps, } \\
\text { assistance needed }\end{array}$ & $\begin{array}{l}\text { - Senior Directors, Directors, } \\
\text { Managers, HFS }\end{array}$ \\
\hline Focus Group & 16 & $\begin{array}{l}\text { All recorded, } \\
\text { transcribed and } \\
\text { electronic } \\
\text { documents }\end{array}$ & $\begin{array}{l}\text { 1. Discrete event simulation findings and discussion of how this could } \\
\text { be integrated into production design } \\
\text { 2. Focus group to convert HF observations into DFF guidelines } \\
\text { 3. Focus group with engineers with previous HF training to evaluate the } \\
\text { training and determine future training needs } \\
\text { 4. Presentation of run-at-rate data for new assembly line and } \\
\text { prioritization of issues for assembly optimization }\end{array}$ & $\begin{array}{ll}\text { - } & \text { Directors (eg. Engineering } \\
& \text { Development) } \\
\text { - } & \text { Managers (eg. Product Focused } \\
& \text { Engineering, Test Hardware) } \\
\text { - } & \text { Engineers (Mechanical Fixture } \\
& \text { Designer, Industrial Engineer, } \\
& \text { New Product Manufacturing) }\end{array}$ \\
\hline Observations & 19 & $\begin{array}{l}\text { Paper converted } \\
\text { to electronic, } \\
\text { and some video } \\
\text { recordings }\end{array}$ & $\begin{array}{l}\text { 1. Scoring HF FMEA while observing workers performing tasks } \\
\text { 2. Observation of mock-up of new lean assembly line } \\
\text { 3. Observations/discussions with workers regarding fixture design } \\
\text { 4. Meeting with floor supervisors and workers to observe new assembly } \\
\text { line and collect video }\end{array}$ & $\begin{array}{l}\text { - } \text { Quality specialists, Product } \\
\text { Focused Specialists, HFS } \\
\text { - Manager Advanced } \\
\text { Manufacturing Engineering } \\
\text { - Floor supervisors, workers } \\
\end{array}$ \\
\hline $\begin{array}{l}\text { Researcher } \\
\text { Notes with each } \\
\text { engry }\end{array}$ & 222 & All electronic & $\begin{array}{l}\text { 1. Reflections from participation in activities and planning of next steps. } \\
\text { Written from field notes on same day or the day following }\end{array}$ & \\
\hline
\end{tabular}


Of the 115 final codes, 42 were classified specifically as facilitators or barriers to the change process (integration of HF in design processes). Of the 25 initial facilitator/barrier codes developed from the literature, 10 were unused and a further 27 added during the coding process, yielding the 42 final codes. Note that the same code (such as visibility) could be a facilitator or a barrier, depending on the context. Table 11 shows results of the coding density (number of times a code was used) for each of the facilitators and barriers. "Support for HF", "compatibility" and "engineering-like" were the most frequently coded facilitators and barriers. Of interest is how many codes had evidence for being both a facilitator and a barrier across different contexts and initiatives, and those that acted alone as only a facilitator or a barrier.

Table 10. Summary of Comparison between Original and Final Coding Scheme

\begin{tabular}{|l|l|l|l|l|l|l|}
\hline $\begin{array}{l}\text { Type of } \\
\text { Code }\end{array}$ & Code Name & Example & $\begin{array}{l}\text { Number } \\
\text { Initial } \\
\text { Codes }\end{array}$ & Unused & Added & $\begin{array}{l}\text { Final } \\
\text { Codes } \\
\text { Used }\end{array}$ \\
\hline HF related & $\begin{array}{l}\text { Facilitators or } \\
\text { Barriers }\end{array}$ & $\begin{array}{l}\text { Compatibility, visibility, } \\
\text { lack awareness }\end{array}$ & 25 & 10 & 27 & 42 \\
\hline HF related & HF activity & $\begin{array}{l}\text { Increased HF, poor HF, } \\
\text { proactive vs reactive }\end{array}$ & 9 & 2 & 11 & 18 \\
\hline HF related & Strategy & $\begin{array}{l}\text { Vision, boundary object, } \\
\text { lobbying }\end{array}$ & 8 & 2 & 1 & 7 \\
\hline HF related & Opportunities & $\begin{array}{l}\text { HF opportunity, } \\
\text { educational }\end{array}$ & 6 & 0 & 1 & 7 \\
\hline HF related & Communication & Support, blame shifting & 12 & 2 & 3 & 13 \\
\hline HF related & Roles \& abilities & Role clarity, ability & 3 & 0 & 2 & 5 \\
\hline HF related & Political & Legitimacy, reputation & 5 & 0 & 0 & 5 \\
\hline HF related & Interpersonal & Trust, networking & 6 & 3 & 0 & 3 \\
\hline HF related & Knowledge & Professional, methods & 6 & 6 & 0 & 0 \\
\hline $\begin{array}{l}\text { HF } \\
\text { Related }\end{array}$ & Totals & & $\mathbf{8 0}$ & $\mathbf{2 5}$ & $\mathbf{4 5}$ & $\mathbf{1 0 0}$ \\
\hline Change & Roles & Navigating, facilitating & 7 & 1 & 0 & 6 \\
\hline Change & Type of change & Planned, unintended & 4 & 4 & 0 & 0 \\
\hline Change & Org. Change & Internal, timing & 8 & 1 & 0 & 7 \\
\hline Change & Substance & Scale, people, timeframe & 9 & 9 & 0 & 0 \\
\hline Change & Totals & & $\mathbf{2 8}$ & $\mathbf{1 5}$ & $\mathbf{0}$ & $\mathbf{1 3}$ \\
\hline Structural & $\begin{array}{l}\text { Role and } \\
\text { Position }\end{array}$ & Operational autonomy & 7 & 6 & 0 & 1 \\
\hline Admin & Contact/Dept & Organizational participants & 14 & 14 & 0 & 0 \\
\hline Admin & Date/hours & & 2 & 2 & 0 & 0 \\
\hline Admin & Purpose/detail & Meeting, telephone call & 17 & 17 & 0 & 0 \\
\hline Admin & Procedural & Cancelled meeting, late & 9 & 9 & 0 & 1 \\
\hline Admin & Operational & Resources, scope & 12 & 12 & 0 & 0 \\
\hline $\begin{array}{l}\text { Admin \& } \\
\text { Structure }\end{array}$ & Totals & & $\mathbf{6 1}$ & $\mathbf{5 9}$ & $\mathbf{0}$ & $\mathbf{2}$ \\
\hline & & & & & \\
\hline
\end{tabular}


Table 11. Coding Density (number of times a code was used) for Facilitators and Barriers sorted by Descending Total Density

\begin{tabular}{|c|c|c|c|}
\hline Sub-code & Number Facilitators & Number Barriers & Total \\
\hline Compatibility & 44 & 30 & 74 \\
\hline Support for HF & 50 & 20 & 70 \\
\hline Engineering-like & 37 & 15 & 52 \\
\hline Visibility of initiative & 20 & 17 & 37 \\
\hline Commitment & 23 & 13 & 36 \\
\hline Ease of implementation & 12 & 24 & 36 \\
\hline Selling HF & 18 & 18 & 36 \\
\hline Resource allocation & 17 & 17 & 34 \\
\hline Level of influence of initiative & 24 & 7 & 31 \\
\hline Permanence of initiative & 22 & 9 & 31 \\
\hline Increased awareness of HF & 16 & 12 (lack of) & 28 \\
\hline Mix of participants & 12 & 16 & 28 \\
\hline Champion/Leadership & 18 & 8 & 26 \\
\hline Complexity & 4 & 22 & 26 \\
\hline Visibility of HF or Ergo's & 25 & & 25 \\
\hline Ergo on team/HF responsibility & 19 & 16 (lack of) & 25 \\
\hline Approval & 19 & 6 & 25 \\
\hline Erqo lack process awareness & & 25 & 25 \\
\hline Ryerson's assistance & 24 & & 24 \\
\hline Lack of plan or comm of plan & & 22 & 22 \\
\hline Reoraanization/restructuring & 11 & 11 & 22 \\
\hline Working aroup composition & 11 & 10 & 21 \\
\hline Time & 9 & 12 & 21 \\
\hline Lack of process where ergo fits in & & 21 & 21 \\
\hline Work culture & 11 & 9 & 20 \\
\hline Rverson's temporary role & 9 & 9 & 18 \\
\hline Proof it works & 9 & 9 & 18 \\
\hline Timing & 12 & 5 & 17 \\
\hline Awareness of initiative & 5 & 10 & 15 \\
\hline Quality of initiative & 14 & & 14 \\
\hline Shop floor experience & 14 & & 14 \\
\hline Proiect manager & 10 & & 10 \\
\hline Nature of work & 3 & 7 & 10 \\
\hline Production requirements & 2 & 8 & 10 \\
\hline Lack engineering network & 5 & 5 & 10 \\
\hline Lack tool & 5 & 5 & 10 \\
\hline Decision makina & 4 & 5 & 9 \\
\hline Personnel turnover & 3 & 5 & 8 \\
\hline Intellectual property & 3 & 3 & 6 \\
\hline Cost & 3 & 3 & 6 \\
\hline Access (documents, meetinas) & 2 & 2 & 4 \\
\hline Lots of ideas & 2 & & 2 \\
\hline
\end{tabular}




\section{Grouping Codes into Categories}

Categories are a higher order grouping of concepts that may include many concepts and may be named differently from any original code names. In this step, the data coded using open coding was put back together in new ways by making connections and grouping concepts into categories. Data within each of the 115 codes was re-read, and the codes were grouped into 12 categories in a way that made sense with respect to the data. Categories were then given names. Figure 13 shows the grouping of codes into categories.

\section{Properties and Dimensions for each Category}

Queries were conducted using the NVivo software to gather all data together within each category according to codes grouped within that category. The data within the newly formed category was re-read for coherency. Memos, which are like interpretative notes, were used to document and summarize the main meaning and quotes within each category. According to the grounded theory methodology, the same data can be coded with more than one code, but all codes and data should be found somewhere within the categories, meaning that data should not be disregarded or unused. Codes that did not fit well within the category, or fell into more than one category upon re-reading were flagged, and later re-sorted or combined into their appropriate category. For example, several of the codes within category 3 (Quality of the Initiative) were found to have overlap and resonance with category 2 (Aligning with Engineering and Business Improvement Programs). As shown in the next analysis step, seeing the similarities in these concepts led to their grouping during the axial coding stage. The twelve categories and their associated concepts are shown in Figure 13. 


\begin{tabular}{|c|}
\hline $\begin{array}{l}\text { 1. Vision, Leadership \& } \\
\text { Support (8) } \\
\text { - } \quad \text { Support for HF } \\
\text { - } \quad \text { Commitment } \\
\text { - } \quad \text { Approval } \\
\text { - } \quad \text { Champion/leadership } \\
\text { - } \quad \text { Recognition from } \\
\text { - } \quad \text { leadership } \\
\text { - } \quad \text { Chaject manager } \\
\text { - } \quad \text { Communion for idea } \\
\end{array}$ \\
\hline
\end{tabular}

4. The Ergonomist - person and role (10)
- $\quad$ Ergonomist lacks process awareness
- $\quad$ Lack of engineering network
- Access (to documents, meetings, etc.)
- Ergonomist lacks knowledge of
- Role clarity
- HF coaching needual abilities
Roles and abilities

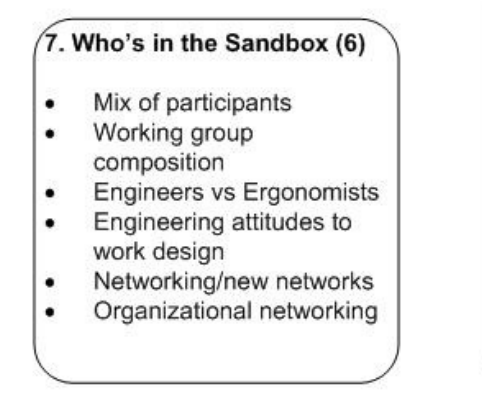

\begin{tabular}{l} 
2. Aligning with Engineering and \\
Business Process Improvement \\
Programs (12) \\
- $\quad$ Compatibility \\
- $\quad$ Engineering-like \\
- $\quad$ Nature of work \\
- $\quad$ Hnderstanding engineering process \\
- HF in design for assembly \\
- $\quad$ HF in product design \\
- $\quad$ Planning activities with deliverables \\
\hline
\end{tabular}

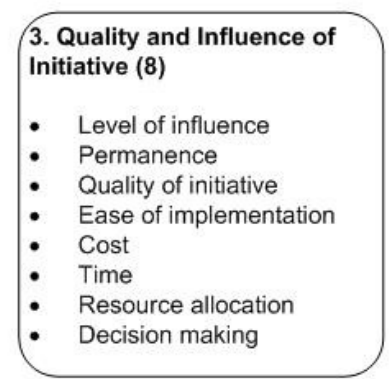

6. HF within the Organization (7)

- Visibility of HF

- Ergonomist on team

- Awareness of HF (lack of)

- Lack process where ergonomics fits

- Lack of internal ergonomist involvement

- Positioning of HF

- Role of Ergonomist

\begin{tabular}{ll} 
10. & Communication (15) \\
- & Interpersonal communication \\
- & Contradiction with management or own \\
& agenda \\
- & Blame shifting \\
- & Lack of understanding \\
- & Management of meaning \\
- & Political legitimacy \\
- & Managing impressions \\
- & Resistance \\
- & Rewer \\
- & Trust \\
\hline & Socialing \\
\hline
\end{tabular}

\section{Application and Uptake of HF (9) \\ - HF integration \\ - Increased HF activity/application \\ - HF link with quality \\ - Increased HF understanding and awareness \\ - Development of HF skills, resources, etc. \\ - HF learning \\ - Poor HF \\ - HF training \\ - HF measurement}

9. Strategizing and Creating Opportunities (16)

- Ergonomics opportunity

- Strategic opportunity

- Increasing visibility and communication of project

- Organizational change opportunity

- Organizational learning

- Engineering opportunity

- Educational opportunity

- Proactive vs reactive

- Aligning agendas

- Backstage/front stage

- Getting others on board

- Lobbying

- Vision/strategy

- Persuasion

- Boundary object

- Lots of ideas

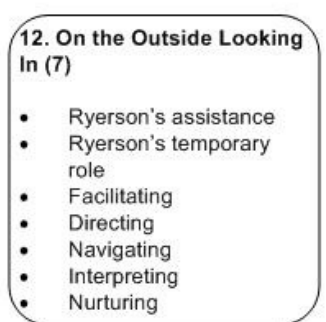

Figure 13. Codes (115) grouped into Categories (12) 
Using the categorical data and memos, the properties and dimensions were drawn out of the data for each category and itemized in tables. Properties are the attributes or characteristics of a category. Using the example "support for human factors", the properties of support may include verbal recognition, access to resources, assistance with networking, etc. These represent characteristics found in the data that describe how support was provided. Dimensions position properties on a continuum. In the example of support, access to resources may have the dimension of "extent" (from very little to a lot), or "frequency" (from once to ongoing). The purpose of detailing properties and dimensions for each conceptual category is for the researcher to ask questions and challenge themselves to more fully understand the data. It provides richness to the researcher's understanding and descriptions of the categories based on the data.

A constant comparison method was used to move between instances of the data to ensure all properties were discovered. Table 12 shows one example of properties and dimensions determined from the data in Category 1 "Vision, Leadership and Support". Properties and dimensions for the remaining 11 categories are found in Appendix $\mathrm{E}$. The category "Òn the Outside" which detailed the researchers' role in the collaboration was not used in the final analysis. 
Table 12. Properties and Dimensions of Category 1: Vision, Leadership and Support

\begin{tabular}{|c|c|}
\hline $\begin{array}{l}\text { Properties of Vision, Leadership and } \\
\text { Support }\end{array}$ & Dimensions \\
\hline Timing of support (when) & $\begin{array}{l}\text { Prior to initiative } \rightarrow \text { during } \rightarrow \text { after demo or } \\
\text { results }\end{array}$ \\
\hline $\begin{aligned} \text { Type of: verbal - frequency } \\
\\
\text { - intensity of support }\end{aligned}$ & $\begin{array}{l}\text { none } \rightarrow \text { occasional } \rightarrow \text { very frequent } \\
\text { none } \rightarrow \text { conditional } \rightarrow \text { full support }\end{array}$ \\
\hline Type of: resources - amount & none $\rightarrow$ some $\rightarrow$ considerable \\
\hline Type of: participation with HF & none $\rightarrow$ some $\rightarrow$ considerable \\
\hline Type of: network/contacts & Lack of $\rightarrow$ some access $\rightarrow$ full access \\
\hline Type of: monitoring progress & none $\rightarrow$ some $\rightarrow$ active \\
\hline $\begin{array}{l}\text { Type of: access to documents, meetings } \\
\text { etc }\end{array}$ & none $\rightarrow$ some $\rightarrow$ full access \\
\hline Type of: legitimizing & none $\rightarrow$ some $\rightarrow$ full support \\
\hline See vision, provide ideas & none $\rightarrow$ some $\rightarrow$ many ideas \\
\hline Locking HF into process & Lack process $\rightarrow$ some $\rightarrow$ full lock-in \\
\hline Provision or nature of support & required $\rightarrow$ some interest $\rightarrow$ voluntary \\
\hline Frequency of support & once $\rightarrow$ several $\rightarrow$ ongoing \\
\hline Increasing org support/share with others & none $\rightarrow$ some $\rightarrow$ ongoing \\
\hline Request for HF input (positioning of HF) & Push HF $\rightarrow$ push/pull $\rightarrow$ pull for HF \\
\hline Level of support within hierarchy & Workers/eng $\rightarrow$ mid mgt $\rightarrow$ Sr. Dir \\
\hline Prior experience with $\mathrm{HF}$ & None/poor $\rightarrow$ some $\rightarrow$ extensive \\
\hline Recognition of "fit" with strategies/bus & None/poor fit $\rightarrow$ some $\rightarrow$ full fit \\
\hline Future impact apparent & none $\rightarrow$ some $\rightarrow$ fully \\
\hline Human factors domain/understanding & $\begin{array}{l}\text { Simple/injuries } \rightarrow \text { broader (fatigue) } \rightarrow \text { many } \\
\text { aspects (perf, cognitive) }\end{array}$ \\
\hline Involvement/participation (meetings, etc) & minimal $\rightarrow$ some $\rightarrow$ fully engaged \\
\hline Recognition of novelty of $\mathrm{HF}$ initiative & Not novel $\rightarrow$ somewhat $\rightarrow$ completely \\
\hline $\begin{aligned} & \text { Recognition of potential impact of } \mathrm{HF} \\
&- \text { extent } \\
&- \text { numbers impacted }\end{aligned}$ & $\begin{array}{l}\text { Small (workstation, tool) } \\
\rightarrow \text { moderate } \rightarrow \text { large (assembly) } \\
\text { few } \rightarrow \text { many } \rightarrow \text { large (EMS sites) }\end{array}$ \\
\hline
\end{tabular}




\section{Axial Coding and Constant Comparison}

This step of axial coding involved using the action-oriented coding paradigm shown below to further develop relationships between the categories that are processural and describe "how" something happens. Conditions must be specified by identifying them as causal, contextual or intervening. These describe relationships between conceptual categories (not actual events), and involves continual movement between deductive (proposing statements about relationships) and inductive thinking (verifying statements by comparing incidents of the phenomenon).

The paradigm, as outlined by Strauss and Corbin (1990) has six parts that describe the action:

A. Causal conditions: the properties and dimensions that brought about the phenomenon.

B. Phenomenon: the integration of HF into production assembly design processes.

C. Context: describes the properties and conditions that gave rise to the phenomenon (i.e. under certain conditions, this action causes this consequence).

D. Intervening Conditions: describe properties of categories that affect the action/interaction strategies.

E. Action/Interaction strategies: describes what was done to manage, handle, carry out, or respond to a phenomenon under certain perceived conditions.

F. Consequences: outcomes, or the conditions for the next action in the action pathway

The process of looking for different patterns and comparing dimensions and instances of the data is constant comparison. To assist with axial coding and the coding paradigm, various analysis techniques were used with the data, such as mini frameworks, logic diagrams, and researcher memos of provisional relationships.

\section{A.. Causal conditions}

In this context, the causal condition was considered the entry point or initiation of action towards HF integration. In some cases the action was initiated by the Ryerson team (for 
example suggesting the process mapping of the design process), at other times the collaborating organization suggested the initiative (such as the HF evaluation of the lean line, and the integration of HF in kaizens and gembas). Some initiatives were jointly initiated by the researchers and participants, such as the HF integration in the design for assembly scorecard.

\section{B. Phenomenon}

The "phenomenon" in this study, called "HF integration in design" is defined as follows:

"where HF guidelines, targets, tools, a person, or a process is integrated

proactively in the design of any part or step or procedure of the production

assembly design process"

The phenomenon is characterized by the properties and dimensions of Category 8 "Application and Uptake of HF", and Category 3 "Quality of Initiative". The following summarizes the main properties of the phenomenon:

- High quality

- How HF is applied (eg. required vs one-off assessment)

- HF tool is developed that is appropriate

- Corrects repeated concerns/lessons learned

- Leads to best practices/benchmarking

- HF aligned with quality

- HF metrics

- HF well scoped

- Well documented

- Influences engineers

- Influences workers

- Influences process

- HF is proactive vs reactive

- Demonstrates change

- Standardization ability

- Permanence

- Not process or person dependent 


\section{Context}

The conditions that gave rise to or influence the phenomenon within the context were a combination of Category 1 "Vision, leadership and support", Category 7 "Who's in the Sandbox" and Category 10 "Communication". The following properties of the context were found to be most important:

- Frequent support from engineering personnel (i.e. not a one-off request)

- Senior management/director level support (via various mechanisms)

- Increased organizational support (eg. sharing with others)

- Involvement and participation with engineers in HF

- Recognition by others of future impact of HF

- Engineers open to HF and to trying it out

- HF works with engineers as a team

- Engineers take ownership of HF

- Right mix of people have knowledge of upstream HF opportunities

- Able to identify the right people to be involved in HF opportunities

- HF answers appropriate question for engineers

\section{Intervening Conditions}

The properties of the categories that influenced the action/interaction strategies were a combination of Category 4 "The HFS: person and role", Category 6 "Human factors within the organization", and Category 11 "Uncontrollable organizational/environmental/structural factors". The main properties of the intervening conditions include:

- HFS is on the shop floor

- HFS is easy access for engineers

- HFS documents examples of HF

- HFS manager maintains profile of group in engineering

- HFS group is well positioned

- HFS roles are well defined

- HFS are aware of new products, processes, tooling etc. 
- HFS reports to engineering managers

- HFS focuses on contributing to engineering goals

- HFS works to understand processes where HF fits

- HFS can adapt tools to integrate with engineering

- HF is being pulled into engineering (or is demonstrating HF) rather than pushing

- Resources provided

- Time provided

- Reorganization causes re-alignment with HF (rather than a disruption)

- HFS and HF work positioned to weather changes

\section{E. Action/Interaction Strategies}

Properties from three large categories were combined to describe the purposeful and goal oriented strategies and tactics for managing, handling, and carrying out the HF integration phenomenon. They are Category 2 "Aligning with Engineering and Business Process Improvement Programs", Category 5 "Hands on and Visible" and Category 9 "Strategizing and Creating Opportunities". The properties that describe "how" the phenomenon came about determined most important for action/interaction strategies include:

- Having a plan with steps and deliverables

- Being quantifiable with thresholds, key performance indicators or targets

- Fits with engineering tools and processes

- Fits with expectations (within engineering department)

- Directly addresses operational goals

- HF Tools have good utility (quick, easy)

- Facilitates action/demonstrates change

- High visibility

- Fits with high priority initiatives in organization

- $\mathrm{HF}$ is specific and tangible

- HF is compatible with engineering workload

- HF piggybacks on other business improvement programs

- Bridges HF with engineering

- Allows HFS to create opportunities/leverage HF 
- Allows HFS to learn who's who

- Allows cross department work with HF

- HFS respond quickly to engineering requests

- HFS are part of the team (vs silo)

\section{$\underline{F . \text { Consequences }}$}

In this collaboration with a goal of HF integration in design processes, the consequences, or outcomes of attempts at HF integration were described as:

- $\mathrm{HF}$ is ignored, initiative is not continued or adopted

- HF is "owned" by the researchers (note that an initiative could be both ignored and owned by researchers)

- HF (specific initiative) is adopted somewhat by the participating organization

- Engineers in organization adopt fully, take ownership and secure in process

\section{Comparative Matrix}

To further enhance understanding of the relationships between properties as developed in the axial coding, a comparative matrix was designed to explore differences within each initiative using the axial coding paradigm. The matrix consisted of the 65 properties determined in step 5, grouped into the A-F axial coding properties as described in the previous sections. See Appendix F for the full comparative matrix. The 65 properties were compared across the 10 main HF initiatives, not for the purposes of rating or making definitive determinations, but to enhance understanding of important causal relationships. A rating of " 0 " was given for the property if it wasn't met by the initiative (eg. tool utility is not quick and easy), a "1" if the property was met somewhat, and a "2" if the property was fully met. The matrix also included an assessment of the 65 properties prior to the collaboration (pre 2010), and near completion of the collaboration (2013) to provide somewhat of an indication about how the HF integration process has progressed based on properties deemed important from the data.

Figure 14 below shows the scores summed for each initiative, with higher scores suggesting more of the properties determined important from the data in step 5 were being met. The matrix shows that over the course of the three years, as HFS became 
more sensitive to the important conditions for HF integration, there was increasing adoption of HF initiatives. The comparison of the properties pre-2010 and in 2013 shows a large difference. To illustrate how the comparative matrix increased understanding and helped build the theoretical model, a comparison of two of the initiatives will be described below. Note that similar comparisons and charting of memos and differences was completed for all initiatives (not shown). The discrete event simulation (DES) is contrasted with the HF design for assembly scorecard. While the DES was a high quality initiative, there were other circumstances, expectations and conditions that hindered adoption of this HF technology. It was also conducted earlier in the collaboration without the benefit of reflection on conditions facilitating HF integration. The table contrasting the two initiatives illustrates these differing conditions.

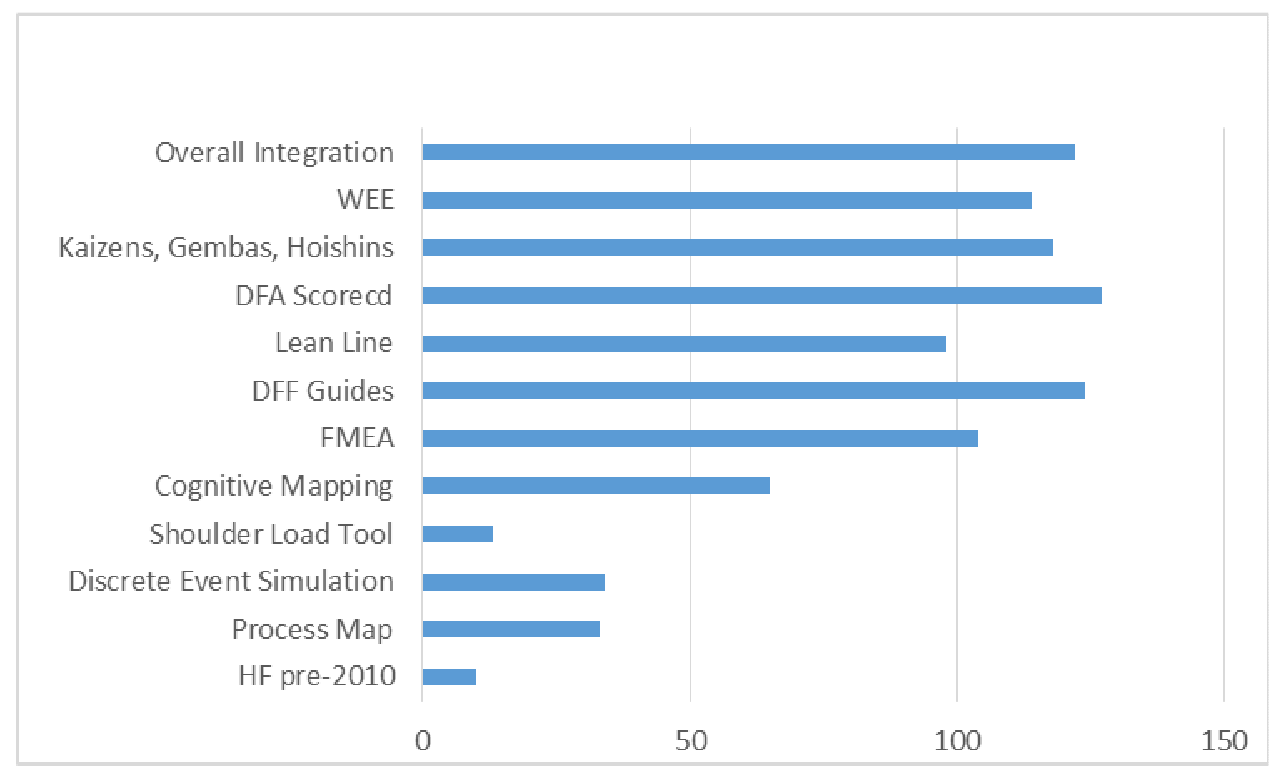

Figure 14. Summed scores from 65 properties in the comparative matrix (in Appendix F) for 10 initiatives, and overall for HF integration pre-2010 and 2013 (max score 130) 
Comparison of discrete event simulation (DES) initiative and the HF design for assembly (DFA) scorecard

\begin{tabular}{|c|c|c|}
\hline $\begin{array}{l}\text { A. Causal } \\
\text { conditions }\end{array}$ & $\begin{array}{l}\text { Discrete event simulation } \\
\text { - Organization PI left company } \\
\text { - Researchers initiated DES }\end{array}$ & $\begin{array}{l}\text { HF DFA scorecard } \\
\text { - Engineers and HFS collaborated with } \\
\text { goal to find ways to integrate HF into } \\
\text { design of production } \\
\text { - Need for scorecard arose from } \\
\text { teams' realization of lack of HF tools } \\
\text { to identify assembly difficulties }\end{array}$ \\
\hline $\begin{array}{l}\text { B. } \\
\text { Phenomenon } \\
\text { (HF initiative, } \\
\text { application } \\
\text { and uptake) }\end{array}$ & $\begin{array}{l}\text { - High quality, well documented } \\
\text { - HF integration unique and } \\
\text { proactive } \\
\text { - Application to assembly line } \\
\text { problem } \\
\text { - Application too late in process } \\
\text { - Dependent on person (with } \\
\text { modeling skills) } \\
\text { - Level of influence in design } \\
\text { uncertain } \\
\text { - Level of influence on workers } \\
\text { uncertain }\end{array}$ & $\begin{array}{l}\text { - High quality, well documented } \\
\text { - Early application of HF } \\
\text { - HF tool appropriate and } \\
\text { communicates target (metrics) } \\
\text { - Corrects repeated concerns and } \\
\text { demonstrates change } \\
\text { - Best practices and benchmarking } \\
\text { - Lessons learned embedded } \\
\text { - HF used to help indicate quality } \\
\text { - } \text { - Influencens engineers, workers and } \\
\text { - design process } \\
\text { - Standardization ability } \\
\text { - Permanence } \\
\text { Not person dependent }\end{array}$ \\
\hline C. Context & $\begin{array}{l}\text { - Senior Director support } \\
\text { - Access to data difficult } \\
\text { - No project manager to } \\
\text { coordinate } \\
\text { - Little involvement from } \\
\text { engineers (no team) } \\
\text { - Engineers not willing to try it } \\
\text { out } \\
\text { - Unsure the right people for } \\
\text { - } \text { Nodeling results } \\
\text { - Some recognition of impact } \\
\text { - Unsure if it answers } \\
\text { appropriate question }\end{array}$ & $\begin{array}{l}\text { - Senior Director support and project } \\
\text { manager assistance } \\
\text { - Access to appropriate people } \\
\text { - Good timing with updating DFA } \\
\text { process } \\
\text { - Involvement from many engineers in } \\
\text { focus groups } \\
\text { - Recognition of impact } \\
\text { - HFS part of team } \\
\text { - Ability to use proactively to drive } \\
\text { - } \text { HF tool changes }\end{array}$ \\
\hline $\begin{array}{l}\text { D. Intervening } \\
\text { Conditions }\end{array}$ & $\begin{array}{l}\text { - HFS not directly involved } \\
\text { - HFS portion and link unclear } \\
\text { - Software for DES not } \\
\text { - } \text { available } \\
\text { - Perceived as cost prohibitive } \\
\text { - Resource allocation an issue } \\
\text { - Onitiative pushed vs pulled } \\
\text { changizational strategy } \\
\text { chang with more }\end{array}$ & $\begin{array}{l}\text { - Engineering and HFS resources and } \\
\text { time for shop floor and meetings } \\
\text { - HFS increases awareness of new } \\
\text { products and processes and } \\
\text { engineering tools } \\
\text { - Findings from HF tool reported to } \\
\text { engineering management } \\
\text { - Contributes to engineers' goals } \\
\text { - Reorganization helped streamline }\end{array}$ \\
\hline
\end{tabular}




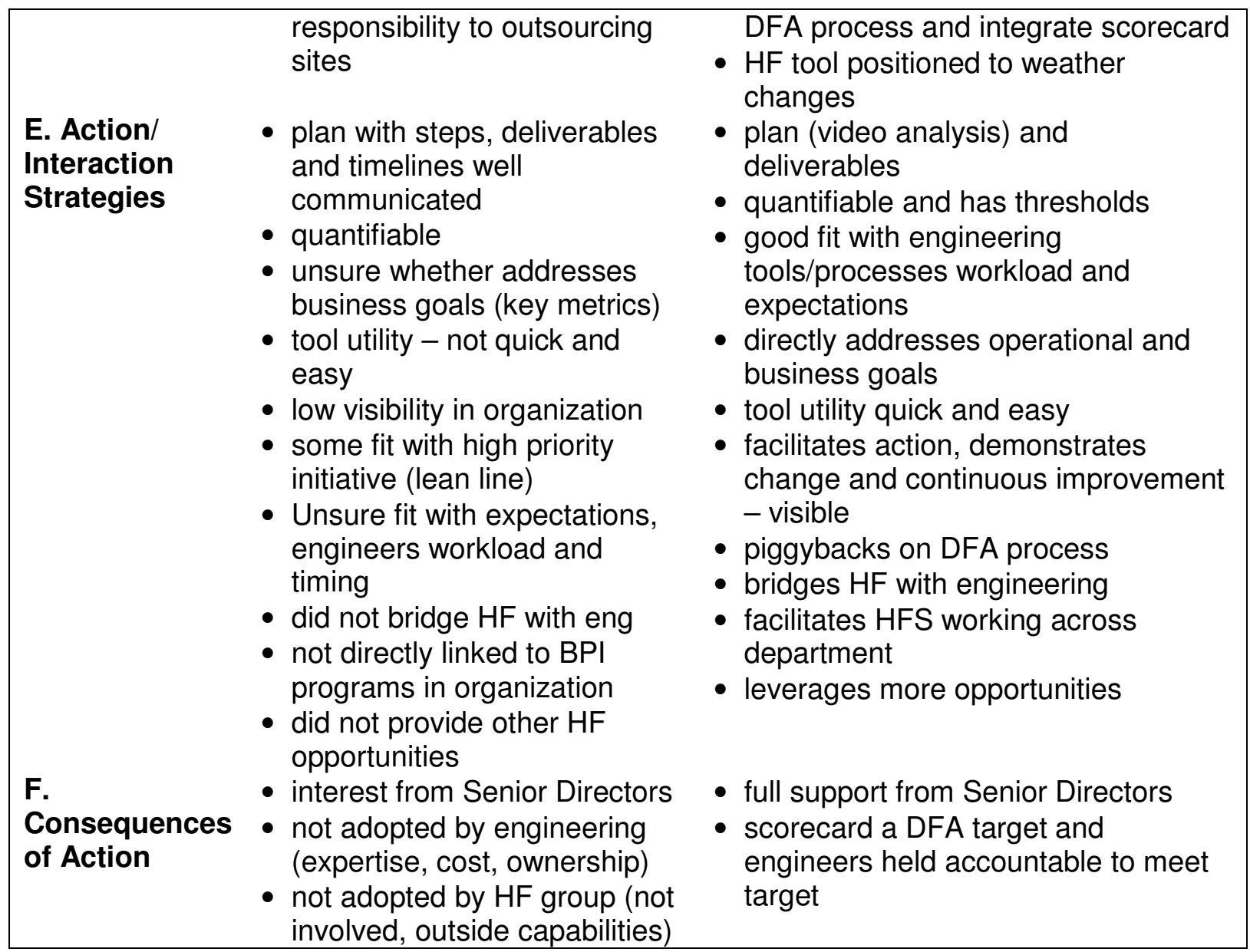

As the example shows, there were many conditions that led to adoption of one initiative compared with the other, some of which were in control and known to researchers, and others which were not in the researchers' control or known at the time of the DES initiative. Contrasting each of the initiatives in this way led to tentative propositions and early theory development in the next analysis stage.

\section{Theory Development - Tentative Propositions}

In this step, selective coding was done to "select" the "core" category, systematically relate it to other categories, validate those relationships with further data, and fill in categories that need further refinement and development. As with axial coding, a constant comparison of the data further validated the relationships and fills in categories that need further refinement. At the end of this step, a list of tentative propositions is developed for theoretical sampling in the next step. 
The core category, seen to be driving the action was a combination of three previous categories ("aligning with engineering and business process improvement programs", "hands on and visible" and "strategizing and creating opportunities"). The properties in this newly formed category described "how" HF became integrated into the design process. This central action, of "how" HF came to be integrated was drawn as "how" in the first iteration of the theory in Figure 15. Working out from the core category were new conceptualizations of "who" was driving the action (the HFS and how they framed their work), and "what" the action looked like (HF uptake in tools). The axial coding revealed that the organizational properties were contextual. The grey square in Figure 15 shows the immediate context for HF integration and one intervening condition. The category of vision, leadership and support, was becoming re-defined as a primary intervening condition based on the comparative analysis of initiatives.

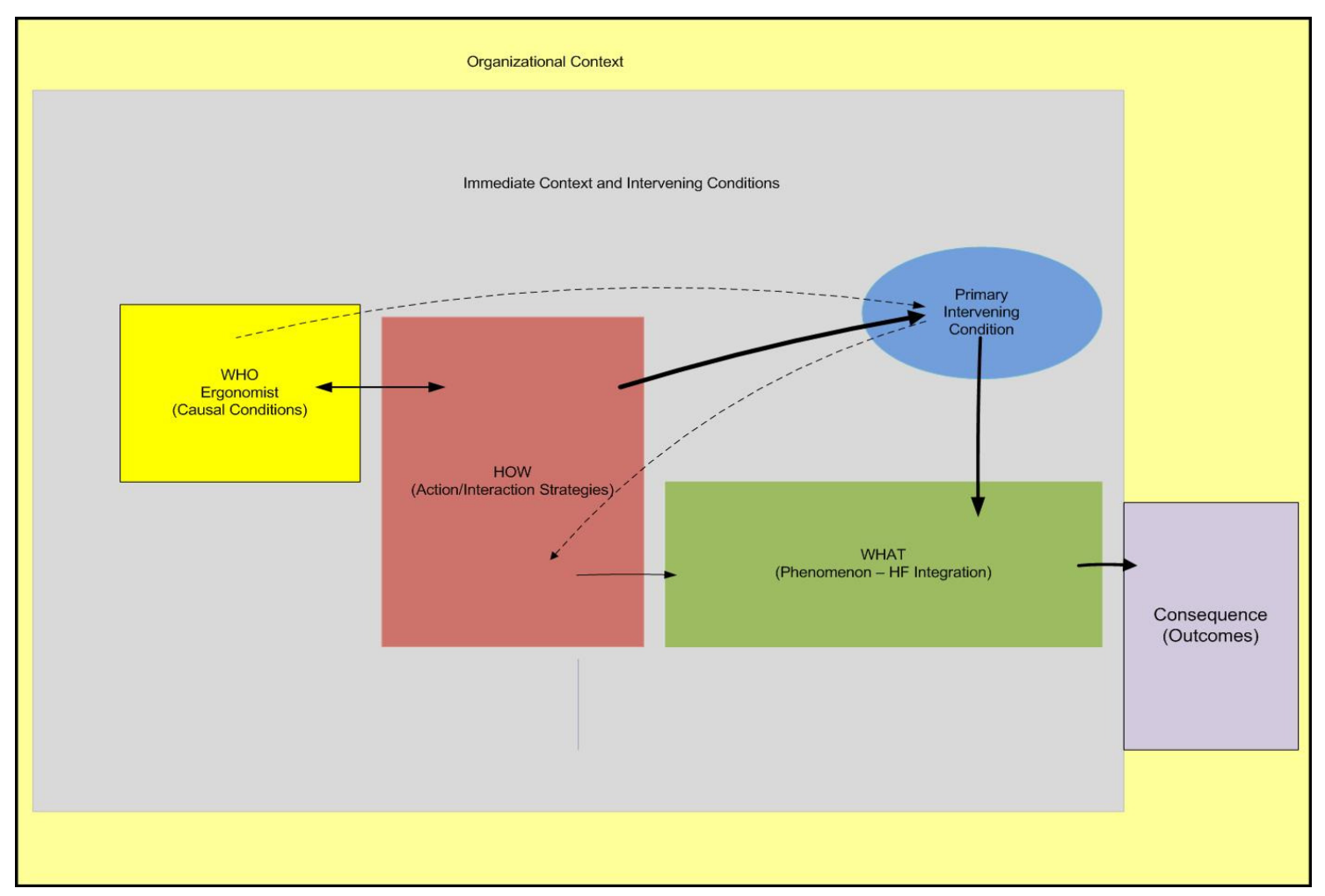

Figure 15. Early exploration of "core" category and its relationship to other categories to describe the action 
In iterations and development of the tentative theory, the relationships in Figure 15 were further developed as shown in another iteration in Figure 16. For the HFS to create the action of HF integration, the concept of "morph to fit" was developed. There were properties of HF and engineering teamwork in several categories, but it was not clear in the original coding where this best fit. Theoretical thinking led to "HF on the engineering team" being positioned as a bridge between the HFS who is acclimating to "fit" within engineering.

Within the immediate context, the concept of "engineer willingness" was added as a tentative link to bridge the HFS with the engineering team, and this was drawn with dotted links to senior management. Another tentative concept in the context was "managing and positioning of HF in the organization". A tentative link was drawn between the HFS and Senior Engineering manager suggesting that direct reporting to engineering would also facilitate the learning and HF fit. Each of these tentative links became propositions that would be further "tested" with data in the theoretical sampling in the next step. The full list of tentative propositions is shown in Appendix G.

The contextual category of "vision, leadership and support" was re-defined in Figure 16 as "accountability for HF from senior management" to better explain what led to the HF uptake. This was strongly linked to the HFS having morphed to engineering language and processes, and strategically aligned their HF activities with engineering and business goals.

In this iteration of the theory, as shown in Figure 16, the phenomenon of HF integration was redefined as "development of appropriate HF methods and tools" and "HF embedded in process". This was because in most cases of HF integration, an appropriate HF tool was necessary to measure and communicate the HF issues, and targets were needed to embed HF in the process. 


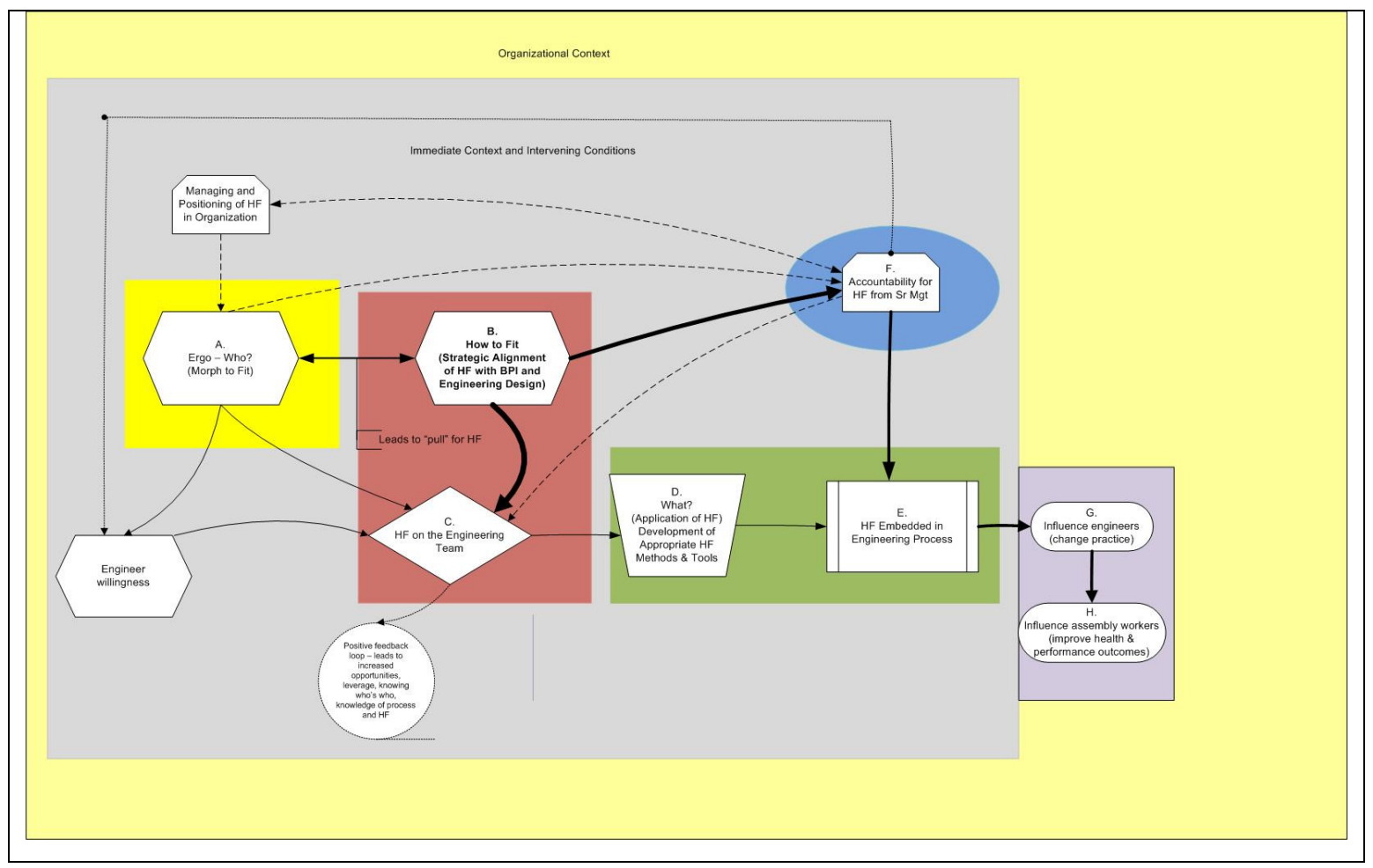

Figure 16. Second iteration of tentative theory

\section{Categories and Properties not Retained in Tentative Theory}

Concepts related to organizational changes and the influence of these disruptions were not retained in the final model. Appendix $\mathrm{H}$ illustrates some of the data from the categories and properties of organizational change. The comparative matrix revealed that the disruptions, while usually having a short term negative impact, did not have a long term influence on whether a HF initiative was adopted or not. In fact, there were examples (eg. HF-DFA), where re-alignment of personnel and intense focus on launch of a new product brought engineers and HFS together since all efforts in the organization had to be focused on a successful launch.

The social, political and interpersonal properties, such as working group composition and communication were also not retained in the tentative theory (See Appendix $\mathrm{H}$ for examples of the empirical data). There were a large number of sections of data coded under these headings early in the project, but not many in the later phases. However, the lack of coding in later phases may reflect that as HFS became acclimated to the needs, language and ways of working of engineers, and they were working towards a 
common goal, any social, political, or interpersonal issues were no longer a facilitator or barrier to HF integration.

Quality of the initiative, one of the properties in the comparative matrix, was also not retained. In all initiatives, the quality was rated highly, so this did not appear as a property in this case that influences uptake of HF. Finally, time and resources, while included in the comparative matrix, showed little variation across initiatives. There were very few sections of coded text related to time and resources. There is therefore insufficient depth and variation of data to suggest that these properties played a role in the action in this case.

\section{Theoretical sampling and theoretical saturation}

Following development of the tentative propositions (Appendix $\mathrm{G}$ ) and tentative theory in step 7, the grounded theory approach involves another stage of data collection and analysis for theoretical sampling to the point of perceived theoretical saturation. A further 42 entries from action/interactions were reviewed from within NVivo qualitative analysis software after development of the tentative theory from October 2012 to March 2013. Table 13 shows the empirical data for the theoretical sampling, including meetings $(n=20)$, interviews with participants involved in the collaboration $(n=11)$, steering committee meetings $(n=2)$, focus groups $(n=8)$, observations $(n=1)$ and researcher notes with each entry $(n=42)$. In these interactions and interviews, following open ended questions about what was helping or hindering HF integration, targeted questions were asked to "test" propositions in the tentative theory. For example, one engineer stated that the increased involvement of the HFS was facilitating HF integration. As a targeted follow-up, the following question was asked of the engineer:

"Why were you willing to work with the HF folks?"

\section{Engineers' Response:}

"I'm interested in any help I can get to make a better assembly"

This data reinforces the construct that if the HFS is helping the engineer achieve their goals, then they are very willing to have them on their team. 


\section{Table 13. Empirical materials $(n=42)$ used for theoretical coding and example events and participants}

\begin{tabular}{|c|c|c|c|c|}
\hline \multicolumn{5}{|c|}{ Theoretical Sampling: 42 entries (Oct 2012-June 2013) } \\
\hline $\begin{array}{l}\text { Empirical } \\
\text { materials }\end{array}$ & Number & Media & Explanation (examples) & Example of participants \\
\hline Meetings & 20 & $\begin{array}{l}\text { Almost all } \\
\text { recorded, } \\
\text { transcribed and } \\
\text { electronic } \\
\text { documents }\end{array}$ & $\begin{array}{l}\text { 1. Meeting to discuss HF role in developing charter for new HF initiative } \\
\text { 2. Meetings to discuss how to integrate the DFF into the HF DFA } \\
\text { process } \\
\text { 3. Update on HF changes in new assembly line }\end{array}$ & $\begin{array}{l}\text { - } \quad \text { Senior Director Engineering } \\
\text { - } \quad \text { Product focused engineers } \\
\text { - } \text { HF specialists } \\
\text { - } \quad \text { Managers (eg. Advanced } \\
\quad \text { Manufacturing) }\end{array}$ \\
\hline Interviews & 11 & $\begin{array}{l}\text { All recorded, } \\
\text { transcribed, and } \\
\text { electronic } \\
\text { documents }\end{array}$ & $\begin{array}{l}\text { 1. Interviews with collaborating participants and steering committee } \\
\text { members in October } 2012 \text { to test theoretical propositions } \\
\text { 2. Value of HF participation in FMEA meetings } \\
\text { 3. Review of HF DFA tool and process after assembly launch } \\
\text { 4. Review of WEE tool modifications and next steps } \\
\text { 5. Next steps and reflections for HFS }\end{array}$ & $\begin{array}{l}\text { - Senior Directors (eg. } \\
\text { Engineering, Manufacturing, } \\
\text { Advanced Process Engineering } \\
\text { - } \quad \text { Managers (eg. HFS, } \\
\text { Manufacturing, Outsourcing) } \\
\text { - HFS }\end{array}$ \\
\hline $\begin{array}{l}\text { Steering } \\
\text { Committee } \\
\text { Meetings }\end{array}$ & 2 & $\begin{array}{l}\text { All recorded, } \\
\text { transcribed and } \\
\text { electronic } \\
\text { documents }\end{array}$ & $\begin{array}{l}\text { 1. Update on progress of initiatives in collaboration, next steps, } \\
\text { assistance needed }\end{array}$ & $\begin{array}{l}\text { Senior Directors, Directors, } \\
\text { Managers, HFS }\end{array}$ \\
\hline Focus Group & 8 & $\begin{array}{l}\text { All recorded, } \\
\text { transcribed and } \\
\text { electronic } \\
\text { documents }\end{array}$ & $\begin{array}{l}\text { 1. Demonstration of WEE tool to directors and outsourcing and } \\
\text { discussion of how best to integrate } \\
\text { 2. Design for fixture focus group for external vendors } \\
\text { 3. Focus group to compare scores and provide revisions to HF DFA tool } \\
\text { 4. Focus group to validate findings from collaboration and DFHF theory }\end{array}$ & $\begin{array}{ll}\text { Directors (eg. Engineering } \\
\text { Development) } \\
\text { - Managers (eg. HFS, Product } \\
\text { Focused Engineering, Test } \\
\text { Hardware) } \\
\text { - Engineers (Mechanical Fixture } \\
\text { Designer, New Product } \\
\text { Manufacturing) }\end{array}$ \\
\hline Observations & 1 & $\begin{array}{l}\text { Paper, } \\
\text { converted to } \\
\text { electronic }\end{array}$ & 1. Review of HF issues corrected on new assembly line & $\begin{array}{l}\text { - HFS } \\
\text { - Floor supervisors, workers }\end{array}$ \\
\hline $\begin{array}{l}\text { Researcher } \\
\text { Notes with each } \\
\text { entry }\end{array}$ & 42 & All electronic & $\begin{array}{l}\text { 1. Reflections from participation and memos regarding strength of } \\
\text { propositions. Written from field notes on same day or the day } \\
\text { following }\end{array}$ & \\
\hline
\end{tabular}


In an interview with another engineer, the response to the open ended question of facilitators was that the development of HF-DFA targets was the reason behind increased HF integration in the past year. To probe deeper and "test" relationships in the tentative theory, the following question was asked:

"Why did the HF-DFA appeal to you?"

Engineers' Response:

"It's engineering-like - like scorecards, like criteria "

This response further reinforced the need for HF tools and targets to be similar to engineering tools, and that when they are, they become integrated more readily.

In an interview with the HFS, the question was posed:

"how have you had to adapt as an ergonomist in this environment?"

HFS response:

"I made the mistake of saying we have a process in place now and it's just going to flow - and it didn't - so what l've learned is a process can break down and I can't let it be - I need to be more involved and more directly involved with engineering day to day - and accountability"

This reinforced that the design for fixture guidelines and process broke down without accountability for the guidelines from engineering management. In another question speaking of participating in a root cause analysis and working with engineers to balance a new line, the question posed to the HFS was:

"did you feel you needed to adapt your skills?"

HFS response:

"Yes - I had to learn root cause analysis - it was new - and the language too - we can talk abductor all we want but they need to know how it applies to their engineering world - it slows down cycle time because the screws are over here becoming more intertwined with their day-to-day operation" 
This point reinforced a number of concepts in the tentative theory. The HFS felt they needed to learn the engineering tools and language, then they had to integrate HF into the "engineering world" and use terminology such as cycle time to integrate the HF concepts.

As another example, in a meeting with a Senior Director of Engineering, he made the statement: "I was skeptical (about HF), but now l'm a convert". This statement was noted in a memo after the meeting with a reminder to follow up and question the Director further about this. To expand understanding, at a later date I asked about this further. The response was:

"just seeing it enough - the scorecard probably brought me around the most - you can quantify it, can score it, can monetize it"

These statements reinforced that the Senior Director of Engineering was not supported and committed to HF in the first phases of the collaboration, as he mentioned, he was skeptical. He became more interested when he saw the link between HF and their process capability goals. His statements also reinforced the need for HF to be quantifiable. Even though "cost" was rarely discussed as a barrier to HF, the notion of engineering-like means if you can measure something, you can monetize it.

The theoretical sampling in the 42 actions/interactions following development of the tentative theory helped refine and deepen understanding about these relationships. Several of the propositions were strengthened or reinforced, while others were found to be less important than originally thought. The proposition that HF integration can be improved if either the HFS reports to engineering management, or if the HFS Manager is connected within engineering was eliminated from the final theory. There were examples where the proposition was supported, but it was not necessary on all occasions. There were no new or different constructs at this point, so saturation of the constructs was deduced. The next iteration of the theory resulted in simplifying and renaming some of the constructs and focusing on only the most important such that the theory would be clean and straight-forward. 


\section{Validation of Final Theory}

The revised theory was re-drawn (see Chapter 7 for final theory), and nine presentations were provided to various groups who could comment on various aspects of validity, including:

- Ergonomics department within the collaborating organization (1)

- Engineering department and Senior Director within the collaborating organization (1)

- Academic researchers and peers from Canada and Europe (7)

Presentations were provided to participants within the collaboration for validation that the relationships in the final theory represented the actions and relationships that occurred in the collaboration, that they made sense with respect to the way HF was integrated, and that they explained what occurred during the three years. Participants were specifically asked to verify each aspect of the theory as it was presented and to provide comments and questions.

Following the presentation of the theory to the engineering group, I asked whether this captures what they believe has happened, the response from one senior director stated:

"I think it does - when I first started - we were trying to figure out how to get involved, and now we are involved - we have metrics now - we've certainly made progress - l'm really impressed actually with the stat you have on the Ergonomists' work (increase in proactive HF over 3 years)"

To this, the HFS in the room replied:

"I remember when the project started, I would walk by a meeting room and say "I should be in there"...

(participants laugh and someone says "and we'd turn out the lights and close the door"...another laugh)

(HFS continues)..."and now I find myself sitting in these meetings"

I also ask whether the theory makes sense. The Senior Director stated:

"it makes sense to me"

Another engineer stated:

"there's bits I recognize - there's stories behind every arrow" 
Presentations to academic peers were made with the intent of validating that the concepts and relationships resonate with their experience and knowledge of the scientific literature. They also provided a check on the clarity of the concepts and on whether the development of the concepts and relationships can be verified and explained by the data collected. For this reason, academic and peer informants were chosen who had not been involved with the collaboration, but were experts in macro ergonomics, participatory ergonomics, ergonomics in design, and engineering design.

\subsection{Discussion: How can qualitative data in an ergonomics action research approach be analyzed using a grounded theory methodology?}

This chapter, instead of presenting findings, demonstrates how qualitative data from a variety of sources in an action research collaboration can be analysed using Strauss and Corbin's (1990) grounded research methodology. The methodology uses a constant comparison method of contrasting the data and a series of three separate coding stages. Each coding stage causes the researcher to review the data in new combinations and abstract the data to a level above specific occurrences to conceptual constructs. The constructs are enriched through the process of returning to the data to look for properties and their dimensions. The process nature of the coding whereby relationships between categories are explored helps position concepts as contributing to, or leading to other concepts. A focus on the "core" category which describes how the action in the phenomenon is thought to occur helps with positioning other aspects of the data as contributory, contextual or intervening. The action-oriented questions posed of the data help explain how the phenomenon occurs. The final constructs in the theory looked very different from original simple codes or even the grouping of categories or themes since the process of developing and testing tentative propositions with further theoretical sampling leads to further refinement and abstraction. 


\subsection{Conclusions}

The grounded theory methodology was a useful technique for analyzing a large amount of qualitative data collected over a three year period in this ergonomics action research collaboration. Data was reduced from 222 coded entries from transcripts and research notes, to 115 codes and further to 12 categories combining the codes. Categories were explored with regrouped data to investigate properties and dimensions of each. Axial coding led to arranging the categories and properties into an action paradigm with causal conditions, context, intervening conditions and action/interaction strategies leading to the phenomenon of HF integration. A comparative matrix of 65 properties was developed to contrast the 10 initiatives in the collaboration and further develop and refine concepts leading to the HF integration. The core category was developed and refined using the comparative matrix and referring back to the data, to explain "how" HF came to be integrated into design processes. Tentative propositions were proposed and further tested by theoretical sampling, where 42 new data entries were collected, and targeted questions were posed to interviewees to confirm or disconfirm relationships in the tentative theory. Theoretical saturation was reached when no further concepts were found in the data. The theory was validated through nine presentations within the organization participants and experienced researchers in the field. The final grounded theory is presented in Chapter 7. 


\section{Chapter 7}

\section{Design-for-Human Factors (DFHF): A Grounded Theory for Integrating HF into Production Design Processes}

\subsection{Introduction and Purpose of Chapter}

The purpose of this chapter is to present the final grounded theory explaining how HF was integrated into design processes in the collaborating organization. The data analysis using the grounded theory methodology is explained fully in Chapter 6. In this chapter, the "Design for Human Factors Grounded Theory" is illustrated in a process flow diagram (Figure 17), the structure of which will first be described in Section 7.1. The main theory proposition and six contributing individual propositions are presented in Section 7.2. Section 7.3 will summarize examples of evidence in support of each of the propositions of the theory and show how each construct was necessary for integration of HF into production design processes in the case collaboration. Further empirical evidence for the constructs and relationships (propositions) are provided as examples in Appendix I. A comparison of data (participant quotes and researcher notes) from different stages of the $\mathrm{HF}$ integration, as well as between different initiatives in the collaboration will be used to describe the constructs and propositions. The final Section, 7.4, discusses the theory with respect to the scientific literature.

\subsection{Description of Process Structure of Theory}

The visual representation of the theory, shown in Figure 17 below, is based on a process drawing with arrows that indicate one construct "leading to" another, or in "parallel operation" in the case of the parallel lines joining constructs. This representation reinforces that integrating $\mathrm{HF}$ into production design processes is a process itself. The shape of each construct, as shown in the keys at the bottom of the figure, was chosen to indicate the type of process. There are three numbered stages, indicated by vertical 
separations and labels at the top of each stage. While the stages and arrows indicate how the process can proceed, it is not necessarily sequential. However, the data supporting the theory suggest that each construct and relationship was necessary. The boundaries of this theory stop at the point where there are indications that HF is embedded into the engineering design process (3b). Therefore, the proposed outcomes in the oval with the dotted line in stage 4 (i.e. improved worker health and business performance) were not formally "tested" in this case collaboration. The scientific literature, reviewed in Chapter 1, provides evidence of improved worker health and business performance outcomes when HF is part of design and business improvement programs. This theory, however, is intended to describe the development process, rather than test the outcomes.

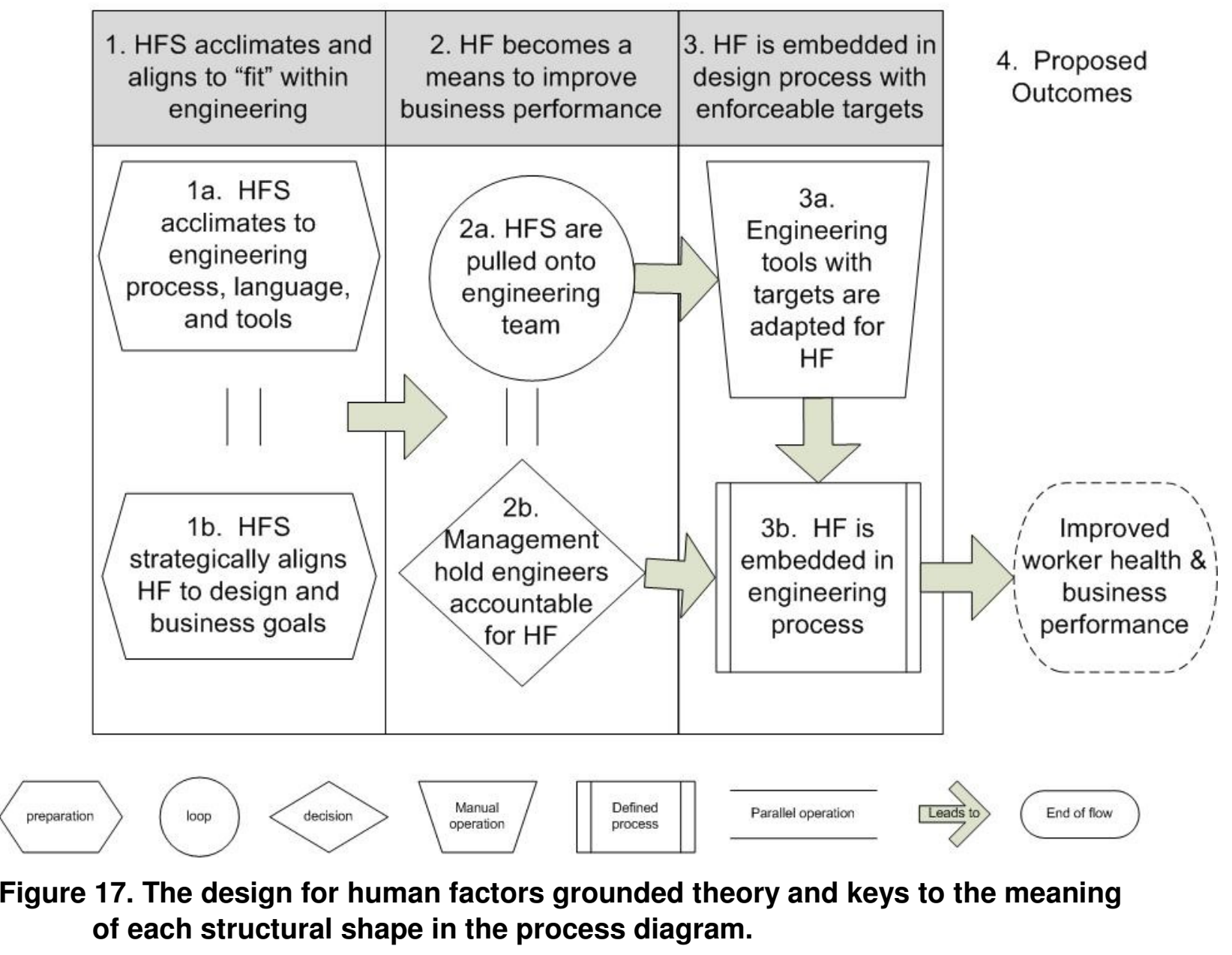




\subsection{Summary of Design for HF Grounded Theory}

The summary proposition and individual contributing propositions in the design for HF theory are as follows.

\section{Summary Proposition:}

When HFS are acclimated and aligned to "fit" within engineering, HFS are pulled onto the engineering team and Senior Management hold engineers accountable for meeting HF targets (in adapted tools) since HF is perceived as a means to improve business performance. This leads to HF becoming embedded in the production design process.

Contributing individual propositions are that:

P1. When human factors specialists (HFS) acclimate to the engineering process, language and tools, and strategically align HF to the design and business goals of the organization, then engineers and managers recognize HF as a means to improve business performance.

P2. When HF is recognized as a means to improve business performance, HFS are "pulled" onto the engineering team.

P3. When HFS are on the engineering team, this leads to more requests for HF from engineers and increased awareness of HF on the part of engineers.

P4. When HF is recognized as a means to improve business performance, senior management want to monitor HF as a key performance indicator and hold engineers responsible for meeting HF targets.

P5. When HFS are acclimated and aligned to "fit" within engineering and they are pulled onto the engineering team, then engineering tools are adapted to include HF targets.

P6. When management want to hold engineers accountable for HF, and there are HF-adapted tools with targets, then HF will become embedded in the engineering design process.

This theory assumes that in so doing, HF will contribute to improved operator health and business performance. 


\subsection{Evidence for Theory}

Evidence for each construct of the DFHF theory shown in Figure 17 will be presented in sections below and further empirical evidence is provided in Appendix I.

\section{HFS Acclimates and Aligns to "Fit" within Engineering}

The two constructs within this first stage represent the "core" of the theory. It describes the actions that were necessary for the phenomenon of HF integration in design processes to occur. The theory suggests both 1a. "HFS acclimates to engineering process, language and tools", and 1b. "HFS strategically aligns HF to design and business goals" describe how the HFS changed focus to "fit" within engineering. These changes were necessary for other constructs in the theory.

\section{1a. Human Factors Specialist Acclimates to Engineering Process, Language and Tools}

The key properties that describe this construct include the HFS gaining an understanding of the engineering design process, including ways of working (such as having plans with steps and deliverables), learning the engineering language, and becoming familiar with tools used by engineers. HF also had to be visible, able to demonstrate change, and able to communicate this in engineering terms - to "fit" within engineering. Our data suggest that when the HFS were not acclimated, they had limited success in working with engineers, and being supported by senior management. By contrast, as the examples below will illustrate, as acclimation increased, there was increasing interest in HF from engineers and management, access to engineering processes, inclusion in design decisions, and recognition of the value of HF.

At the beginning of the collaboration, the HFS reported to an Occupational Health and Safety (OH\&S) Manager, in another physical building, and most of their work was reactively assessing workstation problems in response to an incident/injury report being filed by a worker to OH\&S. While one of the HFS' goals was to integrate HF into production design, they had few connections with the engineering department and had 
experienced little success. Ergonomic guidelines had been developed prior to the collaboration, but few engineers were aware of these and they were not being used. The HFS stated at this time:

“they (engineers) are capturing issues - I don't see what they are - I don't have access to them - it may be that some involve a HF component but we (HF specialists) never know about it"

"I've been at (the company) 4 years and it feels like l'm only starting to get my foot in the door (with engineering)".

In attempts to get "in the door", the HF Specialist, after considerable difficulty getting an email distribution list, sent an email to all the product focused engineers responsible for new assembly designs stating that they (HF Specialists) wanted to be more integrated in the design process and wanted ideas about how to do this. Among dozens of engineers, only one responded to the email. In another effort to get "in the door", a Director of Advanced Manufacturing offered access to the project list in his department and stated that the HFS was welcome to get involved with any that pertained. However, this did not result in any action. The HFS had difficulty understanding what the projects were, what the HF role might be, and how to go about getting involved. Likewise, the Director didn't know what opportunities to expect from HF.

Researcher notes from observations during early meetings with HFS and engineers discussed this need for acclimation to engineering:

"Working with engineers on a design problem requires a lot of technical knowledge about the process, tools, parts, materials etc. It's not enough to describe an awkward posture using a tool - one needs to understand with some detail what the tool is accomplishing, how it is designed, tolerances, why a tool and not a hand (too much force, too little precision, chance of scratching), how the alignment of the part matches the tool - how the material pick-up integrates with the tool - this deeper understanding is necessary to participate in improving the design - this means spending time and being part of these discussions otherwise the HF observations and recommendations become very shallow and irrelevant (eg raise height of workstation) - for HF to be seen by engineers as a 
legitimate help - it has to provide a new perspective on their problems". (Researcher notes)

The HFS needed to spend sufficient time intimately involved with engineers to understand what their tasks and goals were, what HF aspects were connected to this, and how HF could be positioned to help. Similar to some companies putting new engineering staff on the shop floor to perform each job and become acclimated to the production line, the acclimation process for HFS involved spending sufficient time to understand the design process, the people involved, the timelines, the engineering goals, and how HF could contribute.

The more the HFS learned about the engineering process, the more apparent it became that they needed to frame HF in engineering terms. For example, rather than talking about sustained pinch grips when inserting a part (risk factor and injury terminology), HFS discussed how difficulty assembling a part affected cycle time (engineering terminology). Using terms such as "value-added" and "non-value added" led to immediate interest if HFS could demonstrate how reducing a reach could reduce nonvalue added time (even though it reduces load on the worker too). The following quote from the researcher is taken from a meeting with engineers and HFS:

"the kinds of suggestions we made at X (assembly optimization stage), although based on cycle time, were HF issues - we're not calling it HF, but we're making HF changes to get you where you want to get in your operations - we're not doing it with HF measures, we're doing it with operations measures - without thinking about it, we're doing both together"

The acclimation process for HFS also involved learning typical engineering tools, such as failure modes effects analysis (FMEAs), root cause analysis, hoishin, gemba walks, kaizen, etc. Half way through the collaboration, the HFS opted for six days of intense training in engineering tools related to Six Sigma such as value stream mapping. As the HFS began to participate in these meetings and activities and use these engineering tools, they not only became more familiar with the language and tools, but also began to see how HF could "fit" and contribute to the engineering goals. Instead of a focus on 
reducing risk of injury, engineering goals focused on minimizing imbalances, disturbances, non-value added tasks, and wastes. HFS needed to think about how HF could help with minimizing variation, minimizing fatigue, reducing quality problems, enhancing workers ability to detect quality problems, reducing errors, and designing such that operators can consistently assemble in a way to give good quality. These all had HF implications, but required the HFS to change their focus, and it wasn't easy as the following quote from a HFS illustrates:

"it's just so different (looking at a task from the point of view of assembly rather than risk factors) - I'm finding this process really challenging" (HFS)

The HFS also needed to be visible and actively participating on the shop floor to "fit" within engineering. When participating in discussions with engineers, or in Kaizen activities with operators, or in Gemba walks with senior managers, HF was recognized by engineers as a positive influence on design goals. Part way through the collaboration, the HFS physically moved to the engineering floor with closer access to the shop floor. This increased access to discussions, documents, data, and meetings with engineers. Towards the end of the collaboration, the HFS stated:

"I say it took me over a year to learn what engineers were doing, who's who, the language, who reports to who, how does quality fit in, what is a kaizen - this all has to be absorbed to know where you're effective"

\section{1b. HFS Strategically Aligns HF to Design and Business Goals}

In conjunction with acclimating to engineering, the theory proposes that HFS needed to align HF with design and business goals in the organization. In both general and very specific ways, the HFS were told that HF needs to directly address operational goals, and that it has to fit with high priority initiatives. There were numerous quotes to choose from at different times in the collaboration and from different Senior managers and Directors that illustrated this:

"we would like to cooperate but it has to be aligned with the priorities we have and our business objectives" 
"Good HF would be measured by the product being manufacturable - process capability measures (CPK measures - tracking defects)

The cognitive mapping initiative (described in chapter 4) was critical for helping the HFS understand the perceptions of senior management with respect to how HF was connected to the strategic goals in the organization. This initiative made explicit that improved product quality was the main strategic goal for the organization. Management perceived that reducing worker fatigue and improving their consistency of performance, through optimal systems design of the assembly, was directly related to improving product quality and reducing quality losses (in other words, improving business performance). This was illustrated in the following quote from a manager:

"If you could develop a model that can reduce fatigue and increase repeatability this will have a direct impact on quality and productivity"

When HF initiatives "fit" with high priority initiatives, such as the new focus on the Toyota Production System and continuous improvement, they were more readily adopted. For example, the HFS suggested that the ergonomics change team (workers and supervisors with some training in ergonomics of workstation and assembly set-up) conduct a Hoishin to look for work improvements. This was readily supported by Senior Directors as part of their new emphasis on business improvement programs. Training was done for the workers, and the HFS stated that the HF Hoishin became locked in and was spreading to other sites because it was part of the new strategic thinking and safety culture. This "alignment" with a current business program made HF an easy "fit" to help improve business performance.

There was evidence in the data that the strategic alignment of HF with engineering was facilitated when initiatives:

- were similar to, or "fit" with engineering tools and processes;

- had quantifiable thresholds or key performance indicators;

- were visible, specific and tangible;

- facilitate action and demonstrate change; 
- 'fit" expectations of engineers and were compatible with their workload;

- piggyback on other business process improvement programs;

- allow the HFS to respond quickly to engineers; and

- had a plan with steps, deliverables, and timelines

To illustrate with an example, one student during the collaboration was working to develop a workstation assessment tool that the organization could use to proactively design workstation layouts. There were several versions of the tool over the three years with changes being driven by the need for it to be more aligned with business goals (Greig et al, 2013). Initially, the tool tracked hand travel at a workstation. There was little involvement from engineers in this version because they didn't see how this "fit" with their tools and processes. The second version included shoulder loading to indicate fatigue, but as with the first did not contain quantifiable thresholds or metrics. Interest from engineers increased when reach zones and red/green color coding was added. This reinforces the notion of being visible, quantifiable and having thresholds. Interest from engineers further increased when the tool was re-named the "workstation efficiency evaluator", and it included measures in the time domain with the ability to predict cycle time and non-value added tasks from a workstation drawing. At this point the tool was seen as an aid to predict both load on the worker, but also cycle time and potential imbalances between workstations. The HF portion of the tool was now aligned to help achieve assembly design goals and improve business performance.

Another example illustrates the challenges for HFS in adapting and aligning to an engineering environment. In attempts to piggyback on an internal improvement to FMEAs, the HFS proposed an initiative to develop a HF-FMEA (see Village et al, 2012). At this point in time however, the organization was undergoing a turnover of managers and downsizing. The HFS were advised by engineers to develop a "charter" document for the HF-FMEA that outlined deliverables, timelines and ROI. Being from the $\mathrm{OH} \& \mathrm{~S}$ department, the HFS were unaware how to define HF outcomes in ROI terms, and seek engineering sponsorship for the initiative. They felt this need for a charter was an unnecessary road-block. However, the engineers were merely expressing that since many projects were being eliminated, if the HF-FMEA was not positioned as an engineering project with a sponsor and return on investment (ROI), then it would not 
survive as an engineering priority. Despite initial challenges to draft charters, from that point forward all HF initiatives were put into engineering charters to ensure they had sufficient support within engineering and the appropriate participants were involved.

Therefore, the first proposition of the theory states:

P1. When human factors specialists (HFS) acclimate to the engineering process, language and tools, and strategically align HF to the design and business goals of the organization, then engineers and managers recognize HF as a means to improve business performance.

\section{Human Factors becomes as a Means to Improve Business Performance}

As shown in the theory in Figure 17, when the HFS acclimated to engineering processes, language and tools, (1a) and aligned HF with strategic and business goals (1b), this led to two constructs that facilitated HF becoming a means to improve business performance and these occurred in parallel. The first is that the HFS became a member of and resource to the engineering team (2a), rather than a separate entity outside of engineering. The second is that Senior Managers wanted to hold their engineers responsible for $\mathrm{HF}(2 \mathrm{~b})$ because it was a means to improve business performance.

\section{2a. HFS are pulled onto the Engineering Team}

An ongoing theme in the collaboration was whether HFS were trying to "push" HF into engineering versus being "pulled" in by engineers. We recognized tendencies both by engineers and by HFS to want to separate engineering issues from HF issues during the collaboration. For example, during the FMEA meetings, the HFS was performing separate HF analyses and scoring based on strain to the operator (rather than risk of quality defects), but was participating with engineers during the meetings to identify problems and solutions. At one such meeting, when the HF discussion of a task seemed to be slowing progress, the FMEA lead suggested that in future meetings the "HF issues" be reported in the last fifteen minutes of every meeting, rather than as each arose during the meeting. We recognized that this would create a silo effect and make the HF issues separate from engineering, and perhaps even perceived as a problem rather than having 
$\mathrm{HF}$ become part of the solution. We therefore requested that $\mathrm{HF}$ be considered alongside engineering concerns with discussing each potential quality problem in ongoing meetings.

Interestingly, the merging of HF and engineering issues and solutions also posed questions when trying to document HF successes. When the HFS was part of the discussion of solutions for parts or fixture design, it was difficult to separate out the HF influence. One of my researcher notes questioned whether HF solutions need to be separate from engineering ones? As the collaboration progressed, it became clear that no one was asking for HF-specific outcomes or solutions and that it was best if HF became a resource to engineering and another tool they could use to improve assembly design, rather than trying to tease out its own unique HF contribution.

Another example illustrates the effectiveness of a "pull" for HF versus a "push". As previously mentioned, the HFS had developed ergonomic guidelines for workstation design prior to the collaboration and given these to industrial engineers. However, they were not being used. Years later in the collaboration, when HFS and engineers were working together on a common goal of improving the camera insertion step of a new assembly, engineers realized that layout of materials on the work surface was affecting ease of camera insertion. A Director, realizing they lacked a proactive process for optimal workstation design, quickly tasked the industrial engineer with documenting a process. The industrial engineer, in turn, requested a checklist from the HFS department - the same one that the HFS had been unable to "push" in previous years. This illustrates that when engineers recognized HF would help improve business performance, the HF information was quickly "pulled".

The data suggest that once the HFS is on the engineering team and seen as a resource to help improve assembly design, this becomes a positive reinforcing loop whereby increasing teamwork leads to more and more requests for HF information, an increased network in engineering, and increased opportunities for HFS participation in design processes. Being on the team helped the HFS become aware of new products and processes earlier, thereby also improving the effectiveness of the HF initiatives. The 
construct of the HFS being pulled onto the engineering team reinforces the acclimation of HFS in the first stage of the theory. Working together helped the HFS learn how engineers work, their time demands for HF solutions, and the best way to provide appropriate answers to questions. In later stages of the collaboration, the HFS for example stopped writing lengthy reports (common when reporting to $\mathrm{OH} \& \mathrm{~S}$ ), and started providing "issue recommendations and sign-off" within engineering tracking documents. At the beginning of the collaboration, when the HFS was separate from engineering, they did not know about or have access to these tracking documents.

Engineers also became acclimated to HF when working together as a team, and saw the benefits, as reflected in this statement by an engineer:

“this highlights to me something that I hadn't been aware of (thumb pressure) so it's great - we sort of look at the line but this helps us see things precisely-put numbers to it - doesn't matter what they are and makes engineers see things differently"

Getting on the team, making the work visible, and reporting in a timely and appropriate manner all led to increased requests for assistance from engineers. Both the HFS and various engineers made statements about the team approach:

HFS: "trying to mix with those guys in a team environment - the whole integration is about the team - we're identifying the HF component - but it's an engineering process - and we're there as part of the team"

Engineer: "I think he's become more of an engineering resource - he used to be more for ergo and line set-up and dealing more with like capital - chairs, table heights, should we use footstools - but now he's more in with engineers helping us design this - help us modify this, and part of fixture design process where he should be"

We questioned the positioning of constructs in Figure 17, specifically whether the HFS needs to acclimate to engineering and align HF to business goals (stage 1) before being pulled on the team with engineers (stage 2), or whether being on the team could come 
first and lead to acclimation and alignment with engineering. There were situations where teamwork occurred first. For example a new product focused engineer joined the company and based on previous experience with HF, requested an assessment for a particular issue. The HFS recommendations did lead to further teamwork, as the engineer then requested the HFS look at the whole line and provide feedback. There were also infrequent examples prior to the collaboration where engineers had requested input from the HFS. However, these one-off evaluations did not become locked into ongoing processes for HF to be integrated into assembly design. When the HFS had acclimated and aligned HF to fit in engineering prior to being pulled on the engineering team, the HF initiatives, as will be shown below, were more likely to be locked into the design process in this case.

Therefore, the second and third propositions state:

P2. When HF is recognized as a means to improve business performance, HFS are "pulled" onto the engineering team.

P3. When HFS are on the engineering team, this leads to more requests for HF from engineers and increased awareness of HF on the part of engineers.

\section{2b. Management hold Engineers Accountable for HF}

A large portion of our data referred to aspects of management support, which in our final analysis was shown to be insufficient for integration of HF into design processes. This section shows that HF integration into design required management to hold engineers accountable for HF. This managerial accountability for HF only occurred, as suggested by the theory in Figure 17, when the HFS were acclimated to engineering and aligned with design and business goals. This section will provide examples where there was lack of accountability and therefore HF integration, and where accountability led to integration.

In one initiative to proactively integrate HF into design processes, engineers were upgrading design for fixture (DFF) guidelines and requested inclusion of HF-specific DFF guidelines. The engineer responsible developed a process chart, included the HF 
guidelines, and included a sign-off on the guidelines by the HFS for any new fixture designed or procured. Despite the teamwork, the guidelines, and the process, for the next year these were all ignored by engineers. The HFS assumed HF was embedded in the process, but the process collapsed because it lacked accountability from senior managers.

By contrast, another initiative between HFS and engineers involved development of a HF design for assembly (DFA) tool (described in Chapter 4). The tool arose when HFS were working on the team with engineers and together realized the overlap between ease of assembly, HF, and assembly quality. When data was collected using the new HF DFA tool on an early assembly build and shown to senior management and the engineering team, the scores confirmed tasks both engineers and workers thought were problematic. HF was now tangible, measurable, could demonstrate change and was aligned with engineering goals of improving assembly quality. As a result, senior Management perceived HF could be a means to help achieve business goals, and they readily made the HF targets one of their key performance indicators (along with defect rate, cost and yield). Management then monitored HF DFA scores and held their engineers accountable for meeting HF targets in each subsequent product build. When the Senior Director was asked where in the process this might "fit", the response was:

"hand it off to mechanical engineers in the program, make it part of the build - a deliverable, it's measurable and I can measure - (we) need objective ways of evaluating and knowing where to focus"

Therefore, in our collaboration there was "some" support "in principle" from senior management in early and mid-stages (by developing a steering committee and attending meetings), but this did not truly result in HF initiatives being adopted or sustainable in processes. When the HFS could demonstrate the value of HF as a means of achieving business goals, using tools with HF targets, this led to HF becoming a requirement that senior management in turn held engineers responsible for. This shift from support "in principle" to support "in practice" caused a tipping point - a shift in attitude by senior 
management and a more refined definition of accountability as being necessary for HF to become embedded in their engineering processes.

Therefore, the fourth proposition of the theory states:

P4. When HF is recognized as a means to improve business performance, senior management want to monitor HF as a key performance indicator and hold engineers responsible for meeting HF targets.

\section{HF is Embedded in Design Process with Enforceable Targets}

The third stage of the theory proposes that in order for HF to be integrated into design processes, there needs to be a measureable way to communicate HF issues and demonstrate improvement towards business goals. The theory shows that when HFS are aligned to help improve business goals (1b in Figure 17), and senior managers perceive HF will improve business goals (2b), then the bridge that locks HF into the design process is the adaptation of engineering tools that include enforceable HF targets (3a).

\section{3a. Engineering Tools with Targets are Adapted for HF}

This section will show the importance of working together on the engineering team to adapt industrial engineering tools to include enforceable HF targets. We have several examples where lack of a tool hindered progress towards HF integration in design. We also have several examples where working with engineers to adapt a tool for HF came first, followed by being locked into the design process.

The following researcher notes from early in the collaboration describe the struggle to figure out how to proceed in the absence of a HF tool. The HFS had helped identify issues related to HF, but were not sure how this could lead to involvement in the next assembly design cycle:

“We can't just indicate problems - we need tools for sustainable processes.

They see value in our task break down and value added classifications - will 
this help with solutions on the line? Will it help change their processes down the road with other products? We still need to embed HF into analysis - we've provided some indications of problems and how that ties into cycle time and balancing - a key of combining IE and HF - but should the HF be more explicit - how will this work going forward?" (Researcher notes)

In another example prior to the HFS being pulled on the engineering team, when the design for fixture process was established (discussed in section $2 b$ ), the engineer asked the HFS "how would you "qualify" a fixture, now that you have sign-off?" My researcher notes indicated that the HFS did not know how to respond. This suggests that getting HF established in a process requires a tool. Simply adding a HF check in the process (i.e. the HFS assesses and signs off), or collecting HF concerns, doesn't specify what needs to be evaluated, how, what is reported, who gets the information, and where those lessons go. But if a tool has specific features (as described in chapter 4), than it will be ongoing, answer appropriate questions, lead to permanent documentation and lessons learned, and to benchmarking and best practices - all these are consistent with engineering-like approaches. One engineer stated that the engineering process is to develop a tool, use the tool, show results, then talk about the process (who owns it, does it, when and where). Likewise, a HF tool was needed in order to show results and talk about the process.

In this third example, a new line was being ramped up in an outsourcing location and productivity was not as high as expected. The HFS were asked whether they could look at videotape from the line and see from a HF perspective whether there were any obvious concerns that may be affecting fatigue and/or productivity. The following researcher note indicates we puzzled over this:

** "we don't have tools for this or a way to communicate this - a lack in HF literature"

Without a tool in this case, we were unable to provide much HF information that would help solve their productivity problem at outsourcing. 
We identified during this collaboration, a lack of appropriate proactive HF tools adaptable to this hand-arm intensive assembly environment where the focus is not upper limb injuries, but assembly quality and operator consistency. The adapted tools had to focus on assembly design goals and be quick, visible, and quantifiable. One engineer stated:

(we) "need to make sure the methodology is quick enough and nimble enough to not overload people when doing new product realization"

Another engineer stated the need for something visual and engineering-like

"As designers we want a quick reference - quick schematic - ideas are floating around in our head as we design"

A good tool can then lead to targets. A senior director stated:

(we) "like dashboards, with red/yellow/green - Directors get 12

presentations/hour - you've got 5 minutes, so you want data to jump out"

By the end of the collaboration, the HFS, together with engineers, adapted five industrial engineering tools to include HF and these were integrated into different stages of the assembly design process (see chapter 4). The tools provided quantifiable metrics aligned with the business and assembly goals. An example quote from an engineer on review of a demonstration of one such tool (HF-DFA tool) exemplifies this:

"HF that accommodates KPls (key performance indicators, or targets) fits well with DFA - along with cost, scrap etc -this fits in perfectly"

One senior director also remarked on the value of the HF DFA in helping improve the assembly design:

"we're having discussions much earlier because we have data to look at - it will force action if the score is high -we spent longer than we should have because we couldn't have a quantifiable discussion" (about problems with a part).

Therefore, the fifth proposition in the theory states: 
P5. When HFS are acclimated and aligned to "fit" within engineering and they are pulled onto the engineering team, then engineering tools are adapted to include HF targets.

\section{3b. HF is Embedded in Engineering Process}

The final piece of the theory suggests that when senior management hold engineers responsible for $\mathrm{HF}$ by using a $\mathrm{HF}$ tool aligned to help engineers meet business goals, then $\mathrm{HF}$ will become embedded in the engineering process ( $3 \mathrm{~b}$ in Figure 17). Note that chapter 3 (section 3.3) outlines the indications that HF was embedded in the design process at completion of the collaboration and Appendix B provides further empirical evidence. From documentation and observation of subsequent assembly design cycles, the HFS participated with engineers in all assessments and solution development for the new product lines. Changes were documented to parts, processes, materials and fixtures arising from the inclusion of $\mathrm{HF}$ in these early design stages.

Most importantly, there was evidence towards the end of the collaboration of a change in awareness and application of HF early in design processes for others involved including engineers and management. The Senior Director of Engineering involved at the third stage of the collaboration stated that he was "skeptical" of the value of HF at first and did not participate directly for the first two years. However, he later became a "convert". He stated:

"I'm a convert - I thought (the HFS) is a tables and chairs guy. I didn't understand how it (HF) impacted our process -engineers think you're as capable in inspection of a screw at minute 1 as at minute 360 - and it's not true - one of the things l'm missing in my analysis of the system is the variability of the human element things we don't know - I'm a road to Damascus convert - it's like night and day now for me now"

This quote strongly supports the core tenet of our theory - that the HFS needed to acclimate to engineering and align HF with design and business goals. These actions were pivotal for gaining access to the engineering team and being perceived by senior 
managers as a means to improve business performance. The other necessity was the adaptation of industrial engineering tools to include HF in such a way that they can be enforceable targets.

We question whether HF can be embedded in engineering processes without all the other constructs discussed in the theory. Interestingly, at the beginning of the collaboration, we have an example that addresses this question. The Ergonomics Manager tasked the HFS in manufacturing to develop and document a process diagram showing where they wanted HF to fit within engineering design. HFS in other areas of the organization (such as office and workstation design) were asked to do the same. The HFS was unsure how to go about this task and questioned: who would need to be involved?; what would the HF integration look like?; how could engineers be convinced to incorporate HF? It was seemingly impossible for the HFS to determine how HF could be embedded in a design process that they did not yet understand themselves. This work item was not completed at this point in time because it couldn't happen by HFS "pushing" themselves into an engineering process. The HFS were not acclimated and aligned to fit within engineering, they were not on the engineering team, and they lacked appropriate HF tools with targets for locking HF into design processes. They needed each of the constructs of the theory in order to be "pulled" into the design process.

Therefore, the sixth proposition of the theory states:

P6. When management want to hold engineers accountable for HF, and there are HF-adapted tools with targets, then HF will become embedded in the engineering design process.

\subsection{Conclusions}

The Design for Human Factors Theory is based on the developmental process of how HF came to be proactively integrated into assembly design processes in a large electronics manufacturing operation. It has been grounded with three years of data and participation of 70 engineers and five HFS in a longitudinal action research collaboration. Such "embeddedness" in an organization's design process and culture is similar to 
Wilson's (2012) statement that all good HF should take place "in the wild" since HF must be understood in a setting or context, which is increasingly that of complex sociotechnical systems.

We found the grounded theory approach useful, both as an organized set of principles and methodology, and also an organic process of theory emergence (Stillman, 2006; Suddaby, 2006). Stillman (2006) suggest that using a grounded theory methodology, within an action research approach is rooted in the systems perspective, with the theoretical power and potential for systemic change. Grounded theory is increasingly being used in operations management and business research (Bindu and Edwards, 2008; Christiansen, 2011; Randall and Mello, 2011). However, despite calls for more qualitative methodology in HF research and practice (Hignett and Wilson, 2004), its use is rare. Only one study was found using grounded theory to examine the implementation of reactive ergonomics programs in thirteen automotive manufacturing plants in the US (Choi and Liker, 1992). Their empirically-based process model was useful for understanding how ergonomics programs became institutionalized at various levels of the organization by external pressures. However, it did not have similarities to help inform the question of how to integrate HF into proactive design processes.

"Design for HF" deserves its place alongside other $x$-ability design processes since it explains a way to improve HF aspects of production design processes. It also fills a need in the literature for macro-ergonomic theories about the development process. It has the potential, with further development of tools, techniques and processes, and with extension to design of the product as well as the production process, to become a broad movement to improve business performance, similar to design for quality. However, it requires a shift in perspective for $\mathrm{HF}$ practitioners, and researchers alike. It also requires more research on tools, methods and metrics to optimize human performance, such as minimizing fatigue, improving consistency, improving recognition of quality problems, and enhancing flexible assembly capabilities. 


\section{Chapter 8}

\section{Discussion: What is Needed to Increase the Integration of HF into Production Systems Design Processes?}

\subsection{Introduction and Purpose of Chapter}

This chapter refers back to the main research question and discusses in Section 8.1 how the work performed during the three year collaboration and the data analyzed for this thesis answers the main research question. The main findings will be contrasted with findings of other researchers attempting to integrate $\mathrm{HF}$ into design processes. In section 8.2, the design for HF theory and its individual constructs will be compared with other theories, frameworks and models to illustrate its contribution. Section 8.3 discusses the implications arising from the research for HF specialists, organizations and academic education and research. Comments on the methodological approach and study limitations are discussed in section 8.4. The final sections (8.5 and 8.6) present suggestions for future research, conclusions and a summary of the recommendations.

\subsection{Answering the Research Question: How can Human Factors be Integrated into a Company's Production Design Process?}

The review of literature (Chapter 1) outlined the need for early HF integration in design of production assembly systems and that HF considerations can improve both worker well-being and business improvement outcomes, but in this latter respect it is underutilized. Chapter 1 outlined the lack of research on the developmental process of integrating HF into design to help organizations and practitioners know "how" practices and tools can be adapted to help. Finally, the lack of HF-related theory to stimulate further research, and provide guidance to practitioners was identified. 
This research has demonstrated, in a case study approach, how one large manufacturer was able to integrate $\mathrm{HF}$ into their production design processes over a three year period in ways that appear sustainable to their organization. The demonstration involved development or adaptation of several tools and techniques to include HF (Chapter 3 and 4), practical processes for adopting the tools into design stages (Chapter 4), and what HF specialists needed to do to facilitate HF integration (Chapter 7). It also provides a design for HF theory to contribute to the scientific literature and practice in HF (Chapter 7).

The core tenet of the theory, which Christiansen (2011) suggests should explain the main actions and most of the variation in the data, is that change occurred as a result of the HFS changing their focus from a predominately health and safety one, to align with design and strategic business goals in the organization. This involved learning the design process, engineering language and tools, as well as becoming more active and visible on the floor and in design activities and using the engineering project management systems (eg. reporting and project documentation). As part of changing their focus, HFS began to strategically align and discuss $\mathrm{HF}$ as a means to reduce operator fatigue, improve consistency of performance, reduce wasted motions and improve quality - rather than exclusively as a means to reduce injuries. With alignment, engineers and managers realized $\mathrm{HF}$ was a resource to help improve business goals and "pulled" HFS onto the engineering team. To be sustainable in the design process however, the HFS also needed tools that would provide quantitative targets and measures that could be used, like engineering tools, for communication, comparison, continuous improvement and benchmarking. Adapting engineering tools to include HF was effective because they are already focused on business goals, and are familiar to engineers. With HF targets focused on the business goals, senior managers held engineers responsible for the $\mathrm{HF}$ targets, locking $\mathrm{HF}$ into their design processes in a sustainable way. Rather than being a separate entity, HF is now a key resource to engineering design and involved in all new assembly design processes in the collaborating organization. 


\section{Determine the indicators of HF integration in the design process:}

The results in this thesis show indications in the collaborating organization that HF was increasingly integrated into design processes by the third year. These indicators were not identified prior to the collaboration, since it was up to the participating organization to determine what worked best for them. It was also not clear from other studies in the literature what "ideal" HF integration in design processes would look like. Much of the HF literature discusses HF requirements (Wulf et al., 1999), or sign-off as integration (Waterson and Kolose, 2010), and in some cases direct participation with designers (Seims and Broberg, 2012; Sorensen and Broberg, 2012). The indicators in this study included adaptation of industrial engineering tools with HF metrics and inclusion in several stages of the design process, requirements that engineers be accountable for the metrics, sign-off by the HFS, and training for engineers in compliance with the HF metrics. We found increased time spent by the HFS in proactive design activities compared with reactive HF assessments, and access and participation with increasing numbers of engineers over the study period. The HFS was being included on the engineering team when new business improvement initiatives and design activities were initiated and engineers increasingly requested HF assessments and identified HF concerns themselves as a result of working alongside one another. This study has not set out to "prove" HF was integrated into design processes, or specifically define what the gold standard for this would be. We also cannot assume to attribute the indicators of $\mathrm{HF}$ integration solely to the collaboration. It is quite likely indicators of HF integration would be defined differently in other organizations and in different design processes. Regardless, in answering the question of how HF can be integrated into production design processes, one must identify the end-point or goal. The detailing in this thesis of indicators of HF integration in design provides insight into some ways to monitor the integration process. These indicators may provide guidance to other HFS or organizations attempting to also demonstrate change and organizational learning about HF integration. 


\section{HF specialists need to acclimate to the engineering processes, language and tools:}

The acclimation process for HF specialists was found to be a difficult, but necessary step towards being accepted in an engineering environment. It involved considerable data gathering to learn the design process stages, the people involved, how decisions are made, and what metrics are being tracked. The HF Specialists were not organizationally linked to the engineering design department, making it difficult for them to negotiate the people and the processes. They were unaware of the rapid design cycle and the window for continuous improvement of processes, parts and tooling prior to product launch. Their HF assessments, which were limited to reducing injury concerns or returning an injured worker to work, were not communicated to engineering managers or directors. They also initially did not have access to the production and quality databases and communication tools used by engineers. With no previous training in design or business improvement programs, it took considerable time researching and learning the language and tools in order to be accepted in the environment. The learning was facilitated by working alongside engineers during the collaboration. Participating in design review meetings, and working together to solve problems with tooling or parts design familiarized the HFS with engineering language and tools. It also familiarized engineers with what the HFS could contribute.

Others have also found that the first phase of integration of HF into design cycles requires considerable data gathering and acclimation (Kirwan, 2000; Seims and Broberg, 2012). Seims and Broberg (2012) called this first phase in HF integration as "setting the stage" and it included not only data gathering and understanding actors, but also determining boundaries for HF. In attempting to integrate HF into the defense industry, Waterson and Kolose (2010) reported that HFS overcame the barrier of being seen as a "tick box" item by trying to adopt the mindset of the engineers, and modifying the way they express, share or translate HF data. This supports our findings that the HFS were getting more participation from engineers when they aligned HF with engineering language and goals (i.e. reduced defects or scratches from handling, versus less awkward posture and contact stress). Waterson and Kolose's (2010) findings, similar to ours, were that engineers didn't always know when and how best to make use of HF expertise. However, we also found that HF specialists also didn't know how best to 
provide their expertise in ways that helped engineering designers. Neumann et al (2009) also reported the difficulties experienced by HFS in the engineering environment, and in their case study the HFS unfortunately withdrew participation. Wilson (2012) reported that it took years of working within the railway system to find ways HF could best support design, engineering and maintenance of the system, and thus become embedded in the engineering group. The results in this thesis provide empirical evidence of the need for HFS acclimation, and also demonstrate many ways this can be achieved.

\section{HFS need to align HF with Strategic Business Goals of the Organization:}

We found the HF specialists in the collaborating organization to be unaware of the strategic goals of the organization and how HF could help achieve the goals. The HF group had its own goals within the OHS Department to optimize the health of workers. But most efforts were focused on office workers, not production workers and their goals did not align with direct production design goals of delivering a high quality product. Theberge and Neumann (2010) also reported that while OHS can open doors for HFS, it can also limit their practice. The application of HF in the design process could be a means of helping achieve the company's strategic goals, but only if it is actively positioned in such a way. The results of this thesis are unique in that they demonstrate what the HFS needed to do to facilitate alignment with strategic goals. In this work environment, they needed to find ways to continuously improve quality of the assembly build through optimizing worker performance and minimizing fatigue, and also to find ways for operators to better detect quality escapes and defects. The importance of linking HF to strategic goals has been identified in the scientific literature by Berlin (2011) in an interview study with four companies, by Zink et al. (2008) working in a 6000-person automotive plant, and by Munck Ulfsfalt et al (2003) in their successful Volvo ergonomics program. Eklund (1997) and Neumann and Dul (2010) also suggested the field of HF would benefit from a clearer link with leadership and company strategies. In a recent position paper for the International Ergonomics Association, Dul et al (2012) point out that HF specialists have a great potential to contribute to the design of systems, but to contribute they must demonstrate their value, especially with respect to performance to the main stakeholders. The results here show how this can be accomplished. 


\section{Adaptation of Process Mapping and Cognitive Mapping Tools can Facilitate Acclimation and Alignment within Engineering Design:}

The collaboration has resulted in the novel adaptation of two operations research tools to include HF. Lim et al (2013, in press) adapted process mapping as a technique to map the design process and indicate potential opportunities for HF integration in the process. The interactive mapping which involved interviews with key engineers in the design process facilitated understanding of the process for the HFS. Village et al (2013, and 2013 in press) as outlined in Chapter 4, adapted the cognitive mapping tool as a means to determine the perception senior directors have of $\mathrm{HF}$, and how they link $\mathrm{HF}$ to the strategic goals in their organization. This tool resulted in increased understanding of the directors' perceptions of HF. When directors participated in a focus group with the shared map, they also learned from one another the differing opinions about the links between HF and corporate strategies. Tepari and Leppanen (2011) also found managers had different conceptions of $\mathrm{HF}$ from each other and as a group they lacked a shared vision or strategy regarding HF. The authors suggest a strategy and key message from top management is needed because this commits other managerial groups. As we found in this study, HF was not being recognized beyond health and safety functions and yet the mapping illustrated ways it could be integrated into production design processes aligned with strategic goals. Both of these tool adaptations contribute unique methods to the $\mathrm{HF}$ field, specifically when attempting to acclimate to engineering processes and align HF with strategic goals. As will be discussed, there is a need for more tools that HFS can utilize to facilitate acclimation and alignment within engineering design.

\section{Adaptation of Industrial Engineering Tools to Include HF can Facilitate Integration of HF:}

This research clearly demonstrated that HFS need to have tools customized to the particular design stage that can communicate quantitative HF design issues in a way that fits within engineering design processes. Rather than simply communicating $\mathrm{HF}$ concerns, a tool is needed that can provide a structured, systematic, quantifiable metric for HF that can be used for benchmarking and for indicating continuous improvement in design stages. This thesis has demonstrated several industrial engineering (IE) tools that were adapted to include HF considerations. We found that working with engineers to 
adapt IE tools in the collaboration led to greater acceptance of HF, than expecting engineering to use $\mathrm{HF}$ tools. While a wide range of $\mathrm{HF}$ tools and techniques have been documented (David, 2005; Garg and Kapellusch, 2009, Neumann et al, 2006; Wells et al, 2012), there are several problems which limit their application in engineering. First, most HF tools focus on reducing injury risk or system errors (Marhavilas et al., 2011), rather than improving operator performance, and they tend to target the workerworkstation level instead of the system level. Second, HF methods have been developed largely as "expert" methods for use by HFS, with ambiguous process ownership and control (Eklund, 1997). Third, most HF tools are ill-equipped to predict design problems. Although there are a limited number of digital human modeling and virtual human simulation tools (Hu et al, 2011; Duffy, 2007; Lamkull et al, 2009; Gilad and Elnekave, 2006; Yang et al, 2009; Rajan, 1999; Otto and Scholl, 2011), it is questionable whether they are accessible, cost-effective, and practical in manufacturing environments (Perez, in press), and whether they provide meaningful design recommendations to engineers (Kaljun, 2012). We agree with others that HFS have failed to provide useful models, checklists, methodologies, and tools to help designers (Clegg et al, 1996; Wulff, 1999), and that there is a need for improved proactive HF methods and tools appropriate for production engineers (Ma et al., 2010; Falck and Rosenqvist, 2012; Teperi and Leppanen, 2011; Wells et al, 2007).

Zink (2006) suggested that HF needs a paradigm shift, away from compliance with H\&S laws, to a more positive economic mission and towards enhancing (or "maturing") the role of the operator in the system. Woods (2000) describes that HFS need to shift their paradigm from one of evaluating current systems, to being able to predict "envisioned new worlds" in order to anticipate failures earlier in design stages. Woods (2000) suggests that the HF tools and techniques of the past era are too simple and applied too late in the design process for the complex and dynamic systems of this era. We therefore adapted proactive IE tools for HF, including the failure mode effects analysis (FMEA) with a unique scoring to indicate operator failure (Chapter 4). Two other studies were found of modifications to FMEA to consider operator health instead of product or process failure mode (Barsky and Dutta, 1997; Munck-Ulfsfalt et al., 2004), however they did not adopt the same scoring mechanism as the traditional FMEA. We also adapted the continuous improvement shop floor tool called kaizen to include HF, and as found by 
Zink et al. (2008) it could be readily adopted within the current business improvement program. Hendrick (2008) has suggested that HF should "ride the coattails of the latest management fad". We used the root cause analysis prior to adapting the HF design for assembly checklist. Several other researchers have also discussed borrowing from engineering tools, such as the root cause analysis, to demonstrate that improving task performance directly will lead to better acceptance of HF innovation (Carayon et al, 2007; Falck and Rosenqvist, 2012; Gawron et al, 2006).

The data in Chapter 5 of this thesis also includes the unique adaptation process for each tool such that others may learn from the processes in this organization. Participatory adaptation of tools with engineers should encourage better acceptance and use. All of our tools involved participatory focus groups, trials, demonstrations, and in some cases training. Chapter 5 also includes features of an ideal HF tool based on the findings in this thesis. Most importantly the tool needed to be quantitative and provide targets, be quick, visual and demonstrate change. The tools presented in Chapter 5 may need adaptation for different occupational environments, however the features listed may guide researchers and practitioners and encourage further tool adaptation and testing.

\section{Management can hold Engineers Accountable for HF with Enforceable Targets:}

This thesis contributes to the understanding of how HF can become locked into an organizations' design process through management accountability. The results demonstrated that HF guidelines and sign-off in design processes were insufficient to change engineering practice (to include HF), without management holding engineers accountable for the HF targets. The key to management desire for accountability for HF was recognition that it helps improve the design process and business goals. The accountability is strongly linked with the HFS demonstrating acclimation to engineering and alignment with strategic goals. When HF was recognized as a means to improve business performance, it was readily adopted into the design process. This construct contributes to the scientific literature on HF application, and potentially to the engineering literature on business improvement. Most previous models and frameworks both in participatory ergonomics, and in organizational change and business improvement focus on management support (Haines et al, 2002; Holden et al, 2008). 
Yet, few studies indicate how such support manifests itself, or how a practitioner can bring about management support. Our findings of the timing of the support was also interesting. Most literature suggests support is needed up-front. This thesis suggests that while up-front support from management helped somewhat in allowing the development process to proceed, it did not result in HF becoming sustainable in the design process in and of itself.

\subsection{How does the Design for Human Factors Theory Compare to Other Theories, Frameworks and Models?}

The action research framework (Neumann and Village, 2012) was useful during the collaboration to guide the concept of developing initiatives aimed at all levels within the organization and along each stage of the design process. The DFHF theory helps explain with empirical data how HFS can modify their practice to do this. The action research approach used in this thesis was a way to collaborate with organizational participants, try out different initiatives to integrate HF, and reflect and learn what was working and not working. We did not adhere to "strict" action research methods where there was joint goal setting, action plans, and evaluation, since that would not have been appropriate in this organizational setting. With respect to the participatory ergonomics framework, the DFHF theory does not have a series of steps (such as identify, assess and control risks). Instead of suggesting what needs to be in place (such as management support or sufficient resources), the DFHF theory suggests how HFS need to change their focus to integrate into an engineering environment. It is more about the process leading to change, than a suggestion of specific steps to perform. Unlike the participatory ergonomics models used for retro-fitting or redesigning workplaces, we did not include workers in design of the assembly process until the first assembly of prototype parts (in HF Kaizens, see Village et al, 2013). Therefore, the need for, or value of involvement of workers earlier in design stages is untested in this theory.

Our theory does have overlap with Broberg's (2010) description of the HFS as a political reflective navigator - or a change agent. Our HFS spent at least a year acclimating to the engineering process, language and tools in much the same way Broberg suggests. It 
is possible that the use of "navigation tools" described by Broberg (2010) that assist the HFS to take on the role of workspace designer would have been helpful for HFS in our collaboration.

Complexity theory helped the researchers frame what they were observing in the organization. Rather than expecting small incremental improvements, and "planned" increases in HF application, as suggested by the organizational change literature, researchers were instead aware of and anticipated uncertainties, dynamic shifts in HF application, turning points, and unpredicted adaptive behaviour (learning). Complexity also manifested itself in framing the partner organization during major shifts in organizational policy, product development, employee turnover, and management succession which included dynamic, nonlinear and often surprising behaviour that is difficult to predict and control (Mathews, 1999). "High-velocity" industries, such as the industry partner, are described by Brown (1997) as having short product cycles and rapidly shifting competitive landscapes with the need for rapid and relentless continuous change as their crucial capability for survival. The ongoing organizational change we encountered is described by Brown (1997) as "constantly reinventing" themselves. Therefore, change is not seen as negative, but continuous, dynamic, and opportunistic. We likewise learned to frame the HF efforts as continuous, dynamic and opportunistic.

Our DFHF theory resonates closely with the absorptive capacity theory (Cohen, 1990). Absorptive capacity theory suggests that learning is cumulative and learning performance is greatest when the object of learning is related to what is already known, with shared language and symbols, permitting assimilation (Cohen 1990). Firms with higher abilities to absorb new knowledge have an advantage over others who do not. In the DFHF theory, engineers were able to assimilate HF as "new knowledge" because it was in a similar format to their engineering knowledge base. When the HFS acclimated to the engineering knowledge base, and adapted HF to "fit" with this, the new knowledge was more readily absorbed by the organization.

Our DFHF theory also resonates with the Diffusion of Innovations Theory (Rogers, 2002). The later suggests that innovations tend to be adopted more quickly when they 
have a relative advantage over existing methods, are compatible with existing values, past experiences and current needs, are simple to understand, can be tried out or played with by potential adopters, and are observable such that adopters can see the results for themselves (Miles, 2012; Rogers, 2002). Our core tenant of the theory that suggests HFS need to acclimate and adapt to "fit" with engineering processes, language and tools supports the diffusion of innovation theory in that HFS was adopted only when it was compatible with the values, experiences and needs of engineers, as well as having tools that are simple, observable and can demonstrate change.

\subsection{What are the Implications from this thesis?}

There are four implications arising from the research in this thesis. Specific recommendations are included with each implication, directed at HF specialists, organizations and university teaching and research. A full listing of the recommendations will also be provided in Section 8.5.

\section{Human Factors Specialists need to Shift Focus from Health and Safety to Engineering Design. Organizations and Universities can Facilitate the Shift.}

Our findings suggest that HFS in this environment need to shift their mindset from reducing work-related injuries and promoting return-to-work, to improving aspects of production design. Instead of operating at arms-length to production or in reaction to operational problems, HFS need to become a resource to engineering and work towards the same business goals. The shift to engineering requires aligning HF metrics with the business goals and metrics of the specific organization. Part of the shift in mindset therefore is to learn ways to anticipate potential HF impacts on workers at very early design stages. This may mean working from CAD drawings and simulations, rather than direct observation and measurement of workers performing a task. Along with this shift, is a focus on early and continuous improvement of design, rather than identification, assessment and control of risk factors after problems arise. This shift in focus also implies that HFS become part of solution development, rather than focusing only on identification of problems. 
Depending on the training and educational background of the HFS, this shifting of focus may require more formal training in engineering tools, techniques and processes. Recommendations have been made by others for more systems design knowledge, especially of trade-offs and constraints (Campbell, 1996). Wells et al, (2007) suggested knowledge of engineering tools will help practitioners better understand design decisions and to propose strategies that do not pose negative effects. Strasser and Zink (2007) suggested increased training in engineering is essential for ergonomists to have the selfconfidence to challenge systems-ergonomics requirements. Training in specialization modules in universities was suggested by Strasser and Zink (2007). This does not suggest HFS should abandon the goal of improving worker health, but that a focus on design and business goals will be more effective in an engineering environment and can lead to the dual goal of operator performance and well-being.

\section{Recommendations:}

- University academic programs for HFS should offer more coursework in engineering design, engineering tools and project management;

- Researchers should develop and share tools (such as cognitive mapping and process mapping) with HF practitioners to help them learn the internal design process and align HF with strategic goals;

- HF professional associations should offer professional development opportunities in industrial engineering tools and business improvement programs for HFS;

- Organizations should provide apprenticeship programs for HFS in the engineering department and involved in the design process;

- Organizations should ensure that HFSs are positioned with appropriate support and leadership from the engineering department and use the same communication, design, and project management tools as engineers, to facilitate acclimation to engineering processes, language and tools;

- HF Specialists should seek to apply HF as early as possible in design stages in organizations they work within. 
- HF Specialists should network within the organization to learn the people involved in the design processes and to learn the strategic and business goals of the organization.

- HF Specialists should seek ways to demonstrate that human factors aspects of worker performance (such as operator consistency, or precision) can improve business performance (such as improved quality of assembly);

\section{Adaptation or development of appropriate HF tools with metrics can lead to adoption in the design process}

Our findings indicated that an appropriate tool was necessary to systematically communicate HF targets for design improvement and benchmarking. The tool needs to be appropriate to the type of work, design process, and time and effort expectations of engineers. In several situations during the collaboration, a request from engineering could not be satisfied because HFS did not have an appropriate tool to measure the HF implications and communicate improvement.

\section{Recommendations:}

- Researchers in HF should collaborate with engineering departments to adapt, develop and test HF tools for early detection of HF concerns (i.e. prior to design of the assembly system) and continuous improvement of HF considerations in design.

- Researchers should publish HF tools, techniques and benefits in engineering and management journals and trade magazines.

- University academic programs should teach HF-adapted tools to engineers;

- Engineers, HFS and organizations should adopt, test and refine HF tools through application in various industries;

- Engineering professional associations should promote professional development opportunities that improve awareness and use of HF-related tools and methods. 


\section{HFS need to focus on how to measure and improve operator performance}

The HF field has not succeeded in making the business case for designing for HF considerations. This could be because most HF research is not done in engineering or business schools, or it could be that the focus of study on work-causation and risk factors has pre-empted research on optimizing operator performance in a system. Early HF research in military and defense systems had a performance goal, but this work has largely given way to health-based research, especially in Canada. Dempsey (2007) suggested that the additional scrutiny we bring to our field (i.e. seeking epidemiologic evidence) is not required by the total quality management movement and that just as production engineers are willing to accept small continuous improvements in quality that yield large advances over time, they should expect no more from ergonomists making small incremental improvements in working conditions. The HF field would benefit from improving measures and metrics for optimizing human performance, such as precision, operator consistency, attention to defects and reducing operator error in design. The HF metrics should be linked to business metrics, such as quality defects and production yield.

\section{Recommendations:}

- Researchers should investigate ways to define, monitor and improve aspects of operator performance that affect assembly design (such as precision, consistency of performance and minimizing fatigue) and link these to business metrics (such as quality outcomes).

- University researchers and HF practitioners should test and adapt techniques in industry to monitor operator performance aspects and link this to business metrics.

- Researchers in engineering should consider HF aspects in models and tools to improve validity of the models and tools, and ultimately improve operator performance.

- Academic programs in both HF and engineering should be improved in areas of HF aspects of operator performance. 
- HF professional associations should also promote the development and testing of performance-based aspects of $\mathrm{HF}$, in addition to health aspects.

\section{HF can be integrated into production design processes in a sustainable way}

This research has demonstrated that HF can be integrated into production design processes. It has also provided indicators of what integration looked like in the collaborating organization. As a research study, this intensive three year collaboration is not meant as a model to be replicated. Instead, the outcomes of the collaboration, specifically the development of the DFHF theory, is meant to provide guidance to other researchers and practitioners seeking to integrate HF into design in a more timeeffective way. The empirical evidence gathered in the grounded theory methodology supports the various constructs in the DFHF theory. With further attempts to study the constructs, or practically implement the recommendations, the theory will be strengthened or modified as suggested by future research.

\section{Recommendations:}

- HF specialists who are working in organizations are encouraged to implement, adapt and further develop industrial engineering tools adapted for $\mathrm{HF}$ to integrate $\mathrm{HF}$ earlier in design processes;

- HF specialists are encouraged to use the design process map and cognitive mapping tools to increase acclimation within engineering and alignment with strategic business goals;

- University researchers should continue to evaluate the propositions in the DFHF theory facilitating integration of $\mathrm{HF}$ in design processes, individually or in combination, to see if they are supported in other design processes in different organizations

\subsection{Comments on the Methodological Approach and Study Limitations}

The findings in this thesis are based on a single case study conducted in an admittedly unique new product manufacturing design environment in light assembly. The case 
study method is a preferred approach when "how" and "why" questions are posed, when the investigator has little control over events, and when the focus is on studying phenomenon within a real life context (Yin 1994). The exploratory nature of the case study allows flexibility and lends itself to qualitative data collection and analysis (Hignett and Wilson, 2004). It is applicable when understanding why people make choices or carry out tasks in a particular way (Hignett and Wilson, 2004).

The findings and implications may not be directly generalizable to design processes or the engineering environment in other organizations, especially if there are no HFS, or conversely if HFS are already part of the engineering team. More studies with a broader range of industries are needed to see if the findings can be further supported. Instead of generalizability, in qualitative studies where each case is unique to a context (i.e. when, where and who), the concept of transferability is more relevant. A thick description of a case allows respondents to decide, given their unique context, what might be generalizable to their situation, which could be results, tools, abstractions or concepts. Moray $(1994,1995)$ has stated that the value of qualitative studies in ergonomics is to generalize findings from "situations" to other and different systems, rather than generalizing based on statistical analysis. Qualitative studies recognize that it is impossible to achieve repeatability in practice. However, the focus is on a few cases but with many variables, rather than many cases and few variables as in quantitative research (Hignett and Wilson, 2004). Instead of repeatability, the careful documentation of the data collection and analysis, and evidence of some of the empirical findings provides a credible link between the data and the results. Qualitative studies are considered dependable (rather than repeatable) when there is a consistency in patterns of thought and behavior of subjects.

Selection of the company for the study was not done randomly. However, Patton (2011) suggests that purposeful and intentional sampling is a strength because it provides important information about field-based processes in an information-rich case that would otherwise be unavailable. Although the "case", in this study was considered the "organization, since we conducted multiple initiatives with different groups of engineers within the large case study organization, our study design was strengthened with such multiple embedded cases. This allowed us to contrast the strengths and weaknesses of 
each initiative. It also minimizes bias from any single "success" case. Although the series of events leading to organizational change and learning in our collaboration would naturally unfold differently in other organizations and with different people involved, the lessons learned may be valuable for others attempting to conduct ergonomics action research studies, or to integrate HF in their design processes. The generalizability of these findings is consistent with contingency theory which suggests that for a proposition to hold, assumptions must be made about the starting premise, boundaries and system states (Donaldson, 2001). Contingency theory also suggests that concepts in any theory of organizational change must "fit" the environment, rather than be generalized or adopted outright (Miller, 1978).

It would have been ideal if pre and post interviews with the same participants could have been conducted prior to and following the collaboration. Ideally, the cognitive mapping would also have been repeated towards the end of the collaboration to identify changes in perceptions of HF among the senior management. However, significant organizational downsizing and layoffs made this type of study design impossible. We were also unable to track the development process of all the adapted tools beyond one or two product cycles given the three year time frame. The fact that the HF efforts continued in the face of such downsizing and organizational change reinforces that the constructs in the DFHF theory (such as acclimation to engineering) were effective at sustaining change in the organization, regardless of changing personnel and senior management. We collaborated with a large number of varying groups of engineers and managers, minimizing any potential bias resulting from a single relationship or "champion" (for example, with a senior manager, or group of engineers).

As with any qualitative research, there may be different explanations for the events in the case study, depending on the "lens" or background of the researcher. The data in this study, especially the design for HF theory, was analyzed largely from the HFS perspective, not specifically from an engineering or managers' perspective. This establishes a "boundary" for interpretation, rather than a limitation. Regarding the validity of the findings, the systematic and transparent treatment of data collection and analysis described in Chapter 6, including the progressive coding and development of conceptual frameworks provides a truthful representation of the analytic induction and interpretation. 
Further, the analysis included a search for "negative" findings within the data and further validation with both theoretical sampling, and confirmatory presentations of the data with the collaborating organization and academic experts. The interpretation is therefore traceable, and verifiable from the data, as well as being verified in interpretation from the collaborating organization. In qualitative studies, validity is more about the soundness of the arguments, rather than truthfulness of statements.

Using the broad action research approach to identify and try out initiatives and reflect on their success helped the collaboration proceed in ways that made sense to the organization and allowed adaptation to changes in personnel and priorities over the three years. The action research approach using a grounded theory analysis is rare in human factors research. It was a helpful for developing an "inside" understanding and for developing theory for further testing. Similar to the findings of Zink et al. (2008), using an action research approach resulted in many successful initiatives. It is not necessarily recommended as an intervention technique to be repeated in practice due to the time and resource intensity. However, the implications and recommendations may help other researchers and practitioners learn from the experiences to short-cut their HF integration process.

\subsection{Future Research Needs}

Section 8.3 has suggested implications and recommendations arising directly from the research in this thesis, such as further testing of the constructs in the DFHF theory in different applications, further case studies using the recommendations arising from the theory, and development and adaptation of more HF tools for both helping to align HF with strategic goals and engineering design processes, and to monitor and improve aspects of worker performance, such as improving operator consistency. Beyond these direct gaps, there is a need to test whether the adapted tools can be taught to and used by engineers to improve HF integration in design in organizations without HFS. It would also be important to test whether a HFS working in an organization can succeed in the organizational change demonstrated in this thesis, without the support from researchers and an action research approach. 
Two other areas of further research arise from the findings in this thesis. The first is to gather the empirical evidence of the extent to which the integration of $\mathrm{HF}$ in the design processes improves operator well-being and business performance. The limit of this thesis work was answering the question of how HF could be integrated, but the outcomes of HF integration were outside the realm of this work. Outcome research would also require a longitudinal type design to evaluate the organizational change. The second area of research is to test the premise that helping engineers achieve their design goals is consistent with good HF application. We saw little evidence of conflict between the two priorities in our case study, however that is not to say that this will always occur. It would be useful to identify instances in early design where improving worker comfort or performance does not yield operations improvements, and to investigate ways to resolve the conflicts to find optimal solutions.

This research is based on one general framework for integrating HF into production design processes - that of Neumann and Village (2012). However, there may be other approaches, methods and frameworks that are more time effective, or offer alternatives to practitioners. Likewise, different approaches in the collaboration, such as using sociotechnical systems methods (for example, a systems scan or variance matrix), may have led to different actions, and potentially different outcomes. Further investigation is also needed regarding how best to integrate $\mathrm{HF}$ into business process improvement programs and management systems such that the HF is positioned to help organizations improve operator performance as well as business performance.

Finally, the recommendations in Section 8.3 have suggested changes in HF research and application that shifts the focus from risk factor and injury causation and program or intervention approaches to a focus on aligning HF with production goals and metrics and developmental approaches that enhance integration of $\mathrm{HF}$ into engineering processes, language and tools. It was recommended that this could be achieved with increased education for HFS in engineering, apprenticeships, professional development, research collaboration with engineering departments and publications in engineering and business management journals. The success of these and other approaches should be 
monitored, evaluated and promoted such that the HF field can increasingly demonstrate its value to engineering and business management practices.

\subsection{Conclusions}

This thesis is the culmination of a three year longitudinal case study involving an industry-research collaboration. It uses a unique action research approach that combines an intense embeddedness and participation in the organization, while at the same time "researching" what is helping and not helping with HF integration. HF was increasingly integrated into the production design process with HF adapted tools, enforceable HF targets, key HF sign-off, and participation of the HF specialist alongside engineers in each design stage. HF is no longer an after-injury occupational health and safety function. It is recognized as a necessary part of engineering design to optimize human aspects of worker performance, such as detection of quality defects and minimizing fatigue. Senior directors reported that increased HF application has improved the design of more recent assembly lines and made it easier for operators.

Strategically aligning HF to the design and business goals was critical to the changes. An operations research tool called cognitive mapping was adapted and used to identify the HF perceptions of the senior directors and how they linked HF to strategic goals in the organization. As a result of the mapping, HF specialists changed their focus from identifying risk factors to reducing fatigue and improving worker performance. To fill the gap of design-level HF tools focused on performance aspects of light assembly, several industrial engineering tools were adapted to include HF, including the failure mode effects analysis, the design for assembly, design for fixtures, and HF Kaizens. HF tools with quantifiable targets were needed in this environment to communicate HF concerns, drive continuous improvement, visibly demonstrate change, and lead to benchmarking. Senior directors held engineers responsible for meeting HF targets since they were aligned with business and design goals. 
The "design for human factors" theory contributes an explanation about how HF can be integrated into design processes to guide and inform researchers and practitioners and improve proactive application of HF in design processes. The six constructs in the theory show that when the HFS changed focus from predominately a health a safety one to align with design and strategic business goals, HF was increasingly recognized as a means to improve business performance. The theory proposes that when: 1 . HFS acclimate to the engineering process, language and tools; and 2. strategically align HF to design and business goals; then 3. HFS are pulled onto the engineering team, and 4. Management hold engineers accountable for HF targets because it is perceived to help improve business goals. With 5. Engineering tools adapted to include HF targets, then 6 . HF becomes embedded in the design process.

The main implication of this work suggests that for HF Specialists to work proactively in design processes, they need to demonstrate their ability to optimize worker performance consistent with strategic goals in the organization. This has implications for universities, professional HF associations, and organizations in terms of education for HFS in engineering, and the need for more collaborative research to develop engineering-like tools and methods for optimizing worker performance aspects and linking these to business metrics. The potential societal impact of integrating HF earlier in design processes is enormous, not only for reducing occupational injuries, but for improving worker well-being, motivation, and performance, and subsequently for improving aspects of business performance such as efficiency, productivity and quality.

\subsection{Summary of Recommendations}

The recommendations below aim to shift the focus of HF research and application from solely occupational health and safety risk and injury mitigation, to broader aspects of optimizing human performance (such as minimizing fatigue, improving detection of quality defects, and increasing operator consistency). A shift in focus, and subsequent shift in development of measures and tools for early indicators of performance metrics can increase the integration of HF aspects in design of production systems. 
HF Specialists:

- HF Specialists should seek to apply HF as early as possible in design stages in organizations they work within;

- HF Specialists should network within the organization to learn the people and steps involved in the design processes, and to learn the strategic and business goals of the organization;

- HF specialists are encouraged to use the design process map and cognitive mapping tools to increase acclimation within engineering and alignment with strategic business goals;

- HF Specialists should seek ways to demonstrate that human factors aspects of worker performance (such as operator consistency, or precision) can improve business performance (such as improved quality of assembly);

- HF specialists who are working in organizations are encouraged to learn, implement, adapt and further develop industrial engineering tools to include HF, such that they may be integrated earlier in design processes.

University Academic Programs:

- Academic programs for HFS should offer more coursework in engineering design, engineering tools and project management;

- Academic programs for engineers should teach HF-adapted tools;

- Academic programs in both HF and engineering should be improved in areas of $\mathrm{HF}$ aspects of operator performance.

Researchers:

- Researchers should continue to evaluate the constructs facilitating integration of $\mathrm{HF}$ in design processes as suggested by the DFHF theory, individually or in combination, to see if they are supported in other design processes in different organizations 
- Researchers in HF should collaborate with engineering departments to adapt, develop and test HF tools for early detection of HF concerns (i.e. prior to design of the assembly system) and continuous improvement of HF considerations in design.

- Researchers should publish HF tools, techniques and the benefits of HF application in engineering and management journals and trade magazines.

- Researchers should investigate ways to define, monitor and improve aspects of operator performance that affect assembly design (such as precision, consistency of performance and minimizing fatigue) and link these to business metrics (such as quality outcomes).

- Researchers in engineering should consider HF aspects in models and tools to improve validity of the models and tools, and ultimately improve operator performance.

- Researchers should develop and share tools (such as cognitive mapping and process mapping) with HF practitioners to help them learn the an organizations' design process and align HF with strategic goals;

HF professional associations:

- HF professional associations should offer professional development opportunities in industrial engineering tools and business improvement programs for HFS;

- HF professional associations should also promote the development and testing of performance-based aspects of $\mathrm{HF}$, in addition to health aspects.

Engineering professional associations:

- Engineering professional associations should promote professional development opportunities that improve awareness and use of HF-related tools and methods.

Engineers and Management in Organizations:

- Engineers, HF specialists and organizations should adopt, test and refine HF tools through application in various industries; 
- Organizations should provide apprenticeship programs for HFS in the engineering department and in the design process;

- Organizations should ensure that HFSs are positioned with appropriate support and leadership from the engineering department and use the same communication, design, and project management tools as engineers, to facilitate acclimation to engineering processes, language and tools; 


\section{APPENDIX A \\ List of Publications and Conference Proceedings}

Neumann, P.W. and Village, J. 2012. A framework supporting the process of integrating HF into work system design. Ergonomics 55(10): 1140-1156.

Lim, A., Village, J., Salustri, F., Neumann, W.P. 2012 (Apr). Process mapping as a tool for participative integration of human factors into work system design. European Journal of Industrial Engineering (Accepted: Submission code: EJIE-36603).

Village, J., Greig, M., Salustri, F.A. and Neumann, W.P. 2012. Linking human factors to corporate strategy with cognitive mapping techniques, Work 44: 2776-2780.

Village, J., Salustri, F., Neumann, W.P. 2013. Cognitive mapping as a tool to align human factors with strategic goals in organizations, International Journal of Industrial Ergonomics 43; 304-313.

Village, J., Salustri, F., Neumann, W.P. 2013. Cognitive mapping links human factors to corporate strategies. European Journal of Industrial Engineering (Accepted: Submission code: EJIE-RZ-012-13 EJIE_53794).

Village, J., Greig, M., Zolfaghari, S., Salustri, F., Neumann, W.P. (2013 submitted). Adapting industrial engineering tools to include human factors. IIE Transactions in Occupational Ergonomics and Human Factors (accepted with corrections, resubmitted).

Village, J., Greig, M., Salustri, F., Zolfaghari, S., Neumann, W.P. (2013 submitted). An ergonomics action research demonstration: Integrating human factors into assembly design processes. Ergonomics (under review).

Village, J., Salustri, F., Searcy, C., Neumann, W.P. (in progress) Design-for-Human

Factors (DFHF): A Grounded Theory for Integrating HF into Production Design Processes.

\section{Conference Proceedings}

Neumann, P. and Village, J. 2011. A framework for integrating human factors into worksystem design. Human Factors in Organizational Design and Management Conference, South Africa. 
Greig, M., Annett, T.L., Village, J.L. and Neumann, W.P. 2011 (Oct.). Using workstation design parameters to predict workload - proactive assessment approach for light assembly work. Proc of the $42^{\text {nd }}$ Annual Conference of the Association of Canadian Ergonomists, London, Ontario (October 17-20).

Village, J., Annett, T., Lin, E., Greig, M., and Neumann, W.P. 2011 (Oct.). Adapting the failure modes effect analysis (FMEA) for detection of human factors concerns. Proc of the $42^{\text {nd }}$ Annual Conference of the Association of Canadian Ergonomists, London, Ontario (October 17-20).

Village, J., Greig, M., Salustri, F.A. and Neumann, W.P. 2012. Linking human factors to corporate strategy with cognitive mapping techniques. International Ergonomics Association Conference, Recife, Brazil (February 12-16).

Lin, E., Village, J. and Neumann, W.P. 2012. Development and application of a human factors failure mode and effects analysis. Applied Ergonomics Conference, March 26-29, Nashville, TN.

Village, J., Dixon, S., and Neumann, W.P. 2012. Gaining support for human factors in an engineering design culture. Canadian Association of Researchers on Work and Health (CARWH) Conference, Vancouver, British Columbia (June 1-2).

Village, J., Annett, T., Greig, M., and Neumann, W.P. 2012. Ergonomic design-for-fixture guidelines and process of implementation. A Case Study. Association of Canadian Ergonomists Annual Conference, Halifax, Nova Scotia (Aug).

Greig, M., Village, J. and Neumann, W.P. 2013. Predicting work load and efficiency from light assembly workstation design. International Industrial Engineering Conference, Peurto Rico, May 18-22.

Village, J., Greig, M. and Neumann, W.P. 2013. Adaptation of industrial engineering tools to include human factors. International Industrial Engineering Conference, Peurto Rico, May 18-22.

Greig, M., Dixon, S., Annett, T., Village, J. and Neumann, W.P. 2013. User-centered development of a workstation efficiency evaluation tool. Association of Canadian Ergonomists Annual Conference, Whistler, BC, October 8-10.

Village, J., Greig, M. and Neumann. W.P. 2013. Ergonomics training for engineers: Are we meeting their needs? Association of Canadian Ergonomists Annual Conference, Whistler, BC, October 8-10. 


\section{APPENDIX B \\ Examples of Empirical Evidence Indicating Integration of HF In The Design Process}

\begin{tabular}{|c|c|}
\hline Source & Empirical Observation \\
\hline $\begin{array}{l}\text { Researcher } \\
\text { notes: }\end{array}$ & $\begin{array}{l}\text { "A new product focused engineer called the HFS to look at shelving - } \\
\text { then asked him to look at whole line and give feedback - this has never } \\
\text { happened before" }\end{array}$ \\
\hline $\begin{array}{l}\text { Researcher } \\
\text { notes: }\end{array}$ & $\begin{array}{l}\text { FMEA software: "template with HF dropdown menu is used at all } \\
\text { outsourcing plants so HF would be part of process - a sign-off in loop for } \\
\text { manufacturing" }\end{array}$ \\
\hline Manager: & $\begin{array}{l}\text { "we want this to be part of the way we do business when this project is } \\
\text { over, we have the foundation (cycle time and root cause analysis)" }\end{array}$ \\
\hline HFS: & $\begin{array}{l}\text { "I'm getting called more by engineering in the last year - one line } \\
\text { engineer called and wanted all tooling on line verified by our department" }\end{array}$ \\
\hline $\begin{array}{l}\text { Researcher } \\
\text { notes: }\end{array}$ & $\begin{array}{l}\text { "HFS increasingly more networked - putting meetings together, going } \\
\text { down on floor to look at issues without invites - went to (assembly line) } \\
\text { start-up meeting with engineering group - getting more involved and } \\
\text { having more knowledge of process increases profile of HFS" }\end{array}$ \\
\hline $\begin{array}{l}\text { Researcher } \\
\text { notes: }\end{array}$ & $\begin{array}{l}\text { "HFS was invited to meeting with engineer involved with tooling - had in } \\
\text { house design- wasn't getting invited to this a year ago - wanted to know } \\
\text { if any specs available for all engineers" }\end{array}$ \\
\hline $\begin{array}{l}\text { Researcher } \\
\text { notes: }\end{array}$ & $\begin{array}{l}\text { HFS contributes to fixture solution: "HFS' suggestions of new design of } \\
\text { fixture for X in FMEA meeting was not well received initially, until one } \\
\text { engineer jumped up to drawing board and said "this might be possible - } \\
\text { think outside the box" he went on to explain and draw a possible solution } \\
\text { (ended up making semi-auto fixture)" }\end{array}$ \\
\hline $\begin{array}{l}\text { Researcher } \\
\text { notes: }\end{array}$ & $\begin{array}{l}\text { "the meeting of HFS team members and design engineers is happening } \\
\text { by their initiation now - updating on collaborative projects - can see } \\
\text { where this will continue when Ryerson leaves - also HFS chairing } \\
\text { meetings and taking and distributing notes - much greater involvement } \\
\text { with engineering" }\end{array}$ \\
\hline $\begin{array}{l}\text { Researcher } \\
\text { notes: }\end{array}$ & $\begin{array}{l}\text { Increased engineering awareness and involvement in HF: "HFS did a } \\
\text { review of line for } X \text { (product focused engineer, PFE) - then invited him on } \\
\text { ergo change team (increased sensitization to HF issues having PFE on } \\
\text { team)" }\end{array}$ \\
\hline
\end{tabular}




\section{APPENDICES C and D}

Appendix $\mathrm{C}$ is the draft prototype worksheet for the human factors failure mode effects analysis scoring (HF-FMEA). Appendix $D$ is the first version for public release of the human factors design for assembly tool (HF-DFA) and definitions. Both tools were developed and implemented in collaboration with engineers and human factors specialists in the case study organization. We recommend further testing and refinement of the tools, and adaptations to customize them to other design processes and manufacturing sectors.

See the references in the document for further description and illustration of the tools. 


\section{APPENDIX C}

\section{Human Factors Failure Mode Effects Analysis Scoring DRAFT PROTOTYPE}

Step 1. For each task,
score force, posture
and repetition and
multiply the three

\begin{tabular}{|l|l|l|l|}
\hline Score & Force (F) & Posture (P) & Repetition (R) \\
\hline 1 (low) & $\begin{array}{l}<1 \mathrm{~kg} \text { or } 10 \% \\
\text { MVC }\end{array}$ & Optimal posture $\left(<15^{\circ}\right)$ & $\begin{array}{l}<0.1 \mathrm{c} / \mathrm{min} \text { shoulder } \\
<1 / \mathrm{min} \text { hand } \\
<20 / \mathrm{min} \text { fingers }\end{array}$ \\
\hline 2 (med) & $10-25 \% \mathrm{MVC}$ & $\begin{array}{l}\text { Near optimal posture } \\
\text { Shoulder } 15-45^{\circ}\end{array}$ & $\begin{array}{l}0.1-2.5 \mathrm{c} / \mathrm{min} \text { shoulder } \\
1-10 / \mathrm{min} \text { hand } \\
20-200 / \mathrm{min} \text { fingers }\end{array}$ \\
\hline 3 (high) & $>2.3 \mathrm{~kg}$ single \\
& hand, 25\% MVC & $\begin{array}{l}\text { Hand above shoulder height } \\
\text { Arm extended } \\
\text { Shoulder abd }>45^{\circ}\end{array}$ & $\begin{array}{l}>2.5 / \mathrm{min} \text { shoulder } \\
>10 / \mathrm{min} \text { hand } \\
>200 / \mathrm{min} \text { fingers }\end{array}$ \\
\hline
\end{tabular}

Task:

Force:

x Posture:

x Repetition: $=$

Step 2. Add +1 for each other risk factor present (eg. contact stress, vibration, visual demands)

Step 3. Convert HF Score to "Severity" score using verbal descriptors

\begin{tabular}{c|l|l|}
\hline Total HF Score & Severity conversion & Severity Risk $(\mathbf{S})$ \\
\hline $1-4$ & $1-4$ & Low level risk factors \\
\hline $5-8$ & $5-6$ & Low risk with 1 medium risk factor \\
\hline $9-14$ & $7-8$ & Medium risk factors \\
\hline $15-17$ & 9 & Medium with 1 high risk factor \\
\hline 18 and above & 10 & High level risk factors \\
\hline
\end{tabular}

\section{Severity Score:}

Step 4. Estimate "Occurrence" and "Detection" scores from tables below

\begin{tabular}{|l|l|}
\hline & Occurrence Description \\
\hline $1-2$ & Very unlikely to cause injury \\
\hline $3-4$ & Low probability of injury \\
\hline $5-6$ & May cause injury to some workers \\
\hline $7-8$ & Likely to cause injury to some \\
\hline $9-10$ & High likelihood to cause injury \\
\hline
\end{tabular}

\begin{tabular}{|l|l|}
\hline & Detection Description \\
\hline $1-2$ & $\begin{array}{l}\text { Risk factors either not present or } \\
\text { elim inated with controls }\end{array}$ \\
\hline $3-4$ & $\begin{array}{l}\text { Risk factors are low or if present, } \\
\text { controlled with engineering controls }\end{array}$ \\
\hline $5-6$ & $\begin{array}{l}\text { Risk factors are medium, or with some } \\
\text { control but some risk rem ains }\end{array}$ \\
\hline $7-8$ & $\begin{array}{l}\text { Risk factors present, controls in place are } \\
\text { ineffective }\end{array}$ \\
\hline $9-10$ & $\begin{array}{l}\text { Risk factors insufficiently controlled, high } \\
\text { need for risk control }\end{array}$ \\
\hline & Detection Score: \\
\hline
\end{tabular}

Step 5. Multiply for Risk Priority Number (RPN):
Severity
$x$ Occurrence
$x$ Detection $=\mathrm{RPN}$ 


\section{APPENDIX D \\ Human Factors - Design for Assembly Scorecard \\ PUBLIC RELEASE V 1.0}

\begin{tabular}{|c|c|c|c|c|}
\hline Task Consideration & 0 & 1 & 2 & Score \\
\hline 1. Grip time required & None & Short duration & $\begin{array}{l}\text { Sustained or repeated } \\
\text { actions }\end{array}$ & \\
\hline 2. Grip size and type & $\begin{array}{l}\text { Mid-range full } \\
\text { hand }\end{array}$ & $\begin{array}{l}\text { Small grip or slightly } \\
\text { outstretched }\end{array}$ & $\begin{array}{l}\text { Pinch grip or fully } \\
\text { outstretched hand }\end{array}$ & \\
\hline $\begin{array}{l}\text { 3. Re-grasping or re-orienting } \\
\text { hand or part }\end{array}$ & None & $\begin{array}{l}\text { Small amount } \\
\text { (1 re-grasp occasionally) }\end{array}$ & Considerable & \\
\hline $\begin{array}{l}\text { 4. Orientation variability: on pick- } \\
\text { up, placing or assembly }\end{array}$ & $\begin{array}{l}\text { Universal } \\
\text { orientation }\end{array}$ & Multiple orientations & One correct orientation & \\
\hline 5. Ease of placement first time & Consistent & Occasionally need to re-do & $\begin{array}{l}\text { Frequently need to re- } \\
\text { do }\end{array}$ & \\
\hline $\begin{array}{l}\text { 6. Force } \\
\text { (and/or resistance to movement) }\end{array}$ & None or low & Medium & High & \\
\hline $\begin{array}{l}\text { 7. Precision requirements } \\
\text { (consider alignment features and } \\
\text { angle) }\end{array}$ & None or low & Some precision required & $\begin{array}{l}\text { Considerable precision } \\
\text { required }\end{array}$ & \\
\hline 8. Hands required & One handed & $\begin{array}{l}\text { Second hand needed to hold } \\
\text { or guide }\end{array}$ & Two hands required & \\
\hline 9. Task coordination and motions & $\begin{array}{l}\text { Simple/Linear } \\
\text { (one motion) }\end{array}$ & $\begin{array}{l}\text { Two steps } \\
\text { (or motions) }\end{array}$ & $\begin{array}{l}\text { > Two steps } \\
\text { (or motions) }\end{array}$ & \\
\hline $\begin{array}{l}\text { 10.Impact to body due to } \\
\text { sharp/hard surface contact }\end{array}$ & None & Small amount & Considerable & \\
\hline 11. Wrist posture & Mid-range & $\begin{array}{l}\text { Slightly bent } \\
\text { (in any plane) }\end{array}$ & Considerably bent & \\
\hline 12. Shoulder posture (reach) & $\begin{array}{l}\text { Elbows close to } \\
\text { body }\end{array}$ & $\begin{array}{l}\text { Medium reach } \\
\left(<45^{\circ} \text { forward or side }\right)\end{array}$ & $\begin{array}{l}\text { Large reach } \\
\left(>45^{\circ}\right)\end{array}$ & \\
\hline 13. Shoulder loading & $\begin{array}{l}\text { None or arm } \\
\text { supported }\end{array}$ & $\begin{array}{l}\text { Holding weight of arm or } \\
\text { light part }\end{array}$ & $\begin{array}{l}\text { Holding weight of arm } \\
\text { and moderate to heavy } \\
\text { part/tool }\end{array}$ & \\
\hline 14. Task duration & Quick motion & Medium duration & Longer duration & \\
\hline 15. Visual requirements & Clear view & Partial obstruction & Blind assembly & \\
\hline 16. Visual accuracy & None or low & Some visual accuracy & High visual accuracy & \\
\hline $\begin{array}{l}\text { 17. Inspection difficulty } \\
\text { (during and after assembly) }\end{array}$ & None or low & Some inspection required & $\begin{array}{l}\text { High level of inspection } \\
\text { required }\end{array}$ & \\
\hline $\begin{array}{l}\text { 18. Visual Task Contrast } \\
\text { (from surroundings ) }\end{array}$ & Sharp/Distinct & Dull/Blending Tones & None/Matched Tones & \\
\hline $\begin{array}{l}\text { 19. Feedback of task success } \\
\text { (eg. snap or feel) }\end{array}$ & $\begin{array}{l}\text { Unnecessary or } \\
\text { obvious }\end{array}$ & Required but simple & $\begin{array}{l}\text { Required and easy to } \\
\text { miss }\end{array}$ & \\
\hline $\begin{array}{l}\text { 20. Ability to detect problem with } \\
\text { part (quality) }\end{array}$ & Obvious & Moderate & Difficult & \\
\hline 21. Fragility of part (quality) & Slight & Moderate & Significant & \\
\hline $\begin{array}{l}\text { 22. Risk of Damage to Part or } \\
\text { Component (quality) }\end{array}$ & Slight & Moderate & Significant & \\
\hline \multicolumn{4}{|c|}{ TOTAL HF-DFA SCORE (max 44) } & \\
\hline
\end{tabular}




\section{APPENDIX D \\ HF DFA: Definitions and Comments}

\begin{tabular}{|c|c|}
\hline 1.Grip time required & $\begin{array}{l}\text { - Longer duration (sustained }>5 \mathrm{sec} \text { ) and repeated gripping increases } \\
\text { hand/arm fatigue and injury risk }\end{array}$ \\
\hline 2. Grip size and type & $\begin{array}{l}\text { - Small pinch grips use smaller muscles that fatigue more quickly and } \\
\text { have less force } \\
\text { - Outstretched hands cannot generate force and precision }\end{array}$ \\
\hline $\begin{array}{l}\text { 3. Re-grasping or re- } \\
\text { orienting hand or part }\end{array}$ & $\begin{array}{l}\text { - Re-grasping increases muscle fatigue and time } \\
\text { - Multiple handling increase cosmetic quality risk }\end{array}$ \\
\hline $\begin{array}{l}\text { 4. Orientation variability } \\
\text { (on pick-up, placing or assembly) }\end{array}$ & $\begin{array}{l}\text { - Affects ease of task physically (posture), cognitively and visually as } \\
\text { well as time to perform task }\end{array}$ \\
\hline $\begin{array}{l}\text { 5. Ease of placement first } \\
\text { time }\end{array}$ & $\begin{array}{l}\text { - Affects muscle use/fatigue, time for task, potential errors and frustration } \\
\text { - Multiple attempts increases cosmetic and general damage }\end{array}$ \\
\hline $\begin{array}{l}\text { 6. Force } \\
\text { (and/or resistance to movement) }\end{array}$ & - Higher force (>1 kg for pinch grips) increases fatigue and injury risk \\
\hline $\begin{array}{l}\text { 7. Precision requirements } \\
\text { (consider alignment features and } \\
\text { angle) }\end{array}$ & $\begin{array}{l}\text { - Degree of accuracy affects posture, mental workload and time } \\
\text { - Considerable precision }+/-1 \mathrm{~mm} \text { accuracy in placement }\end{array}$ \\
\hline 8. Hands required & $\begin{array}{l}\text { - Two handed tasks increase shoulder load, coordination, precision } \\
\text { requirements and time, and potentially reduce quality }\end{array}$ \\
\hline $\begin{array}{l}\text { 9. Task coordination and } \\
\text { motions }\end{array}$ & $\begin{array}{l}\text { - Increased coordination affects muscle loading/fatigue, time and quality } \\
\text { - Two steps means inserting one side and needing to, for example, turn } \\
\text { and press or snap other side }\end{array}$ \\
\hline $\begin{array}{l}\text { 10.Impact to body due to } \\
\text { sharp or hard surfaces }\end{array}$ & $\begin{array}{l}\text { - Hard or sharp surfaces (on parts, materials, etc) can put pressure on } \\
\text { underlying nerves, arteries, and tendons } \\
\text { - Consider point of contact, size of surfaces, pressure and duration }\end{array}$ \\
\hline 11. Wrist posture & $\begin{array}{l}\text { - Mid-range (neutral) wrist posture associated with less muscle fatigue, } \\
\text { higher force capability and reduced injury risk }\end{array}$ \\
\hline $\begin{array}{l}\text { 12. Shoulder posture } \\
\text { (reach) }\end{array}$ & $\begin{array}{l}\text { - Increasing reach increases muscle load on shoulders and time to } \\
\text { perform task, and reduces precision }\end{array}$ \\
\hline 13. Shoulder loading & $\begin{array}{l}\text { - Work with unsupported arms increases shoulder load and fatigue and } \\
\text { reduces precision, especially with increased weight of a tool or part } \\
\text { - Reduced precision impacts quality and cycle time }\end{array}$ \\
\hline 14. Task duration & - Duration affects muscle loading, fatigue and time \\
\hline 15. Visual requirements & $\begin{array}{l}\text { - Poor visual requirements adversely affect posture of neck and arms } \\
\text { and reduce quality of assembly } \\
\text { - Obstructed assembly increases time }\end{array}$ \\
\hline 16. Visual accuracy & $\begin{array}{l}\text { - Visual accuracy }(<1 \mathrm{~mm}) \text { affects loading on muscles, mental workload } \\
\text { and visual demands/strain on worker }\end{array}$ \\
\hline
\end{tabular}




\begin{tabular}{|l|l|}
\hline $\begin{array}{l}\text { 17. Inspection difficulty } \\
\text { (during and after assembly) }\end{array}$ & $\begin{array}{l}\text { - Affects mental workload, time for task and potentially quality. } \\
\text { - May affect posture. }\end{array}$ \\
\hline $\begin{array}{l}\text { 18. Visual Task Contrast } \\
\text { - Lack of contrast increases visual requirements, and can lead to } \\
\text { awkward postures and operator error }\end{array}$ \\
\hline $\begin{array}{l}\text { 19. Task feedback } \\
\text { (eg. hear or feel snap) }\end{array}$ & $\begin{array}{l}\text { - Affects quality of assembly and mental workload } \\
\text { - Easy feedback improves cycle time }\end{array}$ \\
\hline $\begin{array}{l}\text { 20. Ability to detect quality problem } \\
\text { 21. Fragility of part }\end{array}$ & $\begin{array}{l}\text { - Affects ease of assembly, and need for a work-around } \\
\text { 22. Risk of Damage to Part } \\
\text { or Component (quality) }\end{array}$ \\
\hline
\end{tabular}




\section{APPENDIX E}

\section{Properties and Dimensions for 11 Categories in Grounded Theory Analysis}

\section{Application and Uptake of HF}

\begin{tabular}{|c|c|}
\hline Properties & Dimensions \\
\hline $\begin{array}{l}\text { When HF is applied: } \\
\text {-in design } \\
\text {-frequency }\end{array}$ & $\begin{array}{l}\text { Reactive/too late } \rightarrow \text { some time to make } \\
\text { changes } \rightarrow \text { proactively } \\
\text { low } \rightarrow \text { moderate } \rightarrow \text { high frequency }\end{array}$ \\
\hline Who applies HF in design & $\begin{array}{l}\text { ergonomist } \rightarrow \text { some ergo/some eng } \rightarrow \text { all } \\
\text { engineers }\end{array}$ \\
\hline $\begin{array}{l}\text { How HF is applied: } \\
\text {-HF external to engineering vs inherently } \\
\text {-stand-alone vs integrated in BPI ( } 6 \text { Sigma, etc) } \\
- \text {-HF designed into each process with no gaps (eg } \\
\text { fixtures, workstation layout, DFA) } \\
- \text { HF is a guideline (optional), or a target (required) }\end{array}$ & $\begin{array}{l}\text { External HF person/dept } \rightarrow \\
\text { somewhat by eng } \rightarrow \text { inherent by engineers } \\
\text { Stand-alone } \rightarrow \text { somewhat integrated } \rightarrow \text { fully } \\
\text { integrated with BPI } \\
\text { Gaps/few processes } \rightarrow \text { some process } \rightarrow \text { all } \\
\text { process/no gaps } \\
\text { Optional/guideline } \rightarrow \text { recommended } \rightarrow \\
\text { required/target }\end{array}$ \\
\hline $\begin{array}{l}\text { When HF issue is identified: } \\
\text {-time taken to remedy } \\
\text {-chance of recurrence of HF issue }\end{array}$ & $\begin{array}{l}\text { slow } \rightarrow \text { moderate } \rightarrow \text { very quick } \\
\text { high chance } \rightarrow \text { moderate } \rightarrow \text { little or no chance }\end{array}$ \\
\hline $\begin{array}{l}\text { HF tools: } \\
\text {-appropriate to situation (eg. DFA) } \\
\text {-who uses tool } \\
\text {-tool communicates HF concern }\end{array}$ & $\begin{array}{l}\text { No tool/not appropriate } \rightarrow \text { somewhat } \rightarrow \text { tool } \\
\text { appropriate to situation } \\
\text { ergonomist } \rightarrow \text { ergo and some others } \rightarrow \\
\text { engineers/change team members } \\
\text { poorly } \rightarrow \text { somewhat } \rightarrow \text { fully }\end{array}$ \\
\hline $\begin{array}{l}\text { For repeated designs (eg fixtures) } \\
\text {-HF template with standard features available } \\
\text {-few simple design rules available } \\
\text {-engineers have training in rules }\end{array}$ & $\begin{array}{l}\text { Not available } \rightarrow \text { somewhat } \rightarrow \text { template and } \\
\text { standards available } \\
\text { Not available } \rightarrow \text { somewhat } \rightarrow \text { available } \\
\text { No training } \rightarrow \text { some training } \rightarrow \text { ongoing training }\end{array}$ \\
\hline $\begin{array}{l}\text { HF reviewed after launch for best } \\
\text { practices/benchmarking }\end{array}$ & no $\rightarrow$ somewhat $\rightarrow$ fully \\
\hline $\begin{array}{l}\text { Criteria revised and updated based on lessons } \\
\text { learned }\end{array}$ & no $\rightarrow$ somewhat $\rightarrow$ fully \\
\hline $\begin{array}{l}\text { Outside vendors/designers provided HF rules and } \\
\text { guidelines }\end{array}$ & no $\rightarrow$ somewhat $\rightarrow$ fully \\
\hline HF relationship to quality identified/measured & no $\rightarrow$ somewhat $\rightarrow$ fully \\
\hline Mechanism to indicate HF-related defects in design & no $\rightarrow$ somewhat $\rightarrow$ fully \\
\hline HF metrics available & no $\rightarrow$ somewhat $\rightarrow$ fully \\
\hline
\end{tabular}




\section{Quality and Influence of Initiative}

\begin{tabular}{|c|c|}
\hline Properties & Dimensions \\
\hline Well scoped (range of view, outlook, application) & $\begin{array}{l}\text { Poor or narrow scope } \rightarrow \text { mid } \\
\text { range } \rightarrow \text { wide scope }\end{array}$ \\
\hline Well documented (what, where, when) & $\begin{array}{l}\text { Poorly documented } \rightarrow \text { some } \\
\text { documentation } \rightarrow \text { well documented }\end{array}$ \\
\hline Measured/demonstrated/documented effectiveness & $\begin{array}{l}\text { Not measured/demo } \rightarrow \text { some } \\
\text { measures } \rightarrow \text { well measured/doc'd }\end{array}$ \\
\hline Level of influence within engineering dept & $\begin{array}{l}\text { none } \rightarrow \text { a few/small group } \rightarrow \text { all } \mathrm{mfg} \\
\text { engineers }\end{array}$ \\
\hline Level of influence of initiative on workers & $\begin{array}{l}\text { Few/workstation } \rightarrow \text { small number } \rightarrow \\
\text { widespread (EMS sites) }\end{array}$ \\
\hline Level of influence within a process (eg DFF) & $\begin{array}{l}\text { none } \rightarrow \text { small (check-boxes) } \rightarrow \text { fully } \\
\text { intergrated throughout }\end{array}$ \\
\hline $\begin{array}{l}\text { Ownership influence (eg. full ownership is taking } \\
\text { scorecard and developing spreadsheet \& targets) }\end{array}$ & $\begin{array}{l}\text { Ryerson only } \rightarrow \mathrm{RIM}+\mathrm{Ry} \rightarrow \mathrm{RIM} \text { takes } \\
\text { ownership }\end{array}$ \\
\hline Outcome effect (timing) & $\begin{array}{l}\text { No uptake } \rightarrow \text { partial uptake } \rightarrow \\
\text { immediate institutionalization }\end{array}$ \\
\hline Timing of influence in design cycle & reactive $\rightarrow$ intermediate $\rightarrow$ proactive \\
\hline $\begin{array}{l}\text { Outcome effect - effect of potential change on workers } \\
\text { (eg. small may be single fixture, large may be entire } \\
\text { process design) }\end{array}$ & none $\rightarrow$ some $\rightarrow$ large \\
\hline Proof of quality & $\begin{array}{l}\text { none } \rightarrow \text { informal }(\text { ask people) } \rightarrow \text { formal } \\
\text { (validation of model) }\end{array}$ \\
\hline Demonstration of changes & $\begin{array}{l}\text { None or anticipated } \rightarrow \text { small } \rightarrow \text { good } \\
\text { demonstration of effect }\end{array}$ \\
\hline Interest from Sr. Mgt & $\begin{array}{l}\text { None/small } \rightarrow \text { some/from a few } \rightarrow \\
\text { widespread and many }\end{array}$ \\
\hline Influence on design process & $\begin{array}{l}\text { none } \rightarrow \text { one or two stages } \rightarrow \text { multiple } \\
\text { stages (product, mfg, assembly, EMS) }\end{array}$ \\
\hline $\begin{array}{l}\text { Standardization ability (leads to standardization of } \\
\text { process, design, etc) }\end{array}$ & none $\rightarrow$ some $\rightarrow$ widespread \\
\hline Permanence & $\begin{array}{l}\text { brief } \rightarrow \text { mid range } \rightarrow \text { long range and } \\
\text { permanent }\end{array}$ \\
\hline Person or Process Dependence & $\begin{array}{l}\text { Person dependent } \rightarrow \text { position } \\
\text { dependence } \rightarrow \text { locked in process }\end{array}$ \\
\hline
\end{tabular}




\section{Vision, Leadership and Support}

\begin{tabular}{|c|c|}
\hline Properties & Dimensions \\
\hline Timing of support (when) & $\begin{array}{l}\text { Prior to initiative } \rightarrow \text { during } \rightarrow \text { after demo } \\
\text { or results }\end{array}$ \\
\hline $\begin{array}{r}\text { Type of: verbal - frequency } \\
\text { - intensity of support }\end{array}$ & $\begin{array}{l}\text { none } \rightarrow \text { occasional } \rightarrow \text { very frequent } \\
\text { none } \rightarrow \text { conditional } \rightarrow \text { full support }\end{array}$ \\
\hline Type of: resources - amount & none $\rightarrow$ some $\rightarrow$ considerable \\
\hline Type of: participation with HF & none $\rightarrow$ some $\rightarrow$ considerable \\
\hline Type of: network/contacts & Lack of $\rightarrow$ some access $\rightarrow$ full access \\
\hline Type of: monitoring progress & none $\rightarrow$ some $\rightarrow$ active \\
\hline Type of: access to documents, meetings etc & none $\rightarrow$ some $\rightarrow$ full access \\
\hline Type of: legitimizing & none $\rightarrow$ some $\rightarrow$ full support \\
\hline See vision, provide ideas & none $\rightarrow$ some $\rightarrow$ many ideas \\
\hline Support for locking HF into process & Lack process $\rightarrow$ some $\rightarrow$ full lock-in \\
\hline Provision or nature of support & required $\rightarrow$ some interest $\rightarrow$ voluntary \\
\hline Frequency of support & once $\rightarrow$ several $\rightarrow$ ongoing \\
\hline Increasing org support/share with others & none $\rightarrow$ some $\rightarrow$ ongoing \\
\hline Request for HF input (positioning of HF) & Push HF $\rightarrow$ push/pull $\rightarrow$ pull for HF \\
\hline Level of support within hierarchy & Workers/eng $\rightarrow$ mid mgt $\rightarrow$ Sr. Dir \\
\hline Prior experience with HF & None/poor $\rightarrow$ some $\rightarrow$ extensive \\
\hline Recognition of "fit" with strategies/bus & None/poor fit $\rightarrow$ some $\rightarrow$ full fit \\
\hline Future impact apparent & none $\rightarrow$ some $\rightarrow$ fully \\
\hline Human factors domain/understanding & $\begin{array}{l}\text { Simple/injuries } \rightarrow \text { broader (fatigue) } \\
\rightarrow \text { many aspects (perf, cognitive) }\end{array}$ \\
\hline Involvement/participation (meetings, etc) & minimal $\rightarrow$ some $\rightarrow$ fully engaged \\
\hline Recognition of novelty of HF initiative & Not novel $\rightarrow$ somewhat $\rightarrow$ completely \\
\hline $\begin{aligned} & \text { Recognition of potential impact of HF } \\
&- \text { extent } \\
&- \text { numbers impacted }\end{aligned}$ & $\begin{array}{l}\text { Small (workstation, tool) } \\
\rightarrow \text { moderate } \rightarrow \text { large (assembly) } \\
\text { few } \rightarrow \text { many } \rightarrow \text { large (EMS sites) }\end{array}$ \\
\hline
\end{tabular}




\section{Who's in the Sandbox?}

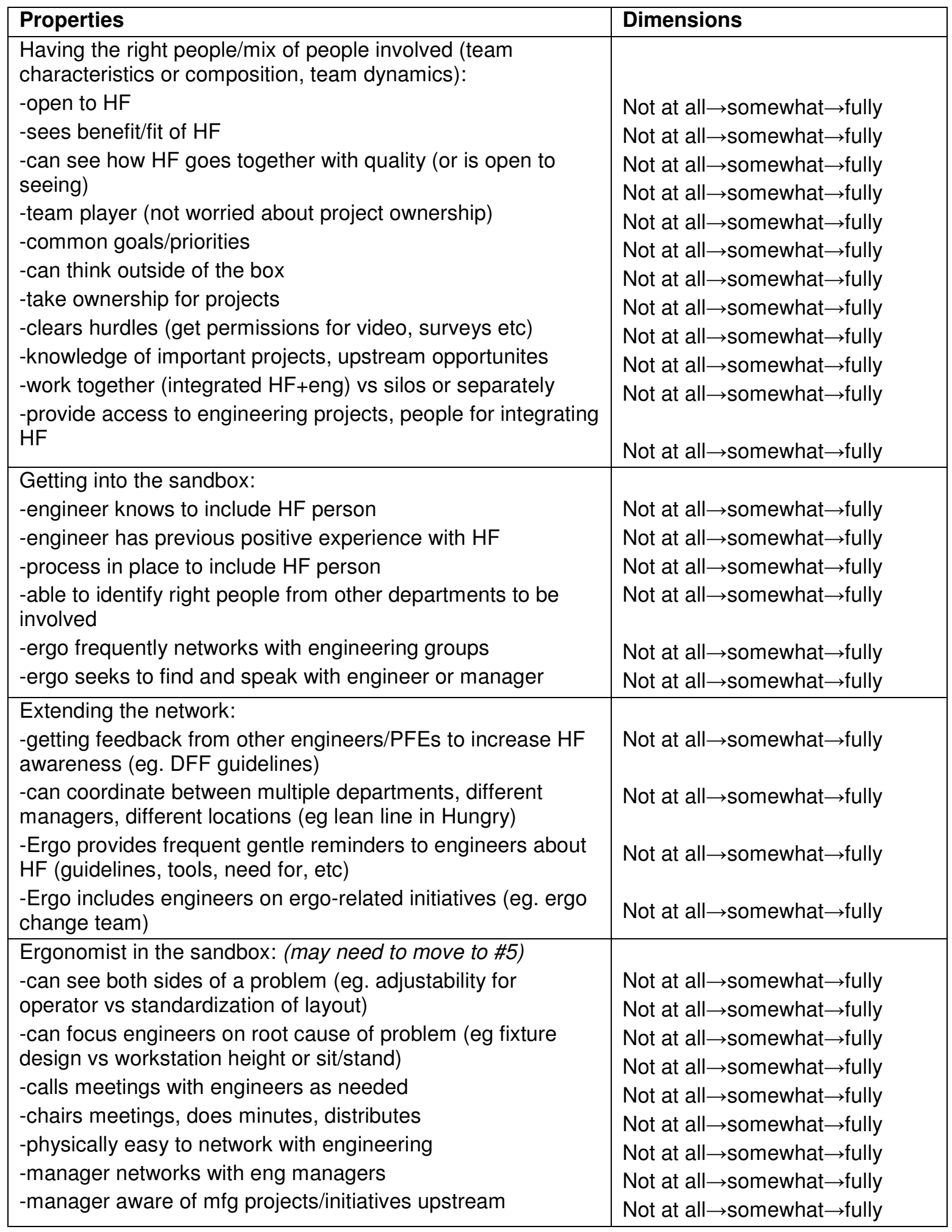




\section{Communication re HF}

\begin{tabular}{|l|l|}
\hline Properties & Dimensions \\
\hline HF activity disruption to others: & $\begin{array}{l}\text { considerable } \rightarrow \text { some } \rightarrow \text { none } \\
\text { considerable } \rightarrow \text { some } \rightarrow \text { none } \\
\text {-senior managers }\end{array}$ \\
-other engineers & $\begin{array}{l}\text { considerable } \rightarrow \text { some } \rightarrow \text { none } \\
\text { considerable } \rightarrow \text { some } \rightarrow \text { none }\end{array}$ \\
-production focused engineers & no $\rightarrow$ somewhat $\rightarrow$ fully \\
-workers on line & no $\rightarrow$ somewhat $\rightarrow$ fully \\
\hline Management and coordination of HF activities: & no $\rightarrow$ somewhat $\rightarrow$ fully \\
-participants aware of what is happening & no $\rightarrow$ somewhat $\rightarrow$ fully \\
-participants know objectives & no $\rightarrow$ somewhat $\rightarrow$ fully \\
-participants know their roles & no $\rightarrow$ somewhat $\rightarrow$ fully \\
-participants expectations clear & no $\rightarrow$ somewhat $\rightarrow$ fully \\
-ergos know who should be involved & no $\rightarrow$ somewhat $\rightarrow$ fully \\
-timeline clear and updated regularly & no $\rightarrow$ somewhat $\rightarrow$ fully \\
\hline HF communicated in non-technical terms & \\
\hline Positive HF communicated (not just problems) & \\
\hline Answers are appropriate to the question (detail, timeframe & \\
etc) & \\
\hline
\end{tabular}




\section{The Ergonomist (skills, education, and role)}

\begin{tabular}{|c|c|}
\hline Properties & Pimensions \\
\hline $\begin{array}{l}\text { Ergo strategy, planning and preparation (eg for meeting): } \\
\text {-objective or goal clear (eg to achieve from meeting) } \\
\text {-planned with audience in mind } \\
\text {-focus on contribution to engineering goals (eg quality) } \\
\text {-focus on aligning with rather than increasing workload } \\
\text {-focus on bigger picture: proactive vs reactive } \\
\text {-focus on large impact (EMS) vs single workstation } \\
\text {-focus on breadth of HF (not just physical risks) }\end{array}$ & $\begin{array}{l}\text { unclear } \rightarrow \text { somewhat } \rightarrow \text { clear } \\
\text { no } \rightarrow \text { somewhat } \rightarrow \text { fully } \\
\text { no } \rightarrow \text { somewhat } \rightarrow \text { fully } \\
\text { no } \rightarrow \text { somewhat } \rightarrow \text { fully } \\
\text { no } \rightarrow \text { somewhat } \rightarrow \text { fully } \\
\text { no } \rightarrow \text { somewhat } \rightarrow \text { fully } \\
\text { no } \rightarrow \text { somewhat } \rightarrow \text { fully }\end{array}$ \\
\hline $\begin{array}{l}\text { Ergo does background work to understand: } \\
\text {-who is involved in which processes (eg quality, FMEA) } \\
\text {-how process (eg assembly, FMEA) works } \\
\text {-boundaries of each process (eg fixtures vs workstation) } \\
\text {-what are the main deliverables, goals and targets (eg CTQ) } \\
\text {-what are timeframes -where does HF best fit }\end{array}$ & $\begin{array}{l}\text { No background work } \rightarrow \\
\text { some background gathered } \\
\rightarrow \text { fully knowledgeable about } \\
\text { people, process and } \\
\text { timeframes }\end{array}$ \\
\hline $\begin{array}{l}\text { Ergo has, or seeks, education in engineering and BPI activities } \\
\text { related to organization }\end{array}$ & educated in related are \\
\hline Ergo can identify roadblocks (difficulties getting engaged) & no $\rightarrow$ somewhat $\rightarrow$ fully \\
\hline Ergo recognizes how to & no $\rightarrow$ somewhat $\rightarrow$ fully \\
\hline $\begin{array}{l}\text { Interactions/communication with engineers: } \\
\text {-raising questions or issues vs blaming/questioning design } \\
\text {-positive and helpful } \\
\text {-translates HF knowledge into accessible form consistent with } \\
\text { engineering and BPI (speak their language) } \\
\text {-provides HF info in documentation consistent with engineering } \\
\text {-can articulate HF benefits }\end{array}$ & $\begin{array}{l}\text { Blame or question } \rightarrow \text { somewhat } \\
\text { question } \rightarrow \text { raise issue neutrally } \\
\text { negative } \rightarrow \text { neutral } \rightarrow \text { positive } \\
\text { and helpful } \\
\text { no } \rightarrow \text { some ability } \rightarrow \\
\text { knowledge accessible } \\
\text { no documentation } \rightarrow \text { some } \rightarrow \\
\text { full and consistent docu'n } \\
\text { no } \rightarrow \text { somewhat } \rightarrow \text { fully }\end{array}$ \\
\hline $\begin{array}{l}\text { Ergo obtains access (documents, software, postings, } \\
\text { engineering plans, building, etc) }\end{array}$ & $\begin{array}{l}\text { oor access } \rightarrow \text { some } \\
\text { ull access }\end{array}$ \\
\hline $\begin{array}{l}\text { Ergo can develop clear project plans: } \\
\text {-clear objective and justification of problem } \\
\text {-action steps -deliverables -measures -ROI -timelines } \\
\text {-resources needed }\end{array}$ & $\begin{array}{l}\text { No or poor plans } \rightarrow \text { some } \\
\text { elements of plan developed } \\
\rightarrow \text { able to develop clear project } \\
\text { plans with all elements }\end{array}$ \\
\hline Role clearly defined and articulated (eg. between ergo and IE) & $\begin{array}{l}\text { no } \rightarrow \text { somewhat } \rightarrow \text { clear roles } \\
\text { and boundaries }\end{array}$ \\
\hline $\begin{array}{l}\text { Ergo can develop o } \\
\text { engineering tools, tc }\end{array}$ & $\begin{array}{l}\text { no } \rightarrow \text { somewhat } \rightarrow \text { fully able to } \\
\text { develop or adapt tools }\end{array}$ \\
\hline $\begin{array}{l}\text { Ergo can respond to eng needs in timely manner (avoid } \\
\text { paralysis due to need for completeness and validity) }\end{array}$ & $\begin{array}{l}\text { no } \rightarrow \text { somewhat } \rightarrow \text { can provide } \\
\text { timely response }\end{array}$ \\
\hline $\begin{array}{l}\text { Ergo actions to integrate with eng: } \\
\text {-proactive vs reactive }\end{array}$ & $\begin{array}{l}\text { Wait for invite } \rightarrow \text { look for oppor- } \\
\text { tunites } \rightarrow \text { creating opportunities } \\
\text { Push/sell } \rightarrow \text { some push/some } \\
\text { pull } \rightarrow \text { pulled because need } \\
\text { demonstrated with action }\end{array}$ \\
\hline
\end{tabular}




\section{7. $\mathrm{HF} /$ Ergo within Organization}

\begin{tabular}{|c|c|}
\hline Properties & Dimensions \\
\hline $\begin{array}{l}\text { Ergo or Ergo group is visible within org: } \\
\text {-seen on shop floor getting data/info } \\
\text {-involved with high profile projects } \\
\text {-contributing to eng meetings } \\
\text {-engineers include ergos in activities and processes } \\
\text {-engineers aware of scope and capabilities of HF } \\
\text {-ergos involve engineers on their activities (eg ergo change } \\
\text { team) } \\
\text {-ergo group seen as go-to place for HF info } \\
\text {-ergos and group easy physically to access for eng's } \\
\text {-ergos collect examples of HF input/changes for } \\
\text { communication and training of engineers } \\
\text {-ergo manager maintains high profile of group to } \\
\text { engineering managers and directors }\end{array}$ & $\begin{array}{l}\text { never } \rightarrow \text { at times } \rightarrow \text { frequently } \\
\text { never } \rightarrow \text { at times } \rightarrow \text { frequently } \\
\text { never } \rightarrow \text { at times } \rightarrow \text { frequently } \\
\text { never } \rightarrow \text { at times } \rightarrow \text { frequently } \\
\text { no } \rightarrow \text { somewhat } \rightarrow \text { completely } \\
\text { never } \rightarrow \text { at times } \rightarrow \text { frequently } \\
\text { never } \rightarrow \text { at times } \rightarrow \text { frequently } \\
\text { never } \rightarrow \text { at times } \rightarrow \text { frequently } \\
\text { never } \rightarrow \text { at times } \rightarrow \text { frequently }\end{array}$ \\
\hline $\begin{array}{l}\text { Ergo group positioning in design process: } \\
\text {-ergo group is linked to appropriate groups with roles } \\
\text { clearly defined (eg. IE, PFE) } \\
\text {-ergo manager aware of high profile processes and projects } \\
\text { and ensures ergo group involved } \\
\text {-processes involve input from ergo's } \\
\text {-ergo documents/guidelines/tools available to eng's } \\
\text {-eng know about ergo documents and input (when to } \\
\text { engage ergo) } \\
\text {-ergos aware of new products, processes and tooling in } \\
\text { advance } \\
\text {-ergo group has specific goals and outcomes } \\
\text {-ergo group uses benchmarking and metrics for } \\
\text { performance measurement } \\
\text {-ergo group activities are integrated with engineering and } \\
\text { not a separate function } \\
\text {-ergo reports to manufacturing engineering so roles and } \\
\text { responsibilities reside within engineering }\end{array}$ & $\begin{array}{l}\text { never } \rightarrow \text { at times } \rightarrow \text { frequently } \\
\text { never } \rightarrow \text { at times } \rightarrow \text { frequently } \\
\text { never } \rightarrow \text { at times } \rightarrow \text { frequently } \\
\text { never } \rightarrow \text { at times } \rightarrow \text { frequently } \\
\text { never } \rightarrow \text { at times } \rightarrow \text { frequently } \\
\text { never } \rightarrow \text { at times } \rightarrow \text { frequently } \\
\text { never } \rightarrow \text { at times } \rightarrow \text { frequently } \\
\text { never } \rightarrow \text { at times } \rightarrow \text { frequently } \\
\text { never } \rightarrow \text { at times } \rightarrow \text { frequently } \\
\text { no } \rightarrow \text { somewhat (cross- } \\
\text { reporting) } \rightarrow \text { completely }\end{array}$ \\
\hline
\end{tabular}




\section{Uncontrollable Organizational/Environmental/Structural Factors}

\begin{tabular}{|c|c|}
\hline Properties & Dimensions \\
\hline $\begin{array}{l}\text { Re-organization, new directors/managers, company } \\
\text { announcement etc. causes disruption (lack clarity of } \\
\text { manager's priorities, job loss, assignment of tasks): } \\
\text {-extent of disruption } \\
\text {-frequency of disruption } \\
\text {-perception of disruption } \\
\text {-company focus/alignment after re-organization } \\
\text {-perception of workload } \\
\text {-availability of time/resources for HF initiatives }\end{array}$ & $\begin{array}{l}\text { None/small } \rightarrow \text { some } \rightarrow \text { large } \\
\text { rare } \rightarrow \text { occasional } \rightarrow \text { frequent } \\
\text { harmful } \rightarrow \text { neutral } \rightarrow \text { helpful } \\
\text { dispersed } \rightarrow \text { neutral } \rightarrow \text { more } \\
\text { focused and aligned to goals } \\
\text { same } \rightarrow \text { slightly more } \rightarrow \text { much } \\
\text { higher } \\
\text { none } \rightarrow \text { some } \rightarrow \text { lots }\end{array}$ \\
\hline $\begin{array}{l}\text { Re-organization within ergo group (loss of } 2 \text { ergo's, chang } \\
2 \text { managers and one director) } \\
\text {-extent of disruption } \\
\text {-frequency of disruption } \\
\text {-perception of disruption } \\
\text {-HF group alignment with business goals } \\
\text {-perception of workload } \\
\text {-availability of time/resources for inventive initiatives }\end{array}$ & $\begin{array}{l}\text { None } / \text { small } \rightarrow \text { some } \rightarrow \text { large } \\
\text { rare } \rightarrow \text { occasional } \rightarrow \text { frequent } \\
\text { harmful } \rightarrow \text { neutral } \rightarrow \text { helpful } \\
\text { dispersed } \rightarrow \text { neutral } \rightarrow \text { more } \\
\text { focused and aligned to goals } \\
\text { same } \rightarrow \text { slightly more } \rightarrow \text { much } \\
\text { higher } \\
\text { same } \rightarrow \text { slightly more } \rightarrow \text { much } \\
\text { higher }\end{array}$ \\
\hline Attitude toward change (new ideas, initiatives, re-org) & harmful $\rightarrow$ neutral $\rightarrow$ helpful \\
\hline $\begin{array}{l}\text { Ergo group positioned structurally to weather changes in } \\
\text { positions/personnel/priorities, etc. }\end{array}$ & no $\rightarrow$ somewhat $\rightarrow$ totally \\
\hline $\begin{array}{l}\text { Ergo initiatives positioned (goals, timelines, deliverables, } \\
\text { span of departments, and sufficient initiatives) to weather } \\
\text { changes in positions/personnel/ } \\
\text { priorities, etc. }\end{array}$ & no $\rightarrow$ somewhat $\rightarrow$ totally \\
\hline
\end{tabular}




\section{Aligning with Engineering and BPI Programs}

\begin{tabular}{|c|c|}
\hline Properties & Dimensions \\
\hline Plan with steps, deliverables, timeframes & none $\rightarrow$ some $\rightarrow$ fully documented \\
\hline Quantifiable: numbers, a model, can be scored or rated & $\begin{array}{l}\text { Not quantifiable } \rightarrow \text { somewhat } \\
\rightarrow \text { very quantifiable }\end{array}$ \\
\hline Has been validated (practically in-house) & $\begin{array}{l}\text { Not validated } \rightarrow \text { somewhat validated } \\
\rightarrow \text { validated }\end{array}$ \\
\hline $\begin{array}{l}\text { Fits with eng tools and processes (5 Why's, } 6 \text { sigma, Cl, } \\
\text { hoishins, kaizens, DES software, etc) }\end{array}$ & Poor fit $\rightarrow$ some fit $\rightarrow$ considerable fit \\
\hline Fit with manager (identify who should own) & Poor fit $\rightarrow$ some fit $\rightarrow$ obvious fit \\
\hline Fit with expectations (eg. level of detail) & Poor fit $\rightarrow$ some fit $\rightarrow$ good fit \\
\hline $\begin{array}{l}\text { Fit with timing (can meet their key milestones and need for } \\
\text { timely information eg. } 10 / 26 \text { wks to improve) }\end{array}$ & Poor fit $\rightarrow$ some fit $\rightarrow$ good fit \\
\hline $\begin{array}{l}\text { Ergo contributes first hand (shop floor) knowledge of } \\
\text { assembly process (materials, techniques, supplies etc) }\end{array}$ & None $\rightarrow$ some $\rightarrow$ considerable \\
\hline $\begin{array}{l}\text { Has thresholds, guidelines, limits, takts, KPIs, benchmark, } \\
\text { red/green zones, etc (measurable with limits) }\end{array}$ & none $\rightarrow$ some $\rightarrow$ considerable \\
\hline $\begin{array}{l}\text { Directly addresses operational/business goals, influences } \\
\text { key metrics (productivity, quality, etc) }\end{array}$ & Doesn't $\rightarrow$ somewhat $\rightarrow$ directly \\
\hline $\begin{array}{l}\text { Tool utility: is visual, quick, easy, nimble, allows engineers } \\
\text { to see problems (eg., design rules, schematics) }\end{array}$ & $\begin{array}{l}\text { Poor utility } \rightarrow \text { some utility } \\
\rightarrow \text { considerable utility }\end{array}$ \\
\hline $\begin{array}{l}\text { Facilitates action - demonstration of improvements - focus } \\
\text { on changes, results in improvements }\end{array}$ & none $\rightarrow$ some $\rightarrow$ considerable \\
\hline $\begin{array}{l}\text { Fit with high priority initiatives, assembly lines (showed } \\
\text { improvement on important program) }\end{array}$ & No fit $\rightarrow$ some $\rightarrow$ high priority fit \\
\hline $\begin{array}{l}\text { Eng. pattern followed: Tool first, show results, discuss } \\
\text { process for integrating }\end{array}$ & $\begin{array}{l}\text { Pattern not followed } \rightarrow \text { somewhat } \\
\rightarrow \text { pattern followed }\end{array}$ \\
\hline $\begin{array}{l}\text { Adapted Ergo Focus: Ergo's have eng process knowledge, } \\
\text { language, familiarity, eng tools etc. (not injuries, HF tools) }\end{array}$ & $\begin{array}{l}\text { Ergo's have not } \\
\text { adapted } \rightarrow \text { somewhat } \rightarrow \text { adapted }\end{array}$ \\
\hline $\begin{array}{l}\text { Can communicate HF concerns consistent with engineers } \\
\text { (items with ratings, vs observations) }\end{array}$ & $\begin{array}{l}\text { Poor communication } \rightarrow \text { some } \rightarrow \\
\text { communicates HF concerns well }\end{array}$ \\
\hline $\begin{array}{l}\text { Sensitizes designers/eng's (allows them to see differently, } \\
\text { to experience, feel, etc) }\end{array}$ & $\begin{array}{l}\text { Not at all } \rightarrow \text { somewhat } \rightarrow \\
\text { sensitizes well }\end{array}$ \\
\hline $\begin{array}{l}\text { HF helps directly with eng job or tasks (making business } \\
\text { case for automation, proving lean line etc) }\end{array}$ & $\begin{array}{l}\text { No help } \rightarrow \text { helps somewhat } \rightarrow \\
\text { direct help with eng tasks }\end{array}$ \\
\hline $\begin{array}{l}\text { HF step embedded in process (eg. FMEA work order, DFF } \\
\text { sign-off) }\end{array}$ & $\begin{array}{l}\text { Not embedded } \rightarrow \text { somewhat } \rightarrow \\
\text { fully embedded }\end{array}$ \\
\hline $\begin{array}{l}\text { Initiation of HF (should be pulled from eng vs pushed from } \\
\text { ergo, eng know value) }\end{array}$ & $\begin{array}{l}\text { pushed } \rightarrow \text { somewhat pushed, somewhat } \\
\text { pulled } \rightarrow \text { pulled from eng }\end{array}$ \\
\hline $\mathrm{HF}$ is specific and tangible & Not at all $\rightarrow$ somewhat $\rightarrow$ very \\
\hline $\begin{array}{l}\text { Compatible with eng workload (doesn't increase, } \\
\text { overwhelm, significantly change, etc) }\end{array}$ & $\begin{array}{l}\text { Not compatible } \rightarrow \text { somewhat } \rightarrow \\
\text { increases eng workload considerably }\end{array}$ \\
\hline $\begin{array}{l}\text { Ergos see strategy for fit (working tog toward business } \\
\text { goal, vs pushing/asking to get in) }\end{array}$ & $\begin{array}{l}\text { No strategy } \rightarrow \text { some strategies } \rightarrow \\
\text { well developed strategy }\end{array}$ \\
\hline Progress obvious, demonstrated, communicated & $\begin{array}{l}\text { Lack of progress } \rightarrow \text { some progress } \rightarrow \\
\text { progress demonstrated }\end{array}$ \\
\hline Transferability and applicability (to EMS sites) & $\begin{array}{l}\text { Not transferable } \rightarrow \text { somewhat } \rightarrow \\
\text { highly transferable }\end{array}$ \\
\hline
\end{tabular}




\section{Hands On and Visible}

\begin{tabular}{|c|c|}
\hline Properties & Dimensions \\
\hline $\begin{array}{l}\text { Visibility of ergo on shop floor, collecting data, observing, } \\
\text { measuring: } \\
\text {-Extent } \\
\text {-Frequency } \\
\text {-Timeliness of } \\
\text {-Reporting back } \\
\text {-Initiation of } \\
\text {-Extent of involvement with engineers on floor }\end{array}$ & $\begin{array}{l}\text { Not at all } \rightarrow \text { some } \rightarrow \\
\text { extensively } \\
\text { never } \rightarrow \text { occasionally } \rightarrow \text { freq } \\
\text { too late } \rightarrow \text { when convenient } \\
\rightarrow \text { in timely fashion } \\
\text { never } \rightarrow \text { informal } \rightarrow \text { written } \\
\text { eng } \rightarrow \text { PFE mgr } \rightarrow \text { Sr Dir } \\
\text { never } \rightarrow \text { at times } \rightarrow \text { frequently }\end{array}$ \\
\hline $\begin{array}{l}\text { Make visible improvements/changes } \\
\text { Document changes as examples - frequency }\end{array}$ & $\begin{array}{l}\text { none } \rightarrow \text { some potential } \rightarrow \\
\text { effective changes made } \\
\text { never } \rightarrow \text { occas } \rightarrow \text { always }\end{array}$ \\
\hline $\begin{array}{l}\text { Visibility of HF issue (photo, video, tool): increased } \\
\text { awareness/action } \\
\text {-revealed design problems to engineers }\end{array}$ & $\begin{array}{l}\text { Not at all } \rightarrow \text { somewhat } \rightarrow \\
\text { considerably } \\
\text { Not at all } \rightarrow \text { somewhat } \rightarrow \\
\text { considerably }\end{array}$ \\
\hline $\begin{array}{l}\text { Make visible or show us (what needs to be done, the changes, } \\
\text { the impact, proof it works) } \\
\text {-extent of } \\
\text {-frequency of }\end{array}$ & $\begin{array}{l}\text { Can't show } \rightarrow \text { can somewhat } \\
\text { show } \rightarrow \text { readily seen } \\
\text { Never/rarely } \rightarrow \text { occasionally } \\
\rightarrow \text { frequently demonstrate }\end{array}$ \\
\hline $\begin{array}{l}\text { Visibility of Ergonomist in Engineering Dept/Meetings } \\
\text {-extent of } \\
\text {-frequency of }\end{array}$ & $\begin{array}{l}\text { none } \rightarrow \text { some } \rightarrow \text { large extent } \\
\text { never } \rightarrow \text { at times } \rightarrow \text { frequently }\end{array}$ \\
\hline $\begin{array}{l}\text { Visibility of HF initiative/tool (eg. shoulder load, ergo } \\
\text { guidelines): } \\
\text {-goals/objectives } \\
\text {-progress } \\
\text {-achievements } \\
\text {-ability to make improvements } \\
\text {-how it can be incorporated }\end{array}$ & $\begin{array}{l}\text { Not at all } \rightarrow \text { somewhat } \rightarrow \\
\text { very visible }\end{array}$ \\
\hline
\end{tabular}




\section{Strategizing and Creating Opportunities}

\begin{tabular}{|c|c|}
\hline Properties & Dimensions \\
\hline $\begin{array}{l}\text { HF is unique or piggybacks on another process initiative (eg. } \\
\text { DFF being formalized) }\end{array}$ & $\begin{array}{l}\text { Unique/stand-alone } \rightarrow \text { fits } \\
\text { somewhat } \rightarrow \text { benefits from other } \\
\text { internal initiative }\end{array}$ \\
\hline Ability to explore the "ideal" (eg tool points to ideal layout) & $\begin{array}{l}\text { No ability } \rightarrow \text { some } \rightarrow \text { provides } \\
\text { ability }\end{array}$ \\
\hline $\begin{array}{l}\text { Bridging HF with engineering (tool, video, etc) i.e. boundary } \\
\text { object }\end{array}$ & $\begin{array}{l}\text { No bridge } \rightarrow \text { somewhat } \rightarrow \\
\text { bridges gap }\end{array}$ \\
\hline Can use examples from elsewhere (eg benchmarking, DFA) & none $\rightarrow$ some $\rightarrow$ extensive \\
\hline $\begin{array}{l}\text { Ergo Strategizing: } \\
\text {-Ergo and ergo mgr have ability to strategize } \\
\text {-frequency ergo and ergo manager plan strategy } \\
\text {-focus is on proactive vs reactive ergo } \\
\text {-reflection on actions (eg meetings, conversations) } \\
\text {-HF document strategies to learn from } \\
\text {-ergos learn who's who } \\
\text {-ergos learn process before embedding HF } \\
\text {-ergos create opportunities (vs waiting) }\end{array}$ & $\begin{array}{l}\text { none } \rightarrow \text { some } \rightarrow \text { extensive } \\
\text { never/rare } \rightarrow \text { occasionally } \rightarrow \\
\text { frequently/regularly } \\
\text { none } / \text { little } \rightarrow \text { some } \rightarrow \text { extensive } \\
\text { none } \rightarrow \text { some } \rightarrow \text { extensive } \\
\text { none } \rightarrow \text { some } \rightarrow \text { extensive } \\
\text { none } \rightarrow \text { some } \rightarrow \text { extensive } \\
\text { none } \rightarrow \text { some } \rightarrow \text { extensive } \\
\text { none } \rightarrow \text { some } \rightarrow \text { extensive }\end{array}$ \\
\hline $\begin{array}{l}\text { Aware of supervisor and reporting structure (of engineers } \\
\text { involved) that facilitates HF initiative }\end{array}$ & no $\rightarrow$ somewhat $\rightarrow$ yes \\
\hline Ergos provide regular updates/promotion on initiatives & no $\rightarrow$ at times $\rightarrow$ frequently \\
\hline Ergos provide info about HF objectives & no $\rightarrow$ at times $\rightarrow$ frequently \\
\hline $\begin{array}{l}\text { Number of HF initiatives ongoing (more ideas, more activity, } \\
\text { more visibility) }\end{array}$ & few $\rightarrow$ some $\rightarrow$ large number \\
\hline Number of cross-departments HF impacts (works with) & few $\rightarrow$ some $\rightarrow$ many \\
\hline Ergo manager ensures HF initiatives well positioned & no $\rightarrow$ somewhat $\rightarrow$ fully \\
\hline Holistic view of HF shared (with productivity/quality) & no $\rightarrow$ somewhat $\rightarrow$ fully \\
\hline Ergos respond quickly to engineer requests & no $\rightarrow$ somewhat $\rightarrow$ fully \\
\hline $\begin{array}{l}\text { Ergos leverage engineer request to look for more } \\
\text { opportunities }\end{array}$ & no $\rightarrow$ somewhat $\rightarrow$ fully \\
\hline Ergo's part of team vs separate (silo) & no $\rightarrow$ somewhat $\rightarrow$ fully \\
\hline Ergos sensitive to phase in HF, not overwhelm engineers & no $\rightarrow$ somewhat $\rightarrow$ fully \\
\hline
\end{tabular}




\section{APPENDIX F. Comparative Matrix of Properties and Initiatives from Grounded Theory Analysis}

\begin{tabular}{|c|c|c|c|c|c|c|c|c|c|c|c|c|}
\hline & 2010 & $\begin{array}{c}\text { Process } \\
\text { Map }\end{array}$ & DES & $\begin{array}{l}\text { Shld } \\
\text { Tool }\end{array}$ & Cog Map & FMEA & $\begin{array}{l}\text { DFF } \\
\text { Guides }\end{array}$ & $\begin{array}{l}\text { Lean } \\
\text { Line }\end{array}$ & $\begin{array}{c}\text { DFA } \\
\text { Scorecd }\end{array}$ & $\begin{array}{l}\text { Kaizens, } \\
\text { Gembas, } \\
\text { Hoishins }\end{array}$ & WEE & $\begin{array}{c}\text { Overall } \\
\text { Integration }\end{array}$ \\
\hline \multicolumn{13}{|l|}{ A. Causal Conditions } \\
\hline $\begin{array}{l}\text { Ry initiated (0), RIM-Ry (1), RIM } \\
\text { (2) }\end{array}$ & 0 & 0 & 0 & 0 & 0 & 1 & 2 & 2 & 1 & 2 & 1 & 1 \\
\hline \multicolumn{13}{|l|}{ B. Application \& Uptake of HF } \\
\hline high quality & 1 & 2 & 2 & 2 & 0 & 2 & 2 & 2 & 2 & 2 & 2 & 2 \\
\hline How - required (vs one-off) & 0 & 0 & 0 & 0 & 0 & 2 & 2 & 0 & 2 & 2 & 1 & 2 \\
\hline HF tool developed (appropriate) & 0 & 0 & 0 & 1 & 2 & 2 & 2 & 0 & 2 & 1 & 2 & 2 \\
\hline $\begin{array}{l}\text { Corrects repeated } \\
\text { concerns/lessons learned }\end{array}$ & 0 & 0 & 0 & 1 & 0 & 2 & 2 & 2 & 2 & 2 & 1 & 2 \\
\hline $\begin{array}{l}\text { Leads to best } \\
\text { practices/benchmarking }\end{array}$ & 0 & 0 & 1 & 2 & 0 & 2 & 2 & 1 & 2 & 2 & 2 & 2 \\
\hline HF aligned with quality & 0 & 0 & 1 & 0 & 2 & 2 & 2 & 1 & 2 & 2 & 1 & 1 \\
\hline HF metrics & 0 & 0 & 1 & 0 & 0 & 2 & 2 & 0 & 2 & 1 & 2 & 2 \\
\hline Well scoped & 1 & 1 & 2 & 1 & 2 & 2 & 1 & 2 & 2 & 2 & 2 & 1 \\
\hline Well documented & 0 & 1 & 2 & 0 & 2 & 1 & 2 & 2 & 2 & 2 & 2 & 1 \\
\hline Influences engineers & 0 & 0 & 0 & 0 & 2 & 1 & 2 & 1 & 2 & 2 & 2 & 2 \\
\hline Influences workers & 1 & 0 & 0 & 0 & 0 & 1 & 2 & 1 & 2 & 2 & 2 & 2 \\
\hline Influences process & 0 & 0 & 1 & 0 & 0 & 1 & 2 & 1 & 2 & 2 & 2 & 2 \\
\hline Proactive (vs reactive) & 0 & 2 & 2 & 2 & 2 & 2 & 2 & 2 & 2 & 1 & 1 & 2 \\
\hline Demonstrates change & 0 & 0 & 2 & 1 & 1 & 2 & 2 & 2 & 2 & 2 & 2 & 2 \\
\hline Standardization ability & 0 & 0 & 0 & 0 & 0 & 2 & 2 & 2 & 2 & 1 & 2 & 2 \\
\hline Permanence & 0 & 0 & 0 & 0 & 0 & 1 & 2 & 1 & 2 & 2 & 2 & 2 \\
\hline Not process or person dependent & 0 & 0 & 0 & 0 & 0 & 1 & 2 & 0 & 2 & 2 & 1 & 1 \\
\hline Total Application \& Uptake & 3 & 6 & 14 & 10 & 13 & 28 & 33 & 20 & 34 & 30 & 29 & 30 \\
\hline
\end{tabular}




\begin{tabular}{|c|c|c|c|c|c|c|c|c|c|c|c|c|}
\hline & 2010 & $\begin{array}{c}\text { Process } \\
\text { Map }\end{array}$ & DES & $\begin{array}{l}\text { Shld } \\
\text { Tool }\end{array}$ & Cog Map & FMEA & $\begin{array}{l}\text { DFF } \\
\text { Guides }\end{array}$ & $\begin{array}{l}\text { Lean } \\
\text { Line }\end{array}$ & $\begin{array}{c}\text { DFA } \\
\text { Scorecd }\end{array}$ & $\begin{array}{l}\text { Kaizens, } \\
\text { Gembas, } \\
\text { Hoishins }\end{array}$ & WEE & $\begin{array}{c}\text { Overall } \\
\text { Integration }\end{array}$ \\
\hline \multicolumn{13}{|l|}{ C. Context } \\
\hline frequent support from eng & 1 & 1 & 1 & 0 & 0 & 2 & 2 & 2 & 2 & 2 & 1 & 2 \\
\hline Sr Mgt/Dir support & 0 & 1 & 2 & 0 & 2 & 2 & 2 & 2 & 2 & 2 & 2 & 2 \\
\hline Increased organizational support & 0 & 0 & 0 & 0 & 1 & 1 & 2 & 1 & 2 & 2 & 1 & 2 \\
\hline $\begin{array}{l}\text { Involvement/participation with } \\
\text { engineers }\end{array}$ & 1 & 2 & 1 & 0 & 2 & 2 & 2 & 2 & 2 & 2 & 2 & 2 \\
\hline Recognition of impact & 0 & 0 & 2 & 0 & 1 & 2 & 2 & 2 & 2 & 2 & 2 & 2 \\
\hline $\begin{array}{l}\text { Engineers open to } \mathrm{HF} \text { and to } \\
\text { trying it out }\end{array}$ & 0 & 0 & 0 & 0 & 2 & 2 & 2 & 1 & 2 & 2 & 2 & 2 \\
\hline HF with eng as team & 0 & 0 & 0 & 0 & 0 & 2 & 2 & 2 & 2 & 2 & 2 & 2 \\
\hline Engineering takes ownership & 0 & 0 & 0 & 0 & 0 & 0 & 2 & 2 & 2 & 2 & 1 & 2 \\
\hline $\begin{array}{l}\text { Provides knowledge of upstream } \\
\text { opportunities }\end{array}$ & 0 & 2 & 0 & 0 & 2 & 1 & 2 & 1 & 2 & 1 & 1 & 2 \\
\hline $\begin{array}{l}\text { Can identify right people to be } \\
\text { involved }\end{array}$ & 0 & 0 & 0 & 0 & 1 & 1 & 2 & 2 & 2 & 2 & 2 & 2 \\
\hline HF answers appropriate question & 0 & 1 & 1 & 0 & 2 & 1 & 2 & 2 & 2 & 2 & 2 & 2 \\
\hline Total Context & 2 & 7 & 7 & 0 & 13 & 16 & 22 & 19 & 22 & 21 & 18 & 22 \\
\hline \multicolumn{13}{|l|}{ D. Intervening Condition } \\
\hline resources provided & 1 & 2 & 2 & 0 & 2 & 2 & 2 & 2 & 2 & 2 & 2 & 2 \\
\hline Time provided & 2 & 2 & 0 & 0 & 2 & 2 & 2 & 2 & 2 & 2 & 2 & 2 \\
\hline Ergo on shop floor & 1 & 0 & 0 & 0 & 0 & 2 & 2 & 2 & 2 & 2 & 2 & 2 \\
\hline Ergo is easy to access for eng & 0 & 0 & 0 & 0 & 0 & 2 & 2 & 1 & 2 & 2 & 2 & 2 \\
\hline Ergo documents examples of HF & 0 & 0 & 0 & 0 & 0 & 2 & 1 & 1 & 2 & 2 & 2 & 2 \\
\hline $\begin{array}{l}\text { Ergo manager maintains profile } \\
\text { of group in eng }\end{array}$ & 0 & 0 & 0 & 0 & 1 & 1 & 1 & 1 & 2 & 1 & 1 & 1 \\
\hline Ergo group well positioned & 0 & 0 & 0 & 0 & 1 & 2 & 2 & 1 & 2 & 2 & 2 & 2 \\
\hline Ergo roles well defined & 0 & 0 & 0 & 0 & 1 & 1 & 2 & 1 & 2 & 2 & 2 & 2 \\
\hline
\end{tabular}




\begin{tabular}{|c|c|c|c|c|c|c|c|c|c|c|c|c|}
\hline & 2010 & $\begin{array}{c}\text { Process } \\
\text { Map }\end{array}$ & DES & $\begin{array}{l}\text { Shld } \\
\text { Tool }\end{array}$ & Cog Map & FMEA & $\begin{array}{l}\text { DFF } \\
\text { Guides }\end{array}$ & $\begin{array}{l}\text { Lean } \\
\text { Line }\end{array}$ & $\begin{array}{c}\text { DFA } \\
\text { Scorecd }\end{array}$ & $\begin{array}{l}\text { Kaizens, } \\
\text { Gembas, } \\
\text { Hoishins }\end{array}$ & WEE & $\begin{array}{c}\text { Overall } \\
\text { Integration }\end{array}$ \\
\hline $\begin{array}{l}\text { Ergos aware of new products, } \\
\text { processes, tooling }\end{array}$ & 0 & 0 & 0 & 0 & 0 & 2 & 2 & 2 & 2 & 2 & 2 & 2 \\
\hline Ergo/results report to eng mgr & 0 & 0 & 0 & 0 & 0 & 1 & 2 & 2 & 2 & 2 & 1 & 2 \\
\hline $\begin{array}{l}\text { Ergo focus on contributing to eng } \\
\text { goals }\end{array}$ & 0 & 0 & 0 & 0 & 2 & 2 & 2 & 2 & 2 & 2 & 2 & 2 \\
\hline $\begin{array}{l}\text { Ergo works to understand } \\
\text { processes where HF fits }\end{array}$ & 0 & 2 & 0 & 0 & 2 & 2 & 2 & 2 & 2 & 2 & 2 & 2 \\
\hline $\begin{array}{l}\text { Ergo can adapt tools to integrate } \\
\text { with eng }\end{array}$ & 0 & 1 & 0 & 0 & 1 & 2 & 2 & 2 & 2 & 1 & 2 & 2 \\
\hline $\begin{array}{l}\text { HF being pulled (or with demo) vs } \\
\text { pushed }\end{array}$ & 0 & 0 & 0 & 0 & 1 & 0 & 2 & 2 & 2 & 2 & 2 & 2 \\
\hline $\begin{array}{l}\text { Re-org causes re-alignment (vs } \\
\text { disruption) }\end{array}$ & 1 & 0 & 0 & 0 & 0 & 1 & 1 & 1 & 2 & 1 & 2 & 2 \\
\hline $\begin{array}{l}\text { Ergo positioned to weather } \\
\text { changes }\end{array}$ & 0 & 0 & 0 & 0 & 1 & 1 & 2 & 1 & 2 & 1 & 1 & 2 \\
\hline Total & 5 & \multirow[t]{2}{*}{7} & \multirow[t]{2}{*}{2} & \multirow[t]{2}{*}{0} & \multirow[t]{2}{*}{14} & \multirow[t]{2}{*}{25} & 29 & 25 & 32 & 28 & 29 & 31 \\
\hline E. Action/Interaction & & & & & & & & & & & & \\
\hline plan with steps, deliverables & 0 & 2 & 2 & 0 & 2 & 2 & 2 & 2 & 2 & 2 & 2 & 2 \\
\hline Quantifiable, thresholds, KPIs & 0 & 0 & 2 & 0 & 0 & 2 & 2 & 1 & 2 & 1 & 2 & 2 \\
\hline Fits with eng tools and processes & 0 & 2 & 2 & 0 & 2 & 2 & 2 & 2 & 2 & 2 & 2 & 2 \\
\hline Fits with expectations & 0 & 0 & 0 & 0 & 1 & 1 & 2 & 2 & 2 & 2 & 2 & 2 \\
\hline $\begin{array}{l}\text { Directly addresses operational } \\
\text { goals }\end{array}$ & 0 & 0 & 0 & 0 & 2 & 2 & 2 & 2 & 2 & 2 & 2 & 2 \\
\hline Tool utility (quick, easy) & 0 & 0 & 0 & 0 & 2 & 2 & 2 & 1 & 2 & 2 & 2 & 2 \\
\hline $\begin{array}{l}\text { Facilitates action/ demonstrates } \\
\text { change }\end{array}$ & 0 & 2 & 2 & 2 & 1 & 2 & 2 & 2 & 2 & 2 & 2 & 2 \\
\hline
\end{tabular}




\begin{tabular}{|c|c|c|c|c|c|c|c|c|c|c|c|c|}
\hline & 2010 & $\begin{array}{c}\text { Process } \\
\text { Map }\end{array}$ & DES & $\begin{array}{l}\text { Shld } \\
\text { Tool }\end{array}$ & Cog Map & FMEA & $\begin{array}{c}\text { DFF } \\
\text { Guides }\end{array}$ & $\begin{array}{l}\text { Lean } \\
\text { Line }\end{array}$ & $\begin{array}{c}\text { DFA } \\
\text { Scorecd }\end{array}$ & $\begin{array}{l}\text { Kaizens, } \\
\text { Gembas, } \\
\text { Hoishins }\end{array}$ & WEE & $\begin{array}{c}\text { Overall } \\
\text { Integration }\end{array}$ \\
\hline Visible & 0 & 2 & 1 & 1 & 2 & 1 & 2 & 2 & 2 & 2 & 2 & 2 \\
\hline Fit with high priority initiatives & 0 & 0 & 1 & 0 & 1 & 2 & 2 & 2 & 2 & 2 & 2 & 2 \\
\hline HF specific and tangible & 0 & 0 & 0 & 0 & 1 & 2 & 2 & 2 & 2 & 2 & 2 & 2 \\
\hline HF compatible with eng workload & 0 & 0 & 0 & 0 & 0 & 2 & 2 & 1 & 2 & 2 & 2 & 2 \\
\hline HF piggybacks on other BPI & 0 & 0 & 0 & 0 & 1 & 2 & 2 & 2 & 2 & 2 & 2 & 2 \\
\hline Bridges HF with eng & 0 & 1 & 0 & 0 & 2 & 2 & 2 & 2 & 2 & 2 & 2 & 2 \\
\hline $\begin{array}{l}\text { Allows ergo's to create } \\
\text { opportunities/leverage }\end{array}$ & 0 & 1 & 0 & 0 & 2 & 2 & 2 & 2 & 2 & 2 & 2 & 2 \\
\hline Allows ergo's to learn who's who & 0 & 0 & 0 & 0 & 2 & 2 & 2 & 1 & 2 & 2 & 2 & 2 \\
\hline Allows cross dept work with HF & 0 & 2 & 1 & 0 & 2 & 2 & 2 & 2 & 2 & 2 & 2 & 2 \\
\hline $\begin{array}{l}\text { Ergos respond quickly to eng } \\
\text { requests }\end{array}$ & 0 & 0 & 0 & 0 & 0 & 1 & 2 & 1 & 2 & 2 & 2 & 2 \\
\hline Ergos part of team (vs silo) & 0 & 1 & 0 & 0 & 1 & 2 & 2 & 2 & 2 & 2 & 2 & 2 \\
\hline Total & $\mathbf{0}$ & 13 & 11 & 3 & 24 & 33 & 36 & 31 & 36 & 35 & 36 & 36 \\
\hline \multicolumn{13}{|l|}{ F. Consequences } \\
\hline $\begin{array}{l}\text { not adopted/ignored (0), } \\
\text { somewhat (1), fully (2) }\end{array}$ & 0 & 0 & 0 & 0 & 1 & 1 & 2 & 1 & 2 & 2 & 1 & 2 \\
\hline
\end{tabular}

\section{Overall Total}

10

33

34

13

65

104

124

98

127

118

114

122 


\section{APPENDIX G}

\section{Tentative Propositions for Theoretical Sampling in Grounded Theory Analysis}

1. When HF Specialists discuss HF in engineering terminology, (such as worker precision, consistency, and task complexity instead of injury risk), they get more attention from engineers and senior management.

2. Instead of needing to "sell" HF with injury costs/benefits, it will be pulled into engineering if it contributes to business goals.

3. Engineers readily bring HF resources onto their team when it helps them with their job (cooperation of engineer helps, but is not necessary).

4. When HFS act as an engineering resource (i.e. provide appropriate answer to engineers question in a timely manner), they gain attention of engineers.

5. When HF is framed as "continuous improvement" (rather than problem identification and problem solving), it fits better within engineering processes.

6. When HFS is on the engineering team, it further strengthens the integration and leads to more HF application (positive experience loop).

7. Adapting engineering and business improvement tools to include HF works better than using HF tools by HFS or expecting engineers to use HF tools.

8. Having the right tool (engineering tool adapted for HF) leads to adoption in process.

9. Having HF guidelines and sign-off in process is insufficient for HF integration if they are not being enforced.

10. When HF has targets, (not guidelines which can be ignored), then HF can be enforced by senior management.

11. Senior Management did not need to be committed to HF integration initially for HFS to work with engineers on $\mathrm{HF}$ integration.

12. Support from Senior Management is helpful but not sufficient. When senior management hold engineers accountable for $\mathrm{HF}$, this ensures process is sustainable.

13. When HFS report directly to Engineering Management, HF integration is facilitated.

14. When the HFS Manager is familiar with Engineering Managers, programs and processes, this facilitates HFS integration. 


\section{APPENDIX H}

\section{Categories not Retained in Final Theory}

\begin{tabular}{|c|c|c|}
\hline $\begin{array}{l}\text { Influence of } \\
\text { Organizational Change } \\
\text { (both positive and } \\
\text { negative, therefore not } \\
\text { retained in final theory) }\end{array}$ & $\begin{array}{l}\text { Senior Director: } \\
\text { Researcher } \\
\text { notes: } \\
\text { Researcher } \\
\text { notes: } \\
\text { Researcher } \\
\text { notes: } \\
\text { Researcher } \\
\text { notes: } \\
\text { Researcher } \\
\text { notes: } \\
\\
\text { Manager: } \\
\text { Researcher } \\
\text { notes: }\end{array}$ & $\begin{array}{l}\text { "the dots keep changing and they change rapidly" } \\
\text { "FMEA project - can't find a sponsor - who is most appropriate? - FMEA on hold } \\
\text { right now - where will Ryerson collaboration project fit (after re-organization)?" } \\
\text { "Principle Investigator let go - new person appointed - can't commit to projects until } \\
\text { know change in dynamics and new directors point of view" } \\
\text { "Some unhappy with change - others think it's helpful -some rumours there may be } \\
\text { another wave let go" } \\
\text { "Regrouping has all engineers together under same bosses in manufacturing - good } \\
\text { change - leaned out organization" } \\
\text { Following meeting with new Senior Director appointed to collaboration after an } \\
\text { organizational change: "Working with X - he's the end customer (operational } \\
\text { excellence) to all groups - monitoring output and working with all groups to make } \\
\text { improvements - this doesn't cut us off from other groups - this makes for better } \\
\text { positioning and compatibility" } \\
\text { Re: organizational changes: we "need to get down to business, if something we } \\
\text { need to implement, we can do it very fast, needs to be very specific and tangible - } \\
\text { can't have you running around doing something that won't have the value added - } \\
\text { won't have the people" } \\
\text { "Organizational change is getting leadership team together - how to be more } \\
\text { aligned with outsourcing to get product out faster - streamlining decision making - } \\
\text { good HF opportunity" } \\
\text { "Re-organization may be beneficial in terms of reporting structure for HF group" }\end{array}$ \\
\hline
\end{tabular}




\begin{tabular}{|c|c|c|}
\hline & $\begin{array}{l}\text { Director: } \\
\text { HFS Manager }\end{array}$ & $\begin{array}{l}\text { "We have impetus for change in this organization - opportunities are tremendous - } \\
\text { almost like an open book - should be very little resistance for change for the better" } \\
\text { (the company) "always changes - for a company to move forward, a lack of stability } \\
\text { is required - if a company reaches stability - they're not moving forward" }\end{array}$ \\
\hline $\begin{array}{l}\text { Who's in the sandbox } \\
\text { (getting right people) } \\
\text { was considered less } \\
\text { important than the } \\
\text { acclimation and } \\
\text { alignment of HFS to fit in } \\
\text { engineering }\end{array}$ & $\begin{array}{l}\text { Researcher } \\
\text { notes: } \\
\text { Researcher } \\
\text { notes: } \\
\text { Researcher } \\
\text { notes: } \\
\text { Engineer: } \\
\text { Researcher } \\
\text { notes: }\end{array}$ & $\begin{array}{l}\text { "Trying to introduce something (FMEA) where there aren't formal practices around - } \\
\text { so maybe we need to do a bit more massaging - when you don't have formal } \\
\text { processes, it's all about getting to the right people - perhaps we haven't got to the } \\
\text { right people yet" } \\
\text { "Impressions: (X) "has great insight, very knowledgeable about assembly process } \\
\text { and the product in particular, also good insights into quality, HF and all the } \\
\text { connections - good fortune that we had the ability to work with him and that he takes } \\
\text { the time for us - he is truly invested in making the assembly system work better" } \\
\text { Composition of HF DFA group allowed for product specific detail (X), big picture } \\
\text { advanced engineering (Y), process related input (Z) - good mix" } \\
\text { "At times previous HF experience (X) a barrier - expectations of HF at workstation } \\
\text { level (rather than proactively in design)" } \\
\text { More about process: "After a year, develop some rules (design for HF) - build in } \\
\text { rules to design to - engineers get it" } \\
\text { Lack of acclimation hindered progress: "Defined steps (actions in meetings, } \\
\text { agendas, charters, process flows, etc) *our challenge to get buy-in is we didn't have } \\
\text { defined steps" }\end{array}$ \\
\hline
\end{tabular}




\section{APPENDIX I}

\section{Examples of Empirical Evidence for Core Constructs and Relationships in Final Theory}

\begin{tabular}{|c|c|c|}
\hline Construct or Relationship & $\begin{array}{l}\text { Source of } \\
\text { Empirical } \\
\text { Evidence }\end{array}$ & Empirical Observation \\
\hline $\begin{array}{l}\text { HFS need to acclimate to engineering } \\
\text { process, language and tools (Core } \\
\text { category) }\end{array}$ & $\begin{array}{l}\text { Researcher } \\
\text { Notes: } \\
\text { Researcher } \\
\text { Notes: } \\
\text { Researcher } \\
\text { notes: } \\
\\
\text { Engineer } \\
\text { quote: } \\
\text { Researcher } \\
\text { Notes: }\end{array}$ & $\begin{array}{l}\text { (HFS) "Needs to start at beginning and document and understand assembly steps - } \\
\text { get out on line and watch, observe, ask questions" } \\
\text { "HFS need to understand design and assembly process from engineers and } \\
\text { operators point of view (train on line and get certified) - do job and can see not only } \\
\text { difficulties but opportunities to damage device and cause quality problems" } \\
\text { "Sept } 2011 \text { brainstorming with HFS team: Researcher (JV) suggested idea of DFA } \\
\text { guidelines or rules - rate steps according to criteria, eg. visual or blind, rate difficulty } \\
\text { of assembly and get score - can't input design guidelines to this (no fit) have to add } \\
\text { HF into scoring - nothing that says too much force for example - I could see this as } \\
\text { a valuable project - couple engineers suggested something similar (no uptake from } \\
\text { HFS at time)" } \\
\text { HFS: "we don't know who does DFA or who owns it" (because they were not yet } \\
\text { acclimated). } \\
\text { Comment about value of HF assessment of new mocked up design because it "fits" } \\
\text { with engineering processes: "steps are obvious, looks like traditional engineering } \\
\text { approach, concrete, practical" } \\
\text { "HFS need to look at HF completely differently to be compatible with engineering - } \\
\text { participating in meetings, the HFS says "it's just so different (looking at assembly } \\
\text { tasks this way) - "I'm finding this process really challenging"(looking at task from } \\
\text { point of view of assembly rather than risk factors) -the HFS need training and } \\
\text { familiarity with engineering and to get on line, try out tools, look at drawings, } \\
\text { familiarize with process, assembly, cost, etc - (I discussed with HFS) that there are } \\
\text { not a lot of injuries and that won't convince them to do HF - but good quality } \\
\text { assembly tasks are important - need for HFS to shift emphasis and even tools to } \\
\text { align" } \\
\text { We're "looking at line for reasons for imbalances and disturbances (vs risk factors) - } \\
\text { the HFS need to be comfortable looking from this outcome" }\end{array}$ \\
\hline
\end{tabular}




\begin{tabular}{|c|c|c|}
\hline & $\begin{array}{l}\text { Researcher } \\
\text { Notes: } \\
\text { HFS: } \\
\text { Researcher } \\
\text { Notes: } \\
\text { Researcher } \\
\text { Notes: } \\
\text { Engineering } \\
\text { manager: } \\
\\
\text { Engineering } \\
\text { manager: } \\
\text { Researcher } \\
\text { notes: }\end{array}$ & $\begin{array}{l}\text { "HFS needs intricate knowledge of the tasks and design issues to be able to } \\
\text { actively contribute - complicated set of variables (parts, materials, design, how they } \\
\text { go together, tolerances, what contributes to poor quality, low yield, CTQ, cost, } \$ 80 \\
\text { defect, detection, etc.)" } \\
\text { HFS after first FMEA meeting when not acclimated: "I had a hard time seeing where } \\
\text { to jump into discussion and couldn't see how to do HF measures in room - it was } \\
\text { difficult imagining steps with no parts available" } \\
\text { "HFS not familiar with process, parts, assembly etc" } \\
\text { Prior to acclimation: "HFS was called in to look at piece of equipment on new line - } \\
\text { and asked who is doing overall design of line - HFS couldn't find out - didn't have } \\
\text { access to internal systems or visio for layout - didn't know who he needed to talk to" } \\
\text { Comment on need to make HF engineering-like: "projects compete against one } \\
\text { another, some will be delayed until next year and some are cancelled - not helping } \\
\text { that our HF projects don't have visibility - put in a way people (engineers) } \\
\text { understand so they do compete with our internal projects" } \\
\text { Comment on making HF visible: "everyone is busy - getting people interested and } \\
\text { supportive of change is a challenge - we all have too much to do - there are things } \\
\text { I never get to - make it visual" } \\
\text { Observation "doing charter is an engineering process that HFS1 and HFS2 had not } \\
\text { been exposed to or needed to do in OH\&S - an example of the difficulty of } \\
\text { knowledge of process in working within engineering world - need to be able to } \\
\text { justify our work, state problem, extrapolate benefits in same way engineers would in } \\
\text { order to be accepted within their project scopes" } \\
\text { "Suggested HF guidelines become an engineering document with a number so } \\
\text { engineers can directly access them" }\end{array}$ \\
\hline $\begin{array}{l}\text { HFS need to align HF to strategic goals } \\
\text { (Core category) }\end{array}$ & $\begin{array}{l}\text { Senior } \\
\text { Director } \\
\text { Director }\end{array}$ & $\begin{array}{l}\text { (HF) "Initiatives have to be aligned with priorities we have and business objectives" } \\
\text { "it would be really helpful if we can say we'll get better quality but it's also better for } \\
\text { the operator" }\end{array}$ \\
\hline
\end{tabular}




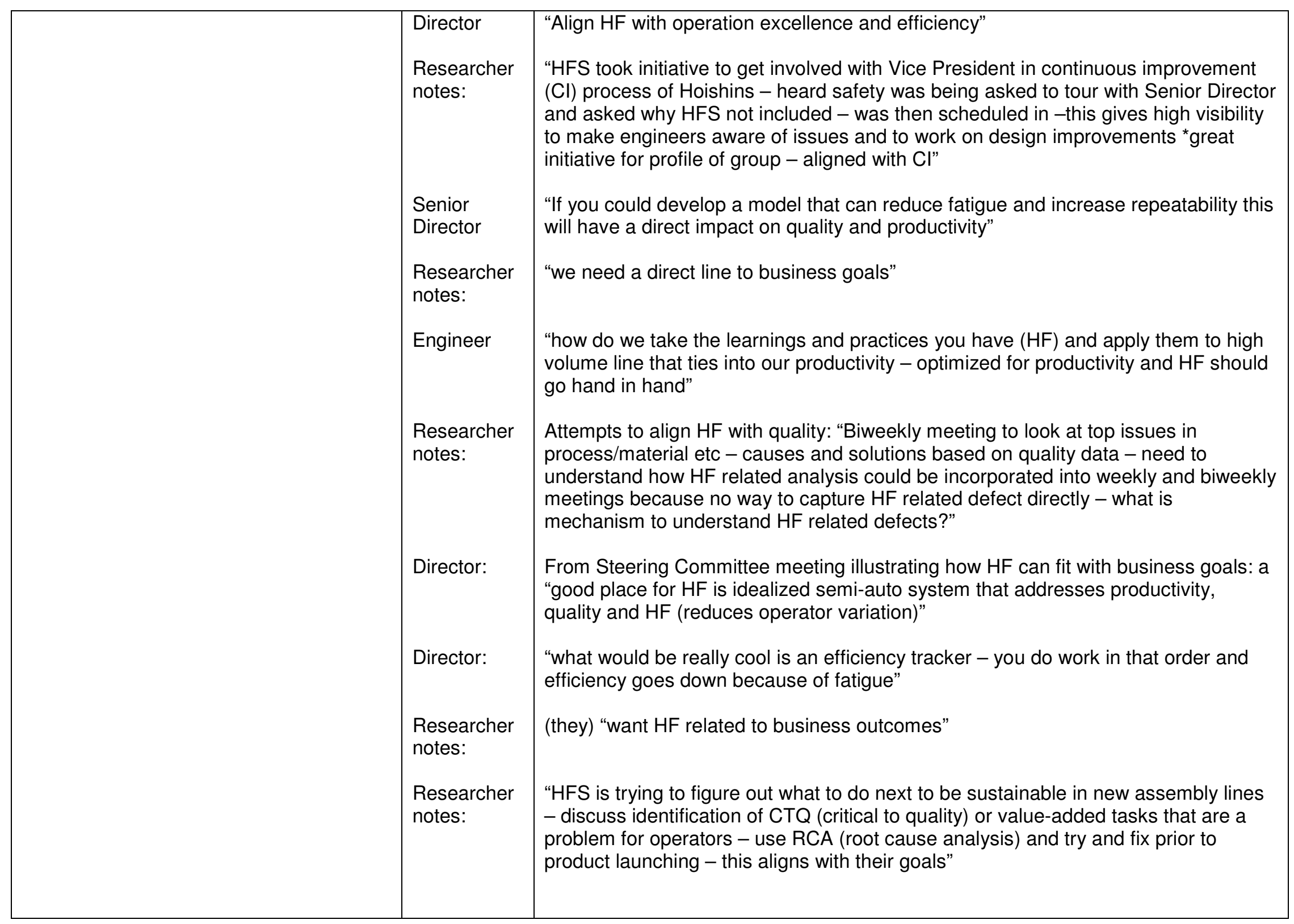




\begin{tabular}{|c|c|c|}
\hline $\begin{array}{l}\text { Pi. When human factors specialists (HFS) } \\
\text { acclimate to the engineering process, } \\
\text { language and tools, and strategically align } \\
\text { HF to the design and business goals of } \\
\text { the organization, then HF is recognized as } \\
\text { a means to improve business } \\
\text { performance. }\end{array}$ & $\begin{array}{l}\text { Engineer: } \\
\text { Director: } \\
\text { Researcher } \\
\text { quote: } \\
\text { Researcher } \\
\text { notes: } \\
\text { Researcher } \\
\text { notes: }\end{array}$ & $\begin{array}{l}\text { When we had few initiatives that were aligned to "fit" within engineering, a manager } \\
\text { stated: "(We) don't have time and resources for something esoteric - has to be very } \\
\text { specific to our business goals" } \\
\text { Suggestion as to how to proceed with HF work in way that is engineering like: "pick } \\
\text { top } 3 \text { problems and improve (the assembly with continuous improvement) using } 5 Y \\
\text { and fault tree (engineering tools), utilize operator opinions through kaizens, look at } \\
\text { value added tasks for improvement" } \\
\text { "HF helped to justify pallet line - (it) moved up (in the) priority list due to savings in } \\
\text { human aspects not previously anticipated" } \\
\text { "We're using HF to help with operations targets - we're not doing it with HF } \\
\text { measures - without thinking - we're doing both together" } \\
\text { "HFS put ergonomics change team on hoishin - this got Senior Director's support, } \\
\text { did training for team and now HF is ingrained in business improvement process - } \\
\text { fits with strategic goals" } \\
\text { Discussion about how HF can help improve business performance: } \\
\text { Engineer: "metric of priority is time - do we want to make an equivalent measure for } \\
\text { HF?" } \\
\text { Researcher notes: "Interesting! Do we need separate measures?" }\end{array}$ \\
\hline $\begin{array}{l}\text { Pii. When HF is recognized as a means to } \\
\text { improve business performance, HFS are } \\
\text { "pulled" onto the engineering team. }\end{array}$ & $\begin{array}{l}\text { Engineering } \\
\text { manager: } \\
\text { Researcher } \\
\text { notes: } \\
\\
\text { Senior } \\
\text { Director: } \\
\\
\text { Researcher } \\
\text { notes: }\end{array}$ & $\begin{array}{l}\text { "The fixture kick-off and design meeting will be by invite on a specific date - you } \\
\text { (HFS) will be one of the key persons to be invited - definitely a must" } \\
\text { "Excellent meeting because HF plus NPR (new product realization) team plus Cl } \\
\text { (continuous improvement) discussed together - noticed gaps in process of } \\
\text { workstation set-up especially materials and worker empowerment/training to change } \\
\text { set-up" } \\
\text { In discussing ways to integrate HF into engineering design: "I think we'll get } 80 \% \\
\text { endorsement (from other Sr Managers) particularly if X (VP) has done this in Toyota" } \\
\text { "When working with engineers and HFS together toward common goal of improved } \\
\text { camera insertion step, a manager saw a HF gap in process (layout of workstations) - } \\
\text { and immediately remedied with getting IE to make a process (which in turn involved }\end{array}$ \\
\hline
\end{tabular}




\begin{tabular}{|c|c|c|}
\hline & $\begin{array}{l}\text { Researcher } \\
\text { notes: }\end{array}$ & $\begin{array}{l}\text { HFS and asked for checklist that HFS weren't able to push in previous year - had to } \\
\text { be pull from engineer) - had to be noticed by engineers and affect their targets } \\
\text { before action" } \\
\text { On teamwork: "how we deliver HF concerns - cannot come across as insulting or } \\
\text { finding fault with what they are doing - also not trying to impose another set of } \\
\text { assessments on them - working with them to improve quality" }\end{array}$ \\
\hline $\begin{array}{l}\text { Piii. When HFS are on the } \\
\text { engineering team, this leads to more } \\
\text { requests for HF from engineers and } \\
\text { increased awareness of HF on the } \\
\text { part of engineers. }\end{array}$ & $\begin{array}{l}\text { Researcher } \\
\text { notes: } \\
\text { Researcher } \\
\text { notes: } \\
\text { Researcher } \\
\text { notes: } \\
\text { Researcher } \\
\text { notes: } \\
\text { Senior } \\
\text { Director: } \\
\text { Researcher } \\
\text { notes: } \\
\text { Researcher } \\
\text { notes: } \\
\text { Engineer }\end{array}$ & $\begin{array}{l}\text { Observation: "When data (from new assembly line) provided with interesting } \\
\text { observations (numbers and findings), then immediate request for more HF analysis } \\
\text { (cycle time, run at rate)" } \\
\text { "Visibility given to HF group through X at (large engineering) community of practice } \\
\text { meeting - everyone was given the new process and it was clear that HF fits within } \\
\text { HF DFA as a target and in the DFF too" } \\
\text { "Profile of HFS raised when talking cycle times and using line data to give HF input } \\
\text { from different perspective than they normally see the line" } \\
\text { "HFS asked to be involved by X (engineer) in lessons learned on line and in } \\
\text { optimization for next line - HFS then asked X (engineer) to be involved in ergo } \\
\text { change team (working together more)" } \\
\text { "we're interested in HF point of view - in itself having HFS involved and the } \\
\text { changes they've made is valuable - I think we're on the right track" } \\
\text { "In the Manufacturing readiness review checklist, HF was given one line for HF } \\
\text { check - however it did open the door for development of the DFF guidelines - and } \\
\text { this has a higher profile" } \\
\text { Following meeting with } 2 \text { engineers "there are } 3 \text { designers at (company) that HFS } \\
\text { should be involved with - and any doing automation and design -engineers later } \\
\text { introduced these designers to HFS (opened doors)" } \\
\text { In focus group "others need to get (HF) knowledge - if we're working with outside } \\
\text { vendors, we need to push them to think about how operator loads device, elbow } \\
\text { height, size of people, type of grip etc" }\end{array}$ \\
\hline $\begin{array}{l}\text { Piv. When HF is recognized as a means } \\
\text { to improve business performance, senior }\end{array}$ & $\begin{array}{l}\text { Senior } \\
\text { Director: }\end{array}$ & $\begin{array}{l}\text { Regarding the HF DFA and accountability: "this will help define a standard for the } \\
\text { team members and level the playing field on tribal knowledge and team knowledge" }\end{array}$ \\
\hline
\end{tabular}




\begin{tabular}{|c|c|c|}
\hline $\begin{array}{l}\text { management want to monitor HF as a key } \\
\text { performance indicator and hold engineers } \\
\text { responsible for meeting HF targets. }\end{array}$ & $\begin{array}{l}\text { Senior } \\
\text { Director: } \\
\text { Director: } \\
\text { Engineering } \\
\text { Manager: } \\
\text { Director } \\
\text { Engineering: } \\
\\
\text { Engineering } \\
\text { Manager }\end{array}$ & $\begin{array}{l}\text { (DFA) "forces us to have right discussion around process development that we're } \\
\text { not having now - need to be conscious we're doing something very challenging to } \\
\text { do and not waiting for scrap to tell us" } \\
\text { Re: how shoulder load tool could be a target: "We can do a quick and dirty kaizen - } \\
\text { this is red/green/yellow shoulder load zone - must be acceptable - reach could be a } \\
\text { standard going forward and could carry that knowledge and distribute globally" } \\
\text { "I definitely see a very exciting development, the HF is not a DFA scorecard, it is } \\
\text { one of key parameters (targets)" } \\
\text { (there is) "strong value in this as a way to get quicker to a decision about a problem } \\
\text { task - by scoring process-related complexity vs person-related (learning, training) } \\
\text { and putting a cost alongside the HF score, then a discussion can occur with product } \\
\text { design and manufacturers about whether the design can change or the } \\
\text { manufacturing can change or whether automation is most cost-effective - at the } \\
\text { moment there is no tool for doing this" } \\
\text { "Start with target for HF DFA - roll out and evaluate and move to second target - } \\
\text { staged approach - when I show to engineers, changes can be made to HF target if } \\
\text { there is supporting evidence to drive for alteration - must be able to justify } \\
\text { exceeding HF target" }\end{array}$ \\
\hline $\begin{array}{l}P v . \text { When HFS are acclimated and } \\
\text { aligned to "fit" within engineering and they } \\
\text { are pulled on the engineering team, this } \\
\text { facilitates adaptation of engineering tools } \\
\text { to include HF targets. }\end{array}$ & $\begin{array}{l}\text { Manager } \\
\text { interview: } \\
\text { Engineer: } \\
\text { Researcher } \\
\text { notes: } \\
\text { Senior } \\
\text { Director } \\
\text { Researcher }\end{array}$ & $\begin{array}{l}\text { (The HF DFA) "scorecard was well accepted - it looks like IE tools - quick and easy } \\
\text { to do, easy to teach/learn, PFEs may be able to take this one" } \\
\text { DFF tool: "I couldn't do it without you guys, seriously - you first introduced the } \\
\text { guideline, when I saw it, I knew this is the right way to go, those fixtures out there } \\
\text { now would probably kill someone eventually" } \\
\text { "engineer uses scorecard in everyday purchasing choices - (he) likes having criteria } \\
\text { and rating" } \\
\text { Re: HF DFA: "I like to have a tool we can track as quantifiable measure of HF } \\
\text { capability that removes element of learning... at end of day I want to understand } \\
\text { how complex my process is - I want to know where to focus automation, tool } \\
\text { design, etc." } \\
\text { After using an engineering tool to determine HF issues: "using root cause analysis - }\end{array}$ \\
\hline
\end{tabular}




\begin{tabular}{|c|c|c|}
\hline & \begin{tabular}{|l} 
notes: \\
Engineer: \\
\\
Senior \\
Director \\
Researcher \\
notes: \\
\\
Engineer:
\end{tabular} & $\begin{array}{l}\text { engineers very accustomed with process and move quickly to solutions - very } \\
\text { visual, not highly quantitative, but quick and easy and HF fits - allowed engineers to } \\
\text { see HF issues using their comfortable tool" } \\
\text { Adapting tools for HF: "HF root cause analysis led us to some problems we already } \\
\text { knew we had - changed some things we're doing to workstation set-up - need to } \\
\text { make sure methodology is quick enough and nimble enough to not overload people } \\
\text { when doing NPR (new product realization)" } \\
\text { Re: HF DFA: "this is good, I really appreciate this, this is one of the outcomes I was } \\
\text { hoping for. I hadn't imagined this, but seeing this makes it very clear" } \\
\text { "how you get tool to this point for Senior Director is by spending time, understanding } \\
\text { what's important to them, what their goals are, how you can help with their goals, } \\
\text { what tool would look like to communicate that" } \\
\text { "You were successful in identifying opportunites (with root cause analysis on new } \\
\text { assembly line), second is real changes - provide tools and mechanisms for making } \\
\text { changes happen" }\end{array}$ \\
\hline $\begin{array}{l}\text { vi. When management want to hold } \\
\text { engineers accountable for HF, and there } \\
\text { are HF-adapted tools with targets, then } \\
H F \text { will become embedded in the } \\
\text { engineering design process. }\end{array}$ & $\begin{array}{l}\text { Researcher } \\
\text { Notes: } \\
\\
\text { Senior } \\
\text { Director: } \\
\\
\text { Researcher } \\
\text { notes: } \\
\\
\text { Senior } \\
\text { Director: }\end{array}$ & $\begin{array}{l}\text { (HF DFA Scorecard) "an engineering manager is taking the lead and developing a } \\
\text { spreadsheet and process with targets and this is being rolled out to all } \\
\text { manufacturing - this has a huge influence" } \\
\text { "this will provide a scale I can take to design team - show them - explain "proof" - } \\
\text { could you do this repeatedly with one hand all day?" } \\
\text { HF FMEA being integrated into FMEA software: "would generate a work order to fix } \\
\text { something - embedded in process" } \\
\text { we're "having discussion much earlier because we have data to look at...it will force } \\
\text { action if score (is) high - (we) spent longer than we should have because we } \\
\text { couldn't have a quantifiable discussion (about problems with a part)" }\end{array}$ \\
\hline
\end{tabular}




\section{References}

Abrahamsson, L. (2000). Production economics analysis of investment initiated to improve working environment. Applied Ergonomics, 31(1), 1-7.

Ackermann, F., Eden, C. and Cropper, S. (1992 (13-15th April)). Getting started with cognitive mapping. Paper presented at the 7th Young OR Conference, University of Warwick.

Adebanjo, D., Abbas, A., Mann, R. (2010). An investigation of the adoption and implementation of benchmarking. International journal of operations and production management, 30(11), 1140-1169.

Adler, P. S., Goldoftas, B., Levine, D.I. (1997). Ergonomics, employee involvement and the Toyota Production System: A case study of NUMMI's 1993 model introduction. Industrial and Labor Relations Review, 50(3), 416-437.

Ahsberg, E. (1998:19) "Perceived fatigue related to work". University of Stockholm, Department of Psychology ISBN 91-7153-830-5, National Institute for Working Life, Department for Work and Health, ISBN 91-7045-485, Sweden.

Antony, J. (2011). Six Sigma vs Lean Some perspectives from leading academics and practitioners. International Journal of Productivity and Performance Management, 60(2), 185-190.

Badham, R. J. (2006). Mudancas Not Removalists: Rethinking the management of organizational change. Human Factors and Ergonomics in Manufacturing, 16(3), 229245.

Badham, R.J., \& Sense, A.J. (2006). Spiraling up or spinning out: A guide for reflecting on action research practice. International Journal of Social Research Methodology, 9(5), 367-377.

Barsky, I., Dutta, S.P. (1997). Cost assessment for ergonomic risk (CAFER). International Journal of Industrial Ergonomics, 20, 307-315.

Battini, D., Faccio, M., Persona, A., Sgarbossa, F. (2011). New methodological framework to improve productivity and ergonomics in assembly system design. International journal of Industrial Ergonomics, 41, 30-42.

Berlin, C. (2011). Human factors experiences in context - comparing four industrial cases using a soft systems framework. The Ergonomics Open Journal, 4, 131-144.

Binder, M., Edwards, J.S. (2008). Using grounded theory method for theory building in operations management research. A study on inter-firm relationship governance. International Journal of Operations Production Management, 30(3), 232-259. 
Bongers, P., de Winter, C.R., Kompier, M.A.J. and Hildebrandt, V.H. (1993) "Psychosocial factors at work and musculoskeletal disease". Scandinavian Journal of Work, Environment \& Health, 19(5), 297-312.

Boothroyd, G., Dewhurst, P. and Knight, W. (2001). Product Design for Manufacture and Assembly, CRC Press, Taylor and Francis, Florida USA, 670 pages.

Boudreau, J., Hopp, W., McLain, J.O., Thomas, L.J. (2003). On the interface between operations management and human resources management. Manufacturing and Service Operations Management, 5(3), 179-202.

Broberg, O. (2007). Integrating ergonomics into engineering: Empirical evidence and implications for the ergonomists. Human Factors and Ergonomics in Manufacturing, 17(4), 353-366.

Broberg, O., Andersen, V. and Seim, R. (2010). Participatory ergonomics in design processes: The role of boundary objects. Applied Ergonomics, in press, 1-9.

Broberg, O. (2010). Workspace design: a case study applying participatory design principles of healthy workplaces in an industrial setting. International Journal of Technology Management, 51(1), 39-57.

Brown, S. M. (1992). Cognitive Mapping and Reprtory Grids for Qualitative Survey Research: Some Comparative Observations. Journal of Management Studies, 29(3), 287-307.

Buckle, P. (2011). The perfect is the enemy of the good - ergonomics research and practice. Institute of Ergonomics and Human Factors Annual Lecture 2010. Ergonomics, 54(1), 111.

Bucciarelli, L. L. Designing Engineers. (1994). The MIT Press, Cambridge, Massachusetts, (220 pages).

Burns, C. M., Vicente, K.J. (2000). Participant-observer study of ergonomics in engineering design: how constraints drive design process. Applied Ergonomics, 31, 73-82.

Campbell, J. L. (1996). The development of human factors design guidelines. International journal of Industrial Ergonomics, 18, 363-371.

Carayon, P., Alvarado, C.J., Schoofs Hundt, A. (2007). Work design and patient safety. Theoretical Issues in Ergonomics Science, 8(5), 395-428.

Carayon, P. (2010). Human factors in patient safety as an innovation. Applied Ergonomics, 41, 657-665.

Carter, S. M. (2007 (December)). Justifying knowledge, justifying method, taking action: Epistemologies, methodologies, and methods in qualitative research. Qualitative Health Research, 17(10), 1316-1328.

Checkland, P. (1985). Achieving "Desirable and Feasible" Change: An Application of Soft 
Systems Methodology. Journal of Operational Research Society, 36(9), 821-831.

Checkland, P. (1985). Optimizing to Learning: Development of systems thinking for the 1990s. Journal of Operational Research Society, 36(9), 757-767.

Christiansen, O. (2011). Rethinking "quality" by classic grounded theory. International Journal of Quality and Service Sciences, 3(2), 199-210.

Choi, T.Y., Liker, J.K. (1992). Institutional conformity and technology implementation: A process model of ergonomics dissemination. Journal of Engineering and Technology Management, 9, 155-195.

Cohen, W. M., Levinthal, D.A. (1990). Absorptive Capacity: A new perspective on learning and innovation. Administrative Science Quarterly, 35, 128-152.

Commissaris, D. A. C. M., Schoenmaker, N., Beune, E.A.Th., Eikhout, S.M. (2006). Applying Principles of Change Management in Ergonomic Projects: A Case Study, Human Factors and Ergonomics in Manufacturing, 16, 195-223.

Coughlan, P., Coughlan, D. (2002). Action research for operations management. International Journal of Operations and Production Management, 22(2), 220-240.

Cuthbertson, R., Piotrowicz, W. (2011). Performance measurement systems in supply chains: A framework for contextual analysis, International Journal of Productivity and Performance Management, 60(6), 583 - 602

David, G. C. (2005). Ergonomic methods for assessing exposure to risk factors for work-related musculoskeletal disorders. Occupational Medicine, 55, 190-199.

Davis, J. M. (2007). Rethinking the architecture. An action researcher's resolution to writing and presenting their thesis. Action Research, 5(2), 181-198.

Dawson, P. (2005). Changing manufacturing practices: An appraisal of the processual approach. Human Factors and Ergonomics in Manufacturing, 15(4), 385-402.

De Looze, M. P., Van Rhign, J.W., Deursen, J.V., Tuinzaad, G.H., Reijneveld, C.N. (2003). A participatory and integrative approach to improve productivity and ergonomics in assembly. Production Planning \& Control, 14(2), 174-181.

Dempsey, P. G. (2007). Effectiveness of ergonomics interventions to prevent musculoskeletal disorders: Beware of what you ask. International journal of Industrial Ergonomics, 37, 169-173.

Dixon, S. M., Therberge, N. and Cole, D.C. (2009). Sustaining management commitment to workplace health programs: The case of participatory ergonomics. Resations Industrielles/Industrial Relations, 64(1), 50-64.

Docherty, P., Forslin, J. and Shani (Rami), A.B. (2002). Creating Sustainable Work Systems. Emerging Perspectives and Practices. Routledge, London. 
Donaldson, L. (2001). The contingency theory of organizations. Foundation of Organizational Science, A Sage Publication Series, California, USA.

Drury, C. G. (2000). Human factors and quality: Integration and new directions. Human Factors and Ergonomics in Manufacturing, 10(1), 45-59.

Duffy, V. G. (2007). Modified virtual build methodology for computer-aided ergonomics and safety. Human Factors and Ergonomics in Manufacturing, 17(5), 413-422.

Dul, J., Neumann, W.P. (2006). The strategic business value of ergonomics. Paper presented at the The International Ergonomics Associations 16th World Congress on Ergonomics, Maastricht, NL.

Dul, J., Neumann, P. (2009). Ergonomics contributions to company strategies. Applied Ergonomics, 40, 745-752.

Dul, J., Bruder, R., Buckle, P., Carayon, P., Falzon, P., Marras, W.W., Wilson, J.R., van der Dolan, B. (2012). A strategy for human factors/ergonomics: developing the discipline and profession. Ergonomics, 55(4), 377-395.

Eden, C. (1992). On the nature of cognitive maps. Journal of Management Studies, 29(3), 261265.

Eden, C. (2004). Analyzing cognitive maps to help structure issues or problems. European Journal of Operational Research, 1(59), 673-686.

Eden, C., Ackermann., F. (2004). Cognitive mapping expert views for policy analysis in the public sector. European Journal of Operational Research, 152, 615-630.

Ellegård, K., Jonsson, D., Engström, T., Johansson, M.I., Medbo, L., Johansson, B. (1992). Reflective production in the final assembly of motor vehicles - en emerging Swedish challenge. International Journal of Operations and Production Management, 12(7), 117134.

Eklund, J. (1995). Relationships between ergonomics and quality in assembly work. Applied Ergonomics, 26(1), 15-20.

Eklund, J. (1997). Ergonomics, quality and continuous improvement - conceptual and empirical relationships in an industrial context. Ergonomics, 40(10), 982-1001.

Eklund, J. (1998). Participative problem solving and organizational congruence. . Paper presented at the Second International EuroCInet Conference on Continuous Improvement: from Idea to Reality, Enschede.

Eklund, J. (1999). Ergonomics and quality management - humans in interaction with technology, work environment and organization. . International Journal of Occupational Safety and Ergonomics, 5(2), 143-160.

Eklund, J. (2000). Development work for quality and ergonomics. Applied Ergonomics, 31, 641- 
648.

Falck, A.-C., Ortengren, R., Hogberg, D. (2010). The impact of poor assembly ergonomics on product quality: A cost-benefit analysis in car manufacturing. Human Factors and Ergonomics in Manufacturing, 20(1), 24-41.

Falck, A.-C., Rosenqvist, M. (2012) What are the obstacles and needs of proactive ergonomics measures at early product development stages? - An interview study in five Swedish companies, International Journal of Industrial Ergonomics, 42, 406-414.

Farris, J., Van Aken, E.M., Letens, G., Ghearskul, P., Coleman, G.D. (2011). Improving the performance review process: A structured approach and case application. International Journal of Operations and Production Management, 31(4), 376-404.

Fiol, C. M., Huff, A.S. (1992). Maps for Managers: Where are we? Where do we go from here? Journal of Management Studies, 29(3), 267-286.

Fisher, K., Phelps, R. (2006). Recipe or performing art? Action Research, 4(2), 143-164.

Friedman, V. J., Rogers, T. (2009). There is nothing so theoretical as good action research. Action Research, 7(1), 31-47.

Garg. A., Kapellusch, J.M. (2009). Applications of biomechanics for prevention of work-related musculoskeletal disorders. Ergonomics, 52(1), 36-59.

Gawron, V. J., Drury, C.G., Fairbanks, R.J., Berger, R.C. (2006). Medical Error and Human Factors Engineering: Where are we Now? American Journal of Medical Quality, 21(1), 57-67.

Genaidy, A. M., Rinder, M.M., A-Rehim, A.D. (2008). The work compatibility improvement framework: an assessment of the worker-work environment interation in the manufacturing sector. Ergonomics, 51(8), 1195-1218.

Genaidy, A. M., Sequeira, R., Rinder, M. M., \& A-Rehim, A. D. (2009). Determinants of business sustainability: An ergonomics perspective. Ergonomics, 52(3), 273-301.

Geraldi, J., Maylor, H., Williams, T. (2011). Now, let's make it really complex (complicated). A systematic review of the complexities of projects. International Journal of Operations \& Production Management, 31(9), 966-990.

Ghobadian, A., Gallear, D. (2001). TQM Implementation: an empirical examination and proposed generic model. Omega, 29, 343-359.

Gilad, I., Elnekave, M. (2006). Inserting cost effectiveness to the ergonomic equation when considering practical solutions. International Journal of Production Economics, 24(15), 5415-5441.

Goggins, R. W., Spielholz, P., Nothstein, G.L. (2008). Estimating the effectiveness of ergonomics interventions through case studies: Implications for predictive cost-benefit 
analysis. Journal of Safety Research, 39, 339-344.

Greig, M., Annett, T.L., Village, J.L. and Neumann, W.P. 2011 (Oct.). Using workstation design parameters to predict workload - proactive assessment approach for light assembly work. Proc of the 42nd Annual Conference of the Association of Canadian Ergonomists, London, Ontario (October 17-20). http://digitalcommons.ryerson.ca/ie/29/).

Greig, M.A., Dixon, S.M., Annett, T.L., Village, J.L., Neumann, W.P. (2013). User-centered development of a workstation efficiency evaluation tool. Proceedings of the $44^{\text {th }}$ Annual Conference of the Association of Canadian Ergonomists, Whiltler, B.C. (October 8-10).

Haines, H. (2002). Validating a framework for participatory ergonomics (the PEF). Ergonomics, 45(4), 309-327.

Hay, D.B., Kinchin, I.M. (2006). Using concept maps to reveal conceptual typologies. Education + Training, 48(2/3), 127-142.

Hendrick, H. W. (2008). Applying ergonomics to systems: Some documented "lessons learned". Applied Ergonomics, 39, 418-426.

Herrera, S. H. M., Huatuco, L.H. (2011). Macroergonomics intervention programs:

Recommendations for their design and implementation. Human Factors and Ergonomics in Manufacturing and Service Industries, 21(3), 227-243.

Hignett, S., Wilson, J.R. (2004). The role for qualitative methodology in ergonomics: A case study to explore theoretical issues. Theoretical Issues in Ergonomics Science, 5(6), 473-493.

Hodgkinson, G. P., Maule, A.J. and Bown, N.J. (2004). Causal Cognitive Mapping in the Organizational Strategy Field: A Comparison of Alternative Elicitation Procedures. Organizational Research Methods, 7(1), 3-26.

Holden, R. J., Or, C.K.L., Alper, S.J., Rivera, A.J. and Karsh, B-T. (2008). A change management framework for macroergonomic field research. Applied Ergonomics, 39, 459-474.

Hu, B., Ma, L., Zhang, W., Salvendy, G., Chablat, D., Bennis, F. (2011). Predicting real-world ergonomic measurements by simulation in a virtual environment. International journal of Industrial Ergonomics, 41, 64-71.

Huxam, C., Vangen, S. (2003 (July)). Researching organizational practice through action research case studies and design choices. Organizational Research Methods, 6(3), 383403.

International Ergonomics Association, 2013. Website:

http://www.iea.cc/01 what/What\%20is\%20Ergonomics.html (accessed October 13, 2013).

Jensen, P. L. (2002). Human factors and ergonomics in the planning of production. International 
journal of Industrial Ergonomics, 29, 121-131.

Johnson, A. P. (2008). A short guide to action research (3rd ed.). Boston: Pearson Education Inc.

Kadefors, R. (1994) An ergonomic model for workplace assessment. Proceedings of International Ergonomics Association, 5. Toronto, Ontario, Canada.

Kaljun, J., Dolsak, B. (2012). Ergonomic design knowledge built in the intelligent decision support system. International journal of Industrial Ergonomics, 42, 162-171.

Karsh, B.-T. (2006). Theories of work-related musculoskeletal disorders: Implications for ergonomic interventions. Theoretical Issues in Ergonomics Science, 7(1), 71-88.

Kelly, G.A. (1955). The Psychology of Personal Constructs: A Theory of Personality. Norton, New York.

Kirwan, B. (2000). Soft systems, hard lessons. Applied Ergonomics, 31, 663-678.

Kleiner, B. M. a. D., C.G. (1999). Large-scale regional economic development: Macroergonomics in theory and practice. Human Factors and Ergonomics in Manufacturing, 9(2), 151-163.

Lamkull, D., Hanson, L., Ortengren, R. (2009). A comparative study of digital human modelling simulation results and their outcomes in reality: A case study within manual assembly of automobiles. International journal of Industrial Ergonomics, 39, 428-441.

Langfield-Smith, K. (1992). Exploring the need for a shared cognitive map. Journal of Management Studies, 29(3), 1-20.

Laring, J., Forsman, M., Kadefors, R., Ortengren, R. (2002) MTM-based ergonomic workload analysis, International journal of Industrial Ergonomics, 30, 135-148.

Lee, S., Courtney, J.F. Jr, O'Keefe, R.M. (1992). A System for Organizational Learning Using Cognitive Maps. Journal of Management Science, 20(1), 23-36.

Leigh, J.P., Markowitz, S.B., Fahs, M., Shin, C., Landrigan, P.J. (1997). Occupational injury and illness in the United States. Estimates of costs, morbidity and mortality. Archives of Internal Medicine, 157(14), 1557-1568.

Levin, M. (2012). Academic integrity in action research. Action Research, 10(2), 133-149.

Lim, A., Village, J., Salustri, F., Neumann, W.P. (2013). Process mapping as a tool for participative integration of human factors into work system design. European Journal of Industrial Engineering, EJIE-36603.

Ma, L., Chablat, D., Bennis, F., Zhang, W., Guillaume, F. (2010). A new muscle fatigue and recovery model and its ergonomics application in human simulation. Virtual and Physical Prototyping, 5(3), 123-137. 
Manos, A. (2007 (Feb)). The benefits of Kaizen and Kaizen Events. Quality Progress, 40(2), 4748.

Manuj, I., Pohlen, T.L. (2011). A reviewer's guide to the grounded theory methodology in logistics and supply chain management research. International Journal of Physical Distribution and Logistics Management, 42(8/9), 784-803.

Marhavilas, P. K., Koulouriotis, D., Gemeni, V. (2011). Risk analysis and assessment methodologies in the work sites: On a review, classification and comparative study of the scientific literature of the period 2000-2009. Journal of Loss Prevention in the Process Industries, 24, 477-523.

Markoczy, L., and Goldberg, J. (1995). A Method for Eliciting and Comparing Causal Maps. Journal of Management, 21(2), 305-333.

Mathews, K. M., White, M.C., Long, R.G. (1999). Why study the complexity sciences in the social sciences. Human Relations, 52(4), 439-461.

Meyer, J. (2000). Qualitative research in health care. Using qualitative methods in health related action research. British Medical Journal, 320, 178-181.

Miles, J.A. (2012). Management and Organization Theory, A Jossey-Bass Reader, John Wiley \& Sons, San Francisco, California.

Miller, J.A. (1978). Contingency theory, values and change. Human Relations, 31(10), 885-904.

Mingers, J., White, L. (2010). A review of the recent contribution of systems thinking to operational and management science. European Journal of Operational Research, 207, 1147-1161.

Mohanty, R. P., Deshmukh, S.G. (1999). Evaluating manufacturing strategy for a learning organization: a case. International journal of operations and production management, 19(3), 308-387.

Moray, N. 1994. 'De Maximum non curat lex' or how context reduces science to art in the practice of human factors. Proceedings of the $38^{\text {th }}$ Annual Meeting of the Human Factors and Ergonomics Society, Nashville, Tennessee, 526-530.

Moray, N. (1995). Ergonomics and the global problems of the twenty-first century. Ergonomics, 38(8), 1691-1707.

Moreroft, J. D. W. (1992). Executive knowledge, models and learning. European Journal of Operational Research, 59, 9-27.

Munck-Ulfsfalt, U., Falck, A., Forsberg, A., Dahlin, C., Eriksson, A. (2003). Corporate ergonomics programme at Volvo car corporation. Applied Ergonomics, 34, 17-22. 
Nathanael, D., Marmaras, N. (2012) A question of our marketing or preconceptions:

Commentary on the paper "A strategy for human factors/ergonomics: developing the discipline and profession"'", Ergonomics, 55, 1612-1617.

Nielsen, A., Svensson, K., Svensson, L. (2006). Action and interactive research beyond practice and theory. Maastricht Shaker Publishing.

Neumann, W.P. (2006) "Inventory of Tools for Ergonomic Evaluation". Arbetslivsrapport ARB2006-21, National Institute for Working Life, Stockholm; 23 pages. ISSN\#14012928. Available at: www.ryerson.ca/hfe.

Neumann, W. P., Dixon, S., Ekman, M. 2007 Action research in ergonomics intervention research - shifting from hypothesis testing to experiential learning? Ergonomics, 55, 1127-1139.

Neumann, W. P., Ekman, M., Winkel, J. (2009). Integrating ergonomics into production system development - the Volvo Powertrain case. Applied Ergonomics, 40, 527-537.

Neumann, W. P., Dul, J. (2010). Human factors: spanning the gap between OM and HRM. International journal of operations and production management, 30(9), 923-950.

Neumann, W. P., Village, J. (2012). A framework supporting the process of integrating human factors into systems design. Ergonomics, 55(10), 1140-1156.

Nicolini, D. (1999). Comparing methods for understanding organizational cognition. Organization Studies, 20(5), 833-860.

Novak, J.S., Canas, A.J. (2008). The theory underlying concept maps and how to construct and use them. In: Technical Report, Institute for Human and Machine Cognition Cmap Tools. Florida Institute for Human and Machine Cognition. www.inmc.us.

Otto, A., Scholl, A. (2011). Incorporating ergonomic risks into assembly line balancing. European Journal of Operational Research, 212, 277-286.

Pacquet, V., Lin, L. (2003). An integrated methodology for manufacturing systems design using manual and computer simulation. Human Factors and Ergonomics in Manufacturing, 13(1), 19-40.

Palmer, I., Dunford, R. (2008). Organizational change and the importance of embedded assumptions. British Journal of Management, 19, 520-532.

Patton, M. Q. (2011). Developmental Evaluation; Applying complexity concepts to enhance innovation and use. New York: The Guildford Press.

Perez, J., \& Neumann, W.P. (accepted Jan 11, 2013). Ergonomists' and engineers' views on the utility of virtual human factors tools. Human Factors and Ergonomics in Manufacturing \& Service Industries (HFM.W-20541). 
Perrow, C. (1983). The organizational context of human factors engineering. Administrative Science Quarterly, 28, 521-541.

Randall, W.S., Mello, J.E. (2011). Grounded theory: an inductive method for supply chain research. International Journal of Physical Distribution and Logistics Management, 42(8/9), 863-880.

Ruiz-Primo, M.A.2(004). Examining concept maps as an assessment tool. In: Canas, A.J., Carff, R., Suri, N., Lott, J., Gomez, G., Eskridge T.C., Arroyo, M., Carvajal, R. (Eds.). Pamplona, Spain.

Robertson, S., Williams, T. (2006). Understanding project failure: Using cognitive mapping in an insurance project. Project Management Insitute, 37(4), 55-71.

Rogers, E.M. (2002). The nature of technology transfer. Science Communication, 23, 323-341.

Rose, L., Orrenius, U.E., Neumann, W.P. (2013). Work environment and the bottom line - a survey of tools relating work environment to business results. Human Factors and Ergonomics in Manufacturing \& Service Industries, 23(5), 368-381.

Ryan, B., Qu, R., Schock, A., Parry, T. (2011). Integrating human factors and operational research in a multidisciplinary investigation of road maintenance. Ergonomics, 54(5), 436-452.

Savolainen, T. I. (1999). Cycles of continuous improvement. Realizing competitive advantages through quality. International Journal of Operations \& Production Management, 19(11), 1203-1222.

Seim, R., Broberg, O., Andersen, V. (2012). Ergonomics in Design Processes: The Journey from Ergonomist toward Workspace Designer. Human Factors and Ergonomics in Manufacturing and Service Industries, new release, 1-15.

Sen, R. N., Yeow, P.H.P. (2003). Ergonomic weighted scores to evaluate critical instructions for improvements in a printed circuit assembly factory. Human Factors and Ergonomics in Manufacturing, 13(1), 41-58.

Senge, P. M. (2006). The Fifth Discipline. The Art \& Practice of the Learning Organization (Second ed.). USA: DoubleDay.

Shaw, D., Eden, C., and Ackermann, F. (2009). Mapping causal knowledge: How managers consider their environment during meetings. International Journal of Management and Decision Making, 10(5/6), 321-340.

Sheetz, S. D., Tegarden, D.P., Kozar, K.A., Zigurs, I. (1994). A group support systems approach to cognitive mapping. Journal of Management Information Systems, 11(1), 31-58.

Siemieniuch, C. E., Sinclair, M.A. (2004). CLEVER: a process framework for knowledge lifecycle management. International Journal of Operations \& Production Management, 24(11), 
1104-1125.

Siemieniuch, C. E., Sinclair, M.A. (2006). Systems integration. Applied Ergonomics, 37, 91-120.

Sinclair, M. A. (2007). Ergonomics issues in future systems. Ergonomics, 50(12), 1957-1986.

Sorensen, L. B., Broberg, O. (2012). Integrating ergonomics in design processes: a case study within an engineering consultancy firm. Work, DOI: 103233, 949-955.

Stillman, S. (2006). Grounded theory and grounded action: rooted in systems theory. World Futures, 62, 498-504.

Stone, K. B. (2010). Kaizen Teams: Integrated HRD Practices for Successful Team Building. Advances in Developing Human Resources, 12(1), 61-77.

Strasser, H., Zink, K. (2007). Modular course provision for professional ergonomists with microand macro-ergonomic design competency in the system "human being-technologyorganization". Theoretical Issues in Ergonomics Science, 8(4), 349-363.

Strauss, A., Corbin, J. (1990). Basics of Qualitative Research. Grounded Theory Procedures and Techniques (5th ed.). Newbury Park, California: SAGE Publications, Inc.

Suddaby, R. (2006). From the Editors: What Grounded Theory is Not. Academy of Management Journal, 40(4), 633-642.

Swan, J. (1997). Using cognitive mapping in management research: Decisions about technical innovation. British Journal of Management, 8, 183-198.

Swan, J. A. (1995). Exploring knowledge and cognitions in decisions about technological innovation: Mapping managerial cognitions. Human Relations, 45(11), 1241-1271.

Sweeny, A. (2009). BlackBerry Planet. The story of Research in Motion and the little device that took the world by storm. John Wiley \& Sons, Canada (284 p).

Tegarden, D. P., Sheetz, S.D. (2003). Group cognitive mapping: a methodology and system for capturing and evaluating managerial and organizational cognition. Omega, 31, 113-125.

Teperi, A.-M., Leppanen, A. (2011). Managers' conceptions regarding human factors in air traffic management and airport operations. Safety Science, 49, 438-449.

Theberge, N., Neumann, W.P. (2010). Doing 'organizational work'” Expanding the conception of professional practice in ergonomics. Applied Ergonomics, 42, 76-84.

Thun, J.-H., Lehr, C.B., Bierwirth, M. (2011). Feel free to feel comfortable - An empirical analysis of ergonomics in the German automotive industry. International Journal of Production Economics, 133, 551-561.

Village, J., Greig, M., Salustri, F.A., Neumann, W.P. (2012). Linking human factors to corporate strategy with cognitive mapping techniques. Work, 41, 2776-2780.

Village, J., Annett, T., Lin, E., Greig, M., and Neumann, W.P. 2011 (Oct.). Adapting the failure mode effect analysis (FMEA) for detection of human factors concerns. Proc. of the 42nd 
Annual Conference of the Association of Canadian Ergonomists, London, Ontario (October 17-20). http://digitalcommons.ryerson.ca/ie/24/.

Village, J., Annett, T., Greig, M., and Neumann, W.P. 2012. Ergonomic design-for-fixture guidelines and process of implementation. A Case Study. Association of Canadian Ergonomists Annual Conference, Halifax, Nova Scotia (Aug). http://digitalcommons.ryerson.ca/ie/27/.

Village, J., Greig, M., Zolfaghari, S., Salustri, F., Neumann, W.P. (2013 accepted with modifications, resubmitted). Adapting industrial engineering tools to include human factors. IIE Transactions in Occupational Ergonomics and Human Factors.

Village, J., Salustri, F.A., Neumann, W.P. (2013). Cognitive mapping: Revealing the links between human factors and strategic goals in organizations. International Journal of Industrial Ergonomics. 43, 304-313.

Village, J., Salustri, F., Neumann, W.P. (2013). Cognitive mapping links human factors to corporate strategies. European Journal of Industrial Engineering (Accepted: Submission code: EJIE-RZ-012-13 EJIE_53794).

Vink, P., Imada, A.S. and Zink, K.J. (2008). Defining stakeholder involvement in participatory design processes. Applied Ergonomics, 39, 519-526.

Waterson, P., Kolose, S.L. (2010). Exploring the social and organizational aspects of human factors integration: A framework and a case study. Safety Science, 48, 482-490.

Wells, R.P., Neumann, W.P., Nagdee, T., \& Theberge, N. (2013). Solution building versus problem convincing: Ergonomists report on conducting workplace assessments. IIE Transactions on Occupational Ergonomics and Human Factors, 1(1), 50-65.

Wertz, F. J., Charmaz, K., McMullen, L.M., Ruthellen, J., Anderson, R., McSpadden, E. (2011). Five Ways of Doing Qualitative Analysis. New York, USA: The Guildford Press.

Westgaard, R. H., Winkel, J. (2011). Occupational musculoskeletal and mental health: Significance of rationalization and opportunities to create sustainable production systems - A systematic review. Applied Ergonomics, 42, 261-296.

Whitehead, J. (2009). Generating living theory and understanding in action research studies. Action Research, 7(1), 85-99.

Whysall, Z.J., Haslam, R.A. and Haslam, C. (2004) Processes, barriers, and outcomes described by ergonomics consultants in preventing work-related musculoskeletal disorders, Applied Ergonomics, 35, 343-351.

Wijk, K., Mathiassen, S.E. (2011). Explicit and implicit theories of change when designing and implementing preventive ergonomics interventions - a systematic literature review. Scand J Work Environ Health, 37(5), 363-375. 
Willen, B. (1997). Integration of ergonomics in the design process. In Proceedings of the $13^{\text {th }}$ Triennial Congress of the International Ergonomics Association, 264-266.

Wilson, J. R. (2012). Fundamentals of Systems Ergonomics Work, 41, 3861-3868.

Wilson-Donnelly, K. A., Priest, H.A., Salas, E. and Burke, S. (2005). The impact of organizational practices on safety in manufacturing: A review and reappraisal. Human Factors and Ergonomics in Manufacturing, 15(2), 135-176.

Womack, S. K., Armstrong, T.J., Liker, J.K. (2009). Lean job design and musculoskeletal disorder risk: A two-plant comparison. Human Factors and Ergonomics in Manufacturing, 19(4), 279-293.

Woods, D., Dekker, S. (2000). Anticipating the effects of technological change: a new era of dynamics for human factors. Theoretical Issues in Ergonomics Science, 1(3), 272-282.

Wulff, I. A., Westgaard, R.H., Rasmussen, B. (1999). Ergonomic criteria in large-scale engineering design - II Evaluating and applying requirements in the real world of design. Applied Ergonomics, 30, 207-221.

Yang, J., Verma, U., Marler, T., Beck, S., Rahmatalla, S., Harrison, C. (2009). Workspace zone differentiation tool for visualization of postural comfort. International journal of Industrial Ergonomics, 39, 267-276.

Yeow, P.H.P., Sen, R.N. (2003). Quality, productivity, occupational health and safety and cost effectiveness of ergonomic improvements in the test workstations of an electronic factory. International Journal of Industrial Ergonomics, 32, 147-163.

Yin, R.K. (1994). Case Study Research: Design and Methods, $2^{\text {nd }}$ Edition (Thousand Oaks, CA: Sage Publications).

Zellner, G. (2011). A structured evaluation of business process improvement approaches. Business Process Management Journal, 17(2), 203-237.

Zink, K.J. (2006). Human factors, management and society. Theoretical Issues in Ergonomics Science, 7(4), 437-445.

Zink, K. J., Steimle, U. and Schroder, D. (2008). Comprehensive change management concepts. Development of a participatory approach. Applied Ergonomics, 38, 527-538. 


\section{GLOSSERY}

Absorptive capacity theory - suggests learning is cumulative and learning performance is greatest when the object of learning is related to what is already known with shared language and symbols, permitting assimilation. Firms with greater ability to absorb new knowledge have an advantage over others who do not.

Action/Interaction strategies - in a grounded theory analysis, the action/interaction strategies are the purposeful and goal oriented strategies and tactics for managing, handling and carrying out the phenomenon.

Action Research - a family of research methodologies which pursue action (or change) and research (or understanding) at the same time and by using a cyclic and spiral process which alternates between action and critical reflection. Researchers work with stakeholders to solve a real-world problem, gaining insight into the problem and factors influencing solution building from an embedded position in the development process.

Axial coding - in grounded theory, axial coding involves using an action-oriented coding paradigm to develop relationships between the categories that are processural and describe "how" something happens. The conditions must be specified as contextual, causal or intervening.

Category - a higher order grouping of concepts that may include many concepts and may be named differently from any original code names.

Central concepts - in a cognitive map, centrality is calculated for each node (concept) using a distance decay function for concepts successively further from the central concept. The central concepts reflect those with the highest overall networks or perceived "influence".

Coding - in qualitative analysis, data (transcripts, notes, etc.) are reviewed and conceptual labels are placed on discrete happenings, events, statements or other instances of the phenomenon. There are various types of coding, such as open coding, axial coding and selective coding.

Coding density - the number of times a code was used in an analysis of qualitative data.

Cognitive map - a graphical representation or visual picture of the content and structure of an individual's belief system.

Comparative matrix - a matrix that compares relationships between properties developed during the axial coding stage of a grounded theory approach. 
Complexity theory or Complex Systems Theory - describes organizations as complex with strategies that must allow for change since the future is unpredictable and characterized by sudden dramatic changes. Complex systems have been characterized by a large number of interacting and interdependent elements in which there is no central control. There is selforganizing and emergent behaviors based on sophisticated information processing that generates learning, evolution and development.

Constant comparison - the process of looking for different patterns and comparing dimensions and instances of the data.

Core category - in grounded theory, the core category is the category seen to be driving the action of the phenomenon and around which all other categories are connected as either contributory, contextual or intervening.

Design for Assembly (DFA) - a process developed by Boothroyd et al (2001) to evaluate manual assembly tasks for their ease, using standardized times, with an aim to improve assembly quality and time to market, and reduce assembly costs.

Developmental evaluation - the evaluator is part of the design team and collaborates to conceptualize, design and test new approaches in an on-going process of development, adaptation and intentional change.

Development work - improving an organization's capabilities, processes and routines such that there is organizational learning.

Diffusion of innovation theory - suggests that innovations tend to be adopted more quickly when they have a relative advantage over existing methods, are compatible with existing values, past experiences and current needs, are simple to understand, can be tried out or played with by potential adopters and are observable such that adopters can see the results for themselves.

Dimension - in grounded theory analysis, a dimension positions a property along a continuum. For example, if a property is access to resources, the dimensions range from very little to a lot. Double loop learning - an organization learns from a change, modifies their goals by asking if they are doing the "right" thing and applies what is learned to the next change or intervention, therefore improving its capabilities.

Ergonomic action research (EAR) - Action research whose goal is to improve the design of work.

Failure mode effects analysis (FMEA) - a quality tool used prior to design of parts and tooling to anticipate and control potential failures. The severity, occurrence and detection of the failure 
are rated to yield a risk priority number. An FMEA may be conducted during product design (dFMEA) or assembly process design (pFMEA).

Fixture - a device used to secure a work piece, while a machine, tool or person performs an assembly task.

Framework - a set of non-linked constructs or ideas.

Grounded theory - a data analysis method that uses qualitative data to look at patterns of relationships between actors and their environment, and develop propositions which then become grounded by the evidence thus producing a theory

Gemba walk - based on the Japanese term "Gemba" which means the place where work happens - it is "management by wandering/walking around" whereby managers are visible and talk with workers on the front line to understand problems.

Generalizability - the extent to which research findings can be transferred to situations or people other than those who were studied. In qualitative research, it is the ability to transfer findings, techniques or lessons from one situation based in a defined context, to other and different situations (rather than generalizing based on statistical analysis).

Heads - in a cognitive map the heads are at the top of the map with multiple concepts leading into them.

Hoishin - translated loosely as "policy management", it is a means to pull together the forces within a company and unite minds internally to improve performance by adjusting quickly to change.

Kaizen - a team activity, translated from Japanese to imply incremental continuous improvement, whose purpose is to turn lean thinking into actions to eliminate waste (or nonvalue added activities) within the work process, job design or equipment.

Links - relationships between concepts in a cognitive map are drawn with arrows (links) to indicate how one concept influences another (as in causality).

Macro-ergonomics - a top down socio-technical system approach to the design of work systems to investigate the organizational design and management factors within systems.

Merged group map - a map containing concepts related to all participants. The merging can be done in various ways but represents the combined perceptions of the group.

Metric - a quantifiable measurement used to track and assess performance. 
Model - a set of constructs with links that illustrate a simplified version of a concept, relationship, system or aspect of the real world.

Nodes - concepts (participants' perceptions about a specific problem or issue) in a cognitive map

Participatory Ergonomics - an intervention strategy whereby end users of ergonomics take an active role in the identification and analysis of ergonomic risk factors, as well as the design and implementation of ergonomics solutions.

Political reflective navigator - a term used by Broberg et al (2010) to describe the HF specialist as a change agent who must navigate within a social system to bring about change.

Processural - processural research seeks to study processes of change over time.

Property - in grounded theory analysis a property is an attribute or characteristic of a category. For example, if the category is "support for human factors", a property may include access to resources, assistance with networking, or verbal support.

Psychosocial factors - a worker's perception of the work organization and design. It includes perceptions such as workload, autonomy, supervisor support and job satisfaction.

Qualitative research - social research relying on text rather than numerical data, and analyzing data in textual form with an aim to understanding the meaning of action.

Reliability - suggests that repeating the study at another time or with a different researcher would yield the same results. In qualitative analysis, dependability is used instead of reliability and it can be illustrated by developing a data base to document all notes, interviews etc., so raw data is available to others. Dependability is consistency in patterns of thought and behavior of subjects.

Saturation - the point of data collection and analysis at which no new information is being learned about the phenomenon.

Single loop learning - an organization learns from a change or intervention

Soft systems thinking - Soft systems thinking assumes the world is complex and affected by social relationships, and using a systems model, it attempts to deal with issues with the goal of accommodation among conflicting interests.

Systems approach - viewing a situation holistically through interactions of various elements of the system. A "system" contains a set of interconnected elements. 
Systems thinking - a conceptual framework containing a body of knowledge and tools to make full patterns clearer and help us understand how to change them effectively. It means viewing a situation holistically rather than reductionistically.

Tails - in a cognitive map, tails are at the bottom of the map and represent the action items leading upward toward strategic goals.

Theoretical sampling - sampling purposefully in grounded theory analysis to "test" tentative propositions with more instances of the data.

Theory - a set of constructs with causal links that explain how and why a phenomenon occurred. A theory is situated within a context (when, where and who).

Toyota Production system - an integrated socio-technical system developed by Toyota that comprises management philosophies and practices with an aim to design out overburden and inconsistency and eliminate waste.

Transferability - in qualitative research, instead of generalizability, the goal is transferability which is a thick description from which participants and others can decide what is generalizable to them - which may be results, abstractions, tools or concepts.

Validity - whether the measures are measuring the "true" thing. In qualitative research, validity is more about the soundness of the arguments - it can be demonstrated with congruency between the respondent and research. It is supported with constant comparison of data and multiple sources of data.

Internal validity - establishes the causal relationship between events. In qualitative research it can be considered similar to "credibility" and is established during the data analysis process by pattern matching, explanation building, addressing rival explanations and using logic models. It is satisfied by prolonged engagement, intense observation periods and triangulation of methods.

External validity - defines the domain for generalization whereby findings are valid to an external world. In qualitative analysis, transferability is used instead of external validity.

Construct validity - the correct measures for the concepts being studied. 